\title{
Enantioselective Intermolecular Mannich-type Interception of Phenolic Oxonium Ylide for the Direct Assembly of Chiral 2,2-Disubstituted Dihydrobenzofurans
}

Kemiao Hong, Shanliang Dong, Xinxin Xu, Zhijing Zhang, Taoda Shi, Haoxuan Yuan, Xinfang $\mathrm{Xu}$, and Wenhao $\mathrm{Hu}^{*}$

Guangdong Key Laboratory of Chiral Molecule and Drug Discovery, School of Pharmaceutical Sciences, Sun Yat-sen University, Guangzhou, Guangdong 510006, China

\author{
E-mail: xuxinfang@mail.sysu.edu.cn \\ huwh9@mail.sysu.edu.cn
}

\section{Table of Contents}

1. General Information

2. General Procedure for the Synthesis of Diazo Compounds 1

3. General Procedure for the Enantioselective Mannich-type Reaction

4. General Procedure for Scale Up and Derivatizations

S30-S34

5. Control Experiments

S34-S36

6. References

S36

7. NMR Spectra of New Compounds 3, 5, 6, 7, 8, and 9

8. HPLC Analyses Figures of Compounds 3, 5, 6, 7, and 8

9. Single-Crystal X-ray Diffraction of 5a

10. General Procedure for the in vitro Anti-tumor Activity Study 


\section{General Information}

All reactions were carried out in oven-dried glassware. Solvents were purified and distilled by following the standard methods. Flash column chromatography was performed using silica gel (300-400 mesh). Analytical thin-layer chromatography was performed using glass plates pre-coated with 200-300 mesh silica gel impregnated with a fluorescent indicator $(254 \mathrm{~nm})$. The ${ }^{1} \mathrm{H}$ NMR, ${ }^{13} \mathrm{C}$ NMR and ${ }^{19} \mathrm{~F}$ NMR spectra were recorded in $\mathrm{CDCl}_{3}$ on $400 \mathrm{MHz}$ and $500 \mathrm{MHz}$ spectrometer; chemical shifts were reported in ppm with the solvent signal as reference, and coupling constants $(J)$ were given in Hertz. The peak information was described as: $\mathrm{s}=\operatorname{singlet}, \mathrm{d}=$ doublet, $\mathrm{t}$ $=$ triplet, $\mathrm{q}=$ quartet, $\mathrm{m}=$ multiplet, comp $=$ composite. The enantioselectivity was determined on HPLC using Daicel Chiralpak AD-H, IA, IC-3, IE-3, IF-3, Daicel Chiralcel OD-H and EnantioPak Y1 column. High-resolution mass spectra (HRMS) were recorded on a commercial apparatus (ESI Source and CI Source). 


\section{General Procedure for the Synthesis of Diazo Compounds $1 .^{1}$}

Diazo compounds $\mathbf{1 a}, \mathbf{1 b}, \mathbf{1 d}$, and $\mathbf{1 j}$ were synthesized according to previously published procedure and had physical and spectral properties identical to those earlier reported. ${ }^{1}$ Diazo compounds $\mathbf{1 1}$ was synthesized according to previously published procedure and had physical and spectral properties identical to those earlier reported. ${ }^{2}$<smiles>[R5]c1ccccc1CI</smiles>

S1<smiles>[R]C(=O)CC(C)=O</smiles>

S2

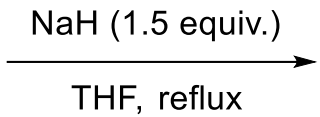

THF, reflux<smiles>[R]OC(=O)C(Cc1ccccc1[SeH])C(C)=O</smiles>

S3

Synthesis of S3: To a 100-mL oven-dried round bottom flask containing a magnetic stirring bar, and sodium hydride (60\% dispersion in mineral oil, $1.20 \mathrm{~g}, 30.0 \mathrm{mmol}$ ) in dry THF (30 mL), $\mathbf{S 2}(40.0 \mathrm{mmol})$ was added dropwise with stirring at $0{ }^{\circ} \mathrm{C}$ under a nitrogen atmosphere. After the reaction mixture turned clear, a solution of S1 (20.0 mmol) in THF $(10 \mathrm{~mL})$ was added dropwise at ambient temperature, and the reaction mixture was refluxed for $4 \mathrm{~h}$. Then, aqueous saturated $\mathrm{NH}_{4} \mathrm{Cl}(30 \mathrm{~mL})$ was added, the organic phase was separated, and the aqueous layer was extracted with ethyl acetate (3 X $50 \mathrm{~mL}$ ). The combined organic layer was washed with brine, dried over anhydrous $\mathrm{MgSO}_{4}$ and concentrated in vacuo after filtration. The residue was purified by chromatography on silica gel $(\mathrm{PE} / \mathrm{EA}=20: 1)$ to afford the product $\mathbf{S 3}$ as a yellow oil in good to high yields.

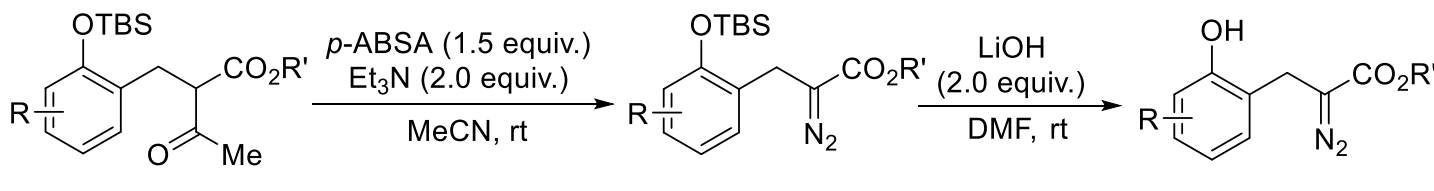
S3 S4

Synthesis of 1: To a 100-mL oven-dried round bottom flask containing a magnetic stirring bar, S3 (15 mmol), and 4-acetamidobenzenesulfonyl azide (p-ABSA, $5.4 \mathrm{~g}$, $22.5 \mathrm{mmol}, 1.5$ equiv.) in $\mathrm{MeCN}(40 \mathrm{~mL})$, triethylamine (4.2 mL, $30 \mathrm{mmol}, 2.0$ equiv.) was added dropwise at $0{ }^{\circ} \mathrm{C}$, and the reaction mixture was stirred overnight at room 
temperature. Then, aqueous saturated $\mathrm{NH}_{4} \mathrm{Cl}(50 \mathrm{~mL})$ was added, the organic phase was separated, and the aqueous layer was extracted with ethyl acetate ( 3 X $50 \mathrm{~mL}$ ). The combined organic layer was washed with brine, dried over anhydrous $\mathrm{MgSO}_{4}$ and concentrated in vacuo after filtration. The residue was purified by chromatography on silica gel $(\mathrm{PE} / \mathrm{EA}=20: 1)$ to afford the product $\mathbf{S 4}$ as a bright yellow oil. To a solution of above obtained product $\mathbf{S 4}(5.0 \mathrm{mmol})$ in DMF $(10 \mathrm{~mL})$, lithium hydroxide hydrate (420 $\mathrm{mg}, 10 \mathrm{mmol}$ ) was added in one portion, and the reaction mixture turned to orange. After stirring for $30 \mathrm{~min}$, ethyl acetate $(40 \mathrm{~mL})$ was added, and the organic layer was washed with saturated $\mathrm{NH}_{4} \mathrm{Cl}(3 \mathrm{X} 20 \mathrm{~mL})$. The combined aqueous layer was extracted with ethyl acetate $(3 \times 50 \mathrm{~mL})$, and the combined organic layer was washed with brine, dried over anhydrous $\mathrm{MgSO}_{4}$ and concentrated in vacuo after filtration. The residue was purified by chromatography on silica gel $(\mathrm{PE} / \mathrm{EA}=5: 1)$ to afford the pure products $\mathbf{1}$ as a bright yellow oil.<smiles>CCOC(=O)Cc1ccccc1O</smiles>

tert-Butyl 2-diazo-3-(2-hydroxyphenyl)propanoate (1c) Yellow oil. ${ }^{1} \mathrm{H}$ NMR (500 $\mathrm{MHz}_{\mathrm{CDCl}}$ ) $(\delta, \mathrm{ppm}) 8.02(\mathrm{~s}, 1 \mathrm{H}), 7.18(\mathrm{t}, J=7.7 \mathrm{~Hz}, 1 \mathrm{H}), 7.05(\mathrm{~d}, J=7.4 \mathrm{~Hz}, 1 \mathrm{H})$, $6.93(\mathrm{~d}, J=7.9 \mathrm{~Hz}, 1 \mathrm{H}), 6.85(\mathrm{t}, J=7.4 \mathrm{~Hz}, 1 \mathrm{H}), 3.52(\mathrm{~s}, 2 \mathrm{H}), 1.48(\mathrm{~s}, 9 \mathrm{H}) ;{ }^{13} \mathrm{C} \mathrm{NMR}$ $\left(125 \mathrm{MHz}, \mathrm{CDCl}_{3}\right)(\delta, \mathrm{ppm}) 168.7,155.1,130.5,129.2,124.5,120.6,117.9,83.2$, 28.4, 25.8; HRMS (TOF MS ESI ${ }^{+}$) calculated for $\mathrm{C}_{13} \mathrm{H}_{16} \mathrm{~N}_{2} \mathrm{O}_{3} \mathrm{Na}[\mathrm{M}+\mathrm{Na}]^{+}$: 271.1053, found 271.1052 .<smiles>C#CCOC(=O)C(=N)Cc1ccccc1O</smiles>

Prop-2-yn-1-yl 2-diazo-3-(2-hydroxyphenyl)propanoate (1e) Yellow oil. ${ }^{1} \mathrm{H}$ NMR $\left(400 \mathrm{MHz}, \mathrm{CDCl}_{3}\right)(\delta, \mathrm{ppm}) 7.18-7.10(\mathrm{comp}, 3 \mathrm{H}), 6.90-6.84(\mathrm{~m}, 2 \mathrm{H}), 4.78(\mathrm{~d}, J=$ $2.4 \mathrm{~Hz}, 2 \mathrm{H}), 3.59$ (s, 2H), $2.49(\mathrm{t}, J=2.4 \mathrm{~Hz}, 1 \mathrm{H}) ;{ }^{13} \mathrm{C} \mathrm{NMR}\left(100 \mathrm{MHz}, \mathrm{CDCl}_{3}\right)(\delta$, 
ppm) 168.6, 154.6, 130.6, 129.2, 123.9, 120.9, 117.3, 75.5, 52.9, 25.4; HRMS (TOF MS ESI ${ }^{+}$) calculated for $\mathrm{C}_{12} \mathrm{H}_{10} \mathrm{~N}_{2} \mathrm{O}_{3} \mathrm{Na}[\mathrm{M}+\mathrm{Na}]^{+}:$253.0584, found 253.0591.<smiles>C[C@H]1CC[C@@H](C(F)(F)F)[C@H](OC(=O)C(=[W])Cc2ccccc2O)C1</smiles>

\section{(1R,2S,5R)-2-Isopropyl-5-methylcyclohexyl}

2-diazo-3-(2-hydroxyphenyl)propanoate (1f) Yellow oil. ${ }^{1} \mathrm{H}$ NMR (400 MHz, $\left.\mathrm{CDCl}_{3}\right)(\delta, \mathrm{ppm}) 7.58(\mathrm{~s}, 1 \mathrm{H}), 7.05-6.95(\mathrm{~m}, 2 \mathrm{H}), 6.79$ - $6.70(\mathrm{~m}, 2 \mathrm{H}), 4.69$ - $4.63(\mathrm{~m}$, 1H), 3.49 - 3.39 (m, 2H), 1.90 (d, $J=11.9 \mathrm{~Hz}, 1 \mathrm{H}), 1.69$ (s, 1H), 1.54 (d, $J=10.3 \mathrm{~Hz}$, 2H), 1.35 - 1.22 (comp, 3H), $0.97-0.87$ (m, 2H), 0.77 - 0.73 (comp, 6H), 0.63 (d, $J=$ $6.9 \mathrm{~Hz}, 3 \mathrm{H}) ;{ }^{13} \mathrm{C} \mathrm{NMR}\left(100 \mathrm{MHz}, \mathrm{CDCl}_{3}\right)(\delta, \mathrm{ppm}) 169.6,154.9,130.5,129.1,124.3$, $120.5,117.5,76.2,47.2,41.3,34.2,31.5,26.5,25.7,23.7,22.0,20.8,16.6$; HRMS (TOF MS ESI ${ }^{+}$) calculated for $\mathrm{C}_{19} \mathrm{H}_{26} \mathrm{~N}_{2} \mathrm{O}_{3} \mathrm{Na}[\mathrm{M}+\mathrm{Na}]^{+}:$353.1836, found 353.1836.<smiles>CCCOC(=O)C(=N)Cc1cc(C)ccc1O</smiles>

tert-Butyl 2-diazo-3-(2-hydroxy-5-methylphenyl)propanoate (1g) Yellow oil. ${ }^{1} \mathrm{H}$ NMR (400 MHz, $\left.\mathrm{CDCl}_{3}\right)(\delta, \mathrm{ppm}) 7.93(\mathrm{~s}, 1 \mathrm{H}), 6.99$ (d, J=8.0 Hz, 1H), $6.90-6.84$ $(\mathrm{m}, 2 \mathrm{H}), 3.51(\mathrm{~s}, 2 \mathrm{H}), 2.27(\mathrm{~s}, 3 \mathrm{H}), 1.50(\mathrm{~s}, 9 \mathrm{H}) ;{ }^{13} \mathrm{C} \mathrm{NMR}\left(100 \mathrm{MHz}, \mathrm{CDCl}_{3}\right)(\delta$, ppm) 169.6, 152.6, 130.9, 129.7, 129.5, 124.3, 117.4, 82.8, 28.4, 25.6, 20.5; HRMS (TOF MS ESI ${ }^{+}$) calculated for $\mathrm{C}_{14} \mathrm{H}_{18} \mathrm{~N}_{2} \mathrm{O}_{3} \mathrm{Na}[\mathrm{M}+\mathrm{Na}]^{+}: 285.1210$, found 285.1211. 


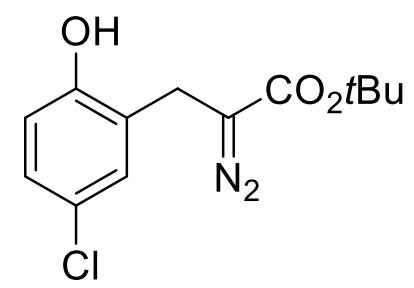

tert-Butyl 3-(5-chloro-2-hydroxyphenyl)-2-diazopropanoate (1h) Yellow oil. ${ }^{1} \mathrm{H}$ NMR (500 MHz, $\left.\mathrm{CDCl}_{3}\right)(\delta, \mathrm{ppm}) 8.28(\mathrm{~s}, 1 \mathrm{H}), 6.98(\mathrm{~s}, 1 \mathrm{H}), 6.93(\mathrm{~d}, J=8.6 \mathrm{~Hz}, 1 \mathrm{H})$, $6.69(\mathrm{~d}, J=8.5 \mathrm{~Hz}, 1 \mathrm{H}), 3.38(\mathrm{~s}, 2 \mathrm{H}), 1.37(\mathrm{~s}, 9 \mathrm{H}) ;{ }^{13} \mathrm{C} \mathrm{NMR}\left(125 \mathrm{MHz}, \mathrm{CDCl}_{3}\right)(\delta$, ppm) 168.7, 153.7, 129.9, 128.3, 126.1, 124.5, 117.8, 82.4, 28.3, 25.6; HRMS (TOF MS ESI ${ }^{+}$) calculated for $\mathrm{C}_{13} \mathrm{H}_{15} \mathrm{ClN}_{2} \mathrm{O}_{3} \mathrm{Na}[\mathrm{M}+\mathrm{Na}]^{+}:$305.0663, found 305.0662.<smiles>CCCOC(=O)C(=N)Cc1c(O)ccc2ccccc12</smiles>

tert-Butyl 2-diazo-3-(2-hydroxynaphthalen-1-yl)propanoate (1i) Yellow oil. ${ }^{1} \mathrm{H}$ NMR $\left(500 \mathrm{MHz}, \mathrm{CDCl}_{3}\right)(\delta, \mathrm{ppm}) 8.81(\mathrm{~s}, 1 \mathrm{H}), 7.79(\mathrm{~d}, J=8.0 \mathrm{~Hz}, 1 \mathrm{H}), 7.69(\mathrm{~d}, J=$ $8.6 \mathrm{~Hz}, 2 \mathrm{H}), 7.48(\mathrm{t}, J=7.6 \mathrm{~Hz}, 1 \mathrm{H}), 7.33(\mathrm{t}, J=7.4 \mathrm{~Hz}, 1 \mathrm{H}), 7.24-7.20(\mathrm{~m}, 1 \mathrm{H})$, $3.98(\mathrm{~s}, 2 \mathrm{H}), 1.47$ (s, 9H); ${ }^{13} \mathrm{C} \mathrm{NMR}\left(125 \mathrm{MHz}, \mathrm{CDCl}_{3}\right)(\delta, \mathrm{ppm}) 170.4,153.3,133.3$, 129.6, 129.3, 129.1, 127.0, 123.2, 121.9, 120.4, 116.9, 83.3, 28.4, 20.0; HRMS (TOF MS ESI ${ }^{+}$) calculated for $\mathrm{C}_{17} \mathrm{H}_{18} \mathrm{~N}_{2} \mathrm{O}_{3} \mathrm{Na}[\mathrm{M}+\mathrm{Na}]^{+}:$321.1210, found 321.1210.<smiles>CCCOC(=N)CCCc1ccccc1O</smiles>

tert-Butyl 2-diazo-5-(2-hydroxyphenyl)pentanoate (1k) Yellow oil. ${ }^{1} \mathrm{H}$ NMR (400 $\left.\mathrm{MHz}, \mathrm{CDCl}_{3}\right)(\delta, \mathrm{ppm}) 7.09$ - $7.03(\mathrm{~m}, 2 \mathrm{H}), 6.85$ - $6.81(\mathrm{~m}, 1 \mathrm{H}), 6.78$ - $6.76(\mathrm{~m}, 1 \mathrm{H})$, $6.23(\mathrm{~s}, 1 \mathrm{H}), 2.68-2.65(\mathrm{~m}, 2 \mathrm{H}), 2.31(\mathrm{t}, J=7.4 \mathrm{~Hz}, 2 \mathrm{H}), 1.86-1.78(\mathrm{~m}, 2 \mathrm{H}), 1.48(\mathrm{~s}$, $9 \mathrm{H}) ;{ }^{13} \mathrm{C} \mathrm{NMR}\left(100 \mathrm{MHz}, \mathrm{CDCl}_{3}\right)(\delta, \mathrm{ppm}) 167.9,154.2,130.4,127.9,127.3,120.6$, 115.7, 81.5, 29.3, 28.5, 28.0, 22.9; HRMS (TOF MS ESI ${ }^{+}$) calculated for $\mathrm{C}_{15} \mathrm{H}_{20} \mathrm{~N}_{2} \mathrm{O}_{3} \mathrm{Na}[\mathrm{M}+\mathrm{Na}]^{+}:$299.1366, found 299.1366. 


\section{General Procedure for the Enantioselective Mannich-type Reaction}

To a 10-mL oven-dried vial containing a magnetic stirring bar, imine 2 ( $0.1 \mathrm{mmol}, 1.0$ equiv.), $\mathrm{Rh}_{2}(\mathrm{OPiv})_{4}(0.6 \mathrm{mg}, 1.0 \mathrm{~mol} \%)$, chiral phosphoric acid $4 \mathbf{c}(0.9 \mathrm{mg}, 1.0 \mathrm{~mol} \%)$, and $4 \AA \mathrm{MS}(50 \mathrm{mg})$ in tert-butyl methyl ether (TBME, $1.0 \mathrm{~mL}$ ), a solution of diazo compound 1 ( 0.15 mmol, 1.5 equiv.) was added in $1.0 \mathrm{~mL}$ TBME via a syringe pump over $0.5 \mathrm{~h}$ under argon atmosphere at $-40{ }^{\circ} \mathrm{C}$. After addition, the reaction mixture was stirred for additional $0.5 \mathrm{~h}$ under these conditions until consumption of the material (monitored by TLC). Then the reaction mixture was purified by column chromatography on silica gel without any additional treatment $($ Hexanes : EtOAc $=$ 20:1 to 10:1) to give the pure products $\mathbf{3}$ or $\mathbf{5}$ in good to high yields and excellent enantioselectivity.

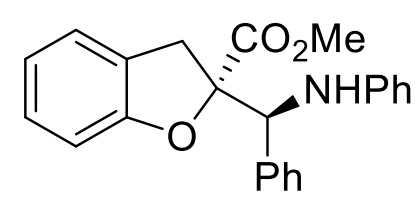

\section{Methyl}

\section{(S)-2-((S)-phenyl(phenylamino)methyl)-2,3-dihydrobenzofuran-2-carboxylate}

(3a) Colorless oil. $27.3 \mathrm{mg}, 76 \%$ yield. $96 \%$ ee, $>20: 1 d r .[\alpha]_{\mathrm{D}}{ }^{20}=81.1(\mathrm{c}=0.033$, DCM); ${ }^{1} \mathrm{H}$ NMR $\left(500 \mathrm{MHz}, \mathrm{CDCl}_{3}\right)(\delta, \mathrm{ppm}) 7.44(\mathrm{~d}, J=7.7 \mathrm{~Hz}, 2 \mathrm{H}), 7.29(\mathrm{t}, J=7.3$ $\mathrm{Hz}, 2 \mathrm{H}), 7.22(\mathrm{t}, J=7.2 \mathrm{~Hz}, 1 \mathrm{H}), 7.17(\mathrm{t}, J=7.7 \mathrm{~Hz}, 1 \mathrm{H}), 7.13(\mathrm{~d}, J=7.4 \mathrm{~Hz}, 1 \mathrm{H})$, $7.07(\mathrm{t}, J=7.4 \mathrm{~Hz}, 2 \mathrm{H}), 7.00(\mathrm{~d}, J=8.0 \mathrm{~Hz}, 1 \mathrm{H}), 6.90(\mathrm{t}, J=7.4 \mathrm{~Hz}, 1 \mathrm{H}), 6.65(\mathrm{t}, J=$ $7.3 \mathrm{~Hz}, 1 \mathrm{H}), 6.58(\mathrm{~d}, J=8.0 \mathrm{~Hz}, 2 \mathrm{H}), 4.97(\mathrm{~s}, 1 \mathrm{H}), 4.53(\mathrm{~s}, 1 \mathrm{H}), 3.80(\mathrm{~d}, J=16.2 \mathrm{~Hz}$, $1 \mathrm{H}), 3.60(\mathrm{~d}, J=16.1 \mathrm{~Hz}, 1 \mathrm{H}), 3.53(\mathrm{~s}, 3 \mathrm{H}) ;{ }^{13} \mathrm{C} \mathrm{NMR}\left(125 \mathrm{MHz}, \mathrm{CDCl}_{3}\right)(\delta, \mathrm{ppm})$ $172.6,158.8,146.4,138.1,129.3,128.5,128.4,128.2$, 125.5, 124.9, 121.8, 118.3, 114.1, 110.0, 92.8, 61.7, 52.8, 38.0; HRMS (TOF MS ESI ${ }^{+}$) calculated for $\mathrm{C}_{23} \mathrm{H}_{22} \mathrm{NO}_{3}$ $[\mathrm{M}+\mathrm{H}]^{+}$: 360.1594 , found 360.1597; HPLC conditions for determination of enantiomeric excess: Chiralpak AD-H, $\lambda=254 \mathrm{~nm}$, hexane : 2-propanol =95:5, flow rate $=1.0 \mathrm{~mL} / \mathrm{min}, t_{\text {minor }}=10.4 \mathrm{~min}, t_{\text {major }}=15.1 \mathrm{~min}$. 
$\overbrace{\mathrm{Ph}}^{\mathrm{CO}_{2} \mathrm{iPr}}$

\section{Isopropyl}

(S)-2-((S)-phenyl(phenylamino)methyl)-2,3-dihydrobenzofuran-2-carboxylate

(3b) Colorless oil. $30.2 \mathrm{mg}, 78 \%$ yield. 96\% ee, $>20: 1 d r .[\alpha]_{\mathrm{D}}{ }^{20}=105.1$ (c $=0.033$, DCM); ${ }^{1} \mathrm{H}$ NMR $\left(500 \mathrm{MHz}, \mathrm{CDCl}_{3}\right)(\delta, \mathrm{ppm}) 7.48(\mathrm{~d}, J=7.2 \mathrm{~Hz}, 2 \mathrm{H}), 7.27(\mathrm{t}, J=7.3$ $\mathrm{Hz}, 2 \mathrm{H}), 7.22-7.14(\mathrm{~m}, 2 \mathrm{H}), 7.11(\mathrm{~d}, J=7.3 \mathrm{~Hz}, 1 \mathrm{H}), 7.07(\mathrm{t}, J=7.8 \mathrm{~Hz}, 2 \mathrm{H}), 7.01$ $(\mathrm{d}, J=8.0 \mathrm{~Hz}, 1 \mathrm{H}), 6.88(\mathrm{t}, J=7.4 \mathrm{~Hz}, 1 \mathrm{H}), 6.64(\mathrm{t}, J=7.3 \mathrm{~Hz}, 1 \mathrm{H}), 6.58(\mathrm{~d}, J=8.0$ $\mathrm{Hz}, 2 \mathrm{H}), 4.94$ (d, J=9.9 Hz, 1H), $4.89-4.80$ (m, 1H), 4.49 (d, J = 10.0 Hz, 1H), 3.76 $(\mathrm{d}, J=16.1 \mathrm{~Hz}, 1 \mathrm{H}), 3.55(\mathrm{~d}, J=16.1 \mathrm{~Hz}, 1 \mathrm{H}), 1.08(\mathrm{~d}, J=6.3 \mathrm{~Hz}, 3 \mathrm{H}), 0.97(\mathrm{~d}, J=$ $6.3 \mathrm{~Hz}, 3 \mathrm{H}) ;{ }^{13} \mathrm{C} \mathrm{NMR}\left(125 \mathrm{MHz}, \mathrm{CDCl}_{3}\right)(\delta, \mathrm{ppm}) 171.4,159.1,146.5,138.2,129.3$, $128.6,128.38,128.35,128.1,125.5,124.8,121.5,118.2,114.1,109.9,92.4,69.8$, 61.7, 38.2, $21.5\left(\mathrm{~d}, J=10.8 \mathrm{~Hz}\right.$ ); HRMS (TOF MS ESI ${ }^{+}$) calculated for $\mathrm{C}_{25} \mathrm{H}_{25} \mathrm{NO}_{3} \mathrm{Na}$ $[\mathrm{M}+\mathrm{Na}]^{+}:$410.1727, found 410.1729; HPLC conditions for determination of enantiomeric excess: Chiralpak IF-3, $\lambda=254 \mathrm{~nm}$, hexane : 2-propanol $=96: 4$, flow rate $=1.0 \mathrm{~mL} / \mathrm{min}, t_{\text {minor }}=6.3 \mathrm{~min}, t_{\text {major }}=5.8 \mathrm{~min}$.

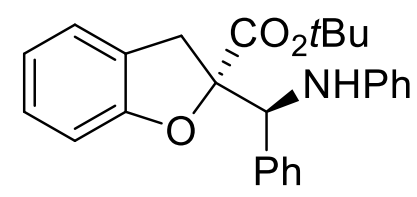

tert-Butyl

(S)-2-((S)-phenyl(phenylamino)methyl)-2,3-dihydrobenzofuran-2-carboxylate (3c) Colorless oil. $34.1 \mathrm{mg}, 85 \%$ yield. $98 \%$ ee, $>20: 1 d r .[\alpha]_{\mathrm{D}}{ }^{20}=93.1(\mathrm{c}=0.033$, DCM); ${ }^{1} \mathrm{H}$ NMR $\left(500 \mathrm{MHz}, \mathrm{CDCl}_{3}\right)(\delta, \mathrm{ppm}) 7.52(\mathrm{~d}, J=7.5 \mathrm{~Hz}, 2 \mathrm{H}), 7.27(\mathrm{t}, J=7.5 \mathrm{~Hz}$, 2H), $7.20(\mathrm{t}, J=7.3 \mathrm{~Hz}, 1 \mathrm{H}), 7.16(\mathrm{t}, J=7.7 \mathrm{~Hz}, 1 \mathrm{H}), 7.11-7.05$ (comp, 3H), 6.99 (d, $J=8.0 \mathrm{~Hz}, 1 \mathrm{H}), 6.88(\mathrm{t}, J=7.4 \mathrm{~Hz}, 1 \mathrm{H}), 6.63(\mathrm{t}, J=7.3 \mathrm{~Hz}, 1 \mathrm{H}), 6.58(\mathrm{~d}, J=8.0 \mathrm{~Hz}$, 2H), $4.91(\mathrm{~d}, J=9.8 \mathrm{~Hz}, 1 \mathrm{H}), 4.45(\mathrm{~d}, J=9.9 \mathrm{~Hz}, 1 \mathrm{H}), 3.72(\mathrm{~d}, J=16.1 \mathrm{~Hz}, 1 \mathrm{H}), 3.49$ $(\mathrm{d}, J=16.0 \mathrm{~Hz}, 1 \mathrm{H}), 1.25(\mathrm{~s}, 9 \mathrm{H}) ;{ }^{13} \mathrm{C} \mathrm{NMR}\left(125 \mathrm{MHz}, \mathrm{CDCl}_{3}\right)(\delta, \mathrm{ppm}) 170.5,159.3$, $146.6,138.5,129.3,128.8,128.4,128.3,128.0,125.5,124.8,121.4,118.1,114.1$, 
109.8, 92.2, 82.8, 61.6, 38.3, 27.8; HRMS (TOF MS $\mathrm{ESI}^{+}$) calculated for $\mathrm{C}_{29} \mathrm{H}_{25} \mathrm{NO}_{3} \mathrm{Na} \quad[\mathrm{M}+\mathrm{Na}]^{+}:$458.1727, found 458.1728; HPLC conditions for determination of enantiomeric excess: Chiralpak IE-3, $\lambda=254 \mathrm{~nm}$, hexane : 2-propanol $=99.5: 0.5$, flow rate $=1.0 \mathrm{~mL} / \mathrm{min}, t_{\text {minor }}=14.4 \mathrm{~min}, t_{\text {major }}=17.6 \mathrm{~min}$.<smiles>O=C(O)[C@@H](c1ccccc1)[C@@]1(C(=O)OCc2ccccc2)Cc2ccccc2O1</smiles>

\section{Benzyl}

\section{(S)-2-((S)-phenyl(phenylamino)methyl)-2,3-dihydrobenzofuran-2-carboxylate}

(3d) Colorless oil. $32.7 \mathrm{mg}, 75 \%$ yield. 98\% ee, $>20: 1 d r .[\alpha]_{\mathrm{D}}{ }^{20}=39.0(\mathrm{c}=0.033$, DCM); ${ }^{1} \mathrm{H}$ NMR $\left(500 \mathrm{MHz}, \mathrm{CDCl}_{3}\right)(\delta, \mathrm{ppm}) 7.41(\mathrm{~d}, J=7.3 \mathrm{~Hz}, 2 \mathrm{H}), 7.29$ - 7.19 (comp, 6H), 7.16 (t, $J=7.6 \mathrm{~Hz}, 1 \mathrm{H}), 7.12-7.04$ (comp, 5H), 6.99 (d, J=8.0 Hz, 1H), $6.89(\mathrm{t}, J=7.4 \mathrm{~Hz}, 1 \mathrm{H}), 6.64(\mathrm{t}, J=7.3 \mathrm{~Hz}, 1 \mathrm{H}), 6.55(\mathrm{~d}, J=8.1 \mathrm{~Hz}, 2 \mathrm{H}), 5.01-4.92$ (comp, 3H), 4.51 (d, $J=9.9 \mathrm{~Hz}, 1 \mathrm{H}), 3.78$ (d, $J=16.1 \mathrm{~Hz}, 1 \mathrm{H}), 3.57$ (d, $J=16.1 \mathrm{~Hz}$, $1 \mathrm{H}) ;{ }^{13} \mathrm{C} \mathrm{NMR}\left(125 \mathrm{MHz}, \mathrm{CDCl}_{3}\right)(\delta, \mathrm{ppm}) 171.8,158.9,146.4,138.0,135.1,129.3$, 128.6, 128.48, 128.46, 128.43, 128.42, 128.4, 128.1, 125.4, 124.8, 121.7, 118.3, 114.1, 110.0, 92.6, 67.5, 61.6, 38.0; HRMS (TOF MS ESI ${ }^{+}$) calculated for $\mathrm{C}_{29} \mathrm{H}_{25} \mathrm{NO}_{3} \mathrm{Na}$ $[\mathrm{M}+\mathrm{Na}]^{+}:$458.1727, found 458.1728; HPLC conditions for determination of enantiomeric excess: Chiralpak IF-3, $\lambda=254 \mathrm{~nm}$, hexane : 2-propanol $=95: 5$, flow rate $=1.0 \mathrm{~mL} / \mathrm{min}, t_{\text {minor }}=8.5 \mathrm{~min}, t_{\text {major }}=7.5 \mathrm{~min}$.<smiles>C#CCOC(=O)[C@@]1([C@H](Nc2ccccc2)c2ccc(F)cc2)Cc2ccccc2O1</smiles>

Prop-2-yn-1-yl

(S)-2-((S)-(4-fluorophenyl)(phenylamino)methyl)-2,3-dihydrobenzofuran-2-carbo xylate (3e) Colorless oil. $28.5 \mathrm{mg}, 71 \%$ yield. 98\% ee, $>20: 1 d r \cdot[\alpha]_{\mathrm{D}}{ }^{20}=60.1(\mathrm{c}=$ 
0.033, DCM); ${ }^{1} \mathrm{H}$ NMR (500 MHz, $\left.\mathrm{CDCl}_{3}\right)(\delta, \mathrm{ppm}) 7.47-7.45(\mathrm{~m}, 2 \mathrm{H}), 7.18(\mathrm{t}, J=$ $7.7 \mathrm{~Hz}, 1 \mathrm{H}), 7.13$ (d, $J=7.3 \mathrm{~Hz}, 1 \mathrm{H}), 7.08$ (t, $J=7.4 \mathrm{~Hz}, 2 \mathrm{H}), 7.01-6.96$ (comp, 3H), $6.91(\mathrm{t}, J=7.3 \mathrm{~Hz}, 1 \mathrm{H}), 6.67(\mathrm{t}, J=7.2 \mathrm{~Hz}, 1 \mathrm{H}), 6.57(\mathrm{~d}, J=7.9 \mathrm{~Hz}, 2 \mathrm{H}), 4.98(\mathrm{~d}, J=$ $9.4 \mathrm{~Hz}, 1 \mathrm{H}), 4.55(\mathrm{q}, J=15.6 \mathrm{~Hz}, 2 \mathrm{H}), 4.44(\mathrm{~d}, J=9.5 \mathrm{~Hz}, 1 \mathrm{H}), 3.80(\mathrm{~d}, J=16.1 \mathrm{~Hz}$, $1 \mathrm{H}), 3.59(\mathrm{~d}, J=16.2 \mathrm{~Hz}, 1 \mathrm{H}), 2.40(\mathrm{~d}, J=1.4 \mathrm{~Hz}, 1 \mathrm{H}) ;{ }^{13} \mathrm{C} \mathrm{NMR}\left(125 \mathrm{MHz}, \mathrm{CDCl}_{3}\right)$ $(\delta, \mathrm{ppm}) 171.0,162.6(\mathrm{~d}, J=246.5 \mathrm{~Hz}), 158.7,146.1,133.7(\mathrm{~d}, J=3.1 \mathrm{~Hz}), 130.1(\mathrm{~d}$, $J=8.2 \mathrm{~Hz}), 129.4,128.6,125.1,124.9,121.9,118.6,115.5$ (d, $J=21.5 \mathrm{~Hz}), 114.2$, 110.1, 92.4, 76.7, 75.8, 61.0, 53.2, 37.9; $\left.{ }^{19} \mathrm{~F} \mathrm{NMR} \mathrm{(471} \mathrm{MHz}, \mathrm{CDCl}_{3}\right)(\delta, \mathrm{ppm})$ -114.13; HRMS (TOF MS ESI ${ }^{+}$) calculated for $\mathrm{C}_{25} \mathrm{H}_{20} \mathrm{FNO}_{3} \mathrm{Na}[\mathrm{M}+\mathrm{Na}]^{+}$: 424.1319, found 424.1335; HPLC conditions for determination of enantiomeric excess: Chiralpak IA, $\lambda=254 \mathrm{~nm}$, hexane $: 2$-propanol $=95: 5$, flow rate $=1.0 \mathrm{~mL} / \mathrm{min}, t_{\text {minor }}$ $=13.6 \mathrm{~min}, t_{\text {major }}=11.7 \mathrm{~min}$.<smiles>CC(C)[C@H]1CC[C@H](C)C[C@H]1OC(=O)[C@]1([C@@H](Nc2ccccc2)c2ccccc2)Cc2ccccc2O1</smiles>

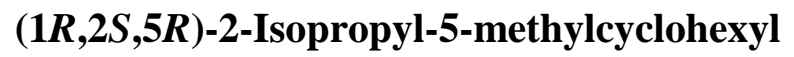

(S)-2-((S)-phenyl(phenylamino)methyl)-2,3-dihydrobenzofuran-2-carboxylate (3f) Colorless oil. $29.5 \mathrm{mg}, 61 \%$ yield. $>20: 1 d r .[\alpha]_{\mathrm{D}}{ }^{20}=69.1(\mathrm{c}=0.033, \mathrm{DCM}) ;{ }^{1} \mathrm{H}$ NMR (400 MHz, $\left.\mathrm{CDCl}_{3}\right)(\delta, \mathrm{ppm}) 7.49(\mathrm{~d}, J=7.2 \mathrm{~Hz}, 2 \mathrm{H}), 7.29-7.25(\mathrm{~m}, 2 \mathrm{H}), 7.22$ - 7.18 (m, 1H), 7.16 - 7.06 (comp, 4H), 6.96 (d, J=8.0 Hz, 1H), 6.87 (t, $J=7.4 \mathrm{~Hz}$, 1H), 6.66 - 6.59 (comp, 3H), 5.02 (s, 1H), 4.50 - 4.44 (comp, 2H), 3.78 (d, $J=16.0$ $\mathrm{Hz}, 1 \mathrm{H}), 3.51$ (d, J=15.9 Hz, 1H), 1.58 - 1.50 (m, 2H), 1.40 - 1.26 (comp, 3H), 1.23 1.09 (m, 2H), $0.92-0.81(\mathrm{~m}, 1 \mathrm{H}), 0.77$ (d, $J=6.5 \mathrm{~Hz}, 3 \mathrm{H}), 0.59$ (d, $J=6.9 \mathrm{~Hz}, 3 \mathrm{H})$, $0.50(\mathrm{~d}, J=11.4 \mathrm{~Hz}, 1 \mathrm{H}), 0.38(\mathrm{~d}, J=6.9 \mathrm{~Hz}, 3 \mathrm{H}) ;{ }^{13} \mathrm{C} \mathrm{NMR}\left(100 \mathrm{MHz}, \mathrm{CDCl}_{3}\right)(\delta$, ppm) 172.5, 159.2, 146.6, 138.4, 129.3, 128.7, 128.4, 128.2, 128.0, 125.6, 124.8, $121.5,118.1,114.0,109.9,93.2,76.2,60.9,46.6,39.9,38.5,34.2,31.3,25.7,23.3$, 
22.0, 20.7, 15.9; HRMS (TOF MS ESI ${ }^{+}$) calculated for $\mathrm{C}_{32} \mathrm{H}_{37} \mathrm{NO}_{3} \mathrm{Na}[\mathrm{M}+\mathrm{Na}]^{+}$: 506.2666, found 506.2669.<smiles>CCOC(=O)[C@@]1([C@H](Nc2ccc(F)cc2)c2ccccc2)Cc2cc(C)ccc2O1</smiles>

tert-Butyl

(S)-2-((S)-((4-fluorophenyl)amino)(phenyl)methyl)-5-methyl-2,3-dihydrobenzofu ran-2-carboxylate (3g) Colorless oil. $37.7 \mathrm{mg}, 87 \%$ yield. > 99\% ee, > 20:1 dr. $[\alpha]_{\mathrm{D}}^{20}=126.1(\mathrm{c}=0.033, \mathrm{DCM}) ;{ }^{1} \mathrm{H}$ NMR $\left(400 \mathrm{MHz}, \mathrm{CDCl}_{3}\right)(\delta, \mathrm{ppm}) 7.49-7.47$ (m, 2H), 7.29 - $7.25(\mathrm{~m}, 2 \mathrm{H}), 7.22$ - $7.19(\mathrm{~m}, 1 \mathrm{H}), 6.98$ - $6.93(\mathrm{~m}, 2 \mathrm{H}), 6.87$ (d, J = 8.1 Hz, 1H), 6.79 - 6.74 (m, 2H), 6.52 - 6.48 (m, 2H), 4.79 (s, 1H), 4.34 (s, 1H), 3.70 (d, J $=16.3 \mathrm{~Hz}, 1 \mathrm{H}), 3.45(\mathrm{~d}, J=16.1 \mathrm{~Hz}, 1 \mathrm{H}), 2.27(\mathrm{~s}, 3 \mathrm{H}), 1.24(\mathrm{~s}, 9 \mathrm{H}) ;{ }^{13} \mathrm{C}$ NMR $(100$ $\left.\mathrm{MHz}, \mathrm{CDCl}_{3}\right)(\delta, \mathrm{ppm}) 170.5,157.2,156.2(\mathrm{~d}, J=235.8 \mathrm{~Hz}), 142.9(\mathrm{~d}, J=1.9 \mathrm{~Hz})$, 138.4, 130.8, 128.8, 128.7, 128.3, 128.0, 125.5, 125.3, 115.7 (d, $J=22.3 \mathrm{~Hz}), 115.2$ (d, $J=7.5 \mathrm{~Hz}), 109.3,92.1,82.7,62.6,38.5,27.8,20.9 ;{ }^{19} \mathrm{~F} \mathrm{NMR}\left(376 \mathrm{MHz}, \mathrm{CDCl}_{3}\right)(\delta$, ppm) -127.20; HRMS (TOF MS ESI ${ }^{+}$) calculated for $\mathrm{C}_{27} \mathrm{H}_{28} \mathrm{FNO}_{3} \mathrm{Na}[\mathrm{M}+\mathrm{Na}]^{+}$: 456.1945, found 456.1943; HPLC conditions for determination of enantiomeric excess: Chiralpak IE-3, $\lambda=254 \mathrm{~nm}$, hexane : 2-propanol $=99: 1$, flow rate $=1.0$ $\mathrm{mL} / \mathrm{min}, t_{\text {minor }}=9.2 \mathrm{~min}, t_{\text {major }}=12.1 \mathrm{~min}$.<smiles>CC(C)(C)OC(=O)[C@]1([C@@H](Nc2ccc(F)cc2)c2ccccc2)Cc2cc(Cl)ccc2O1</smiles>

tert-Butyl

(S)-5-chloro-2-((S)-((4-fluorophenyl)amino)(phenyl)methyl)-2,3-dihydrobenzofur an-2-carboxylate (3h) Colorless oil. $30.9 \mathrm{mg}, 68 \%$ yield. $97 \%$ ee, $>20: 1 d r .[\alpha]_{\mathrm{D}}{ }^{20}=$ $78.08(\mathrm{c}=0.033, \mathrm{DCM}) ;{ }^{1} \mathrm{H} \mathrm{NMR}\left(500 \mathrm{MHz}, \mathrm{CDCl}_{3}\right)(\delta, \mathrm{ppm}) 7.46(\mathrm{~d}, J=7.5 \mathrm{~Hz}$, 2H), $7.29-7.20$ (comp, 3H), $7.13-7.08(\mathrm{~m}, 2 \mathrm{H}), 6.90$ (d, $J=8.5 \mathrm{~Hz}, 1 \mathrm{H}), 6.78(\mathrm{t}, J=$ $8.4 \mathrm{~Hz}, 2 \mathrm{H}), 6.53-6.51(\mathrm{~m}, 2 \mathrm{H}), 4.79(\mathrm{~s}, 1 \mathrm{H}), 4.26(\mathrm{~s}, 1 \mathrm{H}), 3.72(\mathrm{~d}, J=16.2 \mathrm{~Hz}, 1 \mathrm{H})$, 
$3.48(\mathrm{~d}, J=16.2 \mathrm{~Hz}, 1 \mathrm{H}), 1.24(\mathrm{~s}, 9 \mathrm{H}) ;{ }^{13} \mathrm{C} \mathrm{NMR}\left(125 \mathrm{MHz}, \mathrm{CDCl}_{3}\right)(\delta, \mathrm{ppm})$ 170.1, $157.9,156.3(\mathrm{~d}, J=236.3 \mathrm{~Hz}), 142.7(\mathrm{~d}, J=1.9 \mathrm{~Hz}), 137.9,128.7,128.4,128.3$, 128.2, 127.5, 126.2, 124.9, $115.8(\mathrm{~d}, J=22.4 \mathrm{~Hz}), 115.4(\mathrm{~d}, J=7.4 \mathrm{~Hz}), 110.7,92.9$, 83.1, 62.5, 38.1, 27.8; ${ }^{19} \mathrm{~F}$ NMR (471 MHz, $\left.\mathrm{CDCl}_{3}\right)(\delta$, ppm) -126.73; HRMS (TOF MS ESI ${ }^{+}$) calculated for $\mathrm{C}_{26} \mathrm{H}_{26} \mathrm{ClFNO}_{3}[\mathrm{M}+\mathrm{H}]^{+}$: 454.1580, found 454.1580; HPLC conditions for determination of enantiomeric excess: Chiralpak IE-3, $\lambda=254 \mathrm{~nm}$, hexane $: 2$-propanol $=99: 1$, flow rate $=1.0 \mathrm{~mL} / \mathrm{min}, t_{\mathrm{minor}}=7.9 \mathrm{~min}, t_{\mathrm{major}}=9.8 \mathrm{~min}$.

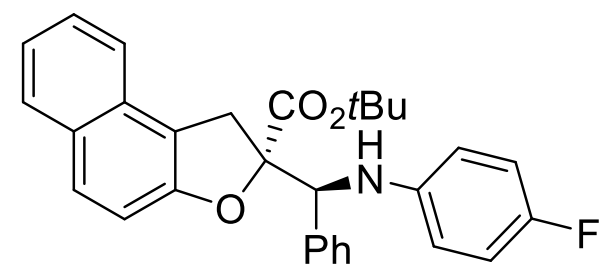

tert-Butyl

(S)-2-((S)-((4-fluorophenyl)amino)(phenyl)methyl)-1,2-dihydronaphtho[2,1-b]fur an-2-carboxylate (3i) Colorless oil. $31.0 \mathrm{mg}, 66 \%$ yield. $96 \% e e,>20: 1 d r \cdot[\alpha]_{\mathrm{D}}{ }^{20}=$ $156.2(\mathrm{c}=0.033, \mathrm{DCM}) ;{ }^{1} \mathrm{H} \mathrm{NMR}\left(500 \mathrm{MHz}, \mathrm{CDCl}_{3}\right)(\delta, \mathrm{ppm}) 7.82(\mathrm{~d}, J=8.2 \mathrm{~Hz}$, 1H), $7.74(\mathrm{~d}, J=8.8 \mathrm{~Hz}, 1 \mathrm{H}), 7.57-7.53$ (comp, 3H), 7.47 (t, $J=7.4 \mathrm{~Hz}, 1 \mathrm{H}), 7.34$ 7.30 (comp, 3H), $7.25-7.21(\mathrm{~m}, 2 \mathrm{H}), 6.76(\mathrm{t}, J=8.2 \mathrm{~Hz}, 2 \mathrm{H}), 6.51(\mathrm{dd}, J=7.7,4.4$ $\mathrm{Hz}, 2 \mathrm{H}), 4.91(\mathrm{~d}, J=9.0 \mathrm{~Hz}, 1 \mathrm{H}), 4.39$ (d, $J=9.1 \mathrm{~Hz}, 1 \mathrm{H}), 3.98(\mathrm{~d}, J=16.0 \mathrm{~Hz}, 1 \mathrm{H})$, $3.80(\mathrm{~d}, J=15.8 \mathrm{~Hz}, 1 \mathrm{H}), 1.25(\mathrm{~s}, 9 \mathrm{H}) ;{ }^{13} \mathrm{C} \mathrm{NMR}\left(125 \mathrm{MHz}, \mathrm{CDCl}_{3}\right)(\delta, \mathrm{ppm}) 170.5$, 156.8, $156.2(\mathrm{~d}, J=235.8 \mathrm{~Hz}), 142.9$ (d, $J=1.8 \mathrm{~Hz}), 138.3,130.5,129.8,129.6$, 128.88, 128.85, 128.4, 128.1, 127.0, 123.5, 123.0, 117.6, 115.7 (d, $J=22.3 \mathrm{~Hz}), 115.3$ $(\mathrm{d}, J=7.4 \mathrm{~Hz}), 112.1,93.0,83.0,62.9,37.5,27.8 ;{ }^{19} \mathrm{~F} \mathrm{NMR}\left(471 \mathrm{MHz}, \mathrm{CDCl}_{3}\right)(\delta$, ppm) -127.10; HRMS (TOF MS ESI ${ }^{+}$) calculated for $\mathrm{C}_{30} \mathrm{H}_{28} \mathrm{FNO}_{3} \mathrm{Na}[\mathrm{M}+\mathrm{Na}]^{+}$: 492.1945, found 492.1947; HPLC conditions for determination of enantiomeric excess: Chiralpak IE-3, $\lambda=254 \mathrm{~nm}$, hexane : 2-propanol $=99: 1$, flow rate $=1.0$ $\mathrm{mL} / \mathrm{min}, t_{\mathrm{minor}}=13.2 \mathrm{~min}, t_{\mathrm{major}}=17.8 \mathrm{~min}$. 


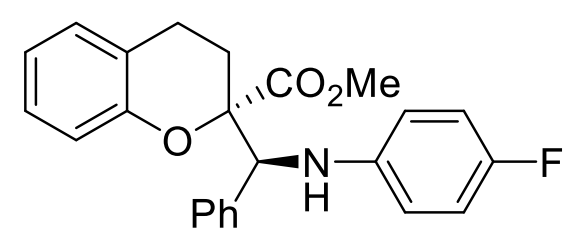

\section{Methyl}

(S)-2-((S)-((4-fluorophenyl)amino)(phenyl)methyl)chromane-2-carboxylate (3j)

Colorless oil. $21.5 \mathrm{mg}, 55 \%$ yield. $90 \%$ ee, $>20: 1 d r .[\alpha]_{\mathrm{D}}^{20}=99.01(\mathrm{c}=0.033$, DCM); ${ }^{1} \mathrm{H}$ NMR $\left(400 \mathrm{MHz}, \mathrm{CDCl}_{3}\right)(\delta, \mathrm{ppm}) 7.43(\mathrm{~d}, J=7.2 \mathrm{~Hz}, 2 \mathrm{H}), 7.32$ - $7.28(\mathrm{~m}$, 2H), $7.25-7.22(\mathrm{~m}, 1 \mathrm{H}), 7.15(\mathrm{t}, J=7.7 \mathrm{~Hz}, 1 \mathrm{H}), 7.02(\mathrm{~d}, J=7.7 \mathrm{~Hz}, 2 \mathrm{H}), 6.88(\mathrm{t}, J=$ $7.4 \mathrm{~Hz}, 1 \mathrm{H}), 6.80$ - $6.76(\mathrm{~m}, 2 \mathrm{H}), 6.52$ - 6.49 (m, 2H), 4.76 - 4.72 (comp, 2H), 3.45 (s, $3 \mathrm{H}), 2.78-2.62(\mathrm{~m}, 2 \mathrm{H}), 2.50-2.38(\mathrm{~m}, 2 \mathrm{H}) ;{ }^{13} \mathrm{C} \mathrm{NMR}\left(100 \mathrm{MHz}, \mathrm{CDCl}_{3}\right)(\delta, \mathrm{ppm})$ $171.8,156.0(\mathrm{~d}, J=235.2 \mathrm{~Hz}), 153.6,143.1(\mathrm{~d}, J=2.0 \mathrm{~Hz}), 138.2,129.5,128.5$, 128.3, 128.1, 127.7, 121.2, 121.1, 117.0, 115.8 (d, $J=22.4 \mathrm{~Hz}), 114.7$ (d, $J=7.4 \mathrm{~Hz})$, 84.4, 63.4, 52.4, 27.2, 22.6; ${ }^{19} \mathrm{~F}$ NMR (376 MHz, $\left.\mathrm{CDCl}_{3}\right)(\delta, \mathrm{ppm})-127.57$; HRMS (TOF MS ESI ${ }^{+}$) calculated for $\mathrm{C}_{24} \mathrm{H}_{23} \mathrm{FNO}_{3}[\mathrm{M}+\mathrm{H}]^{+}$: 392.1656, found 392.1656; HPLC conditions for determination of enantiomeric excess: Chiralpak IA, $\lambda=254 \mathrm{~nm}$, hexane $:$-propanol $=99: 1$, flow rate $=1.0 \mathrm{~mL} / \mathrm{min}, t_{\text {minor }}=18.0 \mathrm{~min}, t_{\text {major }}=18.9$ $\min$.

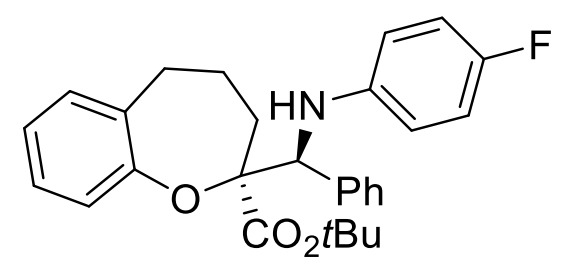

tert-Butyl

(S)-2-((S)-((4-fluorophenyl)amino)(phenyl)methyl)-2,3,4,5-tetrahydrobenzo[b]oxe pine-2-carboxylate (3k) Colorless oil. $22.8 \mathrm{mg}, 51 \%$ yield. 85\% ee, > 20:1 dr. $[\alpha]_{\mathrm{D}}{ }^{20}$ $=-45.0(\mathrm{c}=0.033, \mathrm{DCM}) ;{ }^{1} \mathrm{H} \mathrm{NMR}\left(400 \mathrm{MHz}, \mathrm{CDCl}_{3}\right)(\delta, \mathrm{ppm}) 7.51-7.49(\mathrm{~m}, 2 \mathrm{H})$, 7.32 - $7.29(\mathrm{~m}, 2 \mathrm{H}), 7.13$ - $7.09(\mathrm{~m}, 2 \mathrm{H}), 7.06$ - $7.04(\mathrm{~m}, 2 \mathrm{H}), 6.97$ - $6.95(\mathrm{~m}, 1 \mathrm{H})$, $6.80-6.76(\mathrm{~m}, 2 \mathrm{H}), 6.51-6.47(\mathrm{~m}, 2 \mathrm{H}), 4.92(\mathrm{~s}, 1 \mathrm{H}), 4.63(\mathrm{~s}, 1 \mathrm{H}), 2.77$ - $2.73(\mathrm{~m}$, 2H), 2.44 - $2.38(\mathrm{~m}, 1 \mathrm{H}), 2.23-2.15(\mathrm{~m}, 1 \mathrm{H}), 2.07$ - $1.99(\mathrm{~m}, 1 \mathrm{H}), 1.92-1.88(\mathrm{~m}, 1 \mathrm{H})$, $1.06(\mathrm{~s}, 9 \mathrm{H}) ;{ }^{13} \mathrm{C} \mathrm{NMR}\left(100 \mathrm{MHz}, \mathrm{CDCl}_{3}\right)(\delta, \mathrm{ppm}) 169.6,155.9(\mathrm{~d}, J=235.0 \mathrm{~Hz})$, 
155.8, $143.6(\mathrm{~d}, J=1.5 \mathrm{~Hz}), 138.9,133.9,130.0,129.1,128.1,127.9,126.9,124.1$, 123.6, $115.7(\mathrm{~d}, J=22.3 \mathrm{~Hz}), 114.4$ (d, $J=7.4 \mathrm{~Hz}), 87.8,82.7,65.7,35.9,33.6,27.7$, 22.9; ${ }^{19} \mathrm{~F}$ NMR (376 MHz, $\left.\mathrm{CDCl}_{3}\right)$ ( $\left.\delta, \mathrm{ppm}\right)$-128.07; HRMS (TOF MS ESI ${ }^{+}$) calculated for $\mathrm{C}_{28} \mathrm{H}_{31} \mathrm{FNO}_{3}[\mathrm{M}+\mathrm{H}]^{+}:$448.2282, found 448.2281; HPLC conditions for determination of enantiomeric excess: Chiralpak IA, $\lambda=254 \mathrm{~nm}$, hexane : 2-propanol $=99: 1$, flow rate $=1.0 \mathrm{~mL} / \mathrm{min}, t_{\text {minor }}=7.8 \mathrm{~min}, t_{\text {major }}=12.1 \mathrm{~min}$.<smiles>COC(=O)[C@]1([C@H](Nc2ccccc2)c2ccccc2)CCc2ccccc2N1</smiles>

Methyl (S)-2-((S)-phenyl(phenylamino)methyl)-1,2,3,4-tetrahydroquinoline-2carboxylate (31)

The major one: Colorless oil. $16.4 \mathrm{mg}, 42 \%$ yield. $83 \%$ ee. $[\alpha]_{\mathrm{D}}{ }^{20}=15.0(\mathrm{c}=0.033$, DCM); ${ }^{1} \mathrm{H}$ NMR (500 MHz, $\left.\mathrm{CDCl}_{3}\right)(\delta, \mathrm{ppm}) 7.34$ - 7.26 (comp, 5H), 7.08 7.02(comp, 3H), 6.96 (d, J=7.4 Hz, 1H), 6.72 (t, $J=7.4 \mathrm{~Hz}, 1 \mathrm{H}), 6.67$ (d, J = 7.9 Hz, 1H), 6.61 (t, $J=7.3 \mathrm{~Hz}, 1 \mathrm{H}), 6.52(\mathrm{~d}, J=7.8 \mathrm{~Hz}, 2 \mathrm{H}), 5.00$ (s, 1H), 4.84 (s, 1H), 4.32 (s, 1H), $3.54(\mathrm{~s}, 3 \mathrm{H}), 2.78-2.73(\mathrm{~m}, 1 \mathrm{H}), 2.68-2.60(\mathrm{~m}, 1 \mathrm{H}), 2.45-2.42(\mathrm{~m}, 2 \mathrm{H})$; ${ }^{13} \mathrm{C}$ NMR $\left(125 \mathrm{MHz}, \mathrm{CDCl}_{3}\right)(\delta, \mathrm{ppm}) 174.4,146.6,143.2,138.6,129.3,129.2,128.9$, 128.2, 127.4, 127.2, 121.7, 119.1, 117.5, 116.2, 113.4, 66.0, 62.2, 52.4, 28.7, 24.7. HRMS (TOF MS ESI ${ }^{+}$) calculated for $\mathrm{C}_{24} \mathrm{H}_{25} \mathrm{~N}_{2} \mathrm{O}_{2}[\mathrm{M}+\mathrm{H}]^{+}: 373.1911$, found 373.1913; HPLC conditions for determination of enantiomeric excess: Chiralpak IC, $\lambda$ $=254 \mathrm{~nm}$, hexane $: 2$-propanol $=95: 5$, flow rate $=1.0 \mathrm{~mL} / \mathrm{min}, t_{\text {minor }}=5.4 \mathrm{~min}, t_{\text {major }}$ $=6.9 \mathrm{~min}$.

The minor one: Colorless oil. $7.8 \mathrm{mg}, 21 \%$ yield. $91 \%$ ee. $[\alpha]_{\mathrm{D}}{ }^{20}=-30.0(\mathrm{c}=0.033$, DCM); ${ }^{1} \mathrm{H}$ NMR (500 MHz, $\left.\mathrm{CDCl}_{3}\right)(\delta, \mathrm{ppm}) 7.31$ - 7.25 (comp, 5H), 7.07 - 7.02 (comp, 3H), $6.97(\mathrm{~d}, J=7.4 \mathrm{~Hz}, 1 \mathrm{H}), 6.69(\mathrm{t}, J=7.4 \mathrm{~Hz}, 1 \mathrm{H}), 6.63-6.58(\mathrm{~m}, 2 \mathrm{H})$, $6.51(\mathrm{~d}, J=7.7 \mathrm{~Hz}, 2 \mathrm{H}), 5.22(\mathrm{~s}, 1 \mathrm{H}), 4.58(\mathrm{~s}, 1 \mathrm{H}), 4.33$ (s, 1H), 3.63 (s, 3H), 2.75 $2.64(\mathrm{~m}, 2 \mathrm{H}), 2.33(\mathrm{t}, J=6.7 \mathrm{~Hz}, 2 \mathrm{H}) ;{ }^{13} \mathrm{C} \mathrm{NMR}\left(125 \mathrm{MHz}, \mathrm{CDCl}_{3}\right)(\delta, \mathrm{ppm}) 174.5$, $147.0,142.3,138.5,129.3,129.3,128.6,128.2$, 127.9, 127.3, 120.7, 118.4, 117.8, 115.3, 113.6, 63.8, 62.6, 52.6, 27.7, 23.8; HRMS (TOF MS ESI ${ }^{+}$) calculated for 
$\mathrm{C}_{24} \mathrm{H}_{25} \mathrm{~N}_{2} \mathrm{O}_{2}[\mathrm{M}+\mathrm{H}]^{+}:$373.1911, found 373.1912; HPLC conditions for determination of enantiomeric excess: Chiralpak AD-H, $\lambda=254 \mathrm{~nm}$, hexane : 2-propanol $=95: 5$, flow rate $=1.0 \mathrm{~mL} / \mathrm{min}, t_{\text {minor }}=23.5 \mathrm{~min}, t_{\text {major }}=15.5 \mathrm{~min}$.<smiles>C[C@@](NC(=O)c1ccccc1)(OCc1ccccc1)[C@H](OCc1ccccc1)c1ccccc1</smiles>

\section{Benzyl}

((tert-butoxycarbonyl)amino)(phenyl)methyl)-2,3-dihydrobenzofuran-2-carboxyl ate (3m) Colorless oil. $16.1 \mathrm{mg}, 35 \%$ yield. <5\% ee, 20:1 dr; ${ }^{1} \mathrm{H}$ NMR (500 MHz, $\left.\mathrm{CDCl}_{3}\right)(\delta, \mathrm{ppm}) 7.40(\mathrm{~s}, 2 \mathrm{H}), 7.28-7.26(\mathrm{comp}, 6 \mathrm{H}), 7.19-7.14(\mathrm{~m}, 2 \mathrm{H}), 7.08-7.07$ $(\mathrm{m}, 2 \mathrm{H}), 6.99(\mathrm{~d}, J=7.8 \mathrm{~Hz}, 1 \mathrm{H}), 6.91(\mathrm{t}, J=7.3 \mathrm{~Hz}, 1 \mathrm{H}), 5.31(\mathrm{~d}, J=10.1 \mathrm{~Hz}, 1 \mathrm{H})$, $5.23(\mathrm{~d}, J=10.0 \mathrm{~Hz}, 1 \mathrm{H}), 4.91(\mathrm{q}, J=12.2 \mathrm{~Hz}, 2 \mathrm{H}), 3.67(\mathrm{~d}, J=16.4 \mathrm{~Hz}, 1 \mathrm{H}), 3.51(\mathrm{~d}$, $J=16.4 \mathrm{~Hz}, 1 \mathrm{H}), 1.33(\mathrm{~s}, 9 \mathrm{H}) ;{ }^{13} \mathrm{C} \mathrm{NMR}\left(125 \mathrm{MHz}, \mathrm{CDCl}_{3}\right)(\delta, \mathrm{ppm}) 171.1,159.2$, 155.6, 138.0, 134.9, 128.6, 128.50, 128.48, 128.32, 128.25, 125.2, 124.8, 121.7, 110.0, 92.0, 80.3, 67.5, 58.6, 38.4, 28.3; HRMS (TOF MS $\mathrm{ESI}^{+}$) calculated for $\mathrm{C}_{28} \mathrm{H}_{29} \mathrm{NO}_{5} \mathrm{Na} \quad[\mathrm{M}+\mathrm{Na}]^{+}:$482.1938, found 482.1936; HPLC conditions for determination of enantiomeric excess: Chiralpak IF-3, $\lambda=254 \mathrm{~nm}$, hexane : 2-propanol $=95: 5$, flow rate $=1.0 \mathrm{~mL} / \mathrm{min}, t_{1}=13.5 \mathrm{~min}, t_{2}=12.2 \mathrm{~min}$.<smiles>CO[C@H](Nc1ccccc1)[C@H](c1ccc(F)cc1)C1(C)Cc2ccccc2O1</smiles>

\section{Methyl}

(S)-2-((S)-(4-fluorophenyl)(phenylamino)methyl)-2,3-dihydrobenzofuran-2-carbo xylate (5a) White solid, $\mathrm{mp}=142-143{ }^{\circ} \mathrm{C} .25 .3 \mathrm{mg}, 67 \%$ yield. 95\% ee, > 20:1 dr. $[\alpha]_{\mathrm{D}}^{20}=48.0(\mathrm{c}=0.033, \mathrm{DCM}) ;{ }^{1} \mathrm{H}$ NMR $\left(500 \mathrm{MHz}, \mathrm{CDCl}_{3}\right)(\delta, \mathrm{ppm}) 7.42(\mathrm{dd}, J=$ 7.9, $5.6 \mathrm{~Hz}, 2 \mathrm{H}), 7.18(\mathrm{t}, J=7.7 \mathrm{~Hz}, 1 \mathrm{H}), 7.13(\mathrm{~d}, J=7.3 \mathrm{~Hz}, 1 \mathrm{H}), 7.08(\mathrm{t}, J=7.6 \mathrm{~Hz}$, 
2H), $6.98(\mathrm{t}, J=9.4 \mathrm{~Hz}, 3 \mathrm{H}), 6.91(\mathrm{t}, J=7.4 \mathrm{~Hz}, 1 \mathrm{H}), 6.67(\mathrm{t}, J=7.3 \mathrm{~Hz}, 1 \mathrm{H}), 6.55(\mathrm{~d}$, $J=8.0 \mathrm{~Hz}, 2 \mathrm{H}), 4.96(\mathrm{~d}, J=9.8 \mathrm{~Hz}, 1 \mathrm{H}), 4.46(\mathrm{~d}, J=9.8 \mathrm{~Hz}, 1 \mathrm{H}), 3.79(\mathrm{~d}, J=16.2$ $\mathrm{Hz}, 1 \mathrm{H}), 3.58(\mathrm{~d}, J=16.2 \mathrm{~Hz}, 1 \mathrm{H}), 3.54(\mathrm{~s}, 3 \mathrm{H}) ;{ }^{13} \mathrm{C} \mathrm{NMR}\left(125 \mathrm{MHz}, \mathrm{CDCl}_{3}\right)(\delta$, ppm) $172.6,162.6(\mathrm{~d}, J=246.6 \mathrm{~Hz}), 158.7,146.2,133.9$ (d, $J=3.2 \mathrm{~Hz}), 129.9$ (d, $J=$ 8.2 Hz), 129.4, 128.5, 125.3, 124.9, 121.9, 118.5, 115.5 (d, J = 21.4 Hz), 114.1, 110.0, 92.6, 61.0, 52.8, 37.9; ${ }^{19} \mathrm{~F}$ NMR (376 $\left.\mathrm{MHz}, \mathrm{CDCl}_{3}\right)(\delta$, ppm) -114.14; HRMS (TOF MS ESI ${ }^{+}$) calculated for $\mathrm{C}_{23} \mathrm{H}_{20} \mathrm{FNO}_{3} \mathrm{Na}[\mathrm{M}+\mathrm{Na}]^{+}$: 400.1319, found 400.1310; HPLC conditions for determination of enantiomeric excess: Chiralpak AD-H, $\lambda=254 \mathrm{~nm}$, hexane $: 2$-propanol $=95: 5$, flow rate $=1.0 \mathrm{~mL} / \mathrm{min}, t_{\text {minor }}=11.4 \mathrm{~min}, t_{\text {major }}=16.4$ $\min$.<smiles>COC(=O)[C@]1([C@@H](Nc2ccccc2)c2ccc(C(F)(F)F)cc2)Cc2ccccc2O1</smiles>

Methyl (S)-2-((S)-(phenylamino)(4-(trifluoromethyl)phenyl)methyl)-2,3dihydrobenzofuran-2-carboxylate (5b) Colorless oil. $25.6 \mathrm{mg}, 60 \%$ yield. $90 \%$ $e e,>20: 1 d r .[\alpha]_{\mathrm{D}}{ }^{20}=54.0(\mathrm{c}=0.033, \mathrm{DCM}) ;{ }^{1} \mathrm{H} \mathrm{NMR}\left(500 \mathrm{MHz}, \mathrm{CDCl}_{3}\right)(\delta, \mathrm{ppm})$ $7.68-7.67(\mathrm{~m}, 2 \mathrm{H}), 7.50(\mathrm{~d}, J=7.7 \mathrm{~Hz}, 1 \mathrm{H}), 7.42(\mathrm{t}, J=7.8 \mathrm{~Hz}, 1 \mathrm{H}), 7.18(\mathrm{t}, J=7.7$ Hz, 1H), 7.13 - 7.08 (comp, 3H), 6.99 (d, $J=8.0 \mathrm{~Hz}, 1 \mathrm{H}), 6.91$ (t, $J=7.4 \mathrm{~Hz}, 1 \mathrm{H})$, $6.69(\mathrm{t}, J=7.3 \mathrm{~Hz}, 1 \mathrm{H}), 6.56(\mathrm{~d}, J=8.0 \mathrm{~Hz}, 2 \mathrm{H}), 5.05(\mathrm{~d}, J=9.6 \mathrm{~Hz}, 1 \mathrm{H}), 4.52(\mathrm{~d}, J=$ $9.6 \mathrm{~Hz}, 1 \mathrm{H}), 3.79(\mathrm{~d}, J=16.2 \mathrm{~Hz}, 1 \mathrm{H}), 3.60(\mathrm{~d}, J=16.3 \mathrm{~Hz}, 1 \mathrm{H}), 3.56(\mathrm{~s}, 3 \mathrm{H}) ;{ }^{13} \mathrm{C}$ $\operatorname{NMR}\left(125 \mathrm{MHz}, \mathrm{CDCl}_{3}\right)(\delta, \mathrm{ppm}) 172.3,158.6,145.9,139.3,131.4,130.7$ (q, $J=$ $32.3 \mathrm{~Hz}), 129.5,129.1,128.6,125.3(\mathrm{q}, J=4.0 \mathrm{~Hz}), 125.1,124.9,122.0$ (q, $J=270.4$ $\mathrm{Hz}), 121.96,118.7,114.1,110.0,92.3,61.4,52.8,37.8 ;{ }^{19} \mathrm{~F} \mathrm{NMR}\left(376 \mathrm{MHz}, \mathrm{CDCl}_{3}\right)$ ( $\delta$, ppm) -62.49; HRMS (TOF MS ESI ${ }^{+}$) calculated for $\mathrm{C}_{24} \mathrm{H}_{20} \mathrm{~F}_{3} \mathrm{NO}_{3} \mathrm{Na}[\mathrm{M}+\mathrm{Na}]^{+}$: 450.1287, found 450.1292; HPLC conditions for determination of enantiomeric excess: Chiralpak AD-H, $\lambda=254 \mathrm{~nm}$, hexane : 2-propanol $=90: 10$, flow rate $=1.0$ $\mathrm{mL} / \mathrm{min}, t_{\mathrm{minor}}=5.4 \mathrm{~min}, t_{\mathrm{major}}=6.2 \mathrm{~min}$. 
<smiles>CCCC(=O)N[C@H](c1ccccc1C(F)(F)F)[C@]1(C(=O)OCC)Cc2ccccc2O1</smiles>

tert-Butyl

(S)-2-((S)-(phenylamino)(2-(trifluoromethyl)phenyl)methyl)-2,3-dihydrobenzofur an-2-carboxylate (5c) Colorless oil. $32.9 \mathrm{mg}, 70 \%$ yield. $>99 \%$ ee, $>20: 1 d r .[\alpha]_{\mathrm{D}}{ }^{20}$ $=135.1(\mathrm{c}=0.033, \mathrm{DCM}) ;{ }^{1} \mathrm{H} \mathrm{NMR}\left(500 \mathrm{MHz}, \mathrm{CDCl}_{3}\right)(\delta, \mathrm{ppm}) 8.24(\mathrm{~d}, J=8.0 \mathrm{~Hz}$, 1H), $7.63-7.57(\mathrm{~m}, 2 \mathrm{H}), 7.37(\mathrm{t}, J=7.6 \mathrm{~Hz}, 1 \mathrm{H}), 7.14(\mathrm{t}, J=7.7 \mathrm{~Hz}, 1 \mathrm{H}), 7.07(\mathrm{t}, J=$ $7.7 \mathrm{~Hz}, 2 \mathrm{H}), 7.01-6.99(\mathrm{~m}, 2 \mathrm{H}), 6.83(\mathrm{t}, J=7.4 \mathrm{~Hz}, 1 \mathrm{H}), 6.66(\mathrm{t}, J=7.3 \mathrm{~Hz}, 1 \mathrm{H})$, $6.62(\mathrm{~d}, J=8.0 \mathrm{~Hz}, 2 \mathrm{H}), 5.61(\mathrm{~d}, J=9.6 \mathrm{~Hz}, 1 \mathrm{H}), 4.17(\mathrm{~d}, J=9.9 \mathrm{~Hz}, 1 \mathrm{H}), 3.59$ (q, $J$ $=16.1 \mathrm{~Hz}, 2 \mathrm{H}), 1.13(\mathrm{~s}, 9 \mathrm{H}) ;{ }^{13} \mathrm{C} \mathrm{NMR}\left(125 \mathrm{MHz}, \mathrm{CDCl}_{3}\right)(\delta, \mathrm{ppm}) 170.1,159.2$, $146.4,138.5,132.5,129.8,129.2,128.3,128.2(\mathrm{q}, J=29.8 \mathrm{~Hz}), 128.0,126.3(\mathrm{q}, J=$ $5.9 \mathrm{~Hz}), 125.1,124.7,124.5(\mathrm{q}, J=274.5 \mathrm{~Hz}), 121.4,118.5,114.2,109.6,92.8,82.8$, 56.9 (q, $J=2.3 \mathrm{~Hz}), 39.0,27.5 ;{ }^{19} \mathrm{~F} \mathrm{NMR}\left(471 \mathrm{MHz}, \mathrm{CDCl}_{3}\right)(\delta, \mathrm{ppm})-56.32 ; \mathrm{HRMS}$ (TOF MS ESI ${ }^{+}$) calculated for $\mathrm{C}_{27} \mathrm{H}_{26} \mathrm{~F}_{3} \mathrm{NO}_{3} \mathrm{Na}[\mathrm{M}+\mathrm{Na}]^{+}$: 492.1757, found 492.1756; HPLC conditions for determination of enantiomeric excess: Chiralpak IE-3, $\lambda=254$ $\mathrm{nm}$, hexane $: 2$-propanol $=99: 1$, flow rate $=1.0 \mathrm{~mL} / \mathrm{min}, t_{\text {minor }}=6.5 \mathrm{~min}, t_{\text {major }}=7.3$ $\min$.

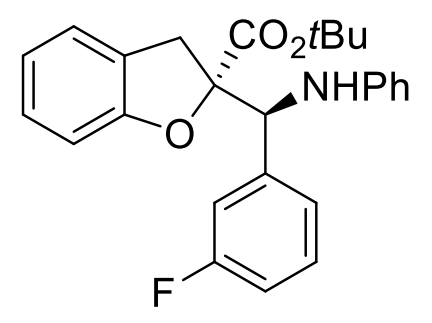

tert-Butyl

(S)-2-((S)-(3-fluorophenyl)(phenylamino)methyl)-2,3-dihydrobenzofuran-2-carbo xylate (5d) Colorless oil. $34.0 \mathrm{mg}, 81 \%$ yield. $>99 \%$ ee, $>20: 1 d r .[\alpha]_{\mathrm{D}}{ }^{20}=108.1(\mathrm{c}$ $=0.033, \mathrm{DCM}) ;{ }^{1} \mathrm{H} \mathrm{NMR}\left(500 \mathrm{MHz}, \mathrm{CDCl}_{3}\right)(\delta, \mathrm{ppm}) 7.30(\mathrm{~d}, J=7.7 \mathrm{~Hz}, 1 \mathrm{H}), 7.26-$ $7.23(\mathrm{~m}, 2 \mathrm{H}), 7.17$ (t, $J=7.7 \mathrm{~Hz}, 1 \mathrm{H}), 7.12-7.07$ (comp, 3H), 6.99 (d, $J=8.0 \mathrm{~Hz}$, 1H), $6.93-6.87(\mathrm{~m}, 2 \mathrm{H}), 6.66(\mathrm{t}, J=7.3 \mathrm{~Hz}, 1 \mathrm{H}), 6.57(\mathrm{~d}, J=7.9 \mathrm{~Hz}, 2 \mathrm{H}), 4.92(\mathrm{~d}, J$ 
$=9.8 \mathrm{~Hz}, 1 \mathrm{H}), 4.42(\mathrm{~d}, J=9.9 \mathrm{~Hz}, 1 \mathrm{H}), 3.72(\mathrm{~d}, J=16.1 \mathrm{~Hz}, 1 \mathrm{H}), 3.49(\mathrm{~d}, J=16.1$ $\mathrm{Hz}, 1 \mathrm{H}), 1.28(\mathrm{~s}, 9 \mathrm{H}) ;{ }^{13} \mathrm{C} \mathrm{NMR}\left(125 \mathrm{MHz}, \mathrm{CDCl}_{3}\right)(\delta, \mathrm{ppm}) 170.3,162.8(\mathrm{~d}, J=$ $245.9 \mathrm{~Hz}), 159.2,146.3,141.1(\mathrm{~d}, J=6.5 \mathrm{~Hz}), 129.8(\mathrm{~d}, J=8.1 \mathrm{~Hz}), 129.4,128.5$, 125.4, 124.8, 124.6 (d, $J=2.8 \mathrm{~Hz}), 121.5,118.4,115.9$ (d, $J=21.9 \mathrm{~Hz}), 115.0$ (d, $J=$ $21.1 \mathrm{~Hz}), 114.1,109.8,91.9,83.0,61.2,38.2,27.8 ;{ }^{19} \mathrm{~F}$ NMR $\left(471 \mathrm{MHz}, \mathrm{CDCl}_{3}\right)(\delta$, ppm) -113.12; HRMS (TOF MS ESI ${ }^{+}$) calculated for $\mathrm{C}_{26} \mathrm{H}_{26} \mathrm{FNO}_{3} \mathrm{Na}[\mathrm{M}+\mathrm{Na}]^{+}$: 442.1789, found 442.1786; HPLC conditions for determination of enantiomeric excess: Chiralpak IE-3, $\lambda=254 \mathrm{~nm}$, hexane : 2-propanol $=99: 1$, flow rate $=1.0$ $\mathrm{mL} / \mathrm{min}, t_{\mathrm{minor}}=8.2 \mathrm{~min}, t_{\mathrm{major}}=10.3 \mathrm{~min}$.<smiles>CCCOC(=O)N[C@@H](c1ccc(F)cc1)[C@]1(C)Cc2ccccc2O1</smiles>

tert-Butyl

(S)-2-((S)-(4-fluorophenyl)(phenylamino)methyl)-2,3-dihydrobenzofuran-2-carbo xylate (5e) Colorless oil. $36.0 \mathrm{mg}, 86 \%$ yield. 99\% ee, $>20: 1 d r .[\alpha]_{\mathrm{D}}{ }^{20}=93.1(\mathrm{c}=$ 0.033, DCM); ${ }^{1} \mathrm{H}$ NMR (500 MHz, $\left.\mathrm{CDCl}_{3}\right)(\delta, \mathrm{ppm}) 7.51-7.49(\mathrm{~m}, 2 \mathrm{H}), 7.17(\mathrm{t}, J=$ $7.7 \mathrm{~Hz}, 1 \mathrm{H}), 7.12$ - 7.06 (comp, 3H), 6.99 - 6.95 (comp, 3H), 6.89 (t, J = 7.4 Hz, 1H), $6.66(\mathrm{t}, J=7.3 \mathrm{~Hz}, 1 \mathrm{H}), 6.56(\mathrm{~d}, J=8.0 \mathrm{~Hz}, 2 \mathrm{H}), 4.91(\mathrm{~d}, J=9.6 \mathrm{~Hz}, 1 \mathrm{H}), 4.39(\mathrm{~d}, J=$ $9.8 \mathrm{~Hz}, 1 \mathrm{H}), 3.71(\mathrm{~d}, J=16.1 \mathrm{~Hz}, 1 \mathrm{H}), 3.49(\mathrm{~d}, J=16.1 \mathrm{~Hz}, 1 \mathrm{H}), 1.26(\mathrm{~s}, 9 \mathrm{H}) ;{ }^{13} \mathrm{C}$ NMR $\left(125 \mathrm{MHz}, \mathrm{CDCl}_{3}\right)(\delta, \mathrm{ppm}) 170.5,162.5(\mathrm{~d}, J=246.2 \mathrm{~Hz}), 159.2,146.4,134.3$ $(\mathrm{d}, J=3.2 \mathrm{~Hz}), 130.5$ (d, $J=8.2 \mathrm{~Hz}), 129.3,128.4,125.4,124.8,121.5,118.4,115.2$ $(\mathrm{d}, J=21.4 \mathrm{~Hz}), 114.1,109.8,92.1,82.9,60.9,38.2,27.8 ;{ }^{19} \mathrm{~F}$ NMR (471 MHz, $\left.\mathrm{CDCl}_{3}\right)(\delta, \mathrm{ppm})$-114.46; HRMS (TOF MS ESI ${ }^{+}$) calculated for $\mathrm{C}_{26} \mathrm{H}_{26} \mathrm{FNO}_{3} \mathrm{Na}$ $[\mathrm{M}+\mathrm{Na}]^{+}:$442.1789, found 442.1792; HPLC conditions for determination of enantiomeric excess: Chiralpak IE-3, $\lambda=290 \mathrm{~nm}$, hexane : 2-propanol $=99: 1$, flow rate $=1.0 \mathrm{~mL} / \mathrm{min}, t_{\text {minor }}=8.2 \mathrm{~min}, t_{\text {major }}=10.2 \mathrm{~min}$. 
<smiles>CC(C)(C)NC(c1ccc(Cl)cc1)[C@@]1(C(=O)OCc2ccccc2)Cc2ccccc2O1</smiles>

tert-Butyl

(S)-2-((S)-(4-chlorophenyl)(phenylamino)methyl)-2,3-dihydrobenzofuran-2-carb oxylate (5f) Colorless oil. $34.9 \mathrm{mg}, 80 \%$ yield. 99\% ee, $>20: 1 d r .[\alpha]_{\mathrm{D}}{ }^{20}=144.1(\mathrm{c}=$ 0.033, DCM); ${ }^{1} \mathrm{H}$ NMR (400 MHz, $\left.\mathrm{CDCl}_{3}\right)(\delta, \mathrm{ppm}) 7.47$ - $7.45(\mathrm{~m}, 2 \mathrm{H}), 7.26-7.24$ $(\mathrm{m}, 2 \mathrm{H}), 7.17(\mathrm{t}, J=7.6 \mathrm{~Hz}, 1 \mathrm{H}), 7.12-7.06(\mathrm{comp}, 3 \mathrm{H}), 6.98(\mathrm{~d}, J=8.0 \mathrm{~Hz}, 1 \mathrm{H})$, $6.88(\mathrm{t}, J=7.4 \mathrm{~Hz}, 1 \mathrm{H}), 6.66(\mathrm{t}, J=7.3 \mathrm{~Hz}, 1 \mathrm{H}), 6.55(\mathrm{~d}, J=7.7 \mathrm{~Hz}, 2 \mathrm{H}), 4.90(\mathrm{~d}, J=$ $9.9 \mathrm{~Hz}, 1 \mathrm{H}), 4.39$ (d, $J=9.9 \mathrm{~Hz}, 1 \mathrm{H}), 3.71(\mathrm{~d}, J=16.1 \mathrm{~Hz}, 1 \mathrm{H}), 3.49$ (d, $J=16.1 \mathrm{~Hz}$, 1H), 1.27 (s, 9H); ${ }^{13} \mathrm{C}$ NMR (100 MHz, $\left.\mathrm{CDCl}_{3}\right)(\delta, \mathrm{ppm})$ 170.4, 159.1, 146.3, 137.1, $133.8,130.2,129.3,128.5,128.4,125.4,124.8,121.6,118.5,114.1,109.8,92.0,83.0$, 61.0, 38.2, 27.9; HRMS (TOF MS ESI ${ }^{+}$) calculated for $\mathrm{C}_{26} \mathrm{H}_{26} \mathrm{ClNO}_{3} \mathrm{Na}[\mathrm{M}+\mathrm{Na}]^{+}$: 458.1493, found 458.1495; HPLC conditions for determination of enantiomeric excess: Chiralpak IE-3, $\lambda=254 \mathrm{~nm}$, hexane $: 2$-propanol $=99: 1$, flow rate $=1.0$ $\mathrm{mL} / \mathrm{min}, t_{\mathrm{minor}}=7.8 \mathrm{~min}, t_{\mathrm{major}}=8.9 \mathrm{~min}$.<smiles>CC(C)(C)NC(c1ccc(Br)cc1)C1(C(=O)OCc2ccccc2)Cc2ccccc2O1</smiles>

tert-Butyl

(S)-2-((S)-(4-bromophenyl)(phenylamino)methyl)-2,3-dihydrobenzofuran-2-carb oxylate (5g) Colorless oil. $35.5 \mathrm{mg}, 74 \%$ yield. 98\% ee, $>20: 1 d r .[\alpha]_{\mathrm{D}}{ }^{20}=129.1(\mathrm{c}=$ 0.033, DCM); ${ }^{1} \mathrm{H}$ NMR (400 MHz, $\left.\mathrm{CDCl}_{3}\right)(\delta, \mathrm{ppm}) 7.40$ (s, 4H), 7.16 (t, J= 7.7 Hz, 1H), 7.12 - 7.06 (comp, 3H), 6.97 (d, $J=8.0 \mathrm{~Hz}, 1 \mathrm{H}), 6.89$ (t, $J=7.4 \mathrm{~Hz}, 1 \mathrm{H}), 6.66$ (t, $J=7.3 \mathrm{~Hz}, 1 \mathrm{H}), 6.55(\mathrm{~d}, J=7.8 \mathrm{~Hz}, 2 \mathrm{H}), 4.89(\mathrm{~d}, J=9.9 \mathrm{~Hz}, 1 \mathrm{H}), 4.39(\mathrm{~d}, J=10.0$ 
$\mathrm{Hz}, 1 \mathrm{H}), 3.71(\mathrm{~d}, J=16.1 \mathrm{~Hz}, 1 \mathrm{H}), 3.49(\mathrm{~d}, J=16.1 \mathrm{~Hz}, 1 \mathrm{H}), 1.27(\mathrm{~s}, 9 \mathrm{H}) ;{ }^{13} \mathrm{C} \mathrm{NMR}$ $\left(100 \mathrm{MHz}, \mathrm{CDCl}_{3}\right)(\delta, \mathrm{ppm}) 170.4,159.1,146.2,137.6,131.4,130.5,129.3,128.4$, 125.3, 124.8, 122.0, 121.6, 118.5, 114.1, 109.8, 91.9, 83.0, 61.1, 38.1, 27.9; HRMS (TOF MS ESI ${ }^{+}$) calculated for $\mathrm{C}_{26} \mathrm{H}_{26} \mathrm{BrNO}_{3} \mathrm{Na}[\mathrm{M}+\mathrm{Na}]^{+}$: 502.0988, found 502.0986; HPLC conditions for determination of enantiomeric excess: Chiralpak IE-3, $\lambda=254$ $\mathrm{nm}$, hexane $: 2$-propanol $=99: 1$, flow rate $=1.0 \mathrm{~mL} / \mathrm{min}, t_{\text {minor }}=8.2 \mathrm{~min}, t_{\text {major }}=9.1$ $\min$.<smiles>CC(C)(C)OC(=O)N[C@H](c1ccc(Cl)c(Cl)c1)[C@]1(C)Cc2ccccc2O1</smiles>

tert-Butyl

(S)-2-((S)-(3,4-dichlorophenyl)(phenylamino)methyl)-2,3-dihydrobenzofuran-2-c arboxylate (5h) Colorless oil. $37.2 \mathrm{mg}, 79 \%$ yield. 99\% ee, $>20: 1 d r .[\alpha]_{\mathrm{D}}{ }^{20}=117.1$ $(\mathrm{c}=0.033, \mathrm{DCM}) ;{ }^{1} \mathrm{H} \mathrm{NMR}\left(500 \mathrm{MHz}, \mathrm{CDCl}_{3}\right)(\delta, \mathrm{ppm}) 7.59(\mathrm{~s}, 1 \mathrm{H}), 7.39$ - $7.34(\mathrm{~m}$, 2H), 7.18 (t, $J=7.7 \mathrm{~Hz}, 1 \mathrm{H}), 7.12-7.08$ (comp, 3H), 6.98 (d, $J=8.0 \mathrm{~Hz}, 1 \mathrm{H}), 6.90$ (t, $J=7.4 \mathrm{~Hz}, 1 \mathrm{H}), 6.68(\mathrm{t}, J=7.3 \mathrm{~Hz}, 1 \mathrm{H}), 6.54(\mathrm{~d}, J=8.1 \mathrm{~Hz}, 2 \mathrm{H}), 4.89(\mathrm{~d}, J=9.7 \mathrm{~Hz}$, 1H), 4.39 (d, $J=9.8 \mathrm{~Hz}, 1 \mathrm{H}), 3.71(\mathrm{~d}, J=16.1 \mathrm{~Hz}, 1 \mathrm{H}), 3.48(\mathrm{~d}, J=16.1 \mathrm{~Hz}, 1 \mathrm{H})$,

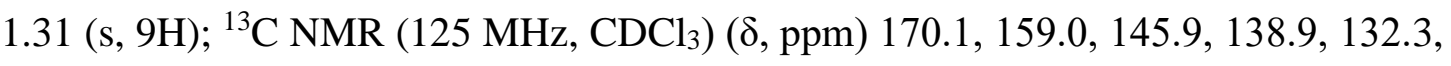
$132.1,131.0,130.4,129.4,128.5,128.0,125.2$, 124.8, 121.7, 118.7, 114.0, 109.9, 91.7, 83.3, 60.6, 38.1, 27.9; HRMS (TOF MS ESI ${ }^{+}$) calculated for $\mathrm{C}_{26} \mathrm{H}_{25} \mathrm{Cl}_{2} \mathrm{NO}_{3} \mathrm{Na}$ $[\mathrm{M}+\mathrm{Na}]^{+}:$492.1104, found 492.1108; HPLC conditions for determination of enantiomeric excess: EnantioPak Y1, $\lambda=254 \mathrm{~nm}$, hexane $:$-propanol = 99:1, flow rate $=1.0 \mathrm{~mL} / \mathrm{min}, t_{\text {minor }}=8.8 \mathrm{~min}, t_{\text {major }}=9.8 \mathrm{~min}$. 


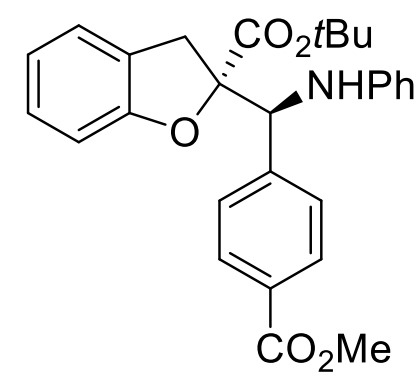

tert-Butyl

(S)-2-((S)-(4-(methoxycarbonyl)phenyl)(phenylamino)methyl)-2,3-dihydrobenzof uran-2-carboxylate (5i) Colorless oil. $32.7 \mathrm{mg}, 71 \%$ yield. $98 \%$ ee, $>20: 1 d r .[\alpha]_{\mathrm{D}}{ }^{20}$ $=84.1(\mathrm{c}=0.033, \mathrm{DCM}) ;{ }^{1} \mathrm{H} \mathrm{NMR}\left(500 \mathrm{MHz}, \mathrm{CDCl}_{3}\right)(\delta, \mathrm{ppm}) 7.96(\mathrm{~d}, J=7.9 \mathrm{~Hz}$, 2H), $7.60(\mathrm{~d}, J=7.9 \mathrm{~Hz}, 2 \mathrm{H}), 7.17(\mathrm{t}, J=7.7 \mathrm{~Hz}, 1 \mathrm{H}), 7.12(\mathrm{~d}, J=7.3 \mathrm{~Hz}, 1 \mathrm{H}), 7.07$ $(\mathrm{t}, J=7.6 \mathrm{~Hz}, 2 \mathrm{H}), 6.99(\mathrm{~d}, J=8.0 \mathrm{~Hz}, 1 \mathrm{H}), 6.89(\mathrm{t}, J=7.4 \mathrm{~Hz}, 1 \mathrm{H}), 6.66(\mathrm{t}, J=7.3$ $\mathrm{Hz}, 1 \mathrm{H}), 6.56(\mathrm{~d}, J=8.1 \mathrm{~Hz}, 2 \mathrm{H}), 4.98(\mathrm{~d}, J=9.4 \mathrm{~Hz}, 1 \mathrm{H}), 4.44(\mathrm{~d}, J=9.7 \mathrm{~Hz}, 1 \mathrm{H})$, $3.88(\mathrm{~s}, 3 \mathrm{H}), 3.74(\mathrm{~d}, J=16.1 \mathrm{~Hz}, 1 \mathrm{H}), 3.51(\mathrm{~d}, J=16.1 \mathrm{~Hz}, 1 \mathrm{H}), 1.25(\mathrm{~s}, 9 \mathrm{H}) ;{ }^{13} \mathrm{C}$ NMR $\left(125 \mathrm{MHz}, \mathrm{CDCl}_{3}\right)(\delta, \mathrm{ppm}) 170.3,167.0,159.2,146.2,143.8,129.8,129.7$, $129.4,128.9,128.5,125.3,124.8,121.6,118.5,114.1,109.8,91.8,83.1,61.4,52.2$, 38.2, 27.8; HRMS (TOF MS ESI ${ }^{+}$) calculated for $\mathrm{C}_{28} \mathrm{H}_{29} \mathrm{NO}_{5} \mathrm{Na}[\mathrm{M}+\mathrm{Na}]^{+}$: 482.1938, found 482.1937; HPLC conditions for determination of enantiomeric excess: Chiralpak IA, $\lambda=254 \mathrm{~nm}$, hexane $: 2$-propanol $=95: 5$, flow rate $=1.0 \mathrm{~mL} / \mathrm{min}, t_{\text {minor }}$ $=17.2 \mathrm{~min}, t_{\mathrm{major}}=11.1 \mathrm{~min}$.<smiles>CC(C)(C)OC(=O)[C@H](c1ccc(C(C)(C)C)cc1)[C@]1(C)Cc2ccccc2O1</smiles>

tert-Butyl

(S)-2-((S)-(4-acetylphenyl)(phenylamino)methyl)-2,3-dihydrobenzofuran-2-carbo xylate (5j) Colorless oil. $32.4 \mathrm{mg}, 73 \%$ yield. $98 \% e e,>20: 1 d r .[\alpha]_{\mathrm{D}}{ }^{20}=141.1(\mathrm{c}=$ 0.033, DCM); ${ }^{1} \mathrm{H}$ NMR $\left(400 \mathrm{MHz}, \mathrm{CDCl}_{3}\right)(\delta, \mathrm{ppm}) 7.88(\mathrm{~d}, J=8.2 \mathrm{~Hz}, 2 \mathrm{H}), 7.63(\mathrm{~d}$, $J=8.3 \mathrm{~Hz}, 2 \mathrm{H}), 7.17$ (t, $J=7.7 \mathrm{~Hz}, 1 \mathrm{H}), 7.13-7.06(\operatorname{comp}, 3 \mathrm{H}), 6.99$ (d, $J=8.0 \mathrm{~Hz}$, 
1H), 6.89 (t, $J=7.4 \mathrm{~Hz}, 1 \mathrm{H}), 6.66(\mathrm{t}, J=7.3 \mathrm{~Hz}, 1 \mathrm{H}), 6.56(\mathrm{~d}, J=7.9 \mathrm{~Hz}, 2 \mathrm{H}), 4.99$ (s, 1H), $4.46(\mathrm{~s}, 1 \mathrm{H}), 3.74(\mathrm{~d}, J=16.1 \mathrm{~Hz}, 1 \mathrm{H}), 3.51(\mathrm{~d}, J=16.1 \mathrm{~Hz}, 1 \mathrm{H}), 2.54(\mathrm{~s}, 3 \mathrm{H})$, 1.26 (s, 9H); ${ }^{13} \mathrm{C}$ NMR (100 MHz, $\left.\mathrm{CDCl}_{3}\right)(\delta, \mathrm{ppm})$ 197.8, 170.2, 159.1, 146.2, 144.0, 136.7, 129.4, 129.1, 128.5, 128.4, 125.3, 124.8, 121.6, 118.6, 114.1, 109.8, 91.8, 83.1, 61.4, 38.2, 27.9, 26.7; HRMS (TOF MS ESI ${ }^{+}$) calculated for $\mathrm{C}_{28} \mathrm{H}_{29} \mathrm{NO}_{4} \mathrm{Na}[\mathrm{M}+\mathrm{Na}]^{+}$: 466.1989, found 466.1988; HPLC conditions for determination of enantiomeric excess: Chiralpak IC-3, $\lambda=254 \mathrm{~nm}$, hexane : 2-propanol $=95: 5$, flow rate $=1.0$ $\mathrm{mL} / \mathrm{min}, t_{\text {minor }}=16.9 \mathrm{~min}, t_{\text {major }}=28.8 \mathrm{~min}$.<smiles>COc1ccc([C@H](Nc2ccc(C(F)(F)F)cc2)[C@]2(C)Cc3ccccc3O2)cc1</smiles>

tert-Butyl

(S)-2-((S)-(4-methoxyphenyl)((4-(trifluoromethyl)phenyl)amino)methyl)-2,3-dihy drobenzofuran-2-carboxylate (5k) Colorless oil. $35.5 \mathrm{mg}, 71 \%$ yield. $93 \%$ ee, 10:1 $d r .[\alpha]_{\mathrm{D}}{ }^{20}=96.1(\mathrm{c}=0.033, \mathrm{DCM}) ;{ }^{1} \mathrm{H} \mathrm{NMR}\left(500 \mathrm{MHz}, \mathrm{CDCl}_{3}\right)(\delta, \mathrm{ppm}) 7.43(\mathrm{~d}, J=$ $8.5 \mathrm{~Hz}, 2 \mathrm{H}), 7.30(\mathrm{~d}, J=8.3 \mathrm{~Hz}, 2 \mathrm{H}), 7.18(\mathrm{t}, J=7.7 \mathrm{~Hz}, 1 \mathrm{H}), 7.12(\mathrm{~d}, J=7.2 \mathrm{~Hz}$, 1H), $7.00(\mathrm{~d}, J=8.0 \mathrm{~Hz}, 1 \mathrm{H}), 6.90(\mathrm{t}, J=7.4 \mathrm{~Hz}, 1 \mathrm{H}), 6.83(\mathrm{~d}, J=8.5 \mathrm{~Hz}, 2 \mathrm{H}), 6.59$ (d, $J=8.3 \mathrm{~Hz}, 2 \mathrm{H}), 4.89$ (s, 1H), 4.79 (s, 1H), 3.75 (s, 3H), 3.63 (d, J=16.1 Hz, 1H), $3.50(\mathrm{~d}, J=16.1 \mathrm{~Hz}, 1 \mathrm{H}), 1.28(\mathrm{~s}, 9 \mathrm{H}) ;{ }^{13} \mathrm{C} \mathrm{NMR}\left(125 \mathrm{MHz}, \mathrm{CDCl}_{3}\right)(\delta, \mathrm{ppm}) 170.2$, 159.5, 159.1, 130.1, 129.9, 129.7, 128.5, 126.7 (q, $J=3.7 \mathrm{~Hz}), 125.3,124.9,121.6$, $113.9,113.2,109.9,92.1,83.0,60.7,55.4,38.2,27.9 ;{ }^{19} \mathrm{~F} \mathrm{NMR}\left(376 \mathrm{MHz}, \mathrm{CDCl}_{3}\right)(\delta$, ppm) -61.16; HRMS (TOF MS ESI ${ }^{+}$) calculated for $\mathrm{C}_{28} \mathrm{H}_{29} \mathrm{~F}_{3} \mathrm{NO}_{4}[\mathrm{M}+\mathrm{H}]^{+}: 500.2043$, found 500.2047; HPLC conditions for determination of enantiomeric excess: EnantioPak Y1, $\lambda=254 \mathrm{~nm}$, hexane $:$-propanol $=99: 1$, flow rate $=1.0 \mathrm{~mL} / \mathrm{min}$, $t_{\text {minor }}=11.7 \mathrm{~min}, t_{\text {major }}=13.2 \mathrm{~min}$. 
<smiles>CCOC(=O)[C@@]1([C@@H](NC(C)(C)CC)c2cccc3ccccc23)Cc2ccccc2O1</smiles>

tert-Butyl

(S)-2-((S)-naphthalen-1-yl(phenylamino)methyl)-2,3-dihydrobenzofuran-2-carbo xylate (5l) Colorless oil. $37.0 \mathrm{mg}, 82 \%$ yield. $>99 \% e e,>20: 1 d r .[\alpha]_{\mathrm{D}}{ }^{20}=-42.0(\mathrm{c}=$ 0.033, DCM); ${ }^{1} \mathrm{H}$ NMR $\left(500 \mathrm{MHz}, \mathrm{CDCl}_{3}\right)(\delta, \mathrm{ppm}) 8.37(\mathrm{~d}, J=8.6 \mathrm{~Hz}, 1 \mathrm{H}), 8.02(\mathrm{~d}$, $J=7.3 \mathrm{~Hz}, 1 \mathrm{H}), 7.80(\mathrm{~d}, J=8.1 \mathrm{~Hz}, 1 \mathrm{H}), 7.73(\mathrm{~d}, J=8.1 \mathrm{~Hz}, 1 \mathrm{H}), 7.56(\mathrm{t}, J=7.6 \mathrm{~Hz}$, 1H), $7.48-7.44(\mathrm{~m}, 2 \mathrm{H}), 7.14-7.09(\mathrm{~m}, 2 \mathrm{H}), 7.01(\mathrm{t}, J=7.8 \mathrm{~Hz}, 2 \mathrm{H}), 6.95(\mathrm{~d}, J=8.0$ $\mathrm{Hz}, 1 \mathrm{H}), 6.86$ (t, $J=7.4 \mathrm{~Hz}, 1 \mathrm{H}), 6.60-6.57$ (comp, 3H), 5.86 (d, $J=9.2 \mathrm{~Hz}, 1 \mathrm{H})$, $4.60(\mathrm{~d}, J=9.3 \mathrm{~Hz}, 1 \mathrm{H}), 3.81(\mathrm{~d}, J=16.0 \mathrm{~Hz}, 1 \mathrm{H}), 3.60(\mathrm{~d}, J=16.0 \mathrm{~Hz}, 1 \mathrm{H}), 0.95(\mathrm{~s}$, $9 \mathrm{H}) ;{ }^{13} \mathrm{C} \mathrm{NMR}\left(125 \mathrm{MHz}, \mathrm{CDCl}_{3}\right)(\delta, \mathrm{ppm}) 170.3,159.1,146.8,135.3,133.8,132.1$, 129.3, 129.0, 128.5, 128.3, 126.21, 126.19, 125.8, 125.5, 125.4, 124.7, 123.8, 121.4, 118.1, 113.9, 109.8, 92.7, 82.8, 55.6, 38.5, 27.4; HRMS (TOF MS ESI ${ }^{+}$) calculated for $\mathrm{C}_{30} \mathrm{H}_{29} \mathrm{NO}_{3} \mathrm{Na}[\mathrm{M}+\mathrm{Na}]^{+}:$474.2040, found 474.2037; HPLC conditions for determination of enantiomeric excess: EnantioPak Y1, $\lambda=254 \mathrm{~nm}$, hexane : 2-propanol $=99.5: 0.5$, flow rate $=1.0 \mathrm{~mL} / \mathrm{min}, t_{\text {minor }}=18.9 \mathrm{~min}, t_{\text {major }}=15.8 \mathrm{~min}$.<smiles>CC(C)(C)N[C@H](c1ccc2ccccc2c1)[C@]1(C)Cc2ccccc2O1</smiles>

tert-Butyl

(S)-2-((S)-naphthalen-2-yl(phenylamino)methyl)-2,3-dihydrobenzofuran-2-carbo xylate (5m) Colorless oil. $37.5 \mathrm{mg}, 83 \%$ yield. $>99 \% e e,>20: 1 d r .[\alpha]_{\mathrm{D}}{ }^{20}=-48.0(\mathrm{c}$ $=0.033, \mathrm{DCM}) ;{ }^{1} \mathrm{H} \mathrm{NMR}\left(500 \mathrm{MHz}, \mathrm{CDCl}_{3}\right)(\delta, \mathrm{ppm}) 8.37(\mathrm{~d}, J=8.6 \mathrm{~Hz}, 1 \mathrm{H}), 8.02$ $(\mathrm{d}, J=7.3 \mathrm{~Hz}, 1 \mathrm{H}), 7.80(\mathrm{~d}, J=8.1 \mathrm{~Hz}, 1 \mathrm{H}), 7.73(\mathrm{~d}, J=8.1 \mathrm{~Hz}, 1 \mathrm{H}), 7.57$ (t, $J=7.7$ $\mathrm{Hz}, 1 \mathrm{H}), 7.48-7.44$ (m, 2H), $7.14-7.09$ (m, 2H), 7.01 (t, $J=7.7 \mathrm{~Hz}, 2 \mathrm{H}), 6.95$ (d, $J$ 
$=8.0 \mathrm{~Hz}, 1 \mathrm{H}), 6.86(\mathrm{t}, J=7.4 \mathrm{~Hz}, 1 \mathrm{H}), 6.60-6.58(\mathrm{comp}, 3 \mathrm{H}), 5.86(\mathrm{~d}, J=8.7 \mathrm{~Hz}$, $1 \mathrm{H}), 4.60(\mathrm{~d}, J=9.0 \mathrm{~Hz}, 1 \mathrm{H}), 3.81(\mathrm{~d}, J=16.0 \mathrm{~Hz}, 1 \mathrm{H}), 3.60(\mathrm{~d}, J=16.0 \mathrm{~Hz}, 1 \mathrm{H})$, 0.95 (s, 9H); ${ }^{13} \mathrm{C}$ NMR (125 MHz, $\left.\mathrm{CDCl}_{3}\right)(\delta, \mathrm{ppm}) 170.3,159.1,146.8,135.3,133.8$, $132.1,129.3,129.0,128.5,128.3,126.21,126.19,125.8,125.5,125.4,124.7,123.8$, 121.4, 118.1, 113.9, 109.8, 92.7, 82.8, 55.6, 38.5, 27.4; HRMS (TOF MS ESI ${ }^{+}$) calculated for $\mathrm{C}_{30} \mathrm{H}_{29} \mathrm{NO}_{3} \mathrm{Na}[\mathrm{M}+\mathrm{Na}]^{+}$: 474.2040, found 474.2039; HPLC conditions for determination of enantiomeric excess: EnantioPak Y1, $\lambda=254 \mathrm{~nm}$, hexane : 2-propanol $=99.5: 0.5$, flow rate $=1.0 \mathrm{~mL} / \mathrm{min}, t_{\mathrm{minor}}=18.4 \mathrm{~min}, t_{\mathrm{major}}=15.5 \mathrm{~min}$.<smiles>CCCOC(=O)C1([C@@H](Nc2ccc(Br)cc2)c2cccs2)Cc2ccccc2O1</smiles>

tert-Butyl

(S)-2-((R)-((4-bromophenyl)amino)(thiophen-2-yl)methyl)-2,3-dihydrobenzofura n-2-carboxylate (5n) Colorless oil. $43.8 \mathrm{mg}, 90 \%$ yield. $98 \% e e,>20: 1 d r .[\alpha]_{\mathrm{D}}{ }^{20}=$ $123.1(\mathrm{c}=0.033, \mathrm{DCM}) ;{ }^{1} \mathrm{H} \mathrm{NMR}\left(500 \mathrm{MHz}, \mathrm{CDCl}_{3}\right)(\delta, \mathrm{ppm}) 7.21$ - 7.15 (comp, 4H), $7.12-7.11(\mathrm{~m}, 2 \mathrm{H}), 6.98(\mathrm{~d}, J=8.0 \mathrm{~Hz}, 1 \mathrm{H}), 6.90-6.87(\mathrm{~m}, 2 \mathrm{H}), 6.51(\mathrm{~d}, J=$ $8.4 \mathrm{~Hz}, 2 \mathrm{H}), 5.18(\mathrm{~d}, J=10.2 \mathrm{~Hz}, 1 \mathrm{H}), 4.24(\mathrm{~d}, J=10.2 \mathrm{~Hz}, 1 \mathrm{H}), 3.64(\mathrm{~d}, J=16.0 \mathrm{~Hz}$, $1 \mathrm{H}), 3.51(\mathrm{~d}, J=16.0 \mathrm{~Hz}, 1 \mathrm{H}), 1.31(\mathrm{~s}, 9 \mathrm{H}) ;{ }^{13} \mathrm{C} \mathrm{NMR}\left(125 \mathrm{MHz}, \mathrm{CDCl}_{3}\right)(\delta, \mathrm{ppm})$ $170.1,159.1,145.4,141.0,132.1,128.5,127.1,126.5,125.5,125.4,124.8,121.6$, 115.9, 110.5, 109.9, 91.7, 83.1, 57.8, 37.5, 27.8; HRMS (TOF MS ESI ${ }^{+}$) calculated for $\mathrm{C}_{24} \mathrm{H}_{24} \mathrm{BrNO}_{3} \mathrm{SNa}[\mathrm{M}+\mathrm{Na}]^{+}$: 508.0552, found 508.0550; HPLC conditions for determination of enantiomeric excess: Chiralcel OD-H, $\lambda=254 \mathrm{~nm}$, hexane : 2-propanol $=99: 1$, flow rate $=1.0 \mathrm{~mL} / \mathrm{min}, t_{\text {minor }}=10.3 \mathrm{~min}, t_{\text {major }}=11.2 \mathrm{~min}$. 


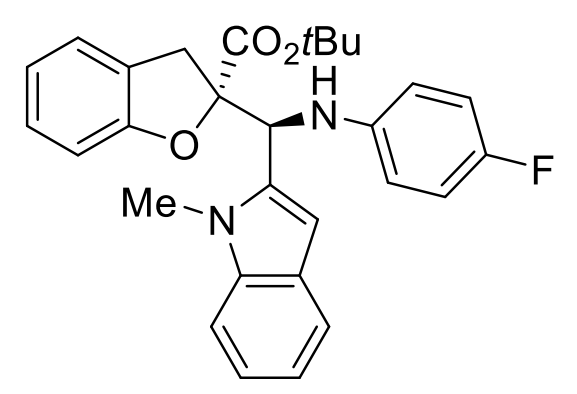

tert-Butyl

(S)-2-((S)-((4-fluorophenyl)amino)(1-methyl-1H-indol-2-yl)methyl)-2,3-dihydrob enzofuran-2-carboxylate (5o) Colorless oil. $33.1 \mathrm{mg}, 70 \%$ yield. 95\% ee, > 20:1 $d r$. $[\alpha]_{\mathrm{D}}^{20}=168.2(\mathrm{c}=0.033, \mathrm{DCM}) ;{ }^{1} \mathrm{H}$ NMR $\left(400 \mathrm{MHz}, \mathrm{CDCl}_{3}\right)(\delta, \mathrm{ppm}) 7.60(\mathrm{~d}, J=$ $7.8 \mathrm{~Hz}, 1 \mathrm{H}), 7.27-7.25(\mathrm{~m}, 1 \mathrm{H}), 7.22-7.16(\mathrm{~m}, 2 \mathrm{H}), 7.14-7.07(\mathrm{~m}, 2 \mathrm{H}), 7.02(\mathrm{~d}, J=$ $8.0 \mathrm{~Hz}, 1 \mathrm{H}), 6.91-6.84$ (comp, 4H), 6.65 - $6.61(\mathrm{~m}, 2 \mathrm{H}), 5.23(\mathrm{~s}, 1 \mathrm{H}), 3.97(\mathrm{~s}, 1 \mathrm{H})$, $3.76(\mathrm{~d}, J=15.9 \mathrm{~Hz}, 1 \mathrm{H}), 3.70(\mathrm{~s}, 3 \mathrm{H}), 3.58(\mathrm{~d}, J=15.9 \mathrm{~Hz}, 1 \mathrm{H}), 1.23(\mathrm{~s}, 9 \mathrm{H}) ;{ }^{13} \mathrm{C}$ NMR $\left(100 \mathrm{MHz}, \mathrm{CDCl}_{3}\right)(\delta, \mathrm{ppm}) 170.7,159.4,156.7(\mathrm{~d}, J=236.9 \mathrm{~Hz}), 143.1(\mathrm{~d}, J=$ 2.1 Hz), 137.9, 137.5, 128.4, 127.7, 125.3, 124.7, 121.8, 121.4, 120.9, 119.6, 116.0 (d, $J=22.5 \mathrm{~Hz}), 115.6(\mathrm{~d}, J=7.5 \mathrm{~Hz}), 109.6,109.2$, 102.0, 92.2, 82.8, 56.2, 38.0, 30.5, 27.8; ${ }^{19} \mathrm{~F}$ NMR (376 MHz, $\left.\mathrm{CDCl}_{3}\right)(\delta, \mathrm{ppm})$-125.98; HRMS (TOF MS ESI $\left.{ }^{+}\right)$ calculated for $\mathrm{C}_{29} \mathrm{H}_{30} \mathrm{FN}_{2} \mathrm{O}_{3}[\mathrm{M}+\mathrm{H}]^{+}:$473.2235, found 473.2234; HPLC conditions for determination of enantiomeric excess: Chiralpak IA, $\lambda=254 \mathrm{~nm}$, hexane : 2-propanol $=99: 1$, flow rate $=1.0 \mathrm{~mL} / \mathrm{min}, t_{\text {minor }}=23.5 \mathrm{~min}, t_{\text {major }}=17.4 \mathrm{~min}$.

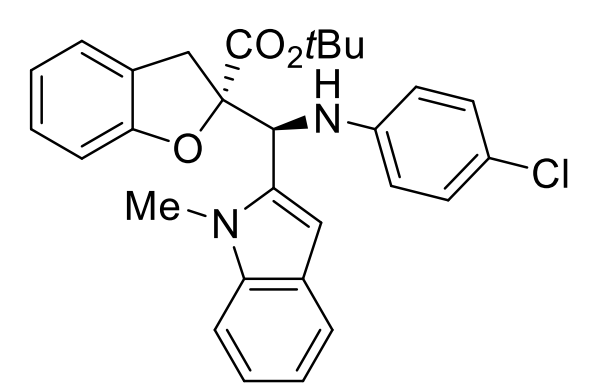

tert-Butyl

$(S)-2-((S)-((4-c h l o r o p h e n y l) a m i n o)(1-m e t h y l-1 H$-indol-2-yl)methyl)-2,3-dihydrob enzofuran-2-carboxylate (5p) Colorless oil. $39.1 \mathrm{mg}, 80 \%$ yield. 96\% ee, > 20:1 $d r$. $[\alpha]_{\mathrm{D}}^{20}=186.2(\mathrm{c}=0.033, \mathrm{DCM}) ;{ }^{1} \mathrm{H}$ NMR $\left(400 \mathrm{MHz}, \mathrm{CDCl}_{3}\right)(\delta, \mathrm{ppm}) 7.56(\mathrm{~d}, J=$ $7.8 \mathrm{~Hz}, 1 \mathrm{H}), 7.24-7.22(\mathrm{~m}, 1 \mathrm{H}), 7.18-7.13$ (m, 2H), 7.08 - 7.04 (comp, 4H), 6.98 (d, 
$J=8.0 \mathrm{~Hz}, 1 \mathrm{H}), 6.86-6.84(\mathrm{~m}, 2 \mathrm{H}), 6.57(\mathrm{~d}, J=8.0 \mathrm{~Hz}, 2 \mathrm{H}), 5.26(\mathrm{~d}, J=6.9 \mathrm{~Hz}, 1 \mathrm{H})$, $4.09(\mathrm{~d}, J=8.5 \mathrm{~Hz}, 1 \mathrm{H}), 3.68-3.65(\mathrm{comp}, 4 \mathrm{H}), 3.53$ (d, $J=15.8 \mathrm{~Hz}, 1 \mathrm{H}), 1.19$ (s, $9 \mathrm{H}) ;{ }^{13} \mathrm{C} \mathrm{NMR}\left(125 \mathrm{MHz}, \mathrm{CDCl}_{3}\right)(\delta, \mathrm{ppm}) 170.6,159.4,145.4,137.5,129.4,128.4$, $127.6,125.2$, 124.7, 123.3, 121.9, 121.4, 121.0, 119.6, 115.0, 109.6, 109.2, 102.2, 92.1, 82.9, 55.0, 38.0, 30.6, 27.8; HRMS (TOF MS $\mathrm{ESI}^{+}$) calculated for $\mathrm{C}_{29} \mathrm{H}_{29} \mathrm{ClN}_{2} \mathrm{O}_{3} \mathrm{Na} \quad[\mathrm{M}+\mathrm{Na}]^{+}:$511.1759, found 511.1756; HPLC conditions for determination of enantiomeric excess: Chiralpak IA, $\lambda=254 \mathrm{~nm}$, hexane : 2-propanol $=99: 1$, flow rate $=1.0 \mathrm{~mL} / \mathrm{min}, t_{\text {minor }}=25.7 \mathrm{~min}, t_{\text {major }}=18.6 \mathrm{~min}$.

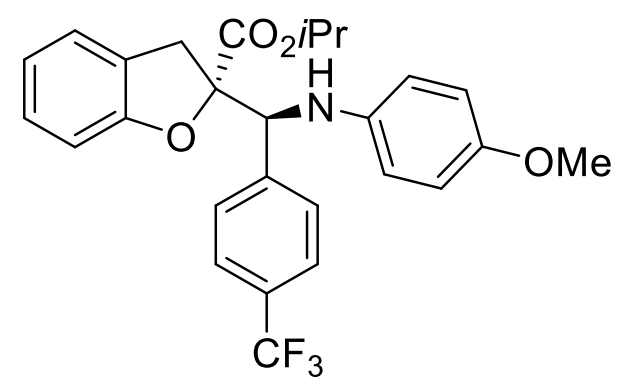

\section{Isopropyl}

(S)-2-((S)-((4-methoxyphenyl)amino)(4-(trifluoromethyl)phenyl)methyl)-2,3-dihy drobenzofuran-2-carboxylate (5q) Colorless oil. $38.9 \mathrm{mg}, 80 \%$ yield. $99 \%$ ee, > $20: 1 d r .[\alpha]_{\mathrm{D}}{ }^{20}=162.2(\mathrm{c}=0.033, \mathrm{DCM}) ;{ }^{1} \mathrm{H} \mathrm{NMR}\left(400 \mathrm{MHz}, \mathrm{CDCl}_{3}\right)(\delta, \mathrm{ppm}) 7.60$ $(\mathrm{d}, J=8.2 \mathrm{~Hz}, 2 \mathrm{H}), 7.53(\mathrm{~d}, J=8.3 \mathrm{~Hz}, 2 \mathrm{H}), 7.19-7.12(\mathrm{~m}, 2 \mathrm{H}), 6.99(\mathrm{~d}, J=8.0 \mathrm{~Hz}$, 1H), $6.90(\mathrm{t}, J=7.4 \mathrm{~Hz}, 1 \mathrm{H}), 6.69-6.65(\mathrm{~m}, 2 \mathrm{H}), 6.53-6.50(\mathrm{~m}, 2 \mathrm{H}), 4.92(\mathrm{~d}, J=9.7$ $\mathrm{Hz}, 1 \mathrm{H}), 4.84(\mathrm{dt}, J=12.5,6.3 \mathrm{~Hz}, 1 \mathrm{H}), 4.21(\mathrm{~d}, J=10.0 \mathrm{~Hz}, 1 \mathrm{H}), 3.82(\mathrm{~d}, J=16.2$ Hz, 1H), $3.67(\mathrm{~s}, 3 \mathrm{H}), 3.55(\mathrm{~d}, J=16.1 \mathrm{~Hz}, 1 \mathrm{H}), 1.07(\mathrm{~d}, J=6.3 \mathrm{~Hz}, 3 \mathrm{H}), 0.96(\mathrm{~d}, J=$ $6.2 \mathrm{~Hz}, 3 \mathrm{H}) ;{ }^{13} \mathrm{C} \mathrm{NMR}\left(100 \mathrm{MHz}, \mathrm{CDCl}_{3}\right)(\delta, \mathrm{ppm}) 171.3,158.9,152.9,142.7,140.0$, $130.2(\mathrm{q}, J=32.5 \mathrm{~Hz}), 129.0,128.5,125.3(\mathrm{q}, J=3.6 \mathrm{~Hz}), 124.8,124.2(\mathrm{q}, J=272.2$ $\mathrm{Hz}), 121.7,115.7,114.9,109.9,92.0,70.0,62.5,55.7,38.1,21.6,21.4 ;{ }^{19} \mathrm{~F}$ NMR $(376$ $\left.\mathrm{MHz}, \mathrm{CDCl}_{3}\right)(\delta, \mathrm{ppm})-62.63 ;{ }^{19} \mathrm{~F} \mathrm{NMR}\left(376 \mathrm{MHz}, \mathrm{CDCl}_{3}\right)(\delta, \mathrm{ppm})-62.63 ; \mathrm{HRMS}$ (TOF MS ESI ${ }^{+}$) calculated for $\mathrm{C}_{27} \mathrm{H}_{26} \mathrm{~F}_{3} \mathrm{NO}_{4} \mathrm{Na}[\mathrm{M}+\mathrm{Na}]^{+}:$508.1706, found 508.1705; HPLC conditions for determination of enantiomeric excess: Chiralpak IF-3, $\lambda=254$ $\mathrm{nm}$, hexane $: 2$-propanol $=97: 3$, flow rate $=1.0 \mathrm{~mL} / \mathrm{min}, t_{\text {minor }}=8.8 \mathrm{~min}, t_{\text {major }}=7.8$ 
$\min$.<smiles>COc1ccc(N[C@H](c2ccc(C(F)(F)F)cc2)[C@]2(C)Cc3ccccc3O2)cc1</smiles>

Methyl

(S)-2-((S)-((4-methoxyphenyl)amino)(4-(trifluoromethyl)phenyl)methyl)-2,3-dihy drobenzofuran-2-carboxylate (5r) Colorless oil. $27.4 \mathrm{mg}$, 60\% yield. 94\% ee, > $20: 1 d r .[\alpha]_{\mathrm{D}}{ }^{20}=162.2(\mathrm{c}=0.033, \mathrm{DCM}) ;{ }^{1} \mathrm{H} \mathrm{NMR}\left(500 \mathrm{MHz}, \mathrm{CDCl}_{3}\right)(\delta, \mathrm{ppm}) 7.54$ $(\mathrm{d}, J=8.7 \mathrm{~Hz}, 4 \mathrm{H}), 7.23-7.11(\mathrm{~m}, 2 \mathrm{H}), 6.99(\mathrm{~d}, J=8.0 \mathrm{~Hz}, 1 \mathrm{H}), 6.92(\mathrm{t}, J=7.4 \mathrm{~Hz}$, $1 \mathrm{H}), 6.67(\mathrm{~d}, J=8.1 \mathrm{~Hz}, 2 \mathrm{H}), 6.51(\mathrm{~d}, J=8.2 \mathrm{~Hz}, 2 \mathrm{H}), 4.95(\mathrm{~d}, J=9.9 \mathrm{~Hz}, 1 \mathrm{H}), 4.24$ $(\mathrm{d}, J=10.0 \mathrm{~Hz}, 1 \mathrm{H}), 3.87(\mathrm{~d}, J=16.1 \mathrm{~Hz}, 1 \mathrm{H}), 3.67(\mathrm{~s}, 3 \mathrm{H}), 3.59(\mathrm{~d}, J=16.1 \mathrm{~Hz}, 1 \mathrm{H})$, $3.54(\mathrm{~s}, 3 \mathrm{H}) ;{ }^{13} \mathrm{C} \mathrm{NMR}\left(125 \mathrm{MHz}, \mathrm{CDCl}_{3}\right)(\delta, \mathrm{ppm}) 172.5,158.7,153.0,142.6,139.9$, $130.3(\mathrm{q}, J=32.0 \mathrm{~Hz}), 128.7,128.6,125.5$ (q, $J=3.4 \mathrm{~Hz}), 125.3,124.9,122.0,115.6$, 115.0, 110.0, 92.4, 62.4, 55.8, 52.9, 38.1; $\left.{ }^{19} \mathrm{~F} \mathrm{NMR} \mathrm{(471} \mathrm{MHz}, \mathrm{CDCl}_{3}\right)(\delta, \mathrm{ppm})$ -62.63; HRMS (TOF MS ESI ${ }^{+}$) calculated for $\mathrm{C}_{25} \mathrm{H}_{22} \mathrm{~F}_{3} \mathrm{NO}_{4} \mathrm{Na}[\mathrm{M}+\mathrm{Na}]^{+}$: 480.1393, found 480.1388; HPLC conditions for determination of enantiomeric excess: Chiralpak AD-H, $\lambda=213 \mathrm{~nm}$, hexane : 2-propanol $=95: 5$, flow rate $=1.0 \mathrm{~mL} / \mathrm{min}$, $t_{\text {minor }}=17.6 \mathrm{~min}, t_{\text {major }}=26.3 \mathrm{~min}$.<smiles>CCC(C)OC(=O)[C@]1([C@@H](Nc2ccc(F)cc2)c2ccccc2)Cc2ccccc2O1</smiles>

tert-Butyl

(S)-2-((S)-((4-fluorophenyl)amino)(phenyl)methyl)-2,3-dihydrobenzofuran-2-car boxylate (5s) Colorless oil. $36.9 \mathrm{mg}, 88 \%$ yield. $99 \%$ ee, $>20: 1 d r .[\alpha]_{\mathrm{D}}{ }^{20}=126.1(\mathrm{c}$ $=0.033, \mathrm{DCM}) ;{ }^{1} \mathrm{H}$ NMR $\left(400 \mathrm{MHz}, \mathrm{CDCl}_{3}\right)(\delta, \mathrm{ppm}) 7.50-7.48(\mathrm{~m}, 2 \mathrm{H}), 7.29-$ $7.26(\mathrm{~m}, 2 \mathrm{H}), 7.23-7.18(\mathrm{~m}, 1 \mathrm{H}), 7.16-7.11(\mathrm{~m}, 2 \mathrm{H}), 6.99(\mathrm{~d}, J=8.0 \mathrm{~Hz}, 1 \mathrm{H}), 6.90$ 
- $6.86(\mathrm{~m}, 1 \mathrm{H}), 6.80-6.74(\mathrm{~m}, 2 \mathrm{H}), 6.53-6.48(\mathrm{~m}, 2 \mathrm{H}), 4.81(\mathrm{~d}, J=10.2 \mathrm{~Hz}, 1 \mathrm{H})$, $4.33(\mathrm{~d}, J=10.2 \mathrm{~Hz}, 1 \mathrm{H}), 3.73(\mathrm{~d}, J=16.1 \mathrm{~Hz}, 1 \mathrm{H}), 3.50$ (d, $J=16.1 \mathrm{~Hz}, 1 \mathrm{H}), 1.24$ (s, $9 \mathrm{H}) ;{ }^{13} \mathrm{C} \mathrm{NMR}\left(100 \mathrm{MHz}, \mathrm{CDCl}_{3}\right)(\delta, \mathrm{ppm}) 170.4,159.3,156.2(\mathrm{~d}, J=235.6 \mathrm{~Hz})$, $142.9(\mathrm{~d}, J=2.0 \mathrm{~Hz}), 138.3,128.8,128.38,128.36,128.1,125.5,124.8,121.4,115.7$ $(\mathrm{d}, J=22.3 \mathrm{~Hz}), 115.2(\mathrm{~d}, J=7.4 \mathrm{~Hz}), 109.8,92.1,82.8,62.6,38.3,27.8 ;{ }^{19} \mathrm{~F}$ NMR $\left(376 \mathrm{MHz}, \mathrm{CDCl}_{3}\right)(\delta, \mathrm{ppm})$-127.09; HRMS (TOF MS $\mathrm{ESI}^{+}$) calculated for $\mathrm{C}_{26} \mathrm{H}_{26} \mathrm{FNO}_{3} \mathrm{Na} \quad[\mathrm{M}+\mathrm{Na}]^{+}:$442.1789, found 442.1790; HPLC conditions for determination of enantiomeric excess: Chiralpak IE-3, $\lambda=254 \mathrm{~nm}$, hexane : 2-propanol $=99: 1$, flow rate $=1.0 \mathrm{~mL} / \mathrm{min}, t_{\text {minor }}=8.6 \mathrm{~min}, t_{\text {major }}=10.2 \mathrm{~min}$.<smiles>CCCOC(=O)[C@]1([C@@H](Nc2ccc(Cl)cc2)c2ccccc2)Cc2ccccc2O1</smiles>

tert-Butyl

(S)-2-((S)-((4-chlorophenyl)amino)(phenyl)methyl)-2,3-dihydrobenzofuran-2-car boxylate (5t) Colorless oil. $37.1 \mathrm{mg}, 85 \%$ yield. 99\% ee, $>20: 1 d r .[\alpha]_{\mathrm{D}}{ }^{20}=132.1(\mathrm{c}$ $=0.033, \mathrm{DCM}) ;{ }^{1} \mathrm{H} \mathrm{NMR}\left(400 \mathrm{MHz}, \mathrm{CDCl}_{3}\right)(\delta, \mathrm{ppm}) 7.49(\mathrm{~d}, J=7.1 \mathrm{~Hz}, 2 \mathrm{H}), 7.30-$ $7.26(\mathrm{~m}, 2 \mathrm{H}), 7.23-7.20(\mathrm{~m}, 1 \mathrm{H}), 7.17(\mathrm{t}, J=7.7 \mathrm{~Hz}, 1 \mathrm{H}), 7.12(\mathrm{~d}, J=7.3 \mathrm{~Hz}, 1 \mathrm{H})$, $7.02-6.98(\mathrm{~m}, 3 \mathrm{H}), 6.89(\mathrm{t}, J=7.4 \mathrm{~Hz}, 1 \mathrm{H}), 6.50(\mathrm{~d}, J=8.8 \mathrm{~Hz}, 2 \mathrm{H}), 4.84(\mathrm{~d}, J=9.7$ $\mathrm{Hz}, 1 \mathrm{H}), 4.48$ (d, $J=9.9 \mathrm{~Hz}, 1 \mathrm{H}), 3.69$ (d, $J=16.2 \mathrm{~Hz}, 1 \mathrm{H}), 3.50$ (d, $J=16.1 \mathrm{~Hz}, 1 \mathrm{H})$, 1.24 (s, 9H); ${ }^{13} \mathrm{C}$ NMR (100 MHz, $\left.\mathrm{CDCl}_{3}\right)(\delta, \mathrm{ppm})$ 170.3, 159.2, 145.2, 138.0, 129.1, $128.8,128.42$, 128.39, 128.2, 125.4, 124.8, 122.8, 121.5, 115.3, 109.8, 92.0, 82.9, 61.9, 38.3, 27.8; HRMS (TOF MS ESI ${ }^{+}$) calculated for $\mathrm{C}_{26} \mathrm{H}_{26} \mathrm{ClNO}_{3} \mathrm{Na}[\mathrm{M}+\mathrm{Na}]^{+}$: 458.1493, found 458.1490; HPLC conditions for determination of enantiomeric excess: EnantioPak Y1, $\lambda=254 \mathrm{~nm}$, hexane : 2-propanol $=99: 1$, flow rate $=1.0$ $\mathrm{mL} / \mathrm{min}, t_{\mathrm{minor}}=10.1 \mathrm{~min}, t_{\mathrm{major}}=11.6 \mathrm{~min}$. 


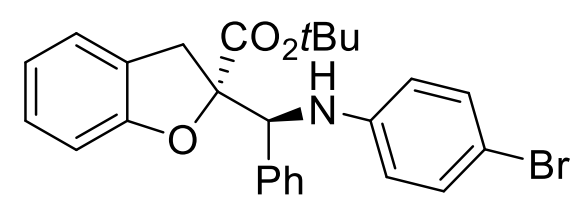

tert-Butyl

(S)-2-((S)-((4-bromophenyl)amino)(phenyl)methyl)-2,3-dihydrobenzofuran-2-car boxylate (5u) Colorless oil. $40.3 \mathrm{mg}, 84 \%$ yield. $99 \% e e,>20: 1 d r .[\alpha]_{\mathrm{D}}{ }^{20}=129.1(\mathrm{c}$ $=0.033, \mathrm{DCM}) ;{ }^{1} \mathrm{H} \mathrm{NMR}\left(400 \mathrm{MHz}, \mathrm{CDCl}_{3}\right)(\delta, \mathrm{ppm}) 7.50-7.48(\mathrm{~m}, 2 \mathrm{H}), 7.30-$ $7.26(\mathrm{~m}, 2 \mathrm{H}), 7.22$ - $7.18(\mathrm{~m}, 1 \mathrm{H}), 7.17$ - 7.11 (comp, 4H), $6.99(\mathrm{~d}, J=8.0 \mathrm{~Hz}, 1 \mathrm{H})$, $6.90-6.87(\mathrm{~m}, 1 \mathrm{H}), 6.47-6.44(\mathrm{~m}, 2 \mathrm{H}), 4.84(\mathrm{~d}, J=10.0 \mathrm{~Hz}, 1 \mathrm{H}), 4.50(\mathrm{~d}, J=10.0$ $\mathrm{Hz}, 1 \mathrm{H}), 3.68(\mathrm{~d}, J=16.1 \mathrm{~Hz}, 1 \mathrm{H}), 3.50(\mathrm{~d}, J=16.1 \mathrm{~Hz}, 1 \mathrm{H}), 1.24(\mathrm{~s}, 9 \mathrm{H}) ;{ }^{13} \mathrm{C} \mathrm{NMR}$ $\left(100 \mathrm{MHz}, \mathrm{CDCl}_{3}\right)(\delta, \mathrm{ppm}) 170.3,159.2,145.6,137.9,132.0,128.8,128.4,128.4$, 128.2, 125.4, 124.8, 121.5, 115.8, 109.9, 92.0, 82.9, 61.8, 38.3, 27.8; HRMS (TOF MS ESI ${ }^{+}$) calculated for $\mathrm{C}_{26} \mathrm{H}_{26} \mathrm{BrNO}_{3} \mathrm{Na}[\mathrm{M}+\mathrm{Na}]^{+}$: 502.0988, found 502.0984; HPLC conditions for determination of enantiomeric excess: Chiralpak IE-3, $\lambda=254$ $\mathrm{nm}$, hexane $: 2$-propanol $=99: 1$, flow rate $=1.0 \mathrm{~mL} / \mathrm{min}, t_{\text {minor }}=11.4 \mathrm{~min}, t_{\text {major }}=12.4$ $\min$.

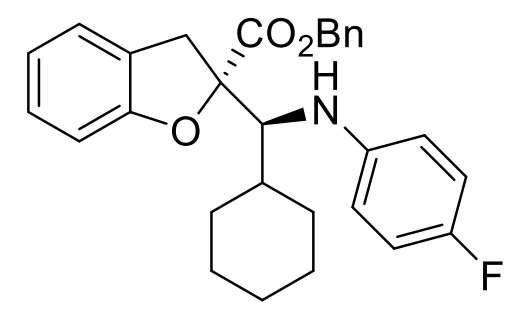

\section{Benzyl}

(S)-2-((S)-cyclohexyl((4-fluorophenyl)amino)methyl)-2,3-dihydrobenzofuran-2-c arboxylate (5v) Colorless oil. $16.1 \mathrm{mg}, 35 \%$ yield (combined yield for all isomers). 90\% ee, 2:1 $d r$. The major one: $[\alpha]_{\mathrm{D}}{ }^{20}=12.00(\mathrm{c}=0.033, \mathrm{DCM}) ;{ }^{1} \mathrm{H}$ NMR $(400 \mathrm{MHz}$, $\left.\mathrm{CDCl}_{3}\right)(\delta, \mathrm{ppm}) 7.35(\mathrm{comp}, 5 \mathrm{H}), 7.14(\mathrm{t}, J=7.8 \mathrm{~Hz}, 1 \mathrm{H}), 7.00(\mathrm{~d}, J=7.3 \mathrm{~Hz}, 1 \mathrm{H})$, $6.91(\mathrm{~d}, J=8.0 \mathrm{~Hz}, 1 \mathrm{H}), 6.86-6.77(\mathrm{comp}, 3 \mathrm{H}), 6.45-6.42(\mathrm{~m}, 2 \mathrm{H}), 5.22(\mathrm{dd}, J=$ 29.0, $12.1 \mathrm{~Hz}, 2 \mathrm{H}), 3.82(\mathrm{~d}, J=7.8 \mathrm{~Hz}, 1 \mathrm{H}), 3.68(\mathrm{~d}, J=9.8 \mathrm{~Hz}, 1 \mathrm{H}), 3.37$ (dd, $J=$ 52.3, $16.2 \mathrm{~Hz}, 2 \mathrm{H}), 2.08$ - 2.06 (m, 1H), 1.68 - 1.67 (m, 1H), 1.50 - 1.33 (comp, 4H), 1.15 - 0.99 (comp, 5H); $\left.{ }^{13} \mathrm{C} \mathrm{NMR} \mathrm{(100} \mathrm{MHz,} \mathrm{CDCl}_{3}\right)(\delta, \mathrm{ppm}) 172.9,159.5,155.6$ (d, 
$J=235.0 \mathrm{~Hz}), 145.5(\mathrm{~d}, J=1.7 \mathrm{~Hz}), 135.3,128.9,128.8,128.7,128.3,125.2,124.7$, 121.3, $115.9(\mathrm{~d}, J=22.3 \mathrm{~Hz}), 113.6(\mathrm{~d}, J=7.3 \mathrm{~Hz}), 109.7,93.6,67.4,62.9,42.1,39.0$, 32.4, 27.7, 26.5, 26.2, 26.1; ${ }^{19} \mathrm{~F}$ NMR (376 MHz, $\left.\mathrm{CDCl}_{3}\right)(\delta, \mathrm{ppm})-128.41$; HRMS (TOF MS ESI ${ }^{+}$) calculated for $\mathrm{C}_{2} \mathrm{H}_{30} \mathrm{FNO}_{3} \mathrm{Na}[\mathrm{M}+\mathrm{Na}]^{+}$: 482.2102, found 482.2103; HPLC conditions for determination of enantiomeric excess: Chiralpak AD-H, $\lambda=254$ $\mathrm{nm}$, hexane $:$-propanol $=98: 2$, flow rate $=1.0 \mathrm{~mL} / \mathrm{min}, t_{\text {minor }}=17.4 \mathrm{~min}, t_{\text {major }}=$ $25.3 \mathrm{~min}$.

\section{General Procedure for Scale up and Derivatizations}<smiles>CCCCC(=O)OCc1ccccc1O</smiles>

1c, $744.9 \mathrm{mg}$ $3.0 \mathrm{mmol}$

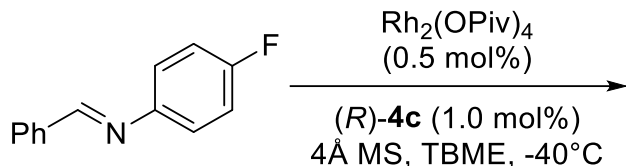

2s, $398.4 \mathrm{mg}$

$2.0 \mathrm{mmol}$

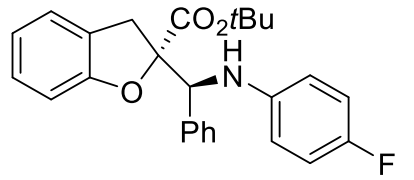

5s, $713.1 \mathrm{mg}$ $85 \%$ yield $99 \%$ ee, $>20: 1 d r$

Scale up: To a 50-mL oven-dried vial containing a magnetic stirring bar, imine $2 \mathrm{~s}$ (398.4 mg, $2.0 \mathrm{mmol}),(R)-4 \mathrm{c}(17.3 \mathrm{mg}, 1.0 \mathrm{~mol} \%), \mathrm{Rh}_{2}(\mathrm{OPiv})_{4}(6.0 \mathrm{mg}, 0.5 \mathrm{~mol} \%)$, and $4 \AA$ MS (500 mg) in TBME (20 mL), a solution of diazo compound 1c (744.9 mg, 3.0 mmol, 1.5 equiv. $)$ in TBME $(10 \mathrm{~mL})$ was added via a syringe pump over $0.5 \mathrm{~h}$ under argon atmosphere at $-40{ }^{\circ} \mathrm{C}$. After addition, the reaction mixture was stirred for additional $1.0 \mathrm{~h}$ under these conditions until consumption of the material (monitored by TLC), Then, the solvent was evaporated under reduced pressure. The residue was purified by column chromatography on silica gel (Hexanes : EtOAc $=20: 1$ to 10:1) to give $713.1 \mathrm{mg}$ pure product $\mathbf{5 s}$ in $85 \%$ yield with $>20: 1 \mathrm{dr}$ and $99 \%$ ee. 


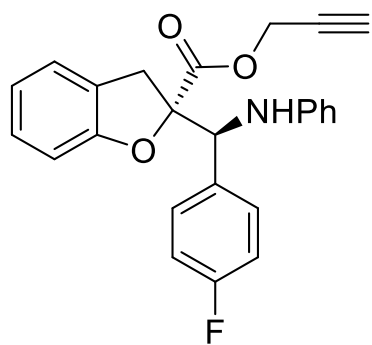

$3 e, 98 \%$ ee, $>20: 1 d r$

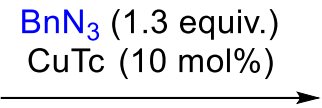

toluene, rt

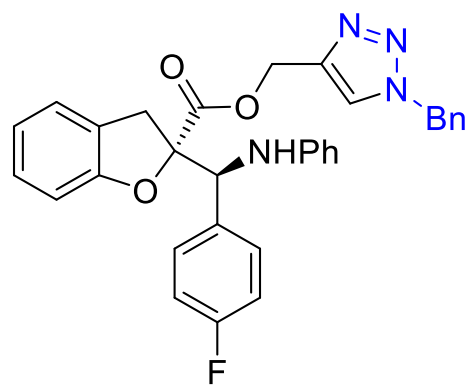

6, $98 \%$ yield $98 \%$ ee, $>20: 1 d r$

Synthesis of 6: To a 10-mL oven-dried vial containing a magnetic stirring bar, CuTc $(1.8 \mathrm{mg}, 10 \mathrm{~mol} \%)$, and $3 \mathbf{e}(37.5 \mathrm{mg}, 0.094 \mathrm{mmol})$ in toluene $(0.5 \mathrm{~mL})$, a solution of benzyl azide (16.3 mg, $0.122 \mathrm{mmol}, 1.3$ equiv.) in toluene $(0.5 \mathrm{~mL})$ was added dropwise at room temperature under a nitrogen atmosphere. After completion of the addition, the reaction mixture was stirred for additional $2.0 \mathrm{~h}$ under these conditions. When the reaction was completed (monitored by TLC), the solvent was removed and the crude residue was purified by flash chromatography on silica gel without any treatment (Hexanes : EtOAc $=5: 1$ to 3:1) to afford pure product 6 as colorless oil (49.2 mg, 98\% yield). $98 \% e e,>20: 1 d r .[\alpha]_{\mathrm{D}}{ }^{20}=42.0(\mathrm{c}=0.033, \mathrm{DCM}) ;{ }^{1} \mathrm{H}$ NMR $\left(500 \mathrm{MHz}, \mathrm{CDCl}_{3}\right)(\delta, \mathrm{ppm}) 7.35$ - 7.31 (comp, 5H), 7.22 - 7.14 (comp, 3H), 7.10 7.05 (comp, 4H), 6.98 (d, $J=8.0 \mathrm{~Hz}, 1 \mathrm{H}), 6.89$ (t, $J=7.4 \mathrm{~Hz}, 1 \mathrm{H}), 6.80$ (t, $J=8.4 \mathrm{~Hz}$, 2H), $6.65(\mathrm{t}, J=7.3 \mathrm{~Hz}, 1 \mathrm{H}), 6.52(\mathrm{~d}, J=8.0 \mathrm{~Hz}, 2 \mathrm{H}), 5.46(\mathrm{~d}, J=14.8 \mathrm{~Hz}, 1 \mathrm{H}), 5.29$ $(\mathrm{d}, J=14.8 \mathrm{~Hz}, 1 \mathrm{H}), 5.17(\mathrm{~d}, J=12.6 \mathrm{~Hz}, 1 \mathrm{H}), 5.10(\mathrm{~d}, J=12.6 \mathrm{~Hz}, 1 \mathrm{H}), 4.92(\mathrm{~s}, 1 \mathrm{H})$, $4.39(\mathrm{~s}, 1 \mathrm{H}), 3.76(\mathrm{~d}, J=16.2 \mathrm{~Hz}, 1 \mathrm{H}), 3.52(\mathrm{~d}, J=16.1 \mathrm{~Hz}, 1 \mathrm{H}) ;{ }^{13} \mathrm{C}$ NMR $(125$ $\left.\mathrm{MHz}, \mathrm{CDCl}_{3}\right)(\delta, \mathrm{ppm}) 171.4,162.3(\mathrm{~d}, J=246.0 \mathrm{~Hz}), 158.7,146.0,142.2,134.3$, $133.6(\mathrm{~d}, J=3.1 \mathrm{~Hz}), 130.2(\mathrm{~d}, J=8.2 \mathrm{~Hz}), 129.3,129.2,129.0,128.5,128.2,125.1$, 124.8, 124.2, 121.8, 118.5, $115.0(\mathrm{~d}, J=21.3 \mathrm{~Hz}), 114.1,109.9,92.0,60.6,58.7,54.2$, 37.9; ${ }^{19} \mathrm{~F}$ NMR (471 MHz, $\left.\mathrm{CDCl}_{3}\right)(\delta, \mathrm{ppm})$-114.03; HRMS (TOF MS ESI ${ }^{+}$) calculated for $\mathrm{C}_{32} \mathrm{H}_{27} \mathrm{FN}_{4} \mathrm{O}_{3} \mathrm{Na} \quad[\mathrm{M}+\mathrm{Na}]^{+}$: 557.1959, found 557.1959; HPLC conditions for determination of enantiomeric excess: Chiralpak IA, $\lambda=254 \mathrm{~nm}$, hexane $:$-propanol $=90: 10$, flow rate $=1.0 \mathrm{~mL} / \mathrm{min}, t_{\text {minor }}=28.1 \mathrm{~min}, t_{\text {major }}=34.9$ $\min$. 
<smiles>CCOC(=O)[C@@]1([C@@H](NC(=O)OC(C)C)c2ccccc2)Cc2ccccc2O1</smiles>

5s, $99 \%$ ee, $>20: 1 d r$

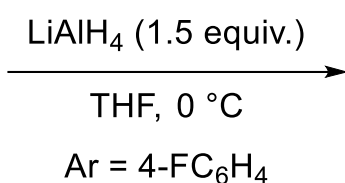

$\mathrm{Ar}=4-\mathrm{FC}_{6} \mathrm{H}_{4}$<smiles>C[C@]1([C@@H](N)[Al])Cc2ccccc2O1</smiles>

7, $80 \%$ yield $99 \%$ ee, $>20: 1 d r$

Synthesis of 7: To a 10-mL oven-dried vial containing a magnetic stirring bar, $5 \mathrm{~s}$ (63 $\mathrm{mg}, 0.15 \mathrm{mmol})$ in THF $(2.0 \mathrm{~mL}), \mathrm{LiAlH}_{4}(8.5 \mathrm{mg}, 0.225 \mathrm{mmol}, 1.5$ equiv. $)$ was added at $0{ }^{\circ} \mathrm{C}$. The resulting mixture was stirred for $1.0 \mathrm{~h}$ before it was quenched with aqueous saturated ammonium chloride $(3.0 \mathrm{~mL})$, and extracted with EtOAc $(3$ X 5.0 $\mathrm{mL}$ ). The combined organic extract was washed with brine, dried with $\mathrm{Na}_{2} \mathrm{SO}_{4}$, and then concentrated under reduced pressure after filtration. The residue was purified by flash chromatography on silica gel (Hexanes : EtOAc $=5: 1$ to 3:1) to afford pure product 7 as a colorless oil $(41.9 \mathrm{mg}, 80 \%$ yield $) .99 \%$ ee, $>20: 1 d r \cdot[\alpha]_{\mathrm{D}}{ }^{20}=33.0(\mathrm{c}=$ 0.033, DCM); ${ }^{1} \mathrm{H}$ NMR $\left(500 \mathrm{MHz}, \mathrm{CDCl}_{3}\right)(\delta, \mathrm{ppm}) 7.45(\mathrm{~d}, J=7.6 \mathrm{~Hz}, 2 \mathrm{H}), 7.31(\mathrm{t}$, $J=7.4 \mathrm{~Hz}, 2 \mathrm{H}), 7.26-7.23(\mathrm{~m}, 1 \mathrm{H}), 7.15-7.11(\mathrm{~m}, 2 \mathrm{H}), 6.88-6.83(\mathrm{~m}, 2 \mathrm{H}), 6.74(\mathrm{t}$, $J=8.3 \mathrm{~Hz}, 2 \mathrm{H}), 6.44(\mathrm{dd}, J=7.9,4.5 \mathrm{~Hz}, 2 \mathrm{H}), 4.59(\mathrm{~s}, 1 \mathrm{H}), 3.67(\mathrm{~d}, J=11.5 \mathrm{~Hz}, 1 \mathrm{H})$, 3.49 - $3.44(\mathrm{~m}, 2 \mathrm{H}), 3.23(\mathrm{~d}, J=15.7 \mathrm{~Hz}, 1 \mathrm{H}) ;{ }^{13} \mathrm{C} \mathrm{NMR}\left(125 \mathrm{MHz}, \mathrm{CDCl}_{3}\right)(\delta, \mathrm{ppm})$ 159.0, $156.1(\mathrm{~d}, J=235.7 \mathrm{~Hz}), 143.2(\mathrm{~d}, J=1.9 \mathrm{~Hz}), 138.7,128.6,128.4,128.2$, 128.0, 126.8, 125.3, 121.2, 115.6 (d, $J=22.3 \mathrm{~Hz}), 115.1$ (d, $J=7.4 \mathrm{~Hz}), 109.6,91.6$, 65.4, 63.3, 35.6; ${ }^{19} \mathrm{~F}$ NMR (471 MHz, $\left.\mathrm{CDCl}_{3}\right)(\delta, \mathrm{ppm})-127.37$; HRMS (TOF MS $\mathrm{ESI}^{+}$) calculated for $\mathrm{C}_{22} \mathrm{H}_{20} \mathrm{FNO}_{2} \mathrm{Na}[\mathrm{M}+\mathrm{Na}]^{+}$: 372.1370, found 372.1371; HPLC conditions for determination of enantiomeric excess: Chiralpak IA-3, $\lambda=254 \mathrm{~nm}$, hexane $:$-propanol $=90: 10$, flow rate $=1.0 \mathrm{~mL} / \mathrm{min}, t_{\text {minor }}=21.1 \mathrm{~min}, t_{\text {major }}=10.7$ $\min$.

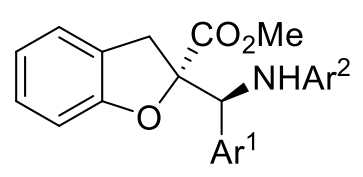

$5 r, 94 \%$ ee, $>20: 1 d r$

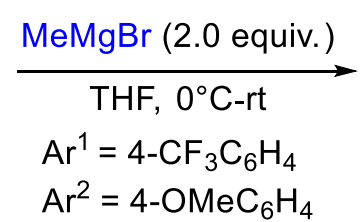

$\mathrm{Ar}^{2}=4-\mathrm{OMeC}_{6} \mathrm{H}_{4}$

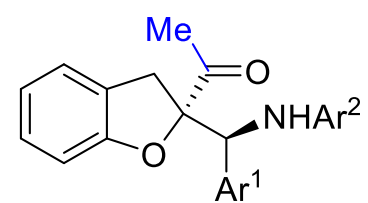

8, $71 \%$ yield $92 \%$ ee, $>20: 1 d r$

Synthesis of 8: To a $10-\mathrm{mL}$ oven-dried vial containing a magnetic stirring bar, $5 \mathbf{r}$ 
(45.7 mg, $0.1 \mathrm{mmol})$ in THF (1.0 mL), MeMgBr (1M in THF, $200 \mu \mathrm{L}, 0.2 \mathrm{mmol}, 2.0$ equiv.) was added dropwise at $0{ }^{\circ} \mathrm{C}$ under a nitrogen atmosphere. After completion of the addition, the reaction mixture was stirred for additional $2.0 \mathrm{~h}$ before it was diluted with cold aqueous saturated ammonium chloride $(3.0 \mathrm{~mL})$ and extracted with EtOAc (3 X $5.0 \mathrm{~mL}$ ). The combined organic layer was dried over $\mathrm{MgSO}_{4}$, concentrated in vасио after filtration. The residue was purified by flash column chromatography on silica gel (Hexanes : EtOAc $=20: 1$ to 5:1) to afford the ketone $\mathbf{8}$ as a colorless oil (31.3 mg, 71\% yield). $92 \% e e,>20: 1 d r .[\alpha]_{\mathrm{D}}{ }^{20}=150.2(\mathrm{c}=0.033, \mathrm{DCM}) ;{ }^{1} \mathrm{H}$ NMR $\left(500 \mathrm{MHz} \mathrm{CDCl}_{3}\right)(\delta, \mathrm{ppm}) 7.56-7.51(\mathrm{comp}, 4 \mathrm{H}), 7.19(\mathrm{t}, J=7.7 \mathrm{~Hz}, 1 \mathrm{H}), 7.14$ (d, $J=7.3 \mathrm{~Hz}, 1 \mathrm{H}), 6.97-6.91(\mathrm{~m}, 2 \mathrm{H}), 6.66(\mathrm{~d}, J=8.2 \mathrm{~Hz}, 2 \mathrm{H}), 6.48(\mathrm{~d}, J=8.1 \mathrm{~Hz}, 2 \mathrm{H})$, $4.87(\mathrm{~s}, 1 \mathrm{H}), 4.23(\mathrm{~s}, 1 \mathrm{H}), 3.80(\mathrm{~d}, J=16.2 \mathrm{~Hz}, 1 \mathrm{H}), 3.66(\mathrm{~s}, 3 \mathrm{H}), 3.44(\mathrm{~d}, J=16.2 \mathrm{~Hz}$, 1H), $1.78(\mathrm{~s}, 3 \mathrm{H}) ;{ }^{13} \mathrm{C} \mathrm{NMR}\left(125 \mathrm{MHz}, \mathrm{CDCl}_{3}\right)(\delta, \mathrm{ppm}) 213.2,158.5,152.9,142.6$, $139.8,130.1(\mathrm{q}, J=32.5 \mathrm{~Hz}), 129.2,128.5,126.0,125.4(\mathrm{q}, J=3.7 \mathrm{~Hz}), 125.2,124.1$ $(\mathrm{q}, J=272.0 \mathrm{~Hz}), 122.1,115.5,115.0,109.8,97.3,61.7,55.7,37.6,27.7 ;{ }^{19} \mathrm{~F}$ NMR $\left(471 \mathrm{MHz}, \mathrm{CDCl}_{3}\right)(\delta, \mathrm{ppm})-62.58$; HRMS (TOF MS $\mathrm{ESI}^{+}$) calculated for $\mathrm{C}_{25} \mathrm{H}_{22} \mathrm{~F}_{3} \mathrm{NO}_{3} \mathrm{Na} \quad[\mathrm{M}+\mathrm{Na}]^{+}:$464.1444, found 464.1442; HPLC conditions for determination of enantiomeric excess: Chiralpak AD-H, $\lambda=254 \mathrm{~nm}$, hexane : 2-propanol $=95: 5$, flow rate $=1.0 \mathrm{~mL} / \mathrm{min}, t_{\text {minor }}=15.4 \mathrm{~min}, t_{\text {major }}=14.4 \mathrm{~min}$.

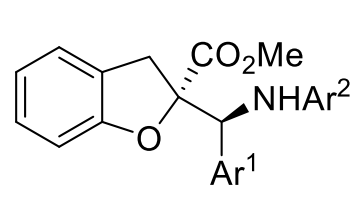

$5 r, 94 \%$ ee, $>20: 1 d r$

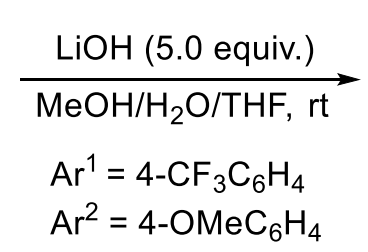

$\mathrm{Ar}^{2}=4-\mathrm{OMeC}_{6} \mathrm{H}_{4}$

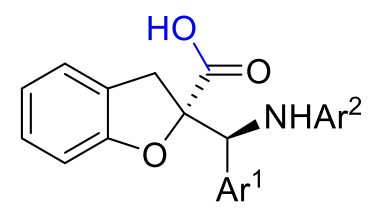

9, $83 \%$ yield $93 \%$ ee, $>20: 1 d r$

Synthesis of 9: To a 10-mL oven-dried vial containing a magnetic stirring bar, $\mathbf{5 r}$ (45.7 mg, $0.1 \mathrm{mmol})$ in a mixture solvent of $\mathrm{MeOH} / \mathrm{H}_{2} \mathrm{O} / \mathrm{THF}$ (5:1:1, total volume: $1.0 \mathrm{~mL}$ ) was added $\mathrm{LiOH}(12 \mathrm{mg}, 0.5 \mathrm{mmol}, 5.0$ equiv.). The reaction mixture was stirred at room temperature overnight. When the reaction was completed (monitored by TLC). An aqueous solution of $\mathrm{KHSO}_{4}(1 \mathrm{~N})$ was added to adjust the $\mathrm{pH}$ value to 2-4. Then the reaction mixture was extracted with ethyl acetate $(3 \times 5.0 \mathrm{~mL})$. The 
combined organic layer was dried over $\mathrm{MgSO}_{4}$ and concentrated in vacuo after filtration. The residue was purified by flash column chromatography on silica gel (DCM : $\mathrm{MeOH}=20: 1$ to 10:1) to afford the acid 9 as a white oil (36.8 mg, 83\% yield). $93 \% e e,>20: 1 d r \cdot[\alpha]_{\mathrm{D}}{ }^{20}=111.1(\mathrm{c}=0.033, \mathrm{DCM}) ;{ }^{1} \mathrm{H} \mathrm{NMR}\left(500 \mathrm{MHz}, \mathrm{CDCl}_{3}\right)(\delta$, ppm) $7.54-7.50$ (comp, 4H), $7.20-7.14(\mathrm{~m}, 2 \mathrm{H}), 6.97-6.93(\mathrm{~m}, 2 \mathrm{H}), 6.66(\mathrm{~d}, J=$ $8.1 \mathrm{~Hz}, 2 \mathrm{H}), 6.50(\mathrm{~d}, J=8.2 \mathrm{~Hz}, 2 \mathrm{H}), 5.74(\mathrm{~s}, 2 \mathrm{H}), 4.93(\mathrm{~s}, 1 \mathrm{H}), 3.88(\mathrm{~d}, J=16.0 \mathrm{~Hz}$, 1H), $3.67(\mathrm{~s}, 3 \mathrm{H}), 3.58(\mathrm{~d}, J=16.2 \mathrm{~Hz}, 1 \mathrm{H}) ;{ }^{13} \mathrm{C} \mathrm{NMR}\left(125 \mathrm{MHz}, \mathrm{CDCl}_{3}\right)(\delta, \mathrm{ppm})$ $175.2,158.1,153.1,141.9,139.6,130.4(\mathrm{q}, J=32.2 \mathrm{~Hz}), 128.8,128.7,125.6(\mathrm{q}, J=$ $3.5 \mathrm{~Hz}), 125.2$, 125.1, 124.1 (q, $J=272.0 \mathrm{~Hz}), 122.5,115.9,115.0,110.0$, 92.2, 62.1, 55.8, 37.9; ${ }^{19} \mathrm{~F}$ NMR (471 MHz, $\left.\mathrm{CDCl}_{3}\right)(\delta, \mathrm{ppm})-62.62$; HRMS (TOF MS ESI ${ }^{+}$) calculated for $\mathrm{C}_{24} \mathrm{H}_{20} \mathrm{~F}_{3} \mathrm{NO}_{4} \mathrm{Na}[\mathrm{M}+\mathrm{Na}]^{+}$: 466.1237, found 466.1236; The ee value of 9 was determined by converting $\mathbf{9}$ to $\mathbf{5 r}$, and measured by the method for $\mathbf{5 r}$.

\section{Control Experiments}

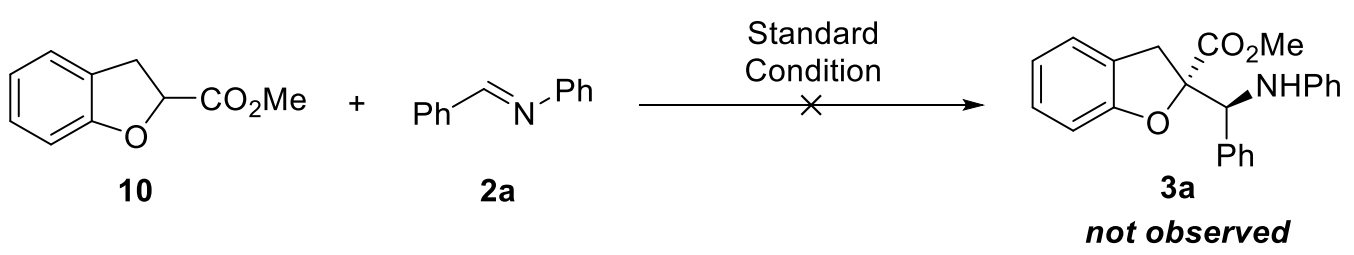

To a 10-mL oven-dried vial containing a magnetic stirring bar, the solution of $2 \mathbf{a}$ (18.1 $\mathrm{mg}, 0.1 \mathrm{mmol}), \mathrm{Rh}_{2}$ (OPiv) 4 (0.6 mg, $\left.1.0 \mathrm{~mol} \%\right),(R)-4 \mathrm{c}(0.9 \mathrm{mg}, 1.0 \mathrm{~mol} \%)$, and $4 \AA$ MS (50 mg) in TBME (1.0 mL), a solution of compound 10 (26.7 mg, $0.15 \mathrm{mmol}, 1.5$ equiv.) in TBME (1.0 mL) was added via a syringe pump over $0.5 \mathrm{~h}$ under argon atmosphere at $-40{ }^{\circ} \mathrm{C}$. After addition, the reaction mixture was stirred for additional $0.5 \mathrm{~h}$. Then, the crude reaction mixture was subjected to proton NMR analysis after evaporation (see third spectra in Figure S1), and no reaction occurred according to these results. 


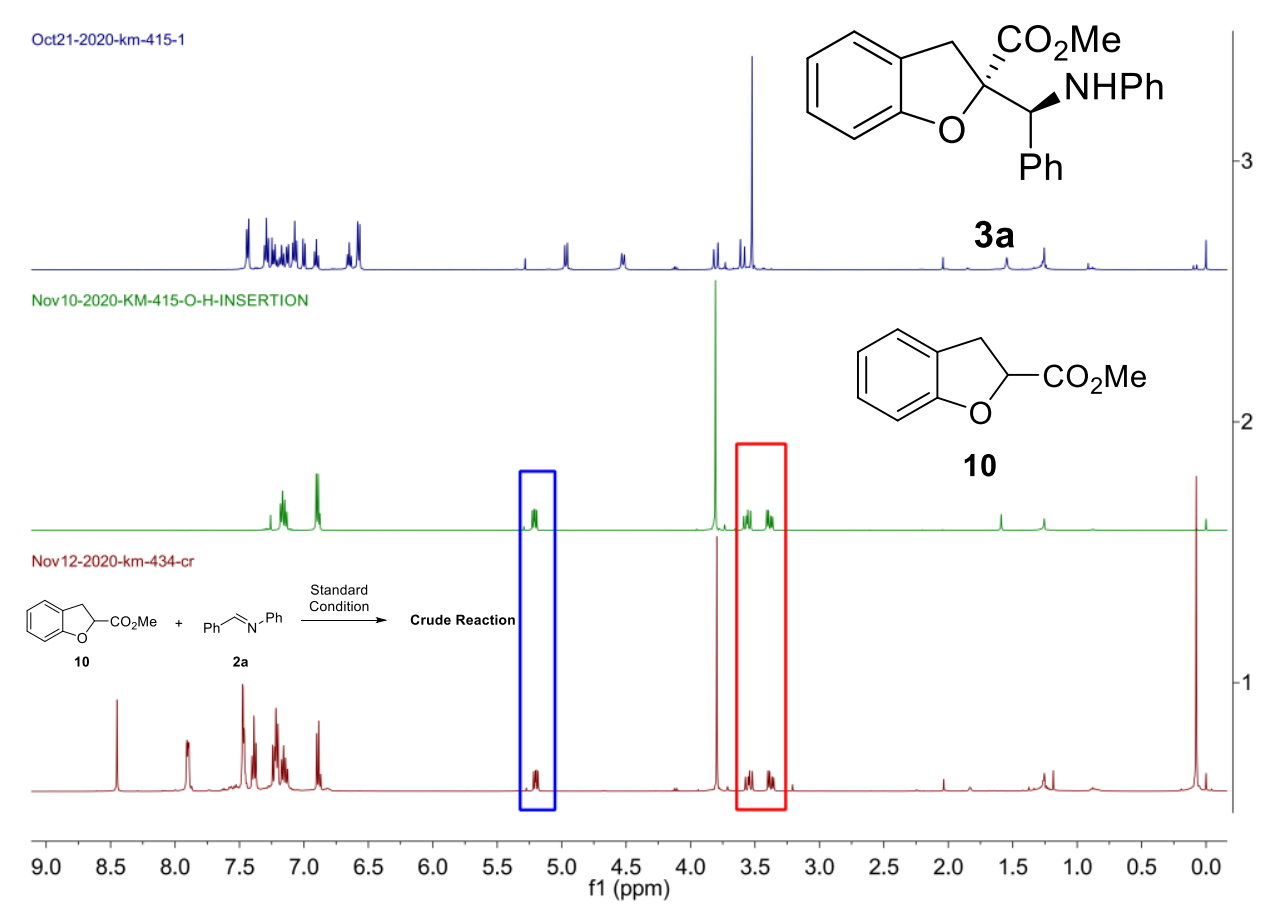

Figure S1. Proton NMR analysis of the crude reaction mixture of $\mathbf{1 0}$ with $\mathbf{2 a}$.<smiles>CC(C)(C)OC(=O)C(=N)Cc1ccccc1O</smiles>

To a 10-mL oven-dried vial containing a magnetic stirring bar, 2a (18.1 mg, 0.1 $\mathrm{mmol}), \mathrm{Rh}_{2}(\mathrm{~S} \text {-PTTL })_{4}(1.2 \mathrm{mg}, 1.0 \mathrm{~mol} \%)$, rac-PPA $(1.7 \mathrm{mg}, 5.0 \mathrm{~mol} \%)$, and $4 \AA \mathrm{MS}$ $(50 \mathrm{mg})$ in TBME $(1.0 \mathrm{~mL})$, a solution of compound $1 \mathrm{c}(37.0 \mathrm{mg}, 0.15 \mathrm{mmol}, 1.5$ equiv.) in TBME $(1.0 \mathrm{~mL})$ was added via a syringe pump over $0.5 \mathrm{~h}$ at $-40{ }^{\circ} \mathrm{C}$ under argon atmosphere. After addition, the reaction mixture was stirred for additional $1.0 \mathrm{~h}$ under these conditions until consumption of the material (monitored by TLC), Then, the reaction mixture was purified by column chromatography on silica gel without any additional treatment (Hexanes : EtOAc $=20: 1$ to 10:1) to give the racemic 
products 3c in $81 \%$ yield with $<5 \%$ ee, $20: 1 d r$.

\section{References:}

(1) Song, X.-G.; Zhu, S.-F.; Xie, X.-L.; Zhou, Q.-L. Enantioselective Copper-Catalyzed Intramolecular Phenolic O-H Bond Insertion: Synthesis of Chiral 2-Carboxy Dihydrobenzofurans, Dihydrobenzopyrans, and Tetrahydrobenzooxepines. Angew. Chem. Int. Ed. 2013, 52, 2555-2558.

(2) Song, X.-G.; Ren, Y.-Y.; Zhu, S.-F.; Zhou, Q.-L. EnantioselectiveCopper-Catalyzed Intramolecular N-H Bond Insertion: Synthesis of Chiral 2-Carboxytetrahydroquinolines. Adv. Synth. Catal. 2016, 358, 2366-2370. 
<smiles>COC(=O)[C@@]1([C@@H](Nc2ccccc2)c2ccccc2)Cc2ccccc2O1</smiles>

$3 a$

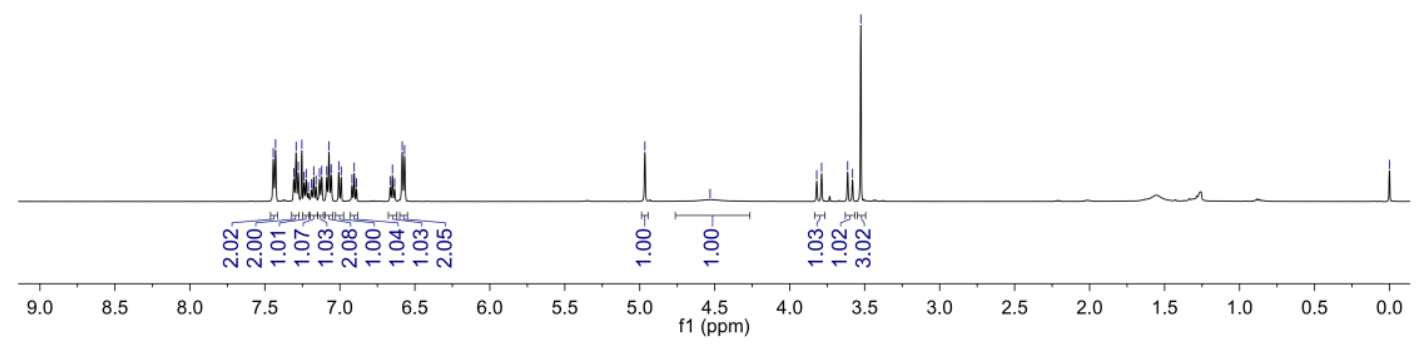

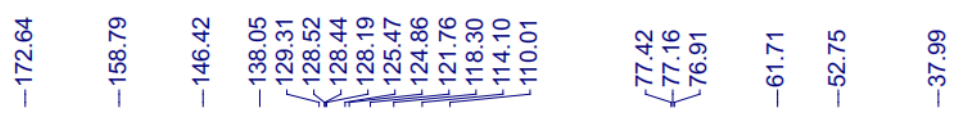<smiles>COC(=O)[C@@]1([C@@H](Nc2ccccc2)c2ccccc2)Cc2ccccc2O1</smiles>

$3 a$

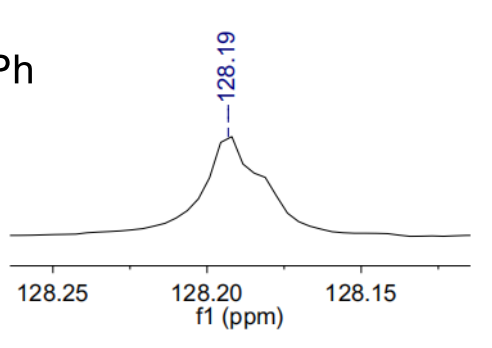

$\stackrel{\bar{m}}{\stackrel{\text { }}{\Gamma}}$

กุ $\stackrel{\infty}{i} \stackrel{\infty}{i}$

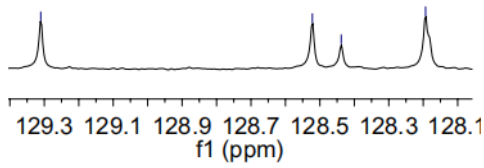

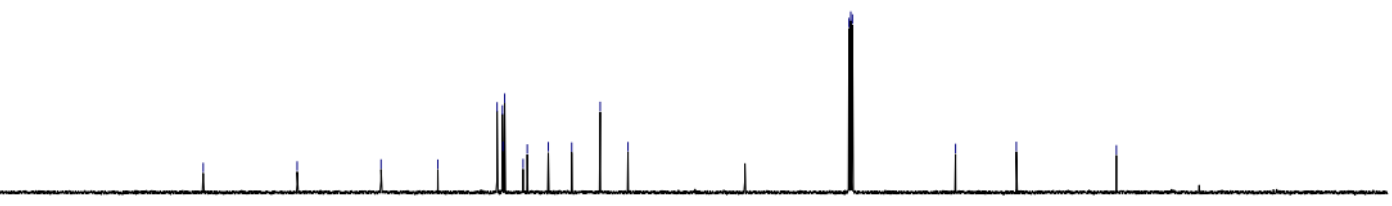

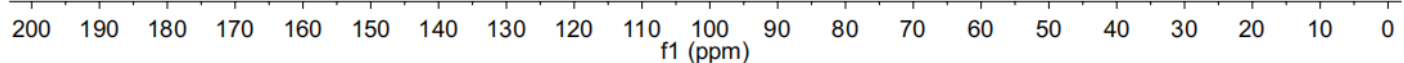



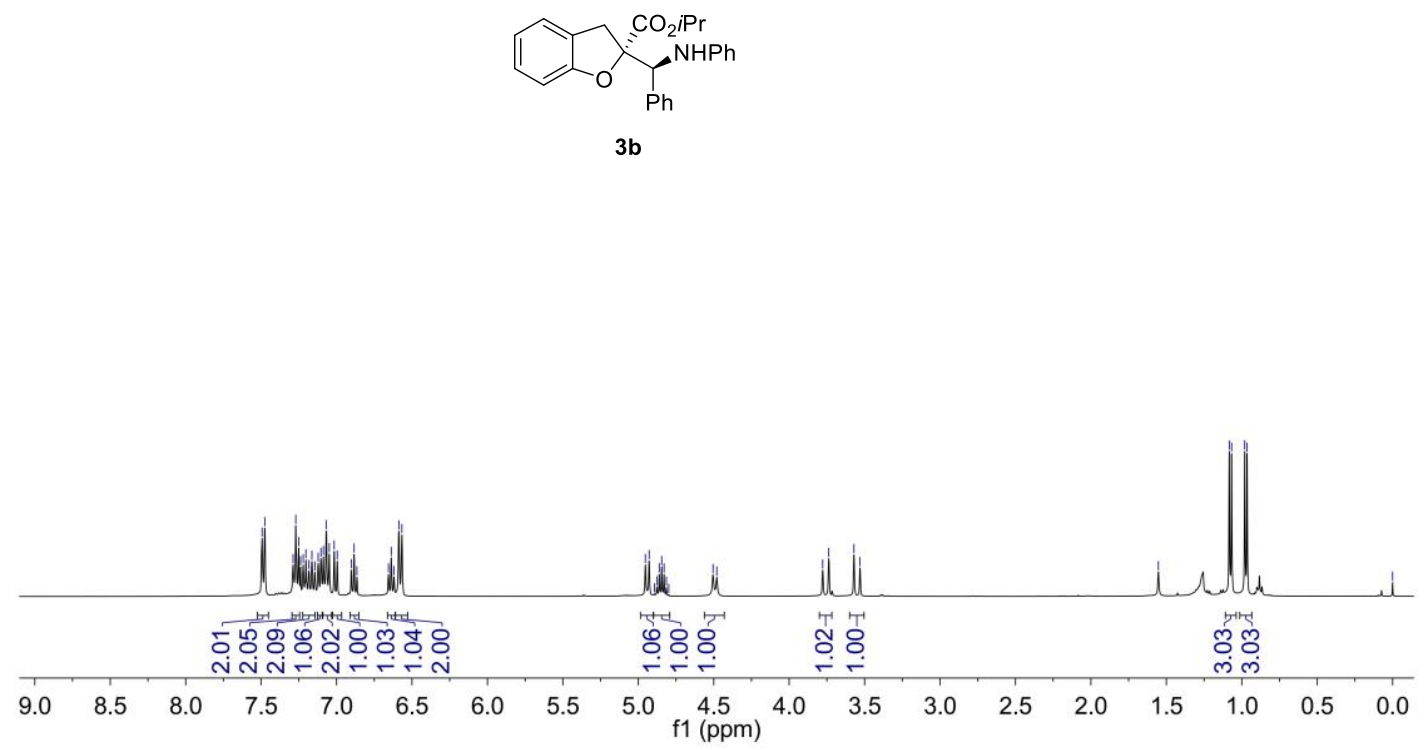

†े

3b

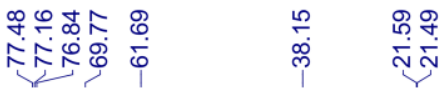
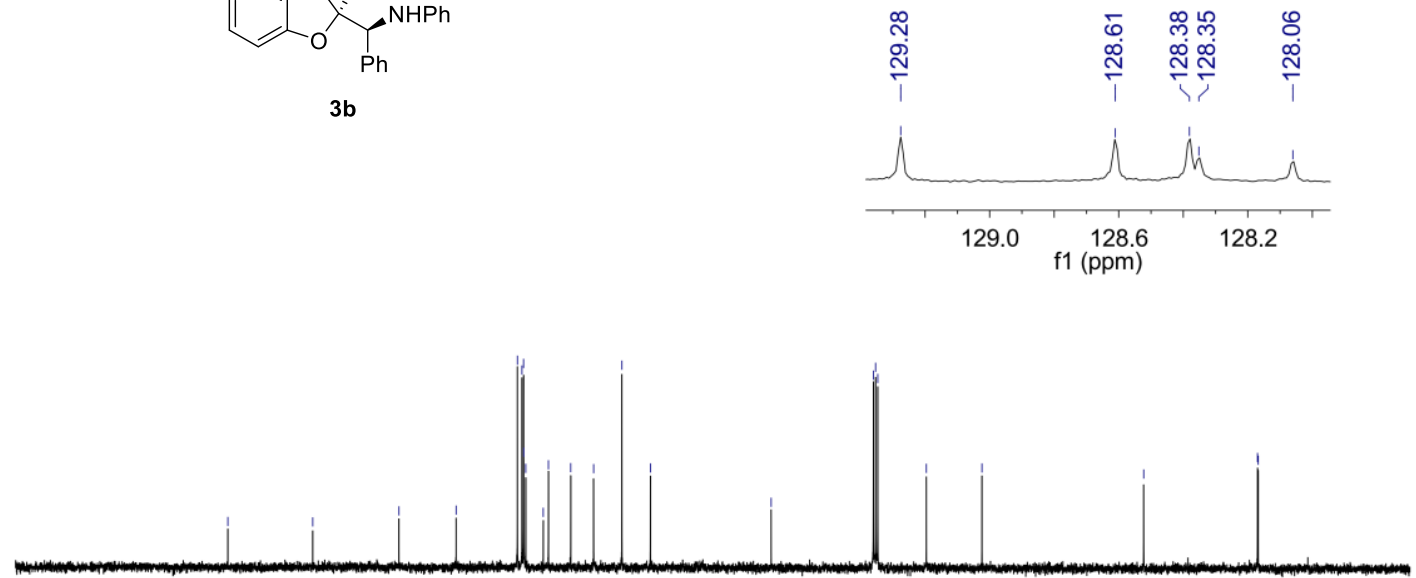

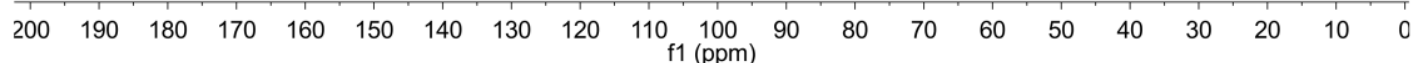




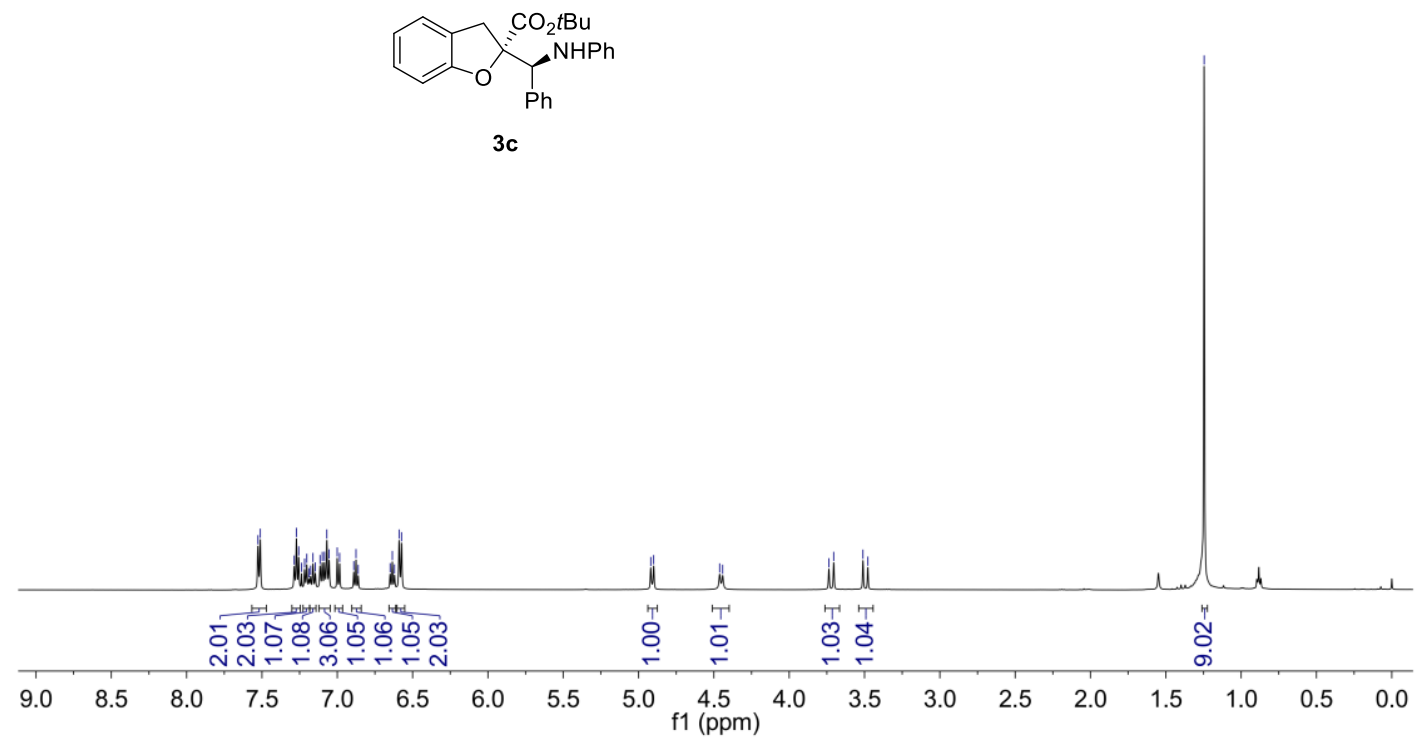

$3 c$

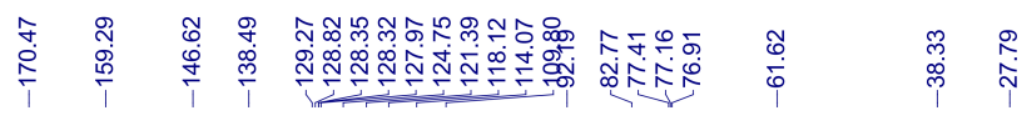

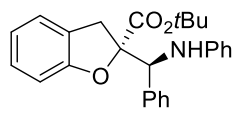

$3 c$
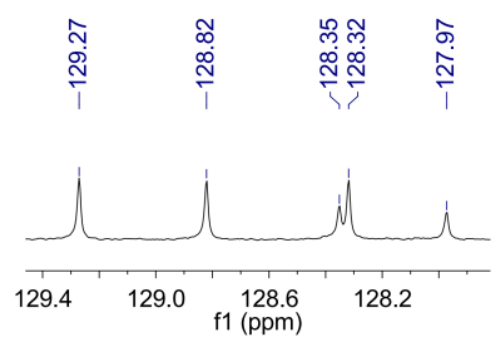

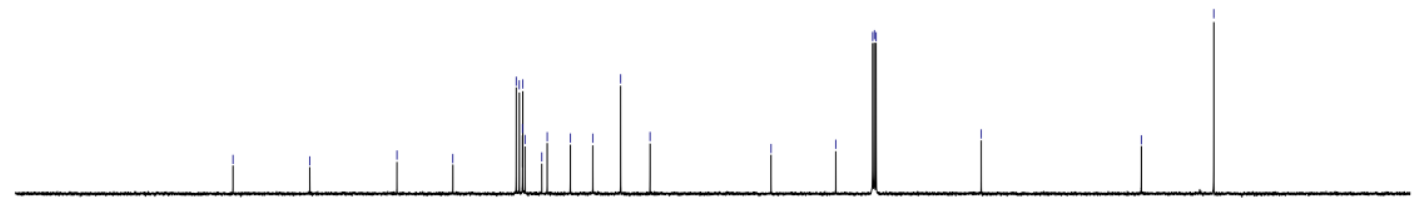

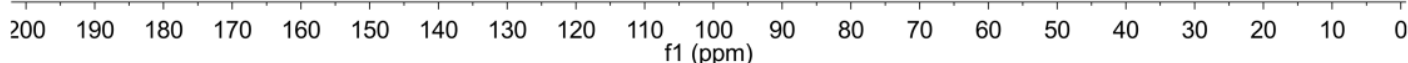



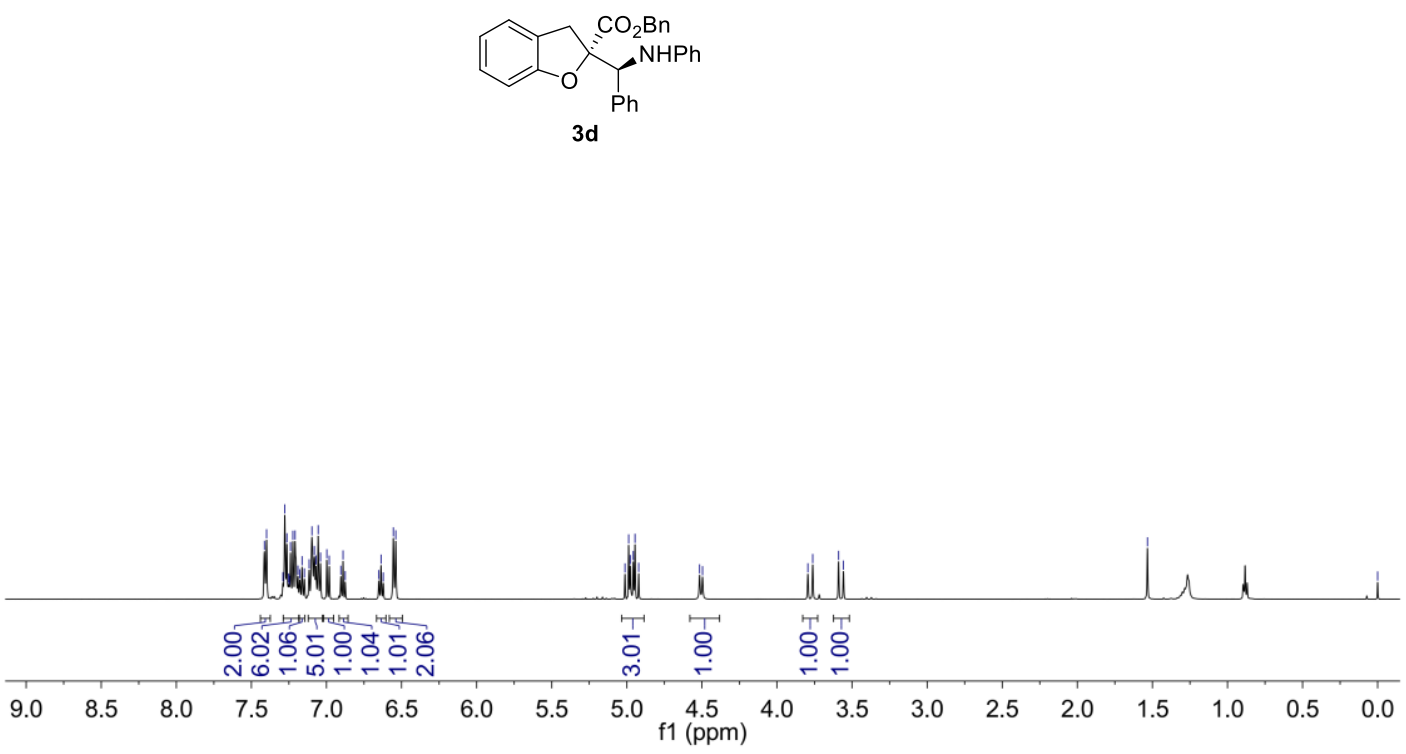

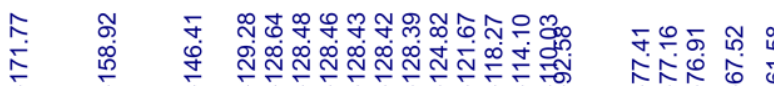

官
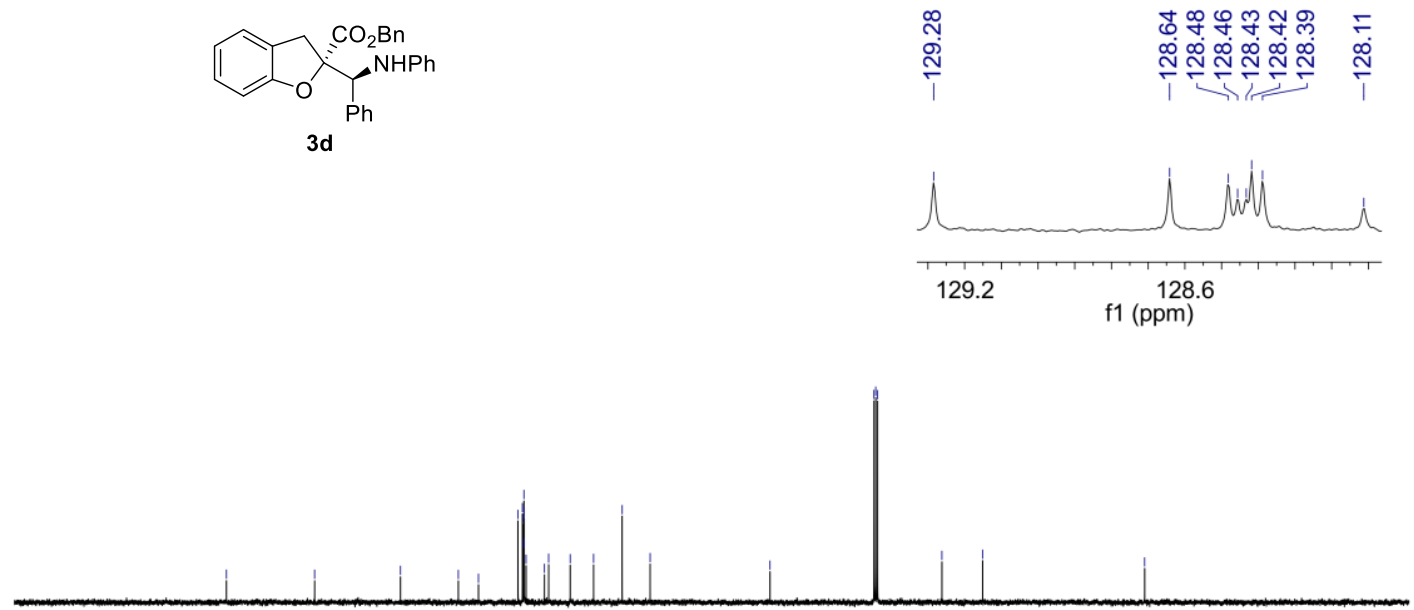

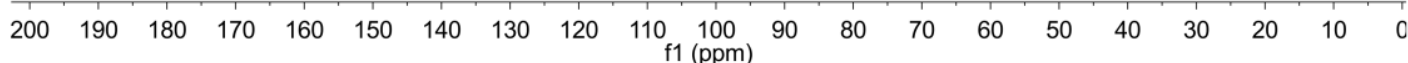




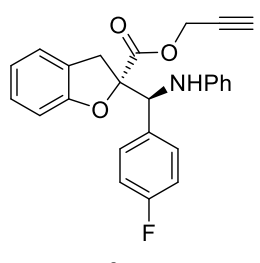

$3 e$

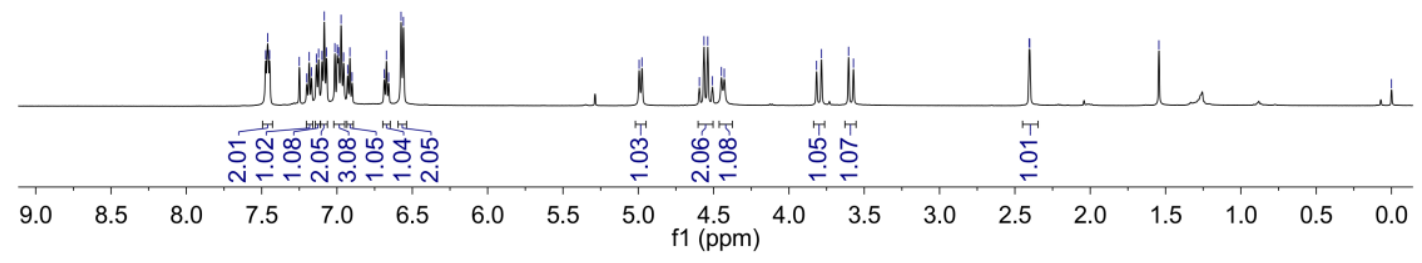

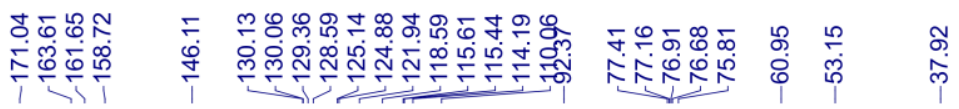

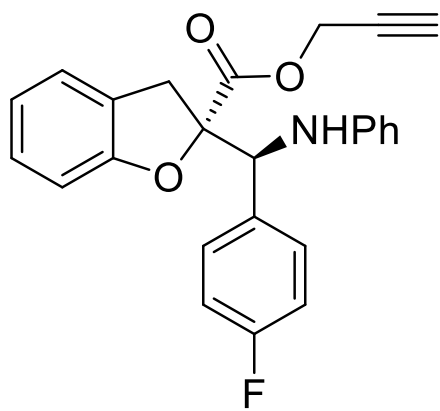

$3 e$

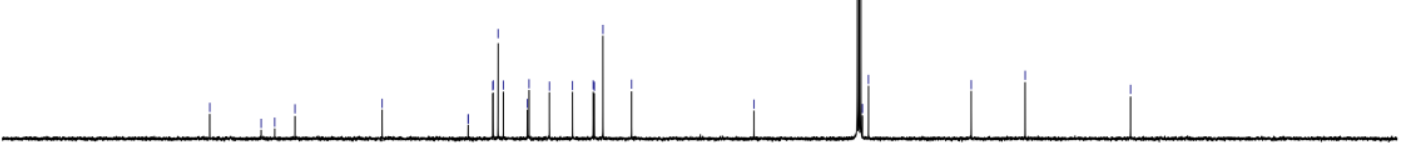

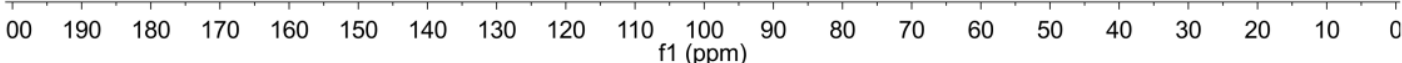



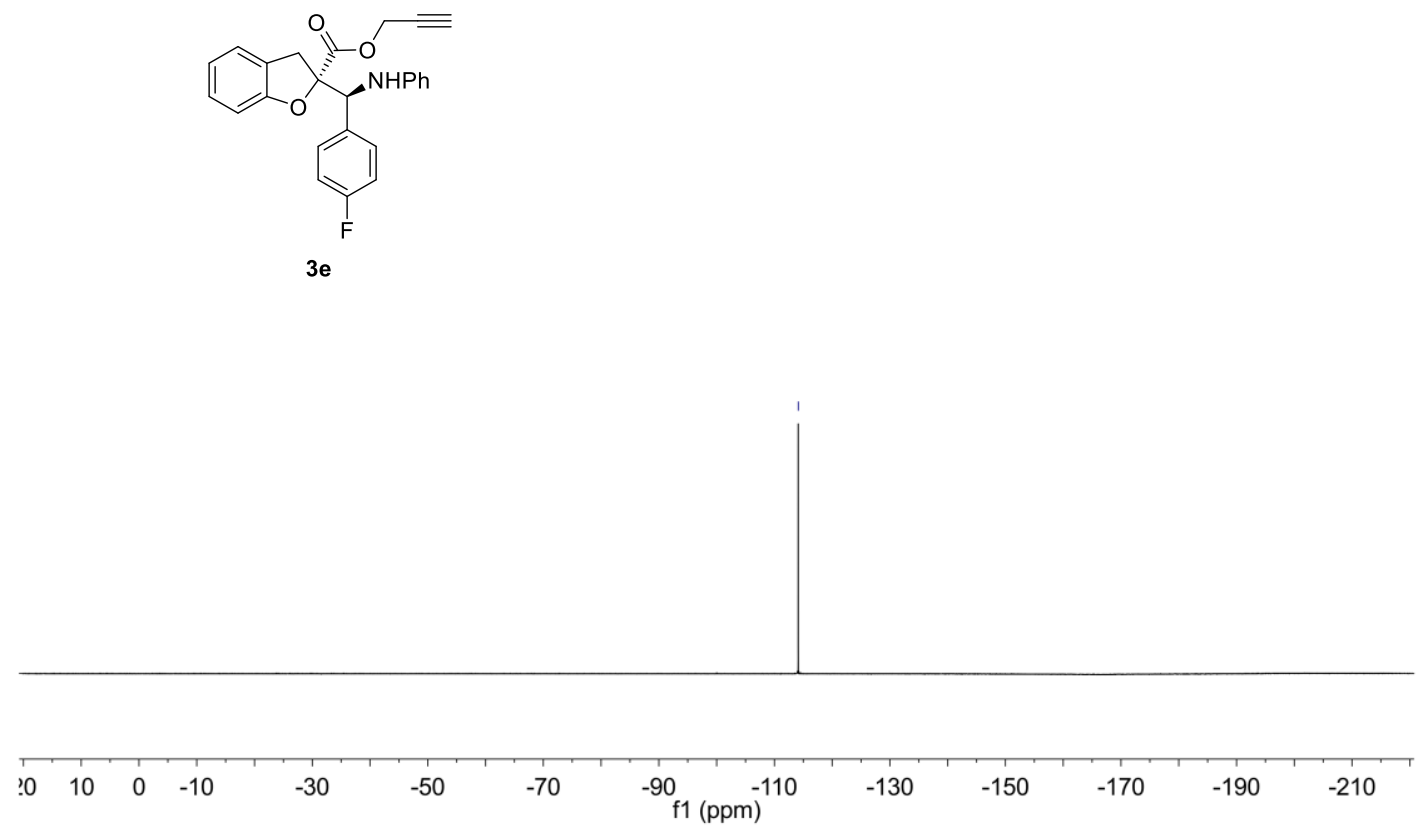

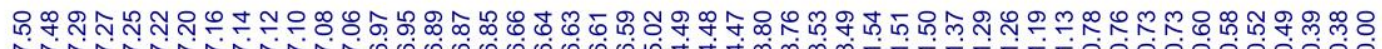

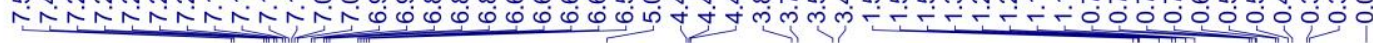<smiles>CC(C)[C@@H]1CC[C@H](C)C[C@H]1OC(=O)[C@]1([C@@H](Nc2ccccc2)c2ccccc2)Cc2ccccc2O1</smiles>

$3 \mathbf{f}$

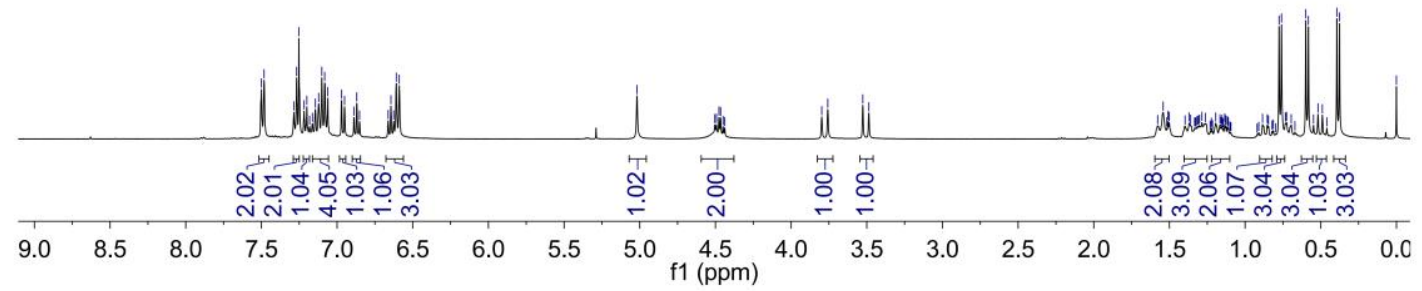




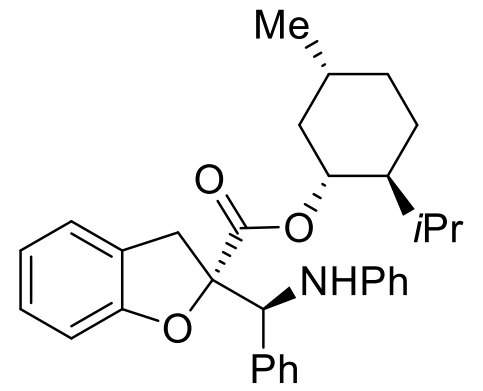

$3 \mathbf{f}$

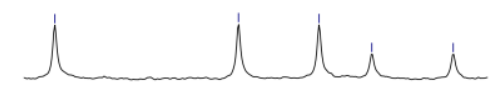

$\begin{array}{rrrr}129.4 & 129.0 & 128.6 & 128.2\end{array}$

$\begin{array}{llllllllllllllllllll}200 & 190 & 180 & 170 & 160 & 150 & 140 & 130 & 120 & 110 \begin{array}{l}100 \\ \mathrm{f} 1(\mathrm{ppm})\end{array} & 90 & 80 & 70 & 60 & 50 & 40 & 30 & 20 & 10 & 0\end{array}$

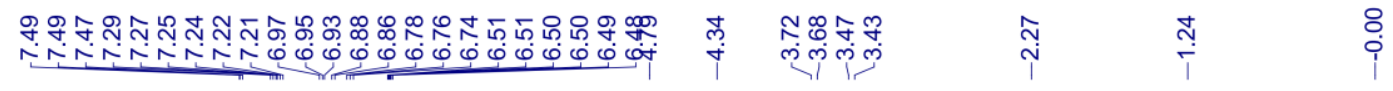<smiles>Cc1ccc2c(c1)CC(C(=O)OC(C)(C)C)([C@H](Nc1ccc(F)cc1)c1ccccc1)O2</smiles>

3g

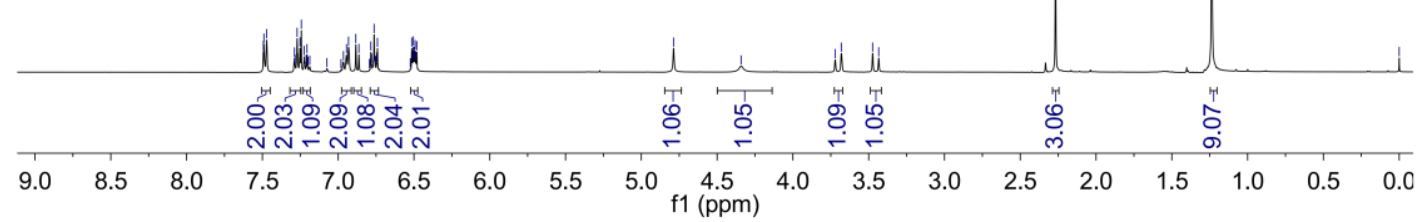




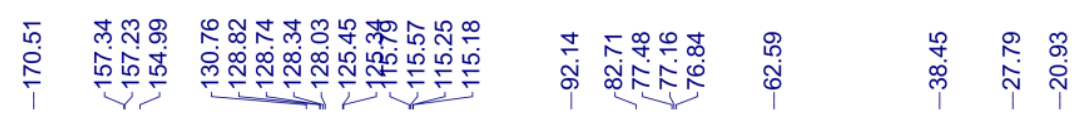<smiles>CCCOC(=O)[C@]1([C@@H](Nc2ccc(F)cc2)c2ccc(C)cc2C)Cc2cc(C)ccc2O1</smiles>

$3 g$
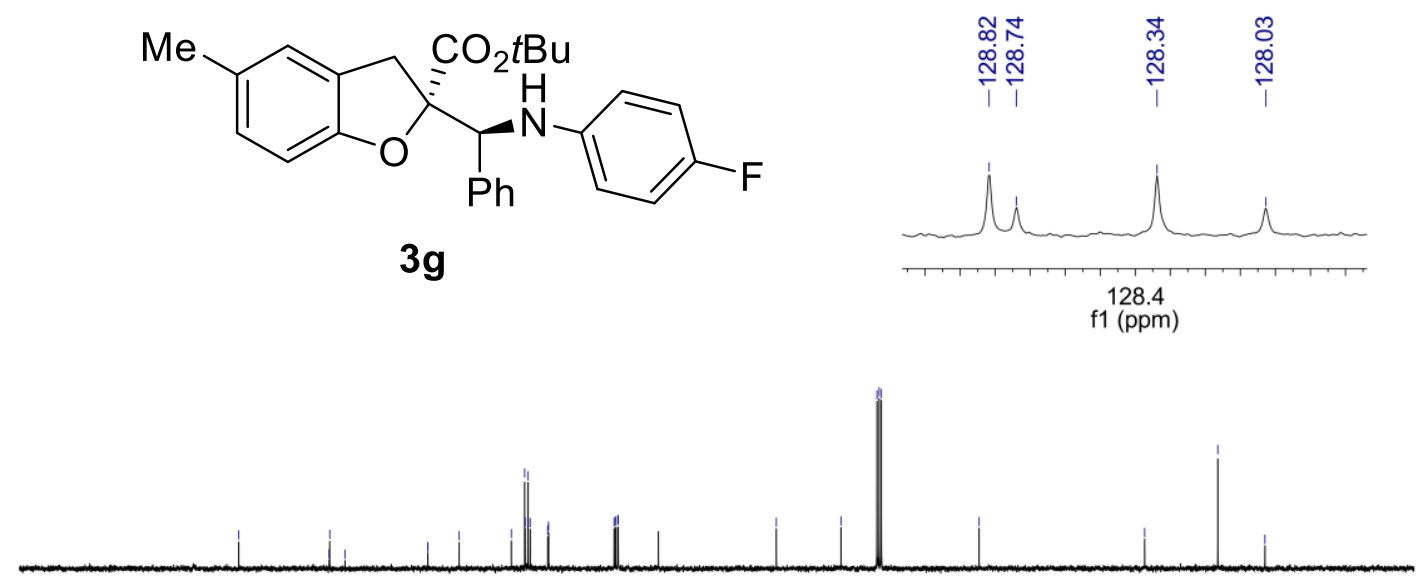

$\begin{array}{lllllllllllllllllllll}200 & 190 & 180 & 170 & 160 & 150 & 140 & 130 & 120 & 110 & 100 & 90 & 80 & 70 & 60 & 50 & 40 & 30 & 20 & 10 & 0\end{array}$<smiles></smiles>

$3 g$

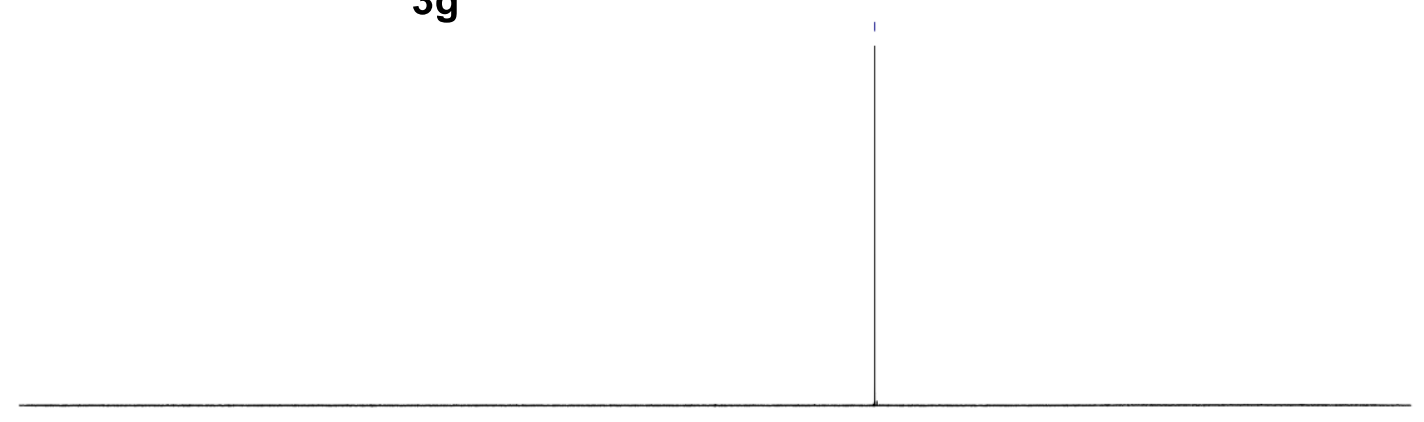

10

$-20$

$-40$

$-60$

$-80 \quad-100$

$\begin{array}{lllll}-120 & -140 & -160 & -180 & -200\end{array}$ 
<smiles>CC(C)(C)OC(=O)[C@]1([C@@H](Nc2ccc(F)cc2)c2ccc(Cl)cc2)Cc2cc(Cl)ccc2O1</smiles>

$3 h$

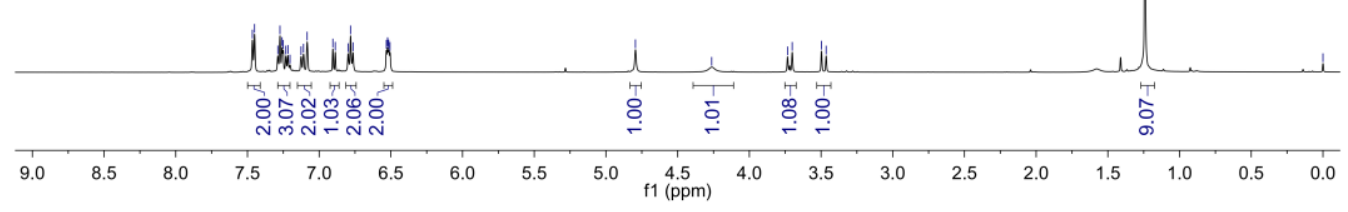

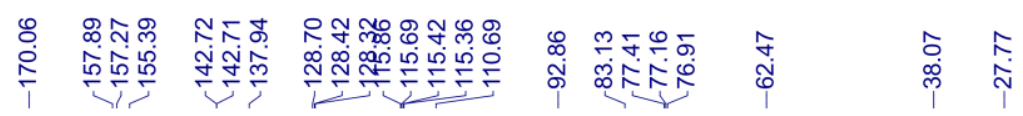<smiles></smiles>

$3 h$

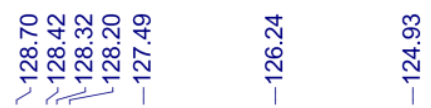

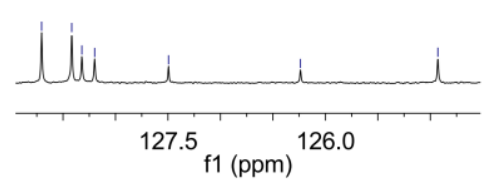

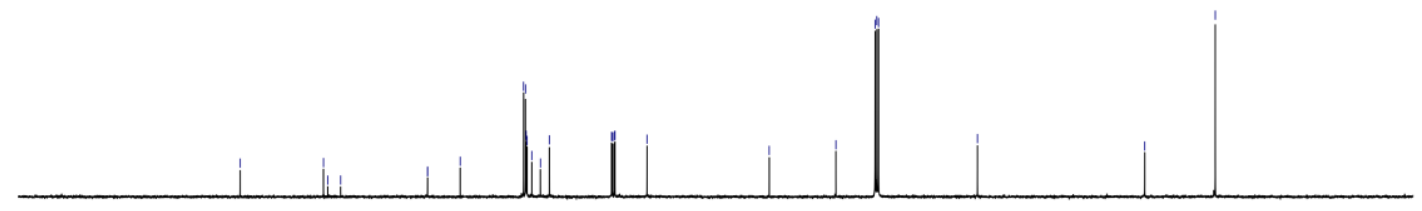

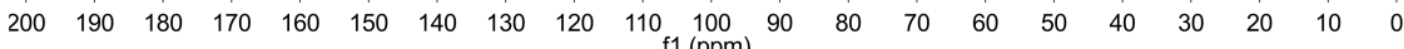


<smiles>CC(C)(C)OC(=O)[C@]1([C@@H](Nc2ccc(F)cc2)c2ccc(Cl)cc2)Cc2cc(Cl)ccc2O1</smiles>

$3 h$

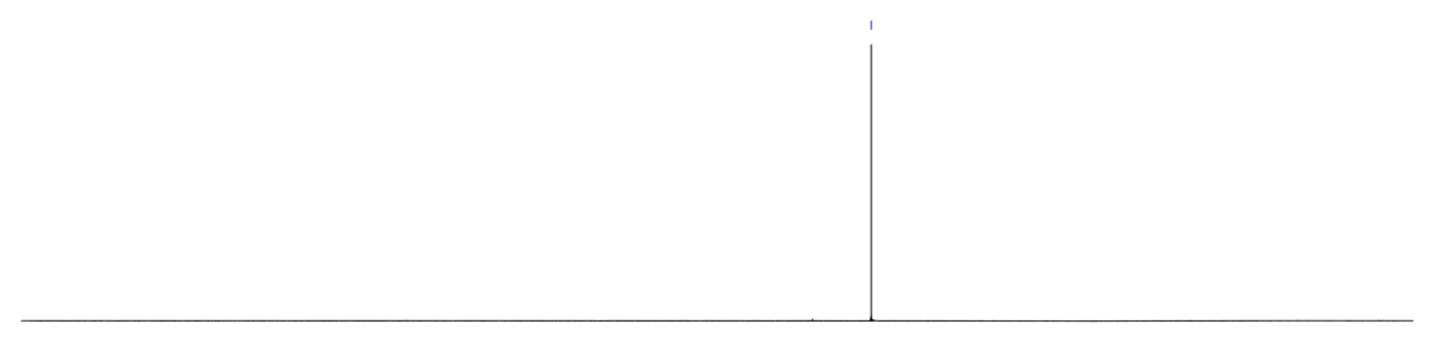

\begin{tabular}{lllllllllllllllllll}
\hline 0 & 10 & 0 & -10 & -20 & -30 & -40 & -50 & -60 & -70 & -80 & -90 & -110 & -130 & -150 & -170 & -190 & -210 \\
\hline
\end{tabular}

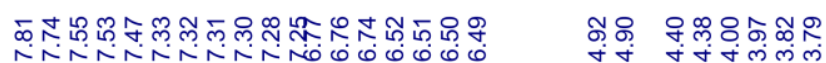

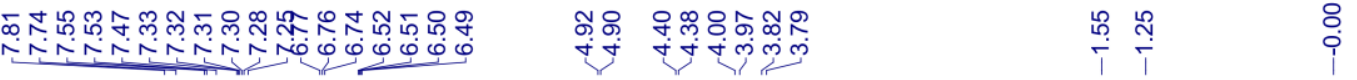

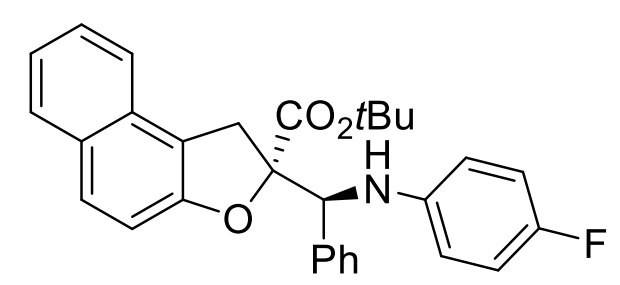

$3 \mathbf{i}$

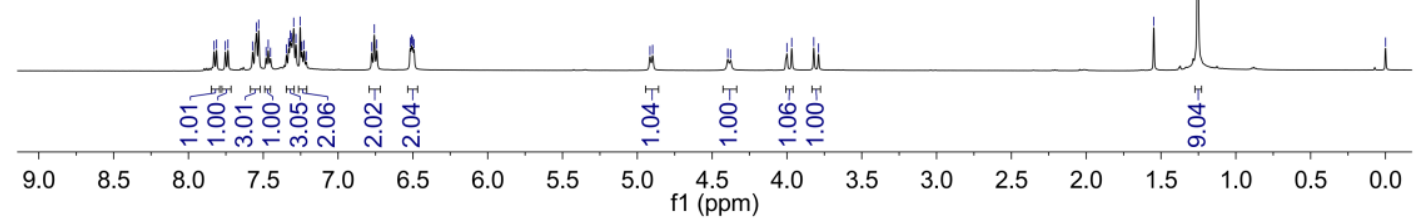




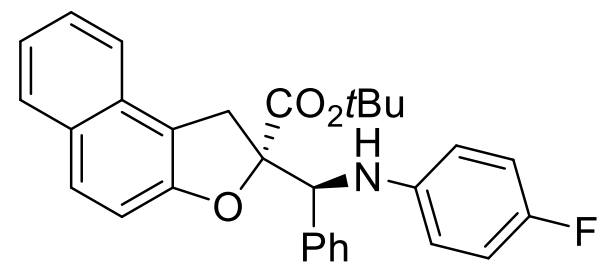

$3 i$

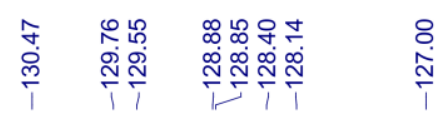

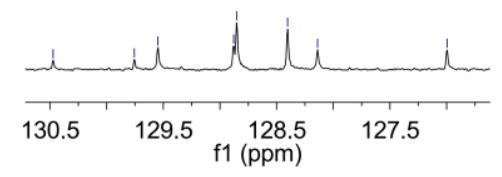

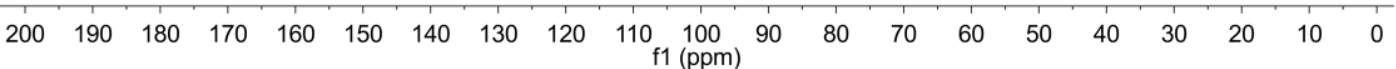

\section{$\stackrel{\stackrel{ }{N}}{\bar{i}}$}<smiles>CC(C)(C)OC(=O)N[C@H](c1ccccc1)[C@]1(c2ccccc2)Cc2c(ccc3ccccc23)O1</smiles>

$3 \mathbf{i}$

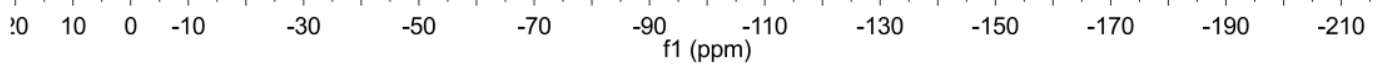




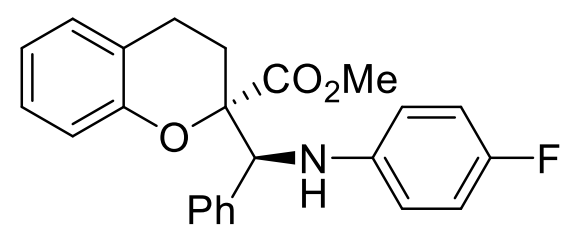

3j

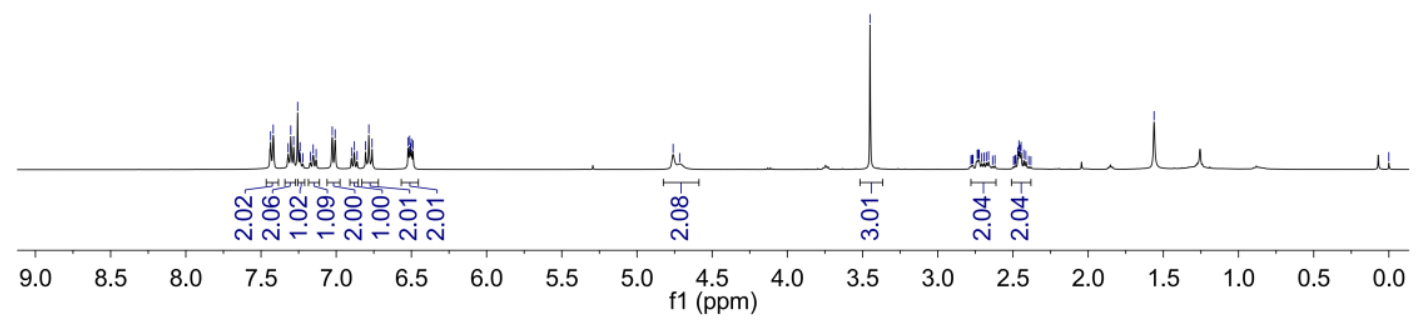

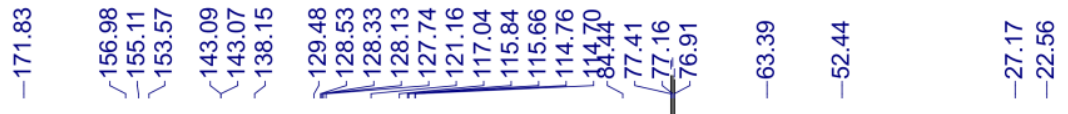

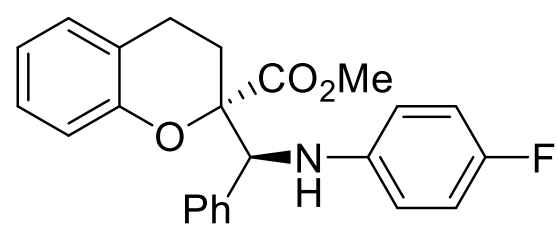

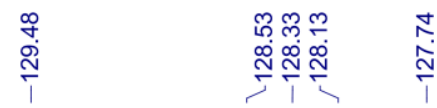

3j

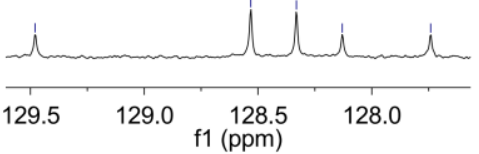

$\begin{array}{llllllllllllllllllll}200 & 190 & 180 & 170 & 160 & 150 & 140 & 130 & 120 & \begin{array}{c}110 \\ \mathrm{f} 1(\mathrm{ppm})\end{array} & \begin{array}{c}100 \\ (\mathrm{ppm})\end{array} & 80 & 70 & 60 & 50 & 40 & 30 & 20 & 10 & 0\end{array}$ 


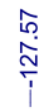

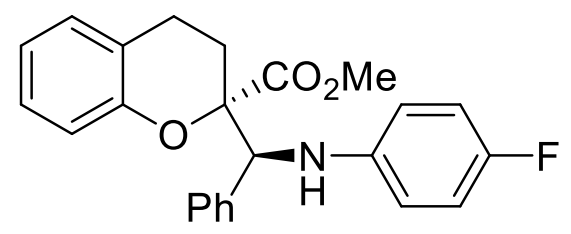

3j

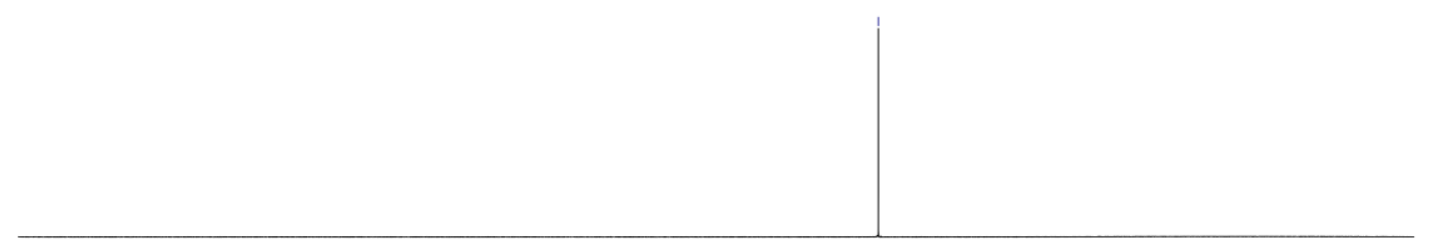

\begin{tabular}{|c|c|c|c|c|c|c|c|c|c|c|c|}
\hline 10 & 0 & -20 & -40 & -60 & -80 & $\begin{array}{c}-100 \\
\mathrm{f} 1 \text { (ppm) }\end{array}$ & -120 & -140 & -160 & -180 & -200 \\
\hline
\end{tabular}

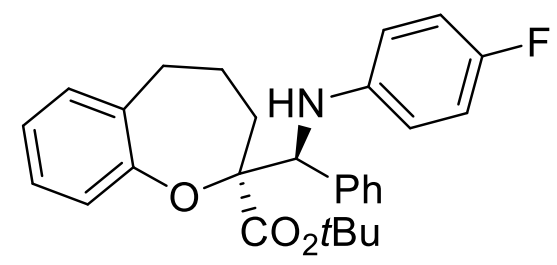

$3 k$

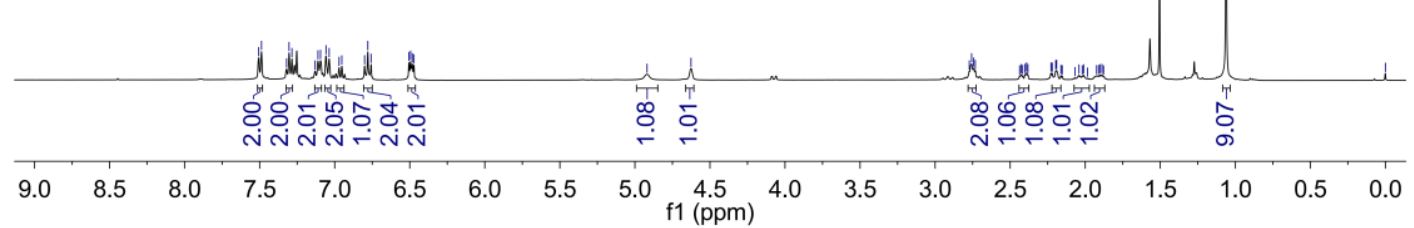


<smiles>CCCOC(=O)[C@]1([C@@H](Nc2ccc(F)cc2)c2ccccc2)CCCc2ccccc2O1</smiles>

3k

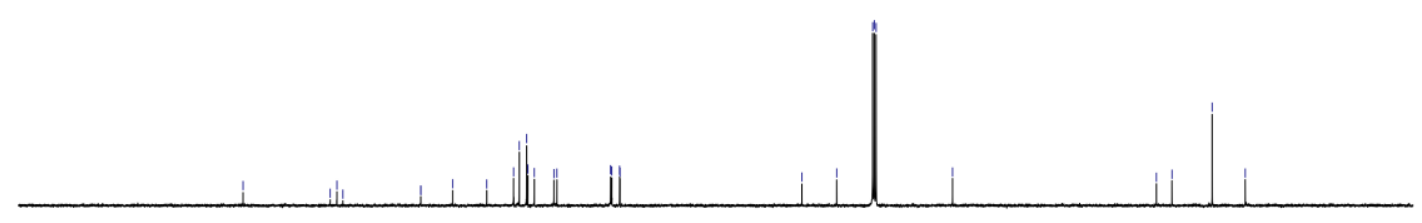

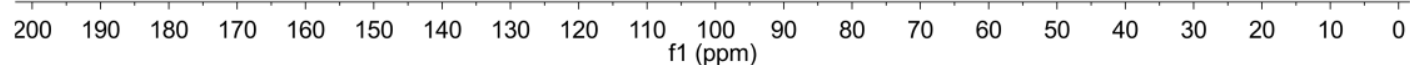

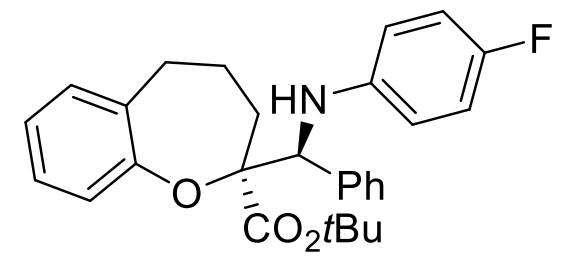

3k

\begin{tabular}{|c|c|c|c|c|c|c|c|c|c|c|c|}
\hline 10 & 0 & -20 & -40 & -60 & -80 & $\begin{array}{c}-100 \\
\mathrm{f} 1(\mathrm{ppm})\end{array}$ & -120 & -140 & -160 & -180 & -200 \\
\hline
\end{tabular}




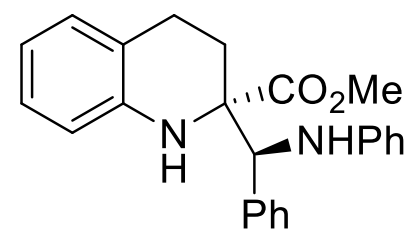

syn-3|

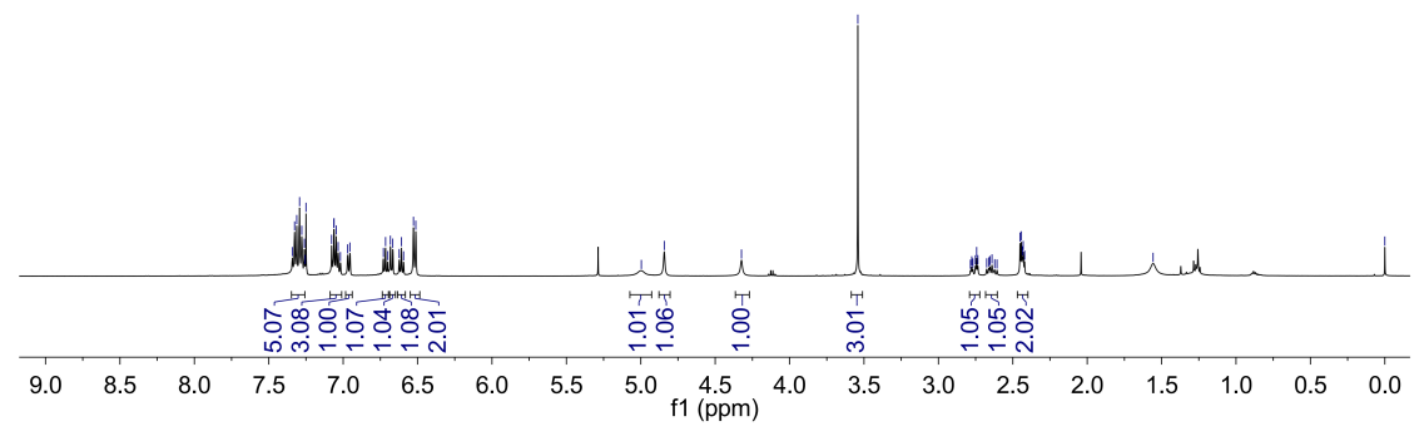

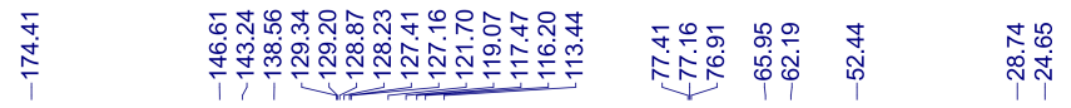

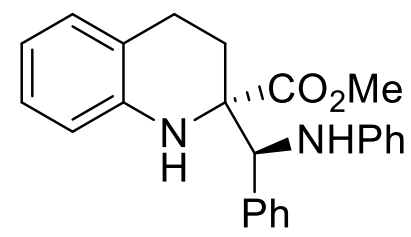

syn-31

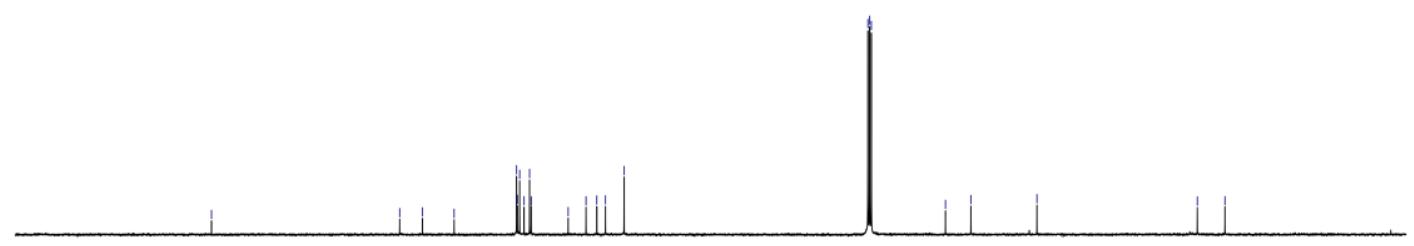

$\begin{array}{lllllllllllllllllllll}200 & 190 & 180 & 170 & 160 & 150 & 140 & 130 & 120 & 110 \underset{\mathrm{f} 1(\mathrm{ppm})}{100} & 90 & 80 & 70 & 60 & 50 & 40 & 30 & 20 & 10 & 0\end{array}$ 


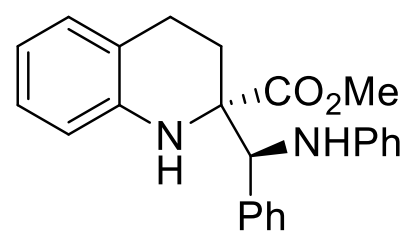

anti-31
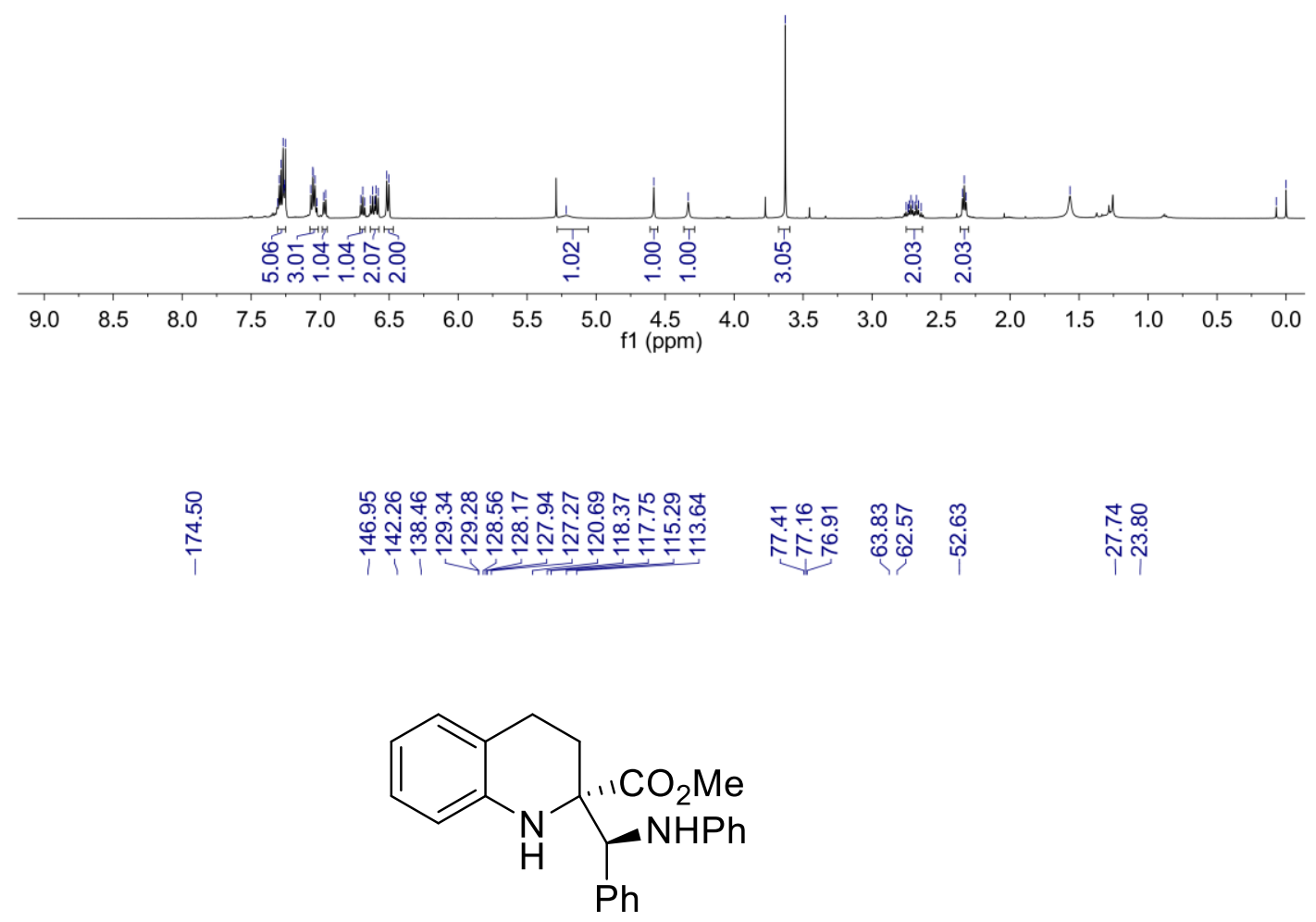

anti-3|

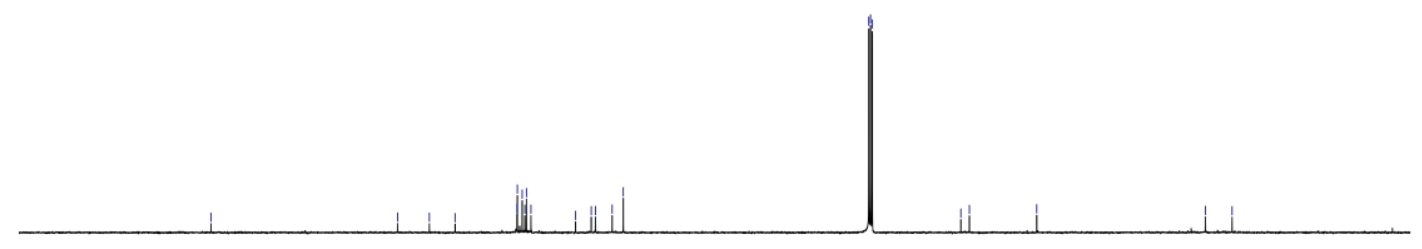

\begin{tabular}{lllllllllllllllllllllllll}
\hline & 190 & 180 & 170 & 160 & 150 & 140 & 130 & 120 & $110 \begin{array}{l}100 \\
\mathrm{f} 1(\mathrm{ppm})\end{array}$ & 90 & 80 & 70 & 60 & 50 & 40 & 30 & 20 & 10 & 0
\end{tabular} 


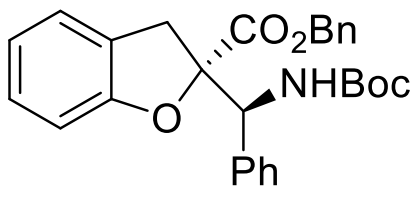

$3 m$

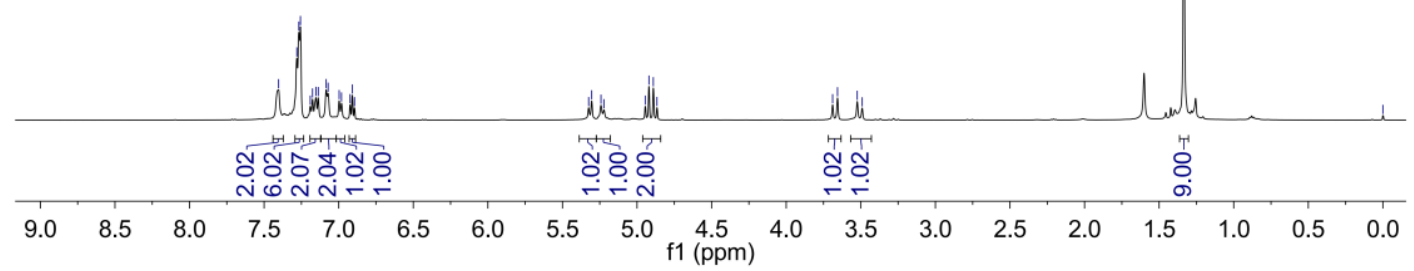

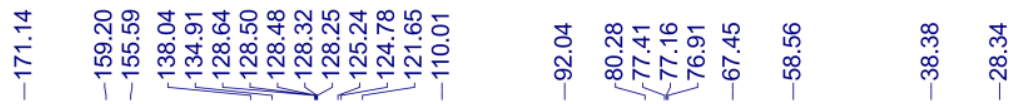<smiles>O=C(N[C@@H](C(=O)OBr)[C@]1(C(=O)Br)Cc2ccccc2O1)OCc1ccccc1</smiles>

$3 m$

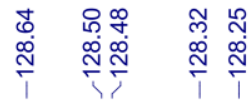

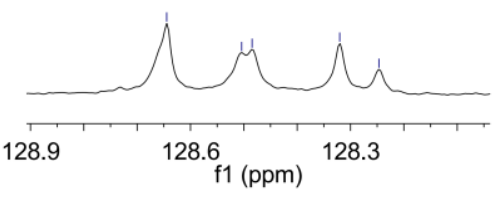

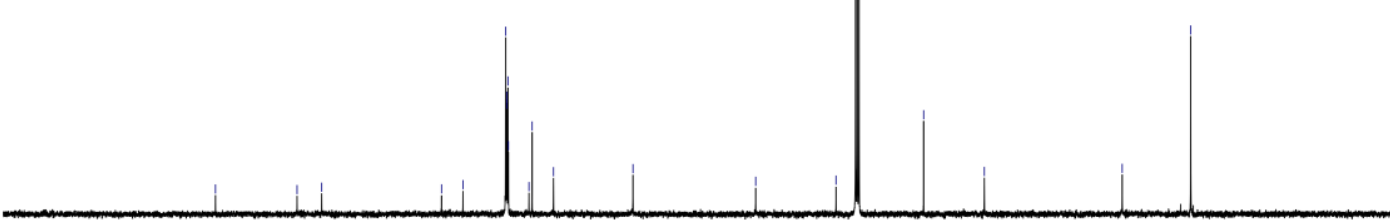

$\begin{array}{llllllllllllllllllll}200 & 190 & 180 & 170 & 160 & 150 & 140 & 130 & 120 & 110 \begin{array}{c}100 \\ \mathrm{f} 1(\mathrm{ppm})\end{array} & 90 & 80 & 70 & 60 & 50 & 40 & 30 & 20 & 10 & 0\end{array}$ 


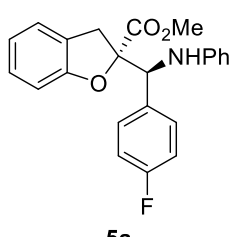

$5 a$

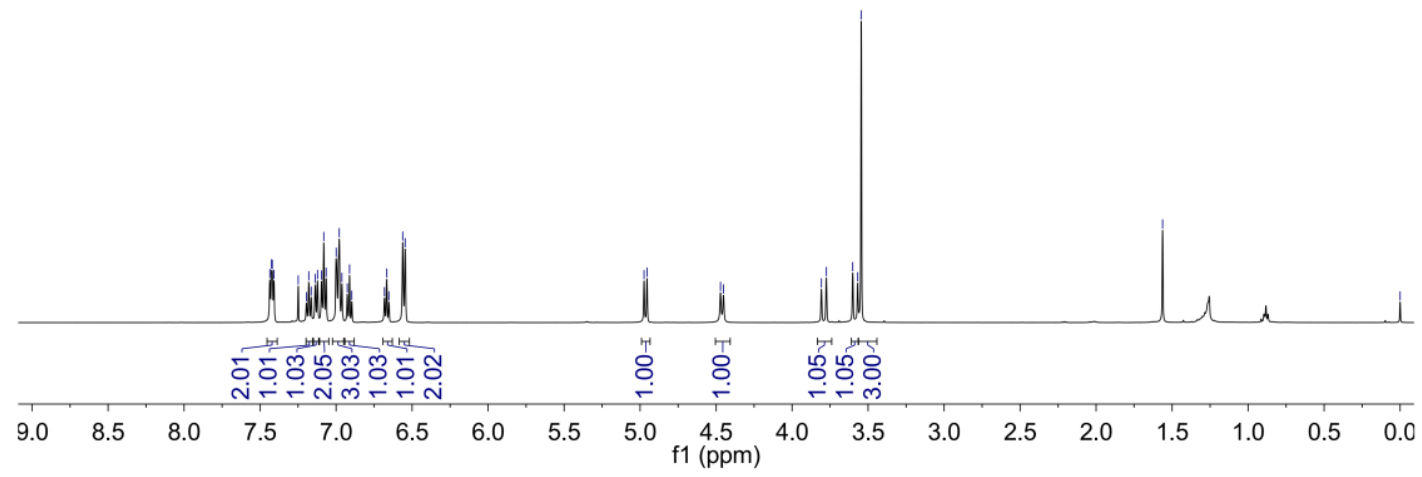

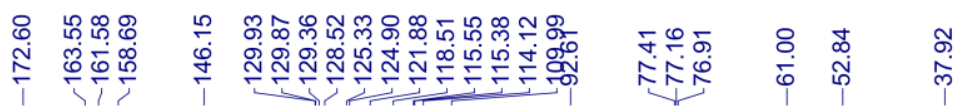<smiles>CC(=O)N[C@@H](c1ccc(F)cc1)C1(C(C)=O)Cc2ccccc2O1</smiles>

$5 a$

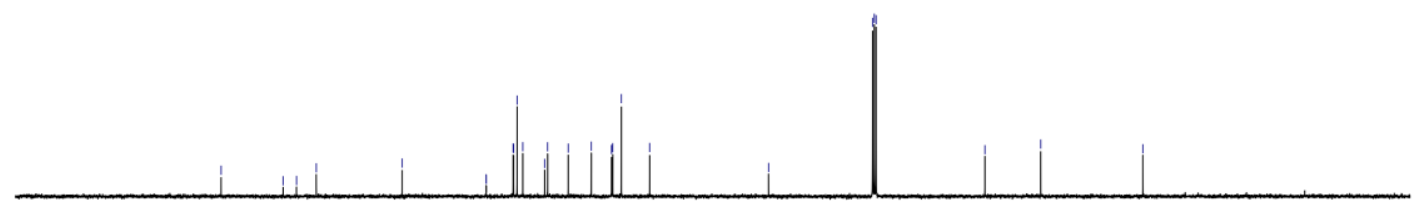

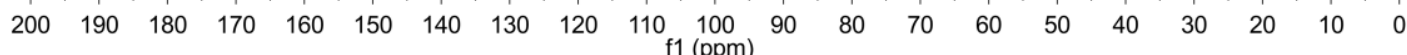




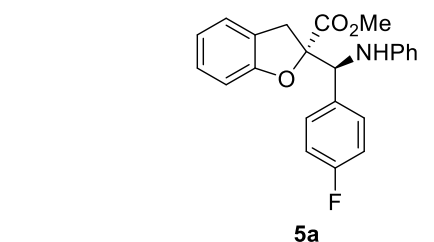

$5 a$

\begin{tabular}{|c|c|c|c|c|c|c|c|c|c|c|c|}
\hline 10 & 0 & -20 & -40 & -60 & -80 & $\begin{array}{c}-100 \\
\mathrm{f} 1(\mathrm{ppm})\end{array}$ & -120 & -140 & -160 & -180 & -200 \\
\hline
\end{tabular}

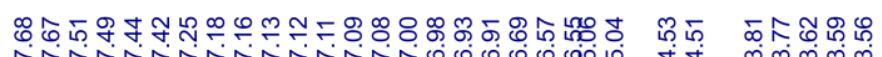

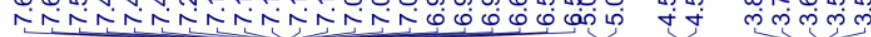

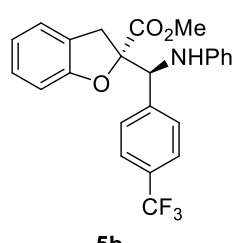

$5 \mathbf{b}$

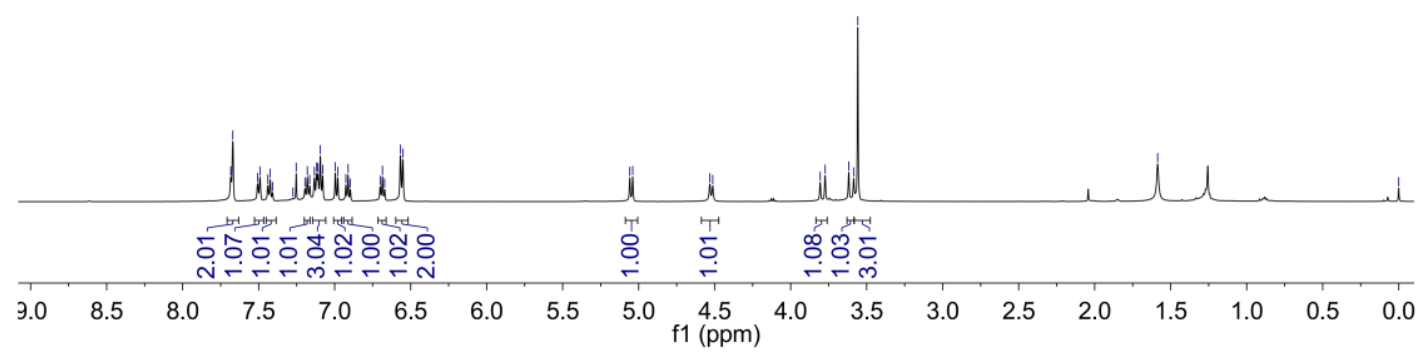



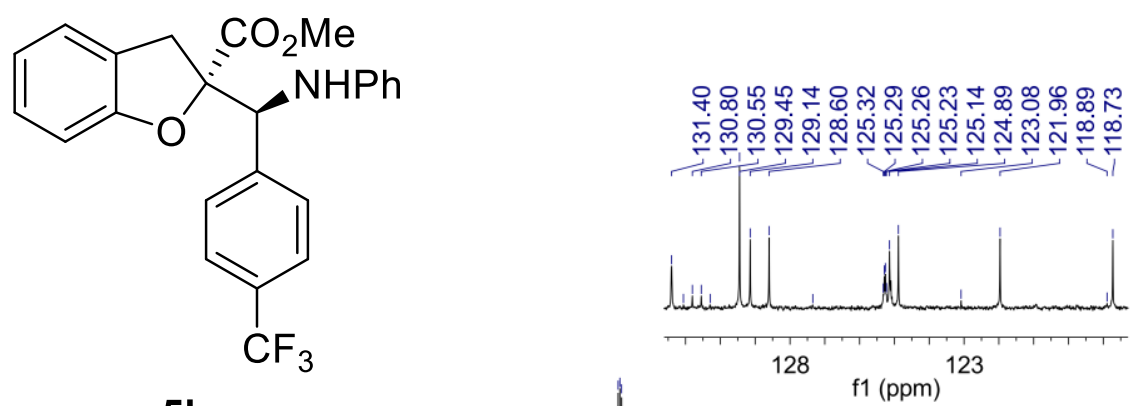

$5 b$

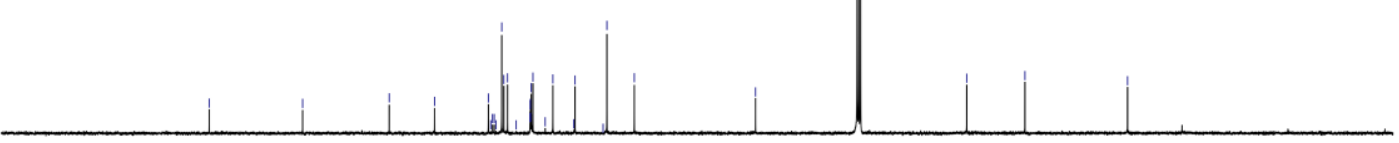

$\begin{array}{llllllllllllllllllll}200 & 190 & 180 & 170 & 160 & 150 & 140 & 130 & 120 & \begin{array}{c}110 \\ \mathrm{f} 1(\mathrm{ppm})\end{array} & 90 & 80 & 70 & 60 & 50 & 40 & 30 & 20 & 10 & 0\end{array}$

ִָ

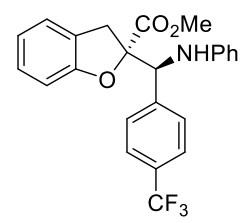

$5 b$

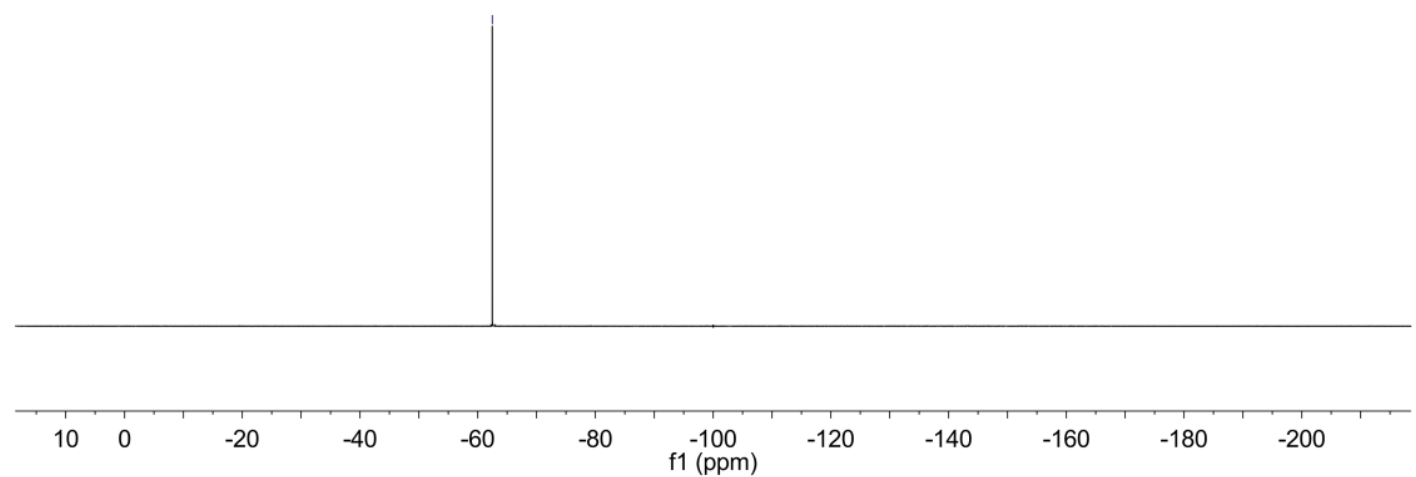




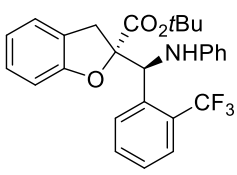

5c

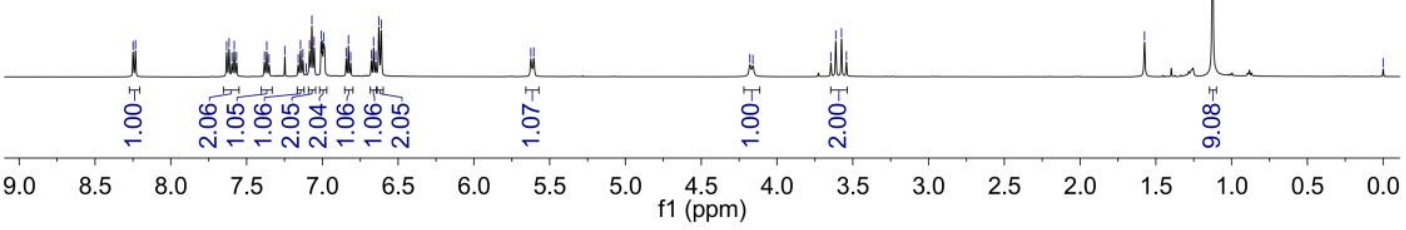

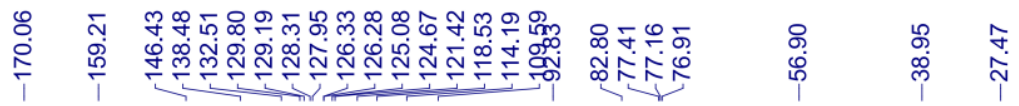

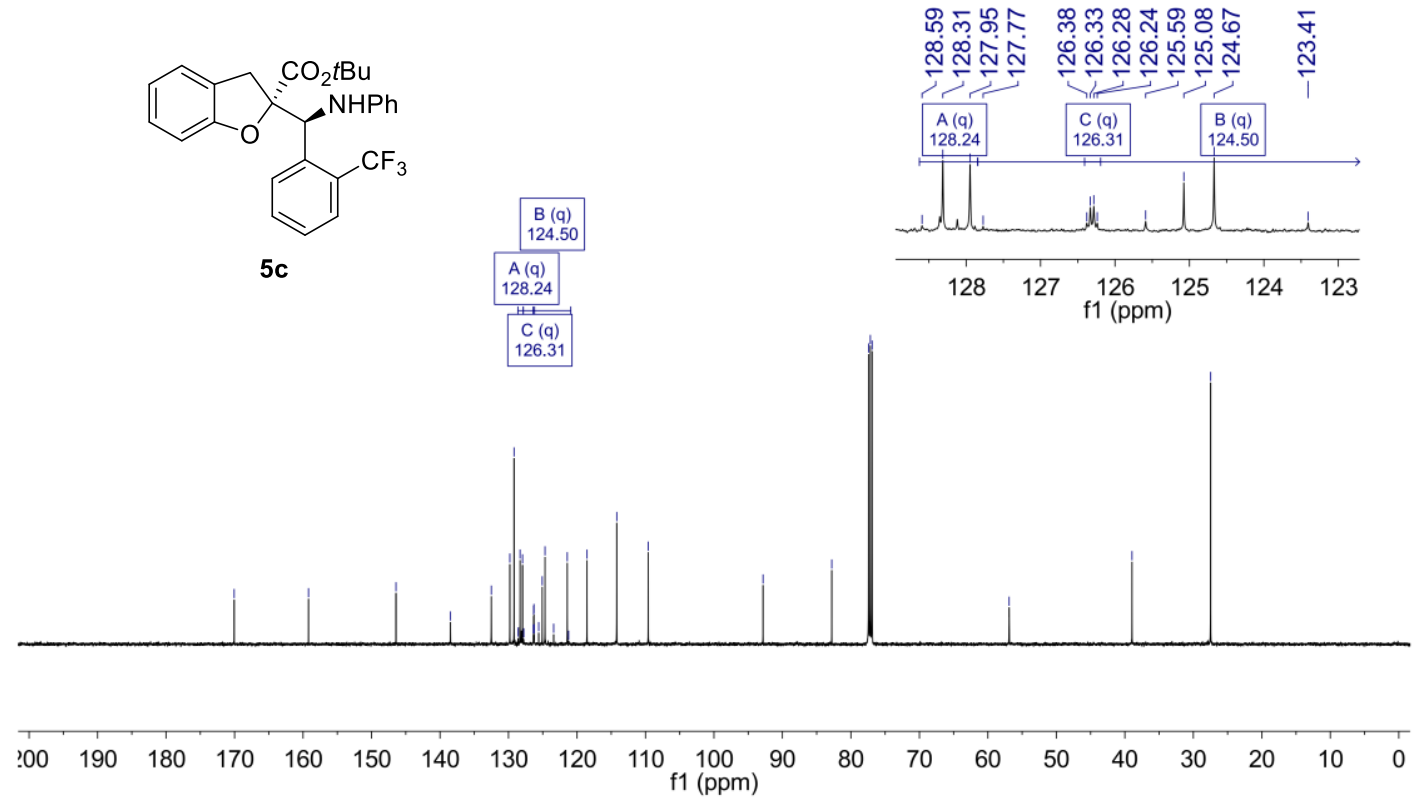


กิ

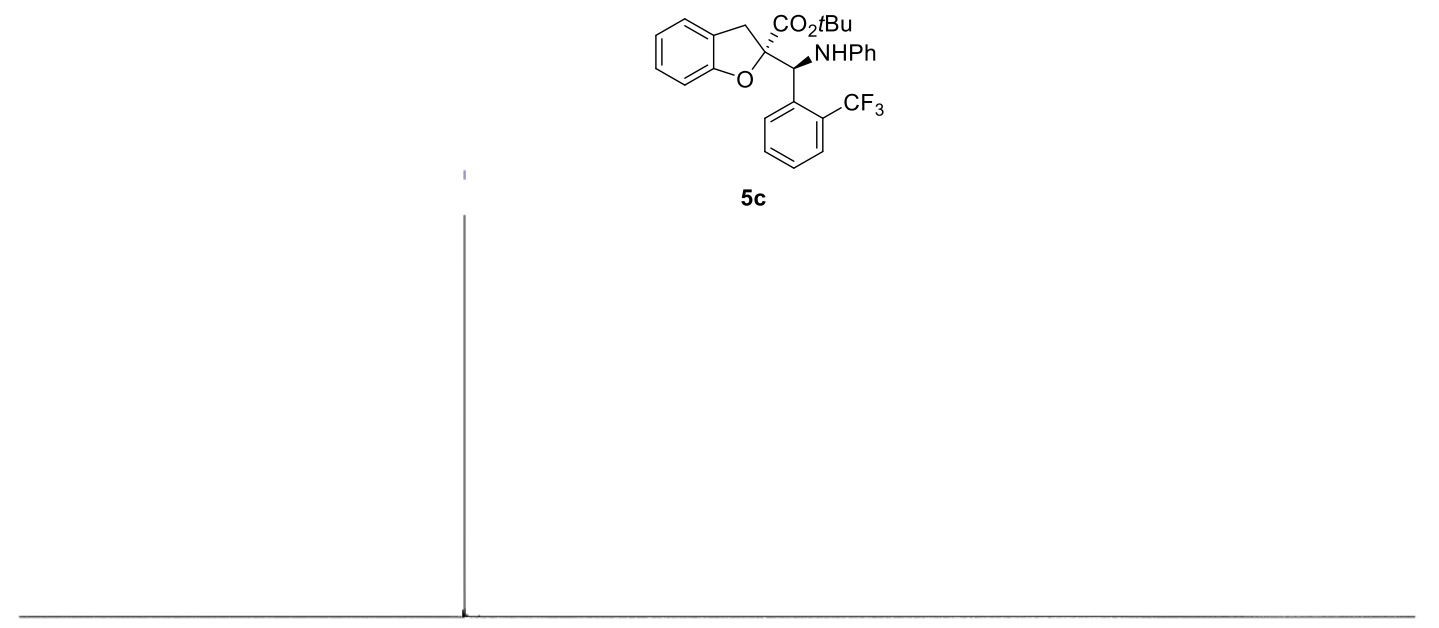

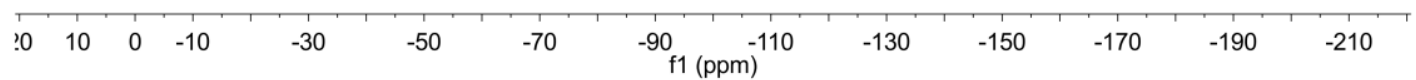

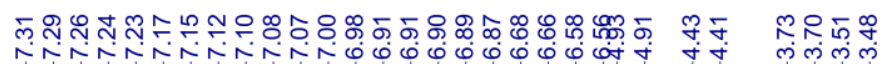

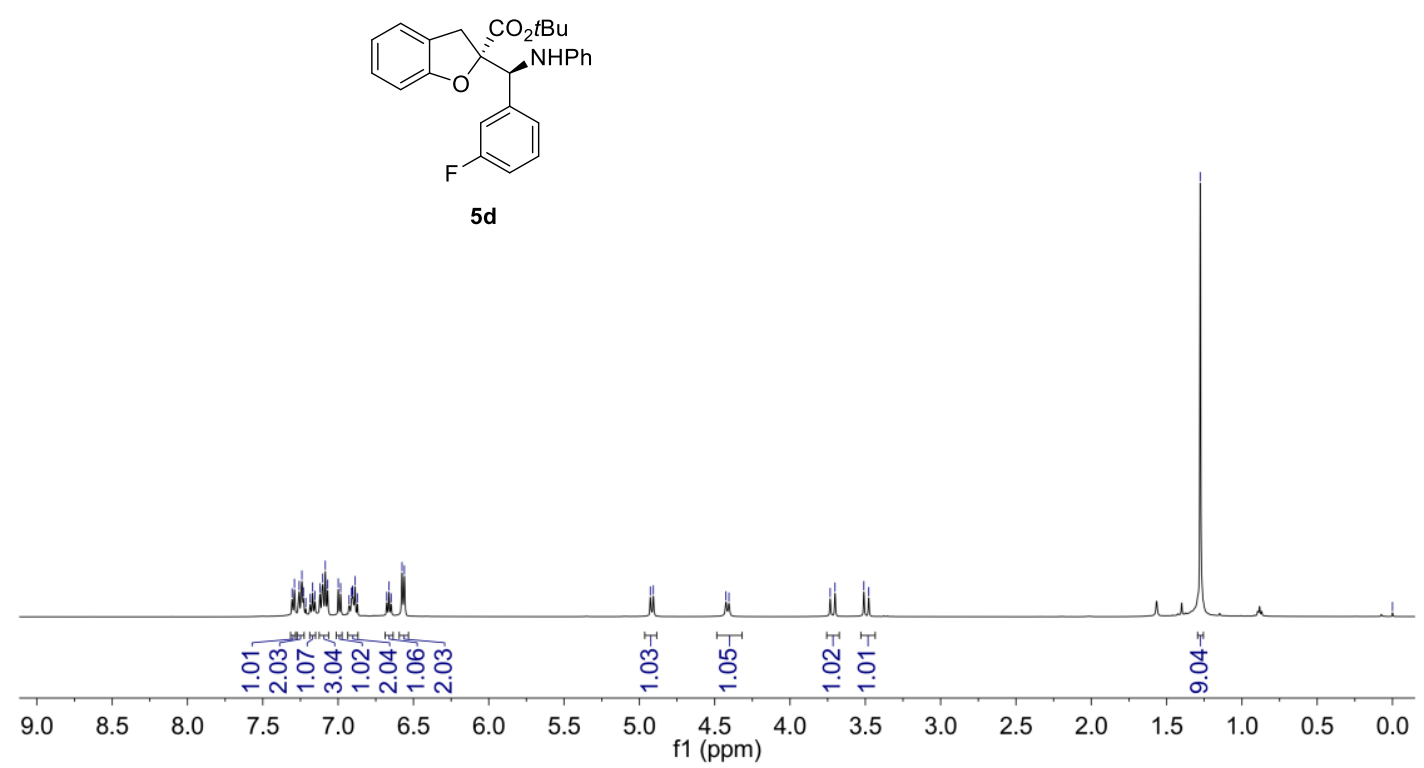




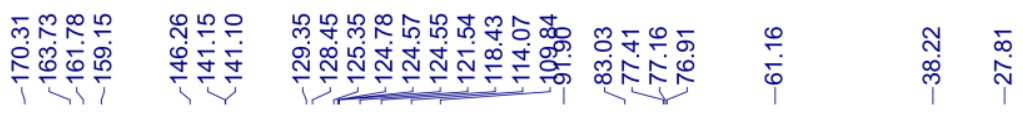

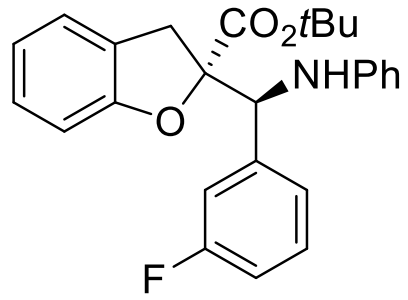

$5 d$

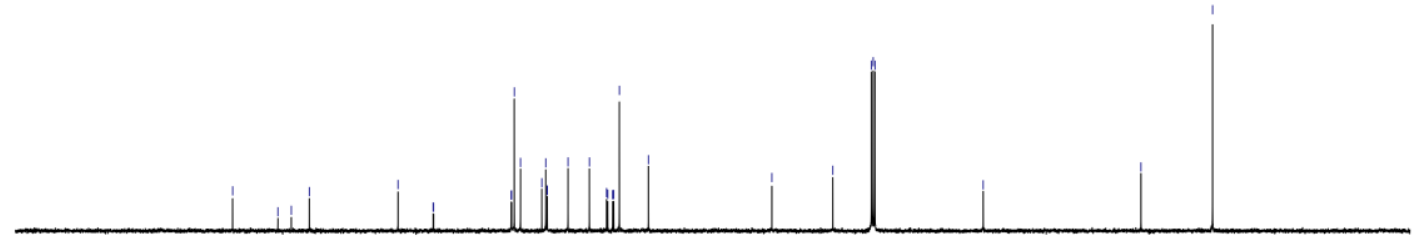

$\begin{array}{llllllllllllllllllllllll}200 & 190 & 180 & 170 & 160 & 150 & 140 & 130 & 120 & 110 & 100 & 90 & 80 & 70 & 60 & 50 & 40 & 30 & 20 & 10 & 0\end{array}$

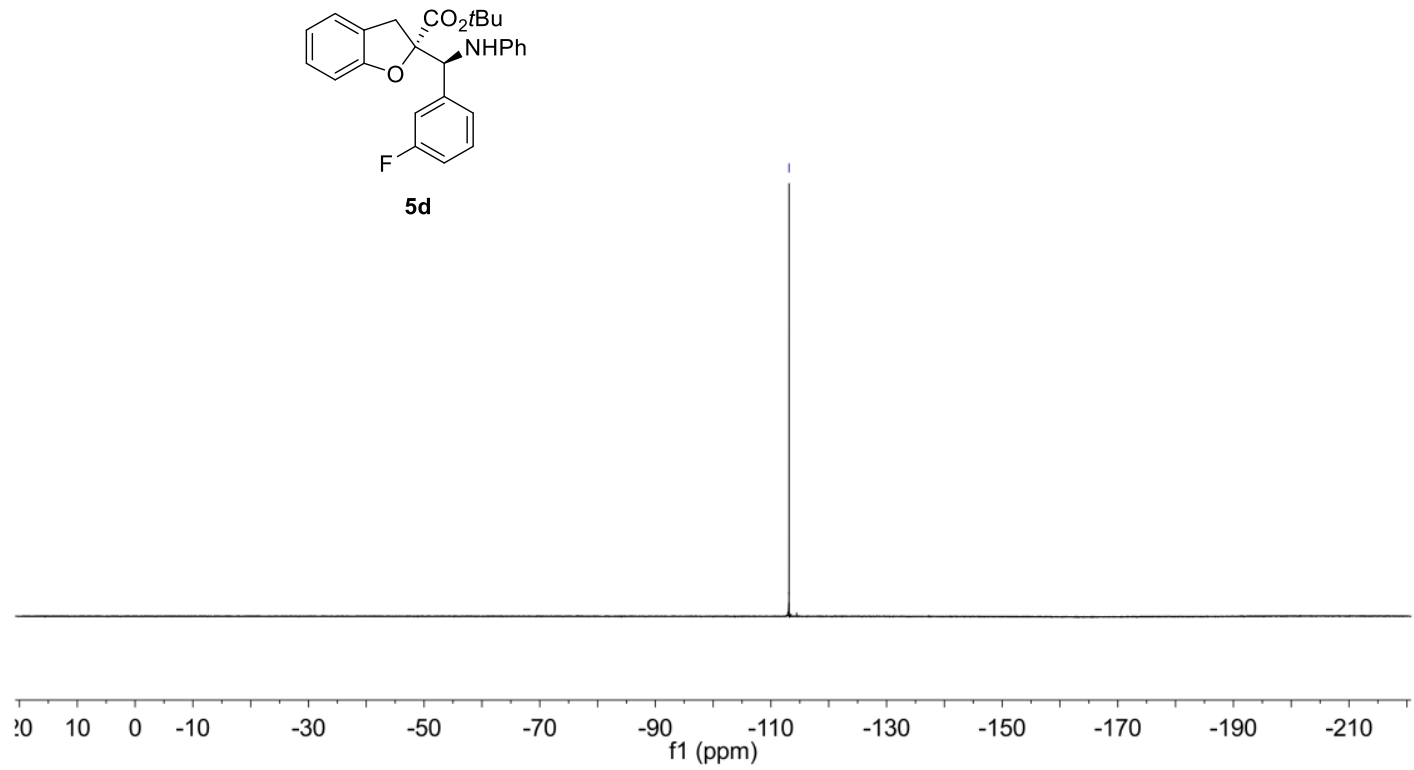

$5 d$ 


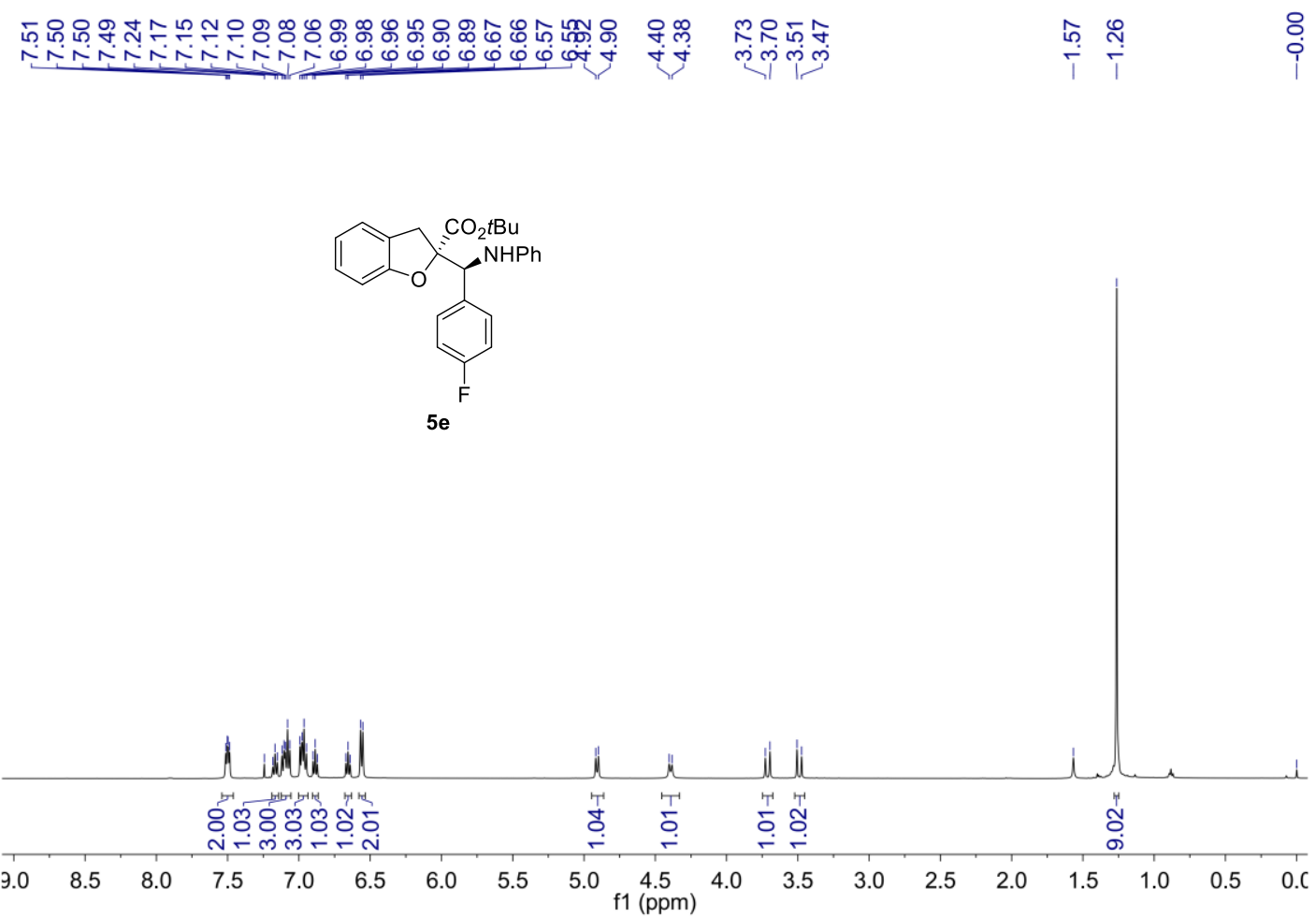

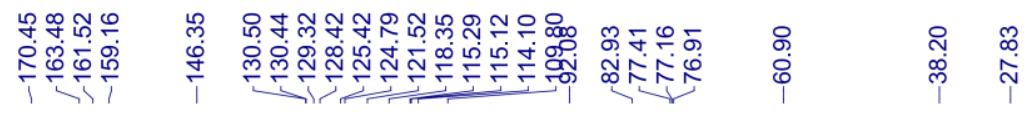<smiles>CC(C)(C)OC(=O)N[C@@H](c1ccc(F)cc1)C1(C(=O)O)Cc2ccccc2O1</smiles>

5 e

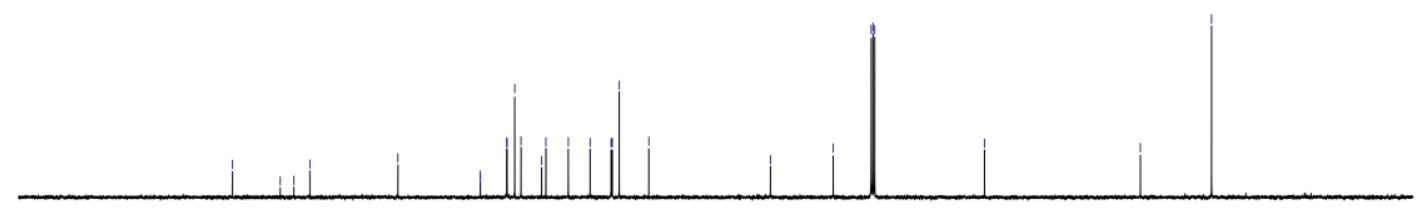

$\begin{array}{llllllllllllllllllllllll}100 & 190 & 180 & 170 & 160 & 150 & 140 & 130 & 120 & 110 & 100 & 90 & 80 & 70 & 60 & 50 & 40 & 30 & 20 & 10 & 0\end{array}$ 


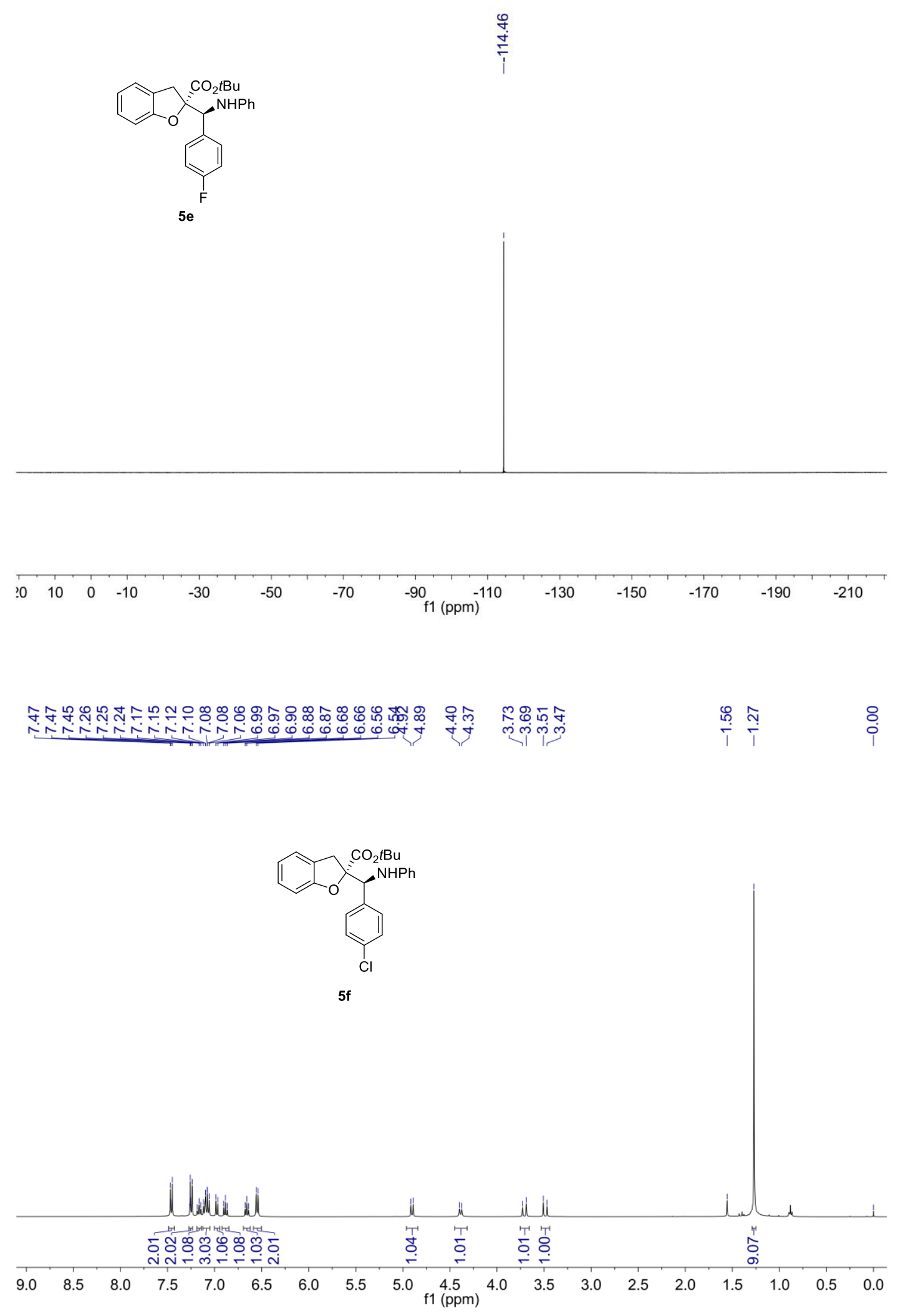




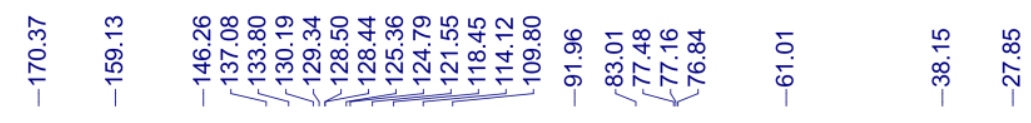

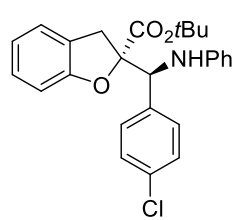

$5 \mathbf{f}$
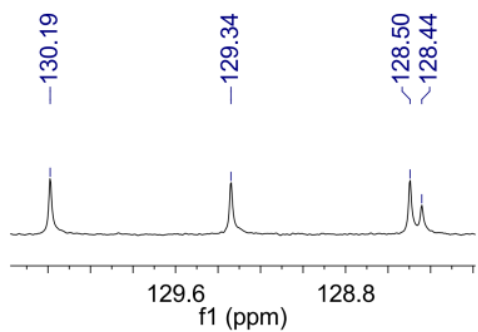

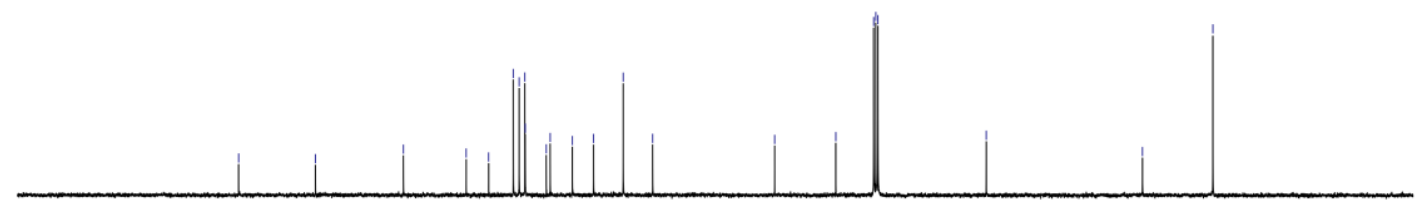

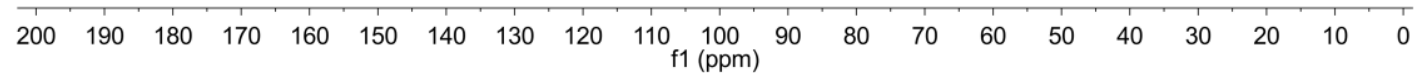

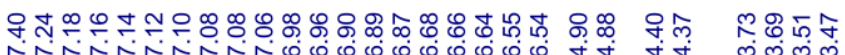

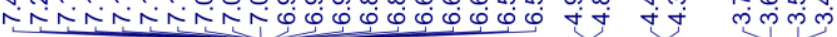

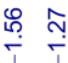

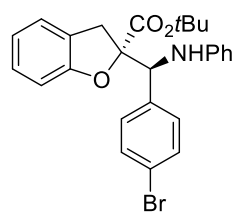

5g

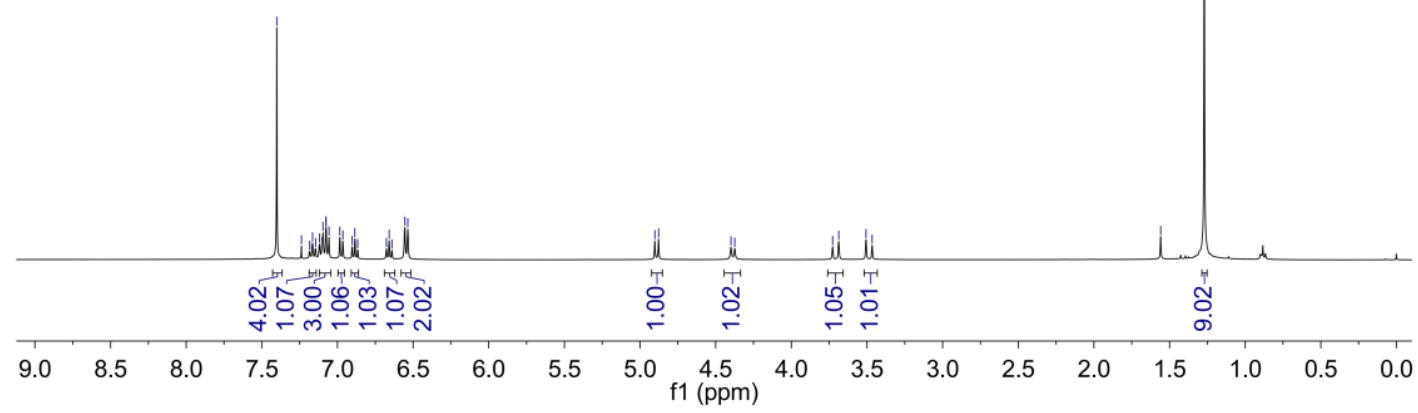



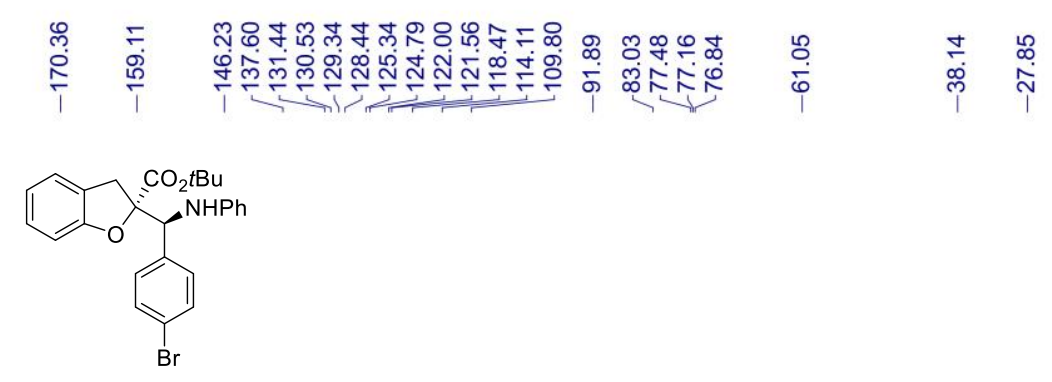

$5 g$

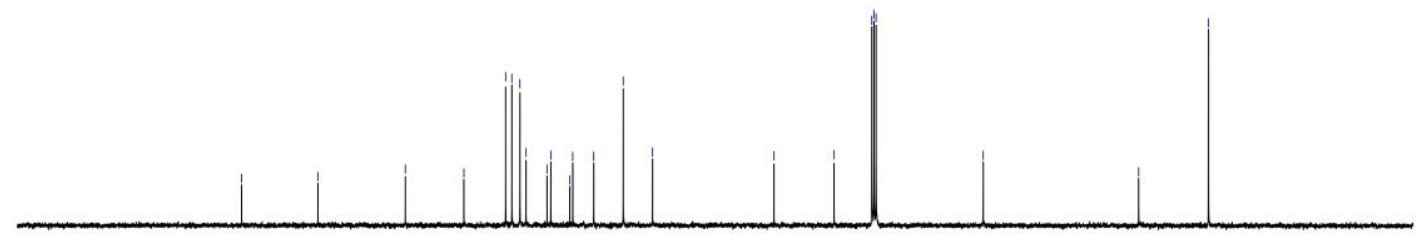

\begin{tabular}{lllllllllllllllllllllllll}
\hline 200 & 190 & 180 & 170 & 160 & 150 & 140 & 130 & 120 & 110 & 100 & 90 & 80 & 70 & 60 & 50 & 40 & 30 & 20 & 10 & 0
\end{tabular}

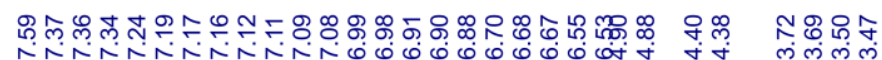

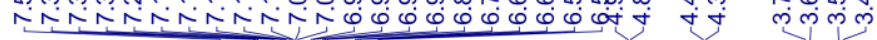

$\stackrel{\bar{m}}{i} \quad \stackrel{8}{i}$

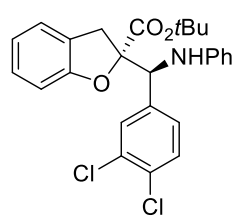

$5 \mathrm{~h}$

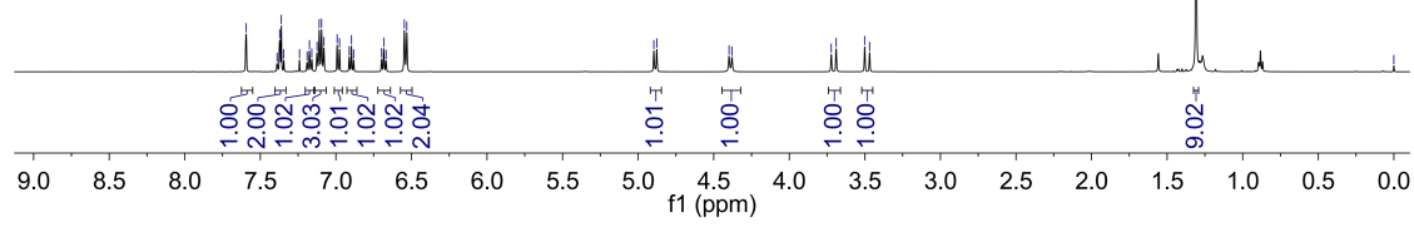




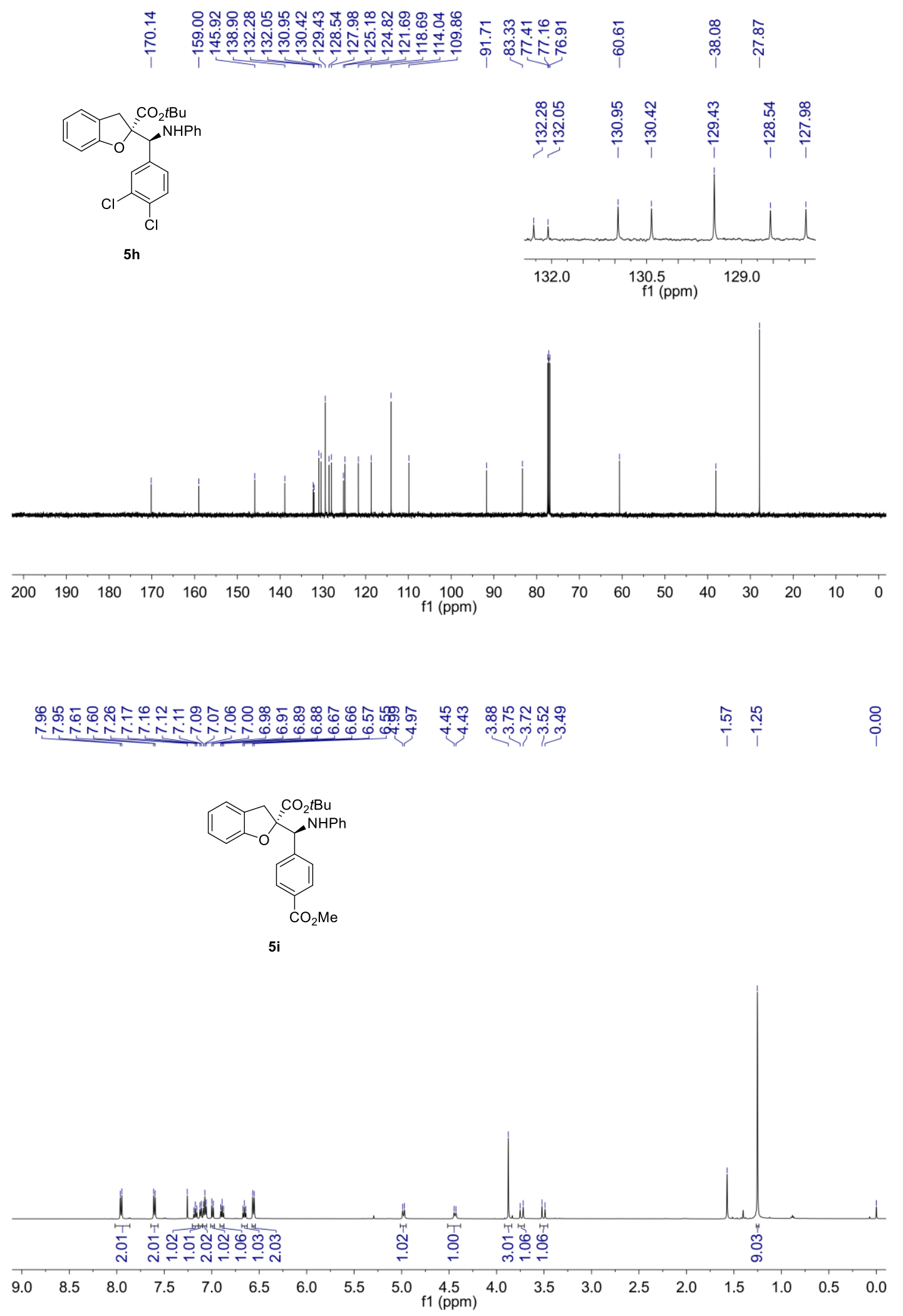




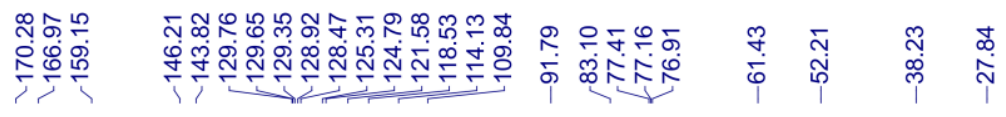

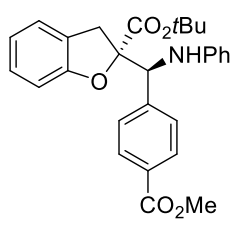

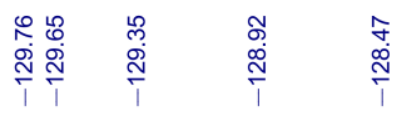

$5 \mathbf{i}$
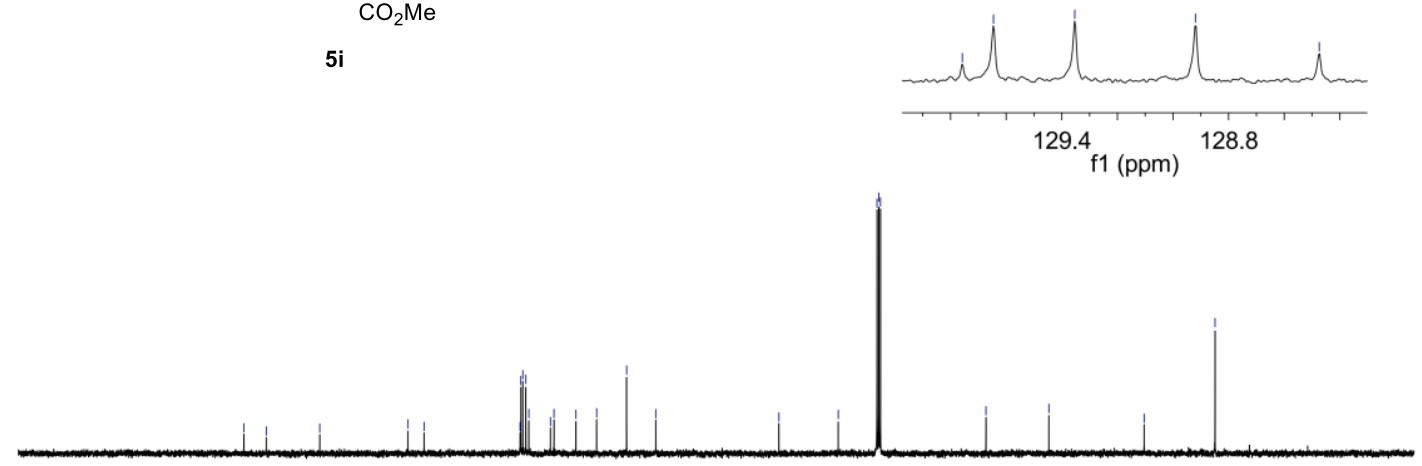

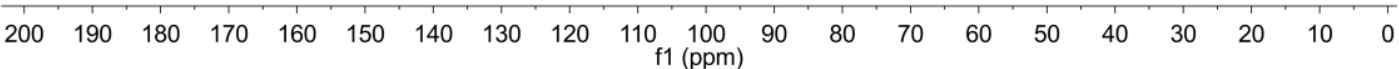

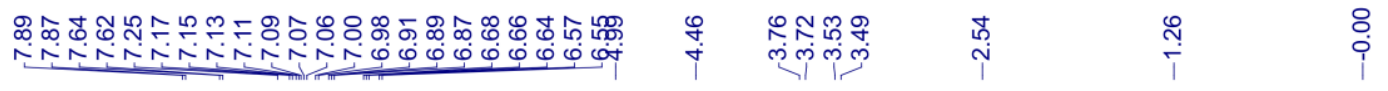

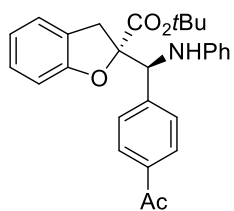

$5 j$

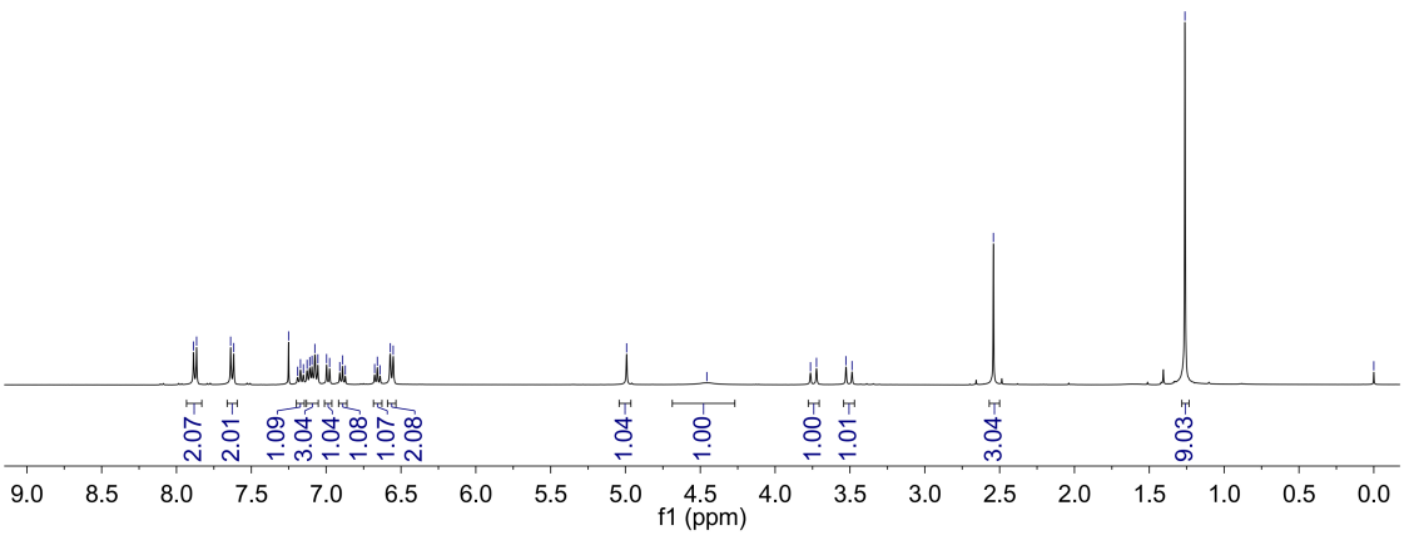




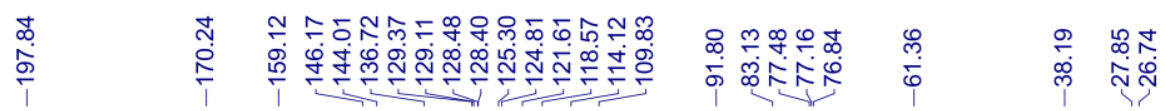

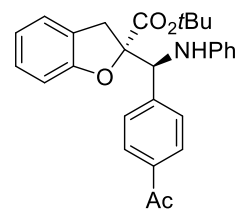

5j
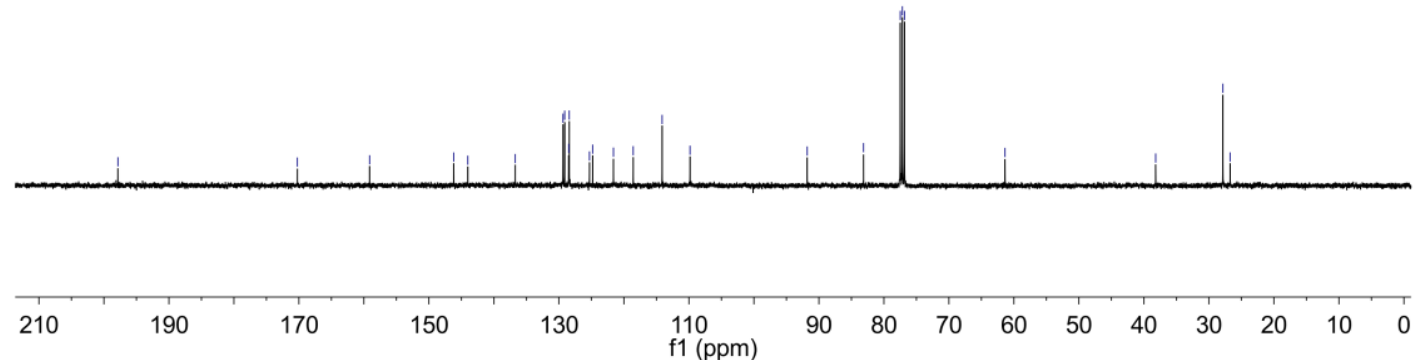

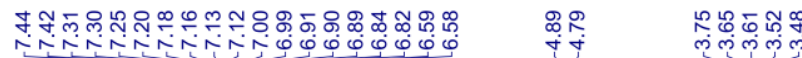

$\stackrel{\stackrel{8}{i}}{\stackrel{8}{i}} \quad \stackrel{0}{i}$

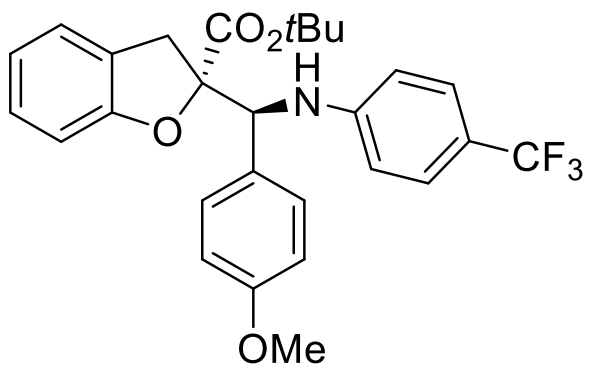

$5 k$

Hidull

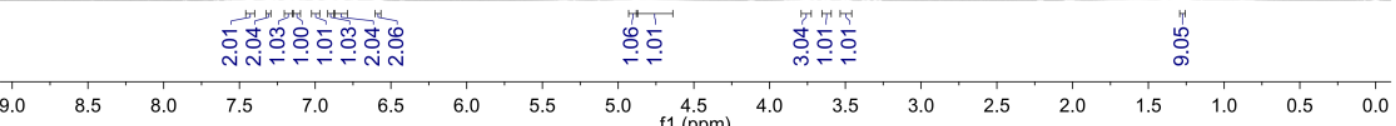




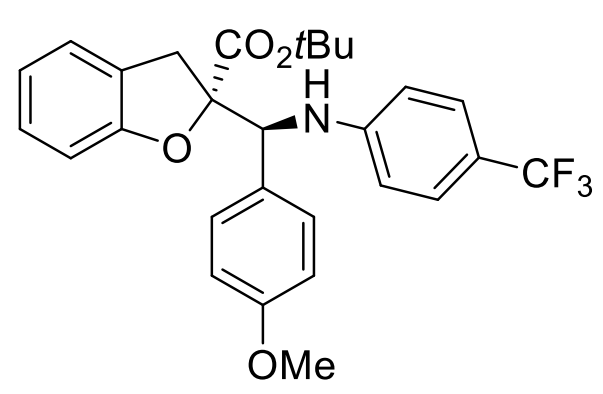

5k

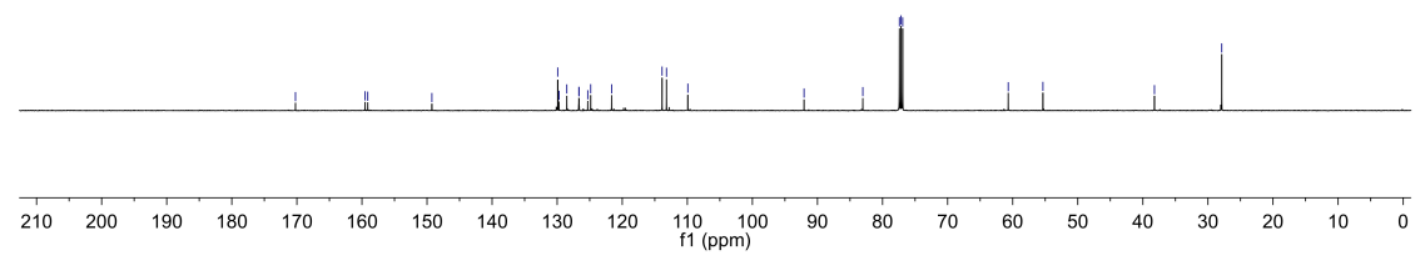

$\frac{\varphi}{\dot{\varphi}}$

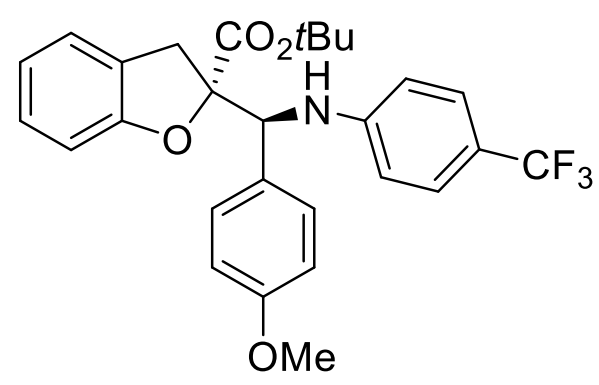

5k

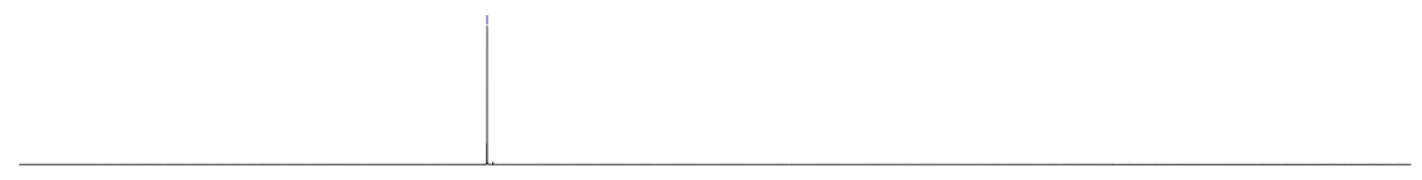

\begin{tabular}{|c|c|c|c|c|c|c|c|c|c|c|c|}
\hline 10 & 0 & -20 & -40 & -60 & -80 & $\begin{array}{c}-100 \\
\mathrm{f} 1(\mathrm{ppm})\end{array}$ & -120 & -140 & -160 & -180 & -200 \\
\hline
\end{tabular}




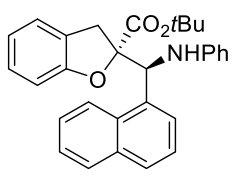

51

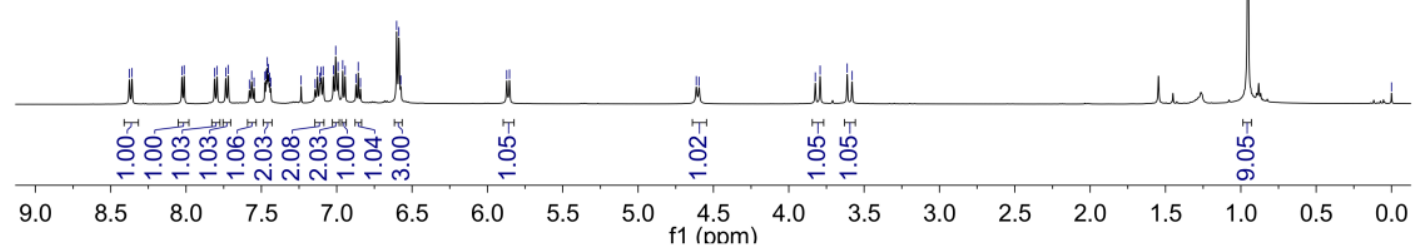

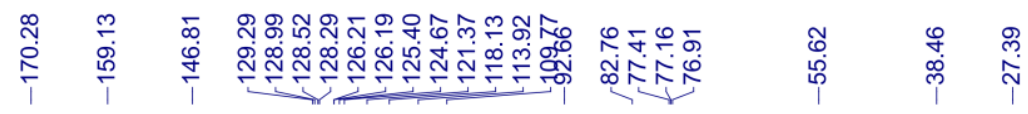

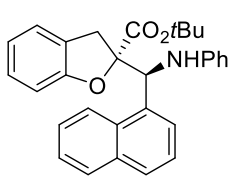

51
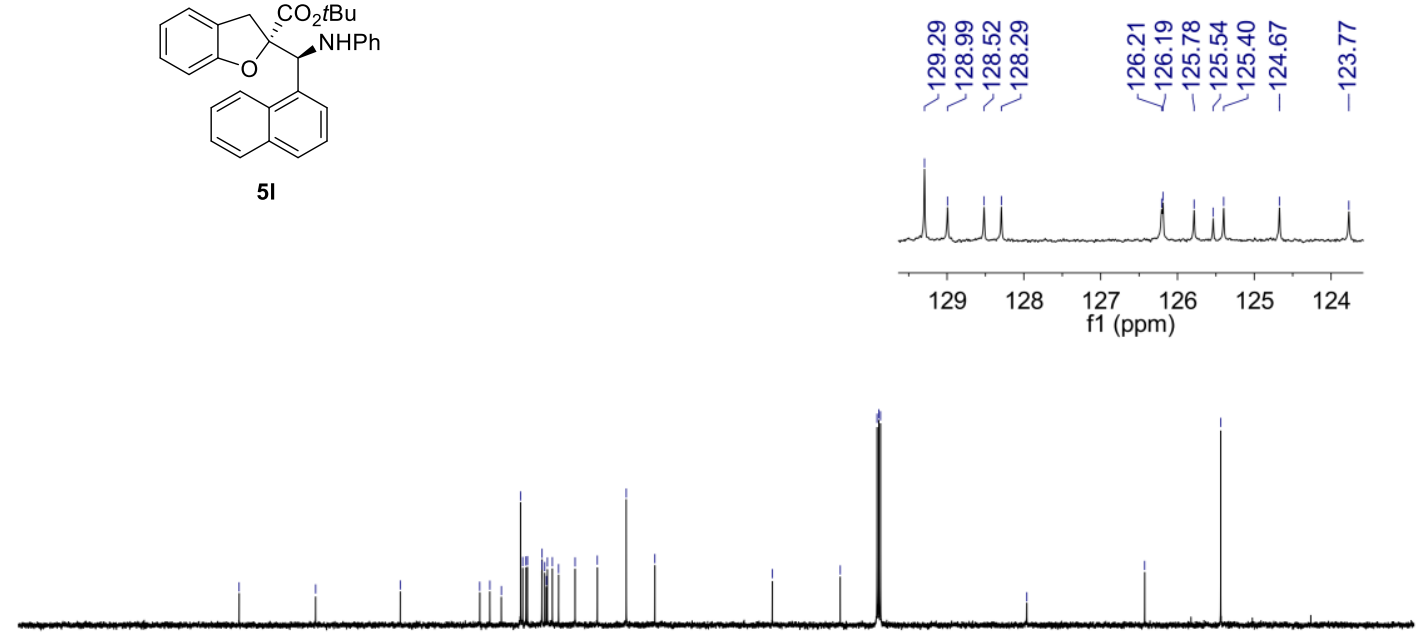

$\begin{array}{llllllllllllllllllll}200 & 190 & 180 & 170 & 160 & 150 & 140 & 130 & 120 & 110 \begin{array}{c}100 \\ \mathrm{f} 1(\mathrm{ppm})\end{array} & 90 & 80 & 70 & 60 & 50 & 40 & 30 & 20 & 10 & 0\end{array}$ 


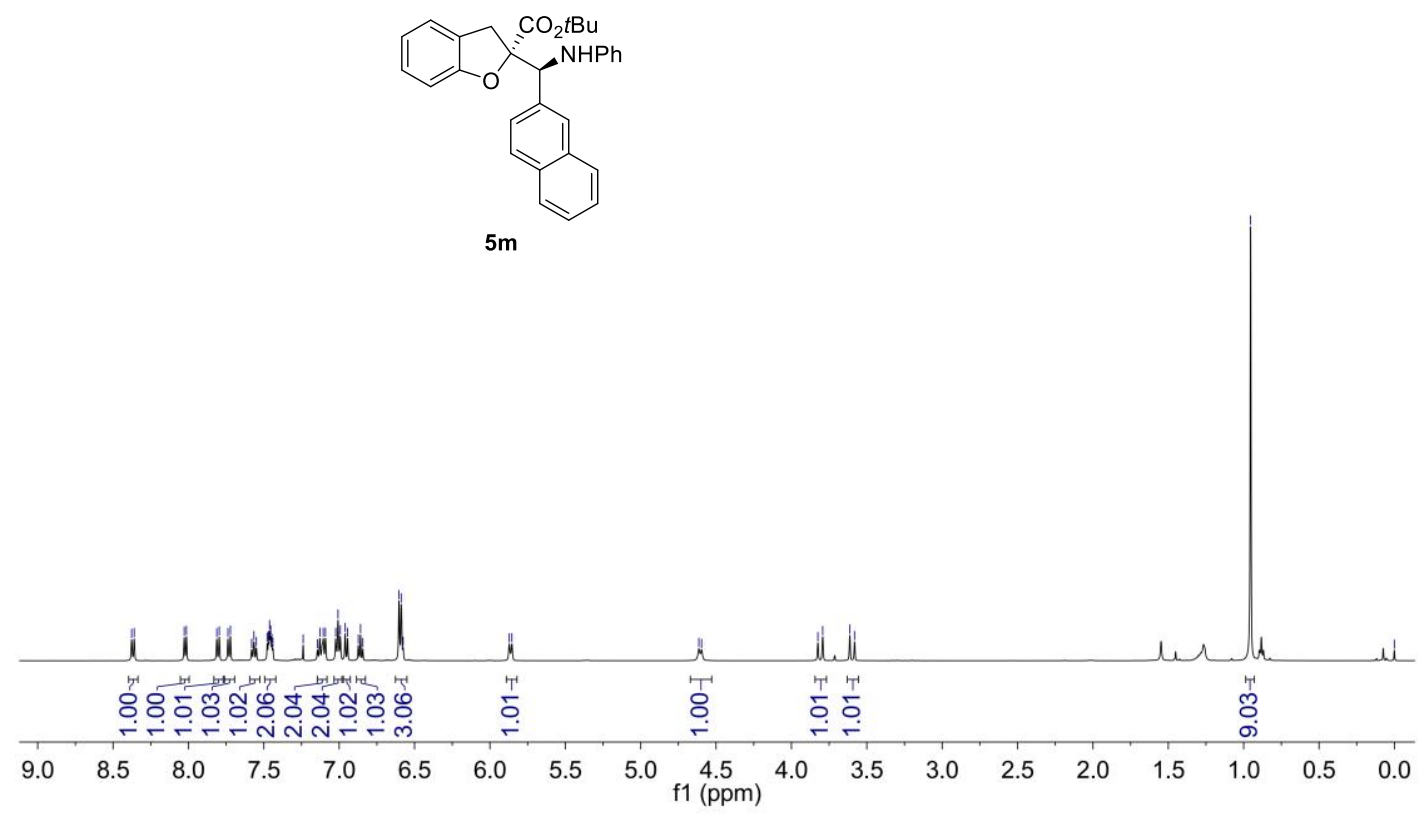

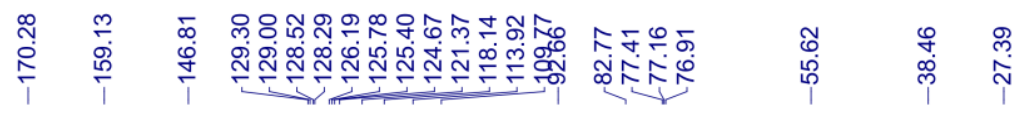
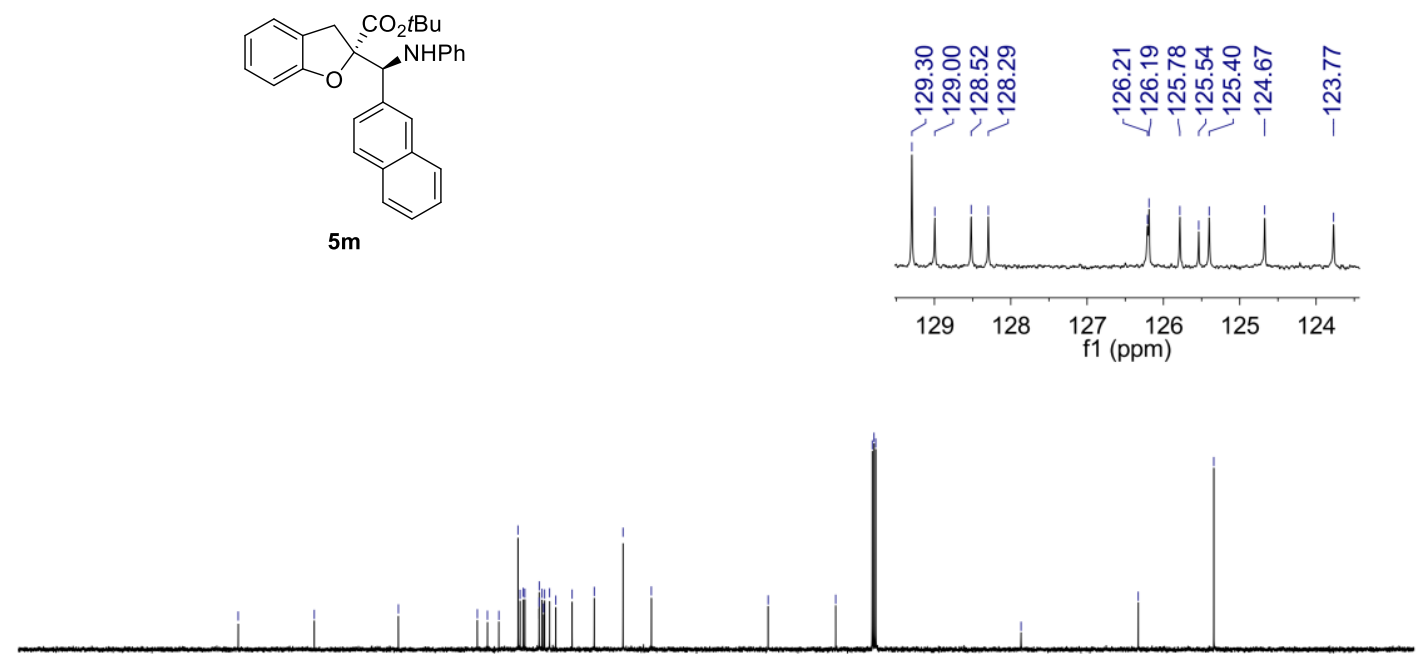

$\begin{array}{llllllllllllllllllll}200 & 190 & 180 & 170 & 160 & 150 & 140 & 130 & 120 & 110 \begin{array}{c}100 \\ \mathrm{f} 1(\mathrm{ppm})\end{array} & 90 & 80 & 70 & 60 & 50 & 40 & 30 & 20 & 10 & 0\end{array}$ 


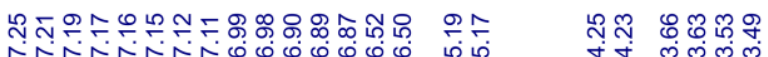

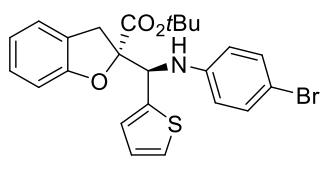

$5 n$

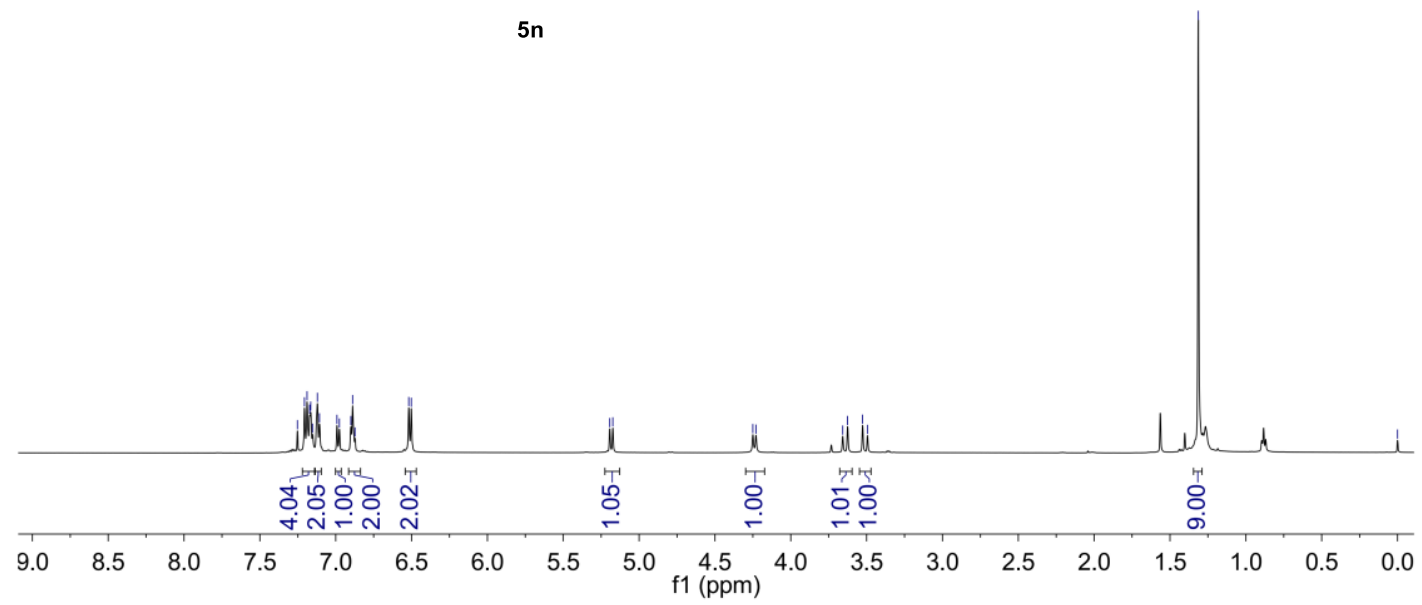

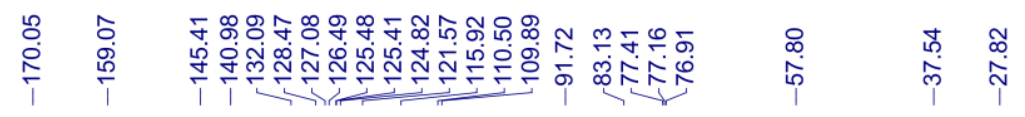

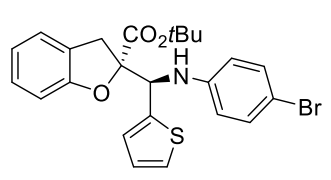

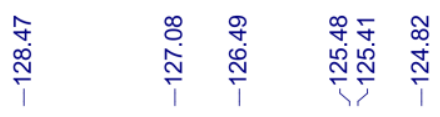

$5 n$
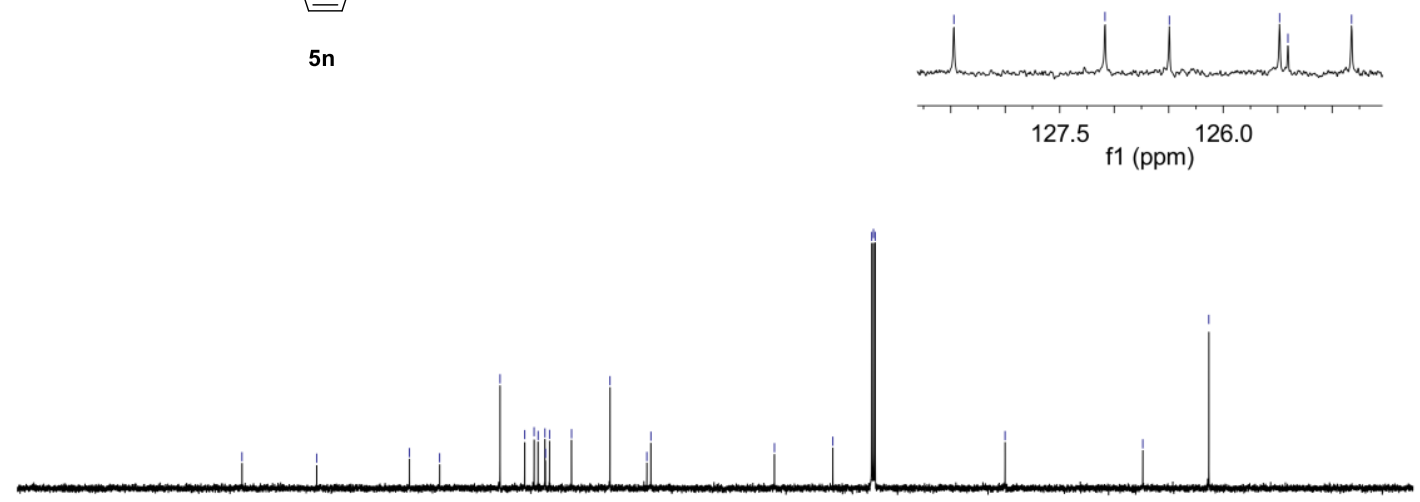

$\begin{array}{llllllllllllllllllll}200 & 190 & 180 & 170 & 160 & 150 & 140 & 130 & 120 & 110 \begin{array}{l}100 \\ \mathrm{f} 1(\mathrm{ppm})\end{array} & 90 & 80 & 70 & 60 & 50 & 40 & 30 & 20 & 10 & 0\end{array}$ 


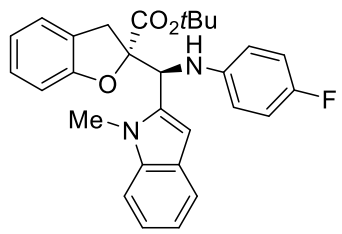

5o

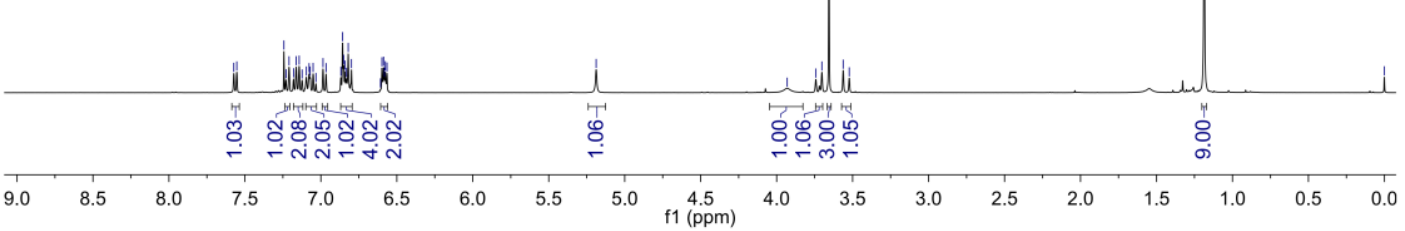

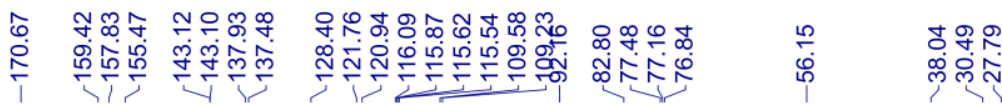
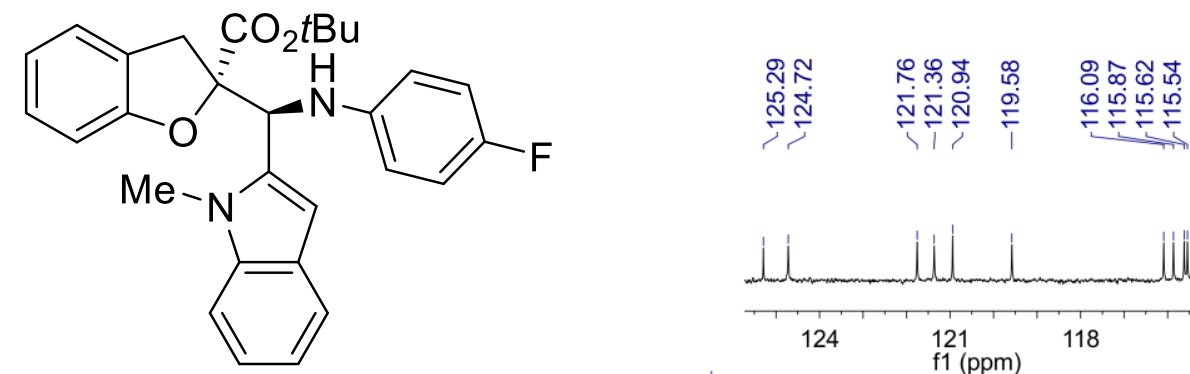

50

$\begin{array}{llllllllllllllllllll}200 & 190 & 180 & 170 & 160 & 150 & 140 & 130 & 120 & 110 \begin{array}{l}100 \\ \mathrm{f} 1(\mathrm{ppm})\end{array} & 90 & 80 & 70 & 60 & 50 & 40 & 30 & 20 & 10 & 0\end{array}$ 


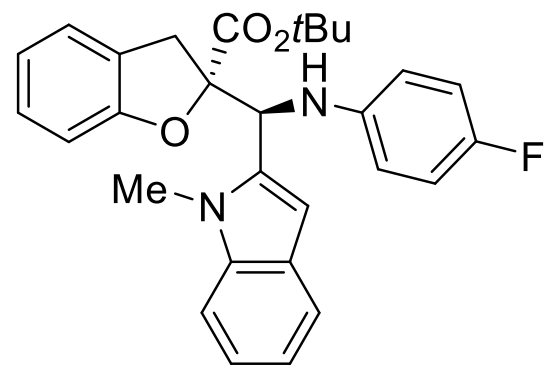

50

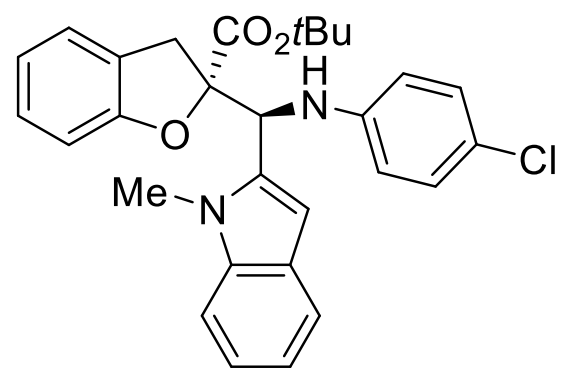

$5 p$

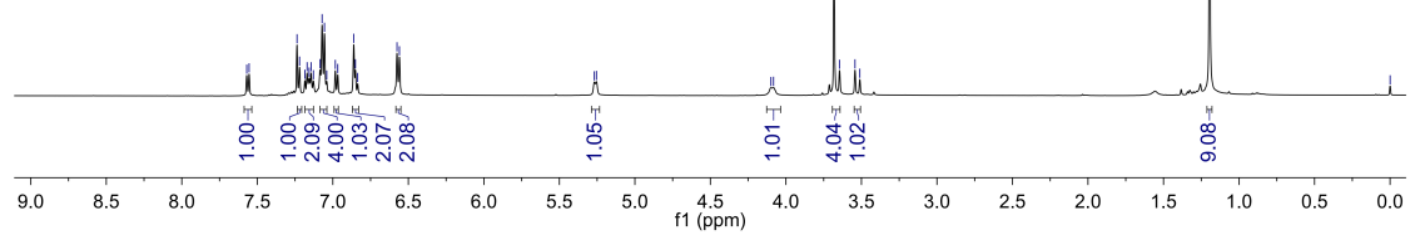



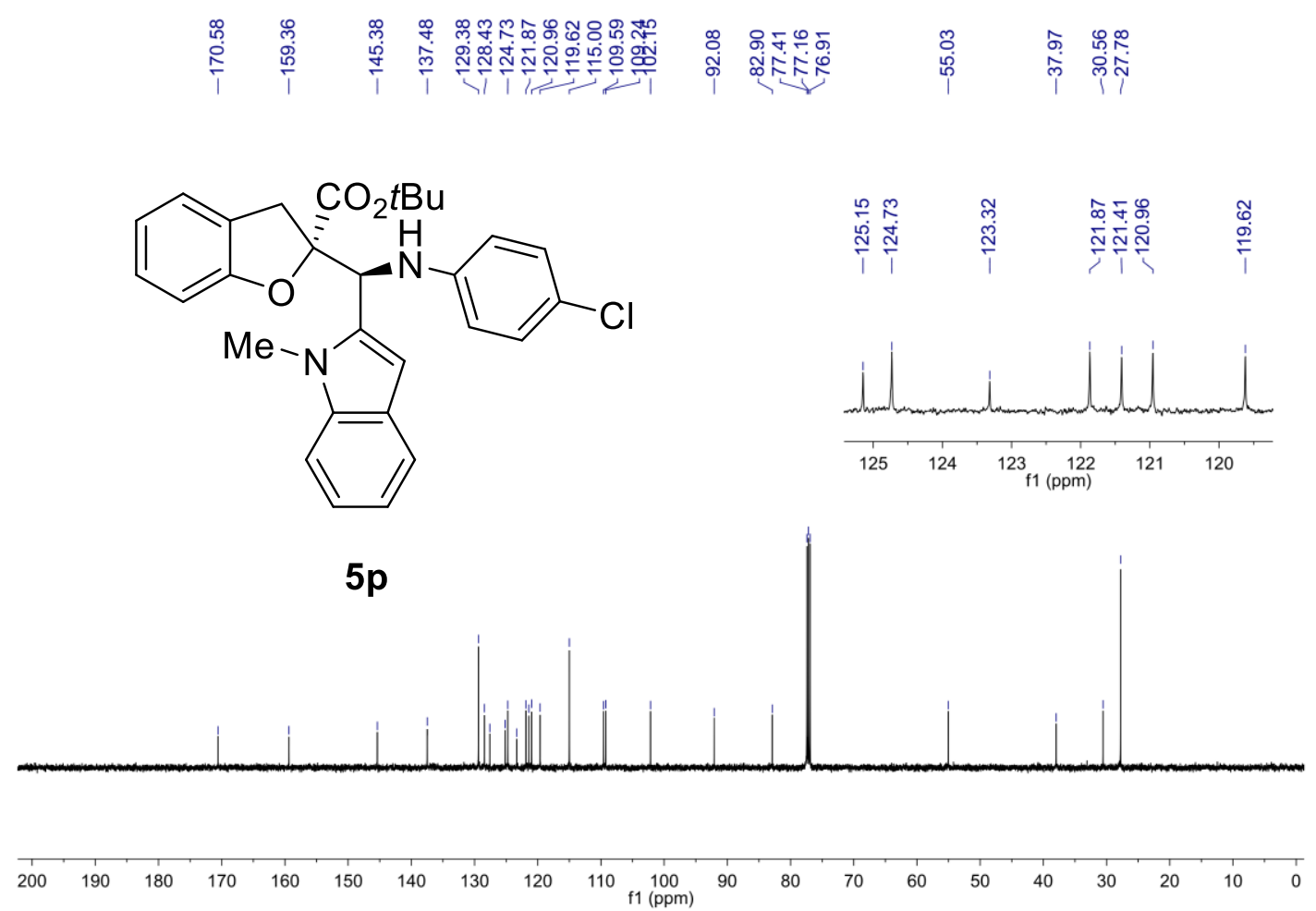

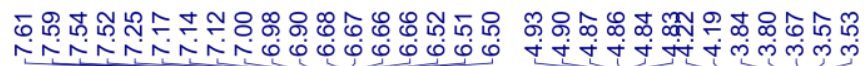

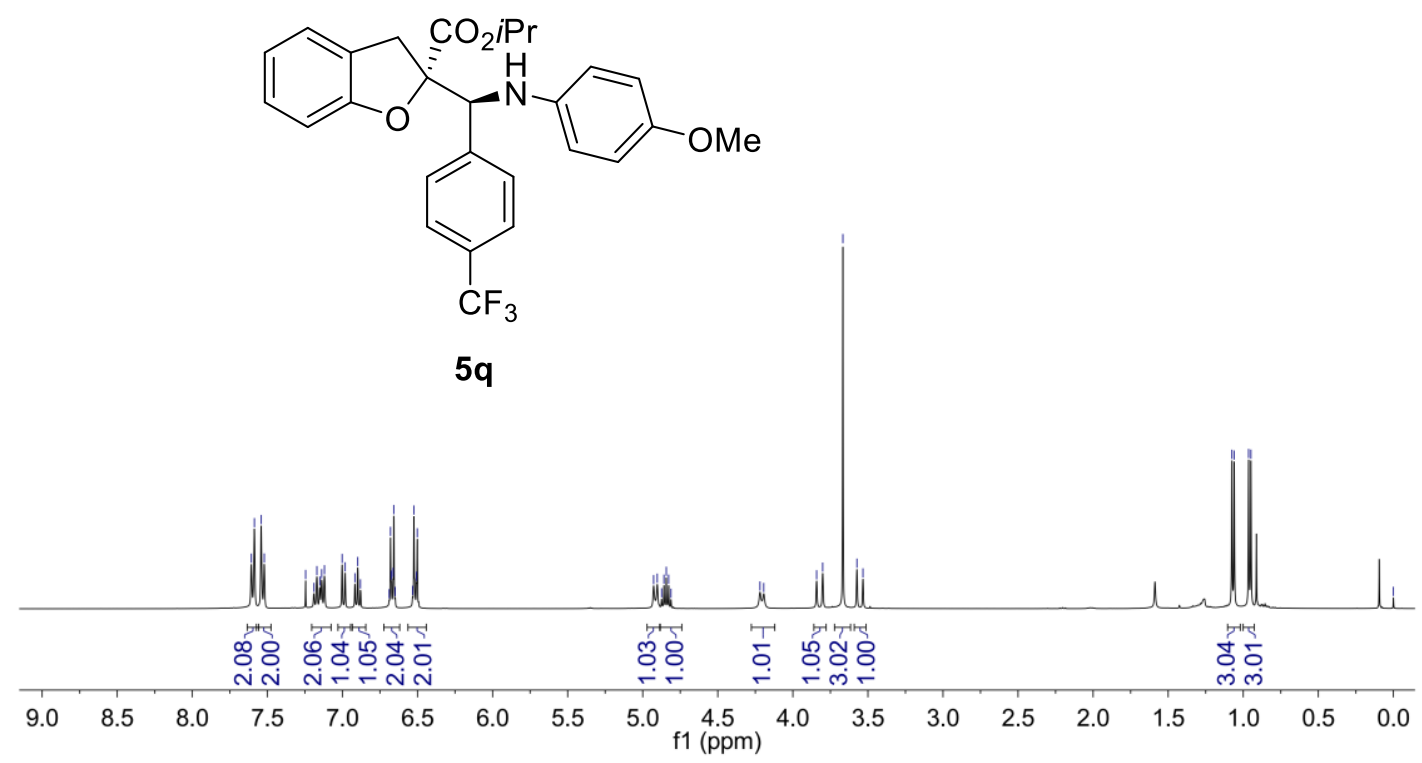




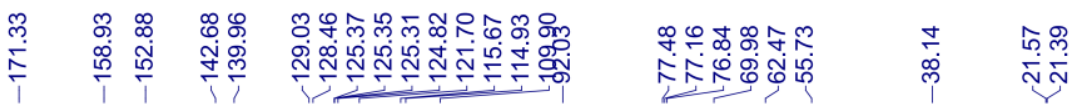<smiles></smiles>

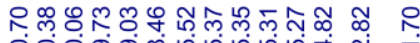

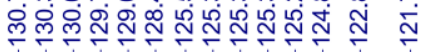
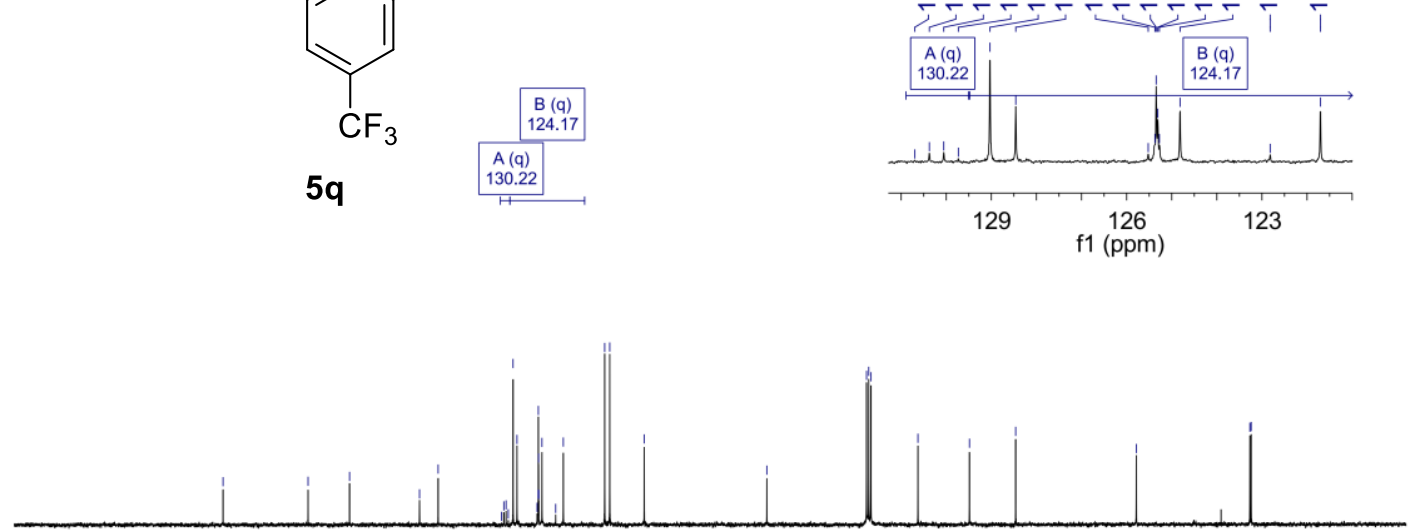

$\begin{array}{llllllllllllllllllllll}200 & 190 & 180 & 170 & 160 & 150 & 140 & 130 & 120 & 110 \begin{array}{l}100 \\ \mathrm{f} 1(\mathrm{ppm})\end{array} & 90 & 80 & 70 & 60 & 50 & 40 & 30 & 20 & 10 & 0\end{array}$

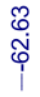

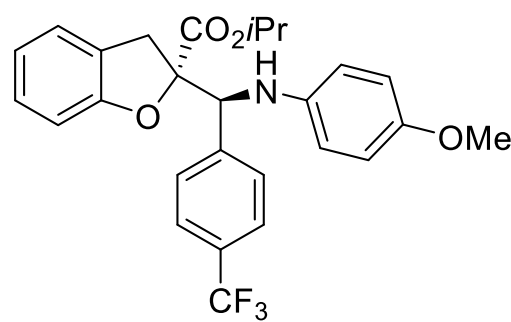

$5 q$

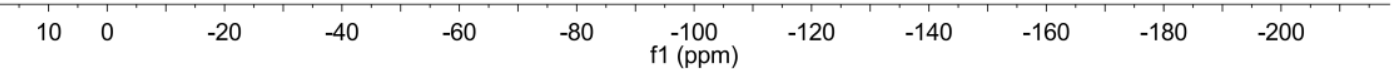




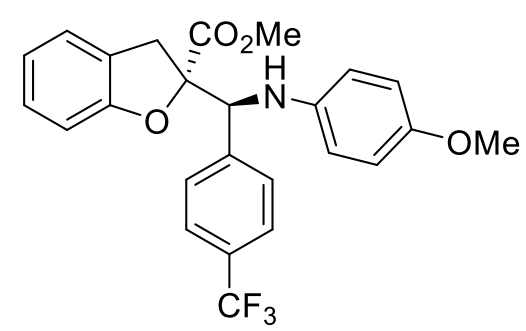

$5 r$

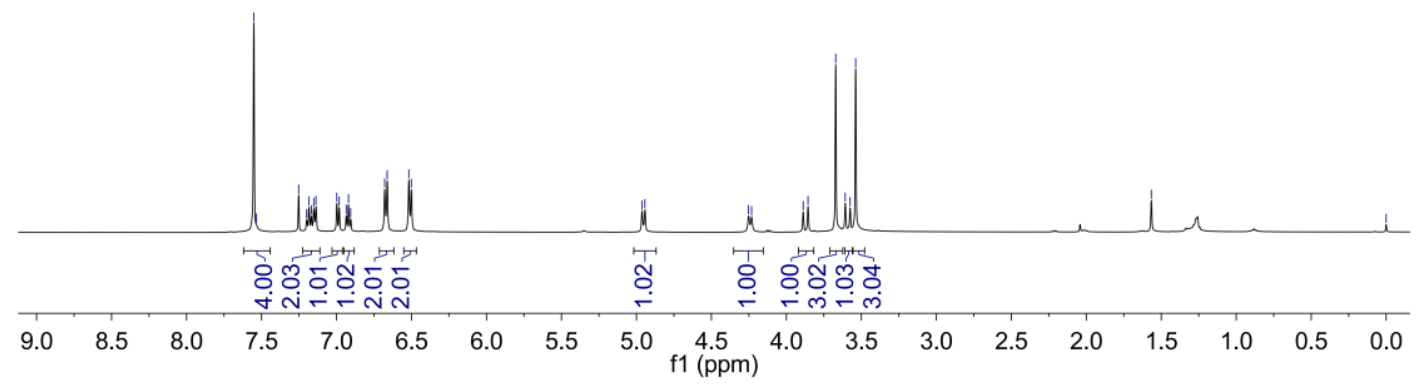

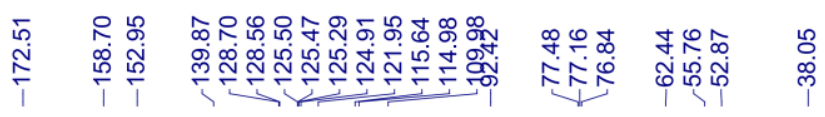

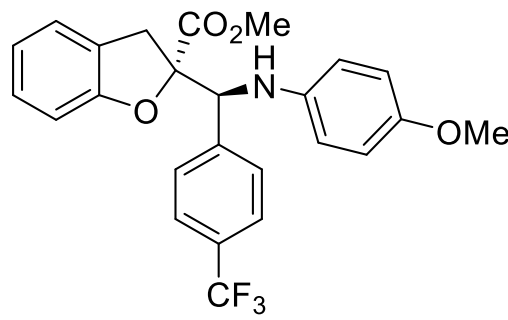

$5 r$
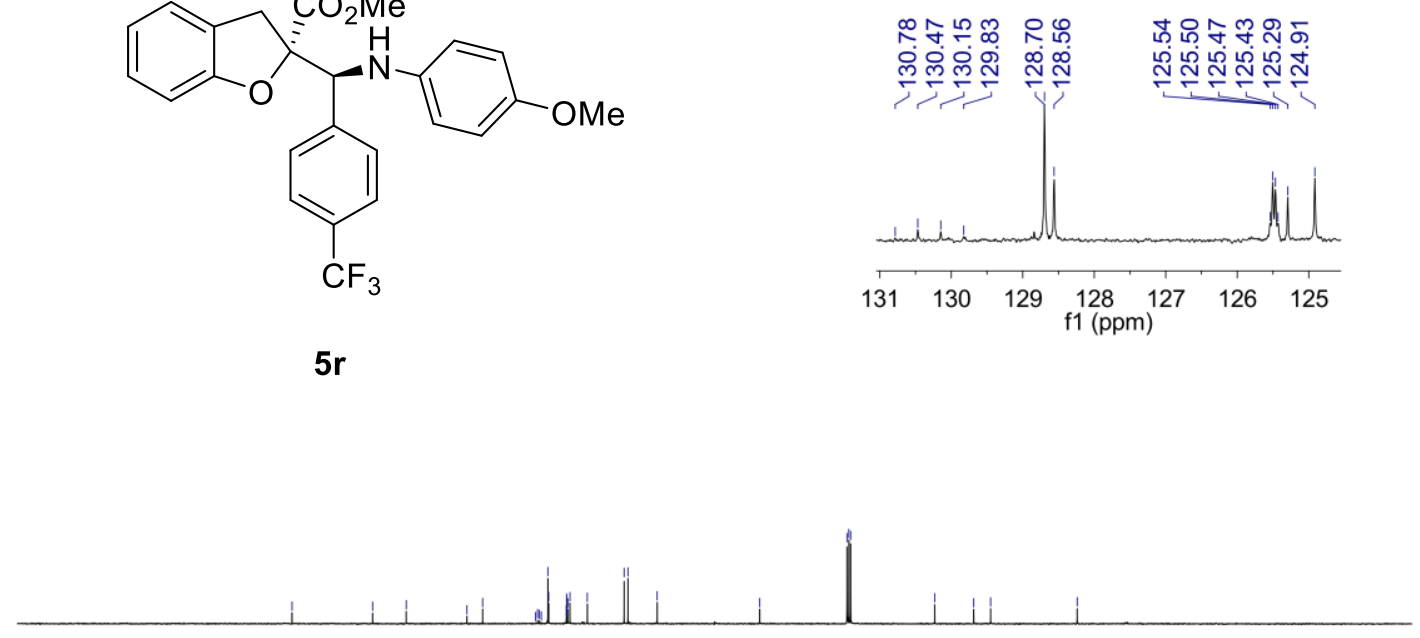

$\begin{array}{lllllllllllllllllll}210 & 190 & 170 & 150 & 130 & 110_{\mathrm{f} 1(\mathrm{ppm})} & 90 & 80 & 70 & 60 & 50 & 40 & 30 & 20 & 10 & 0\end{array}$ 


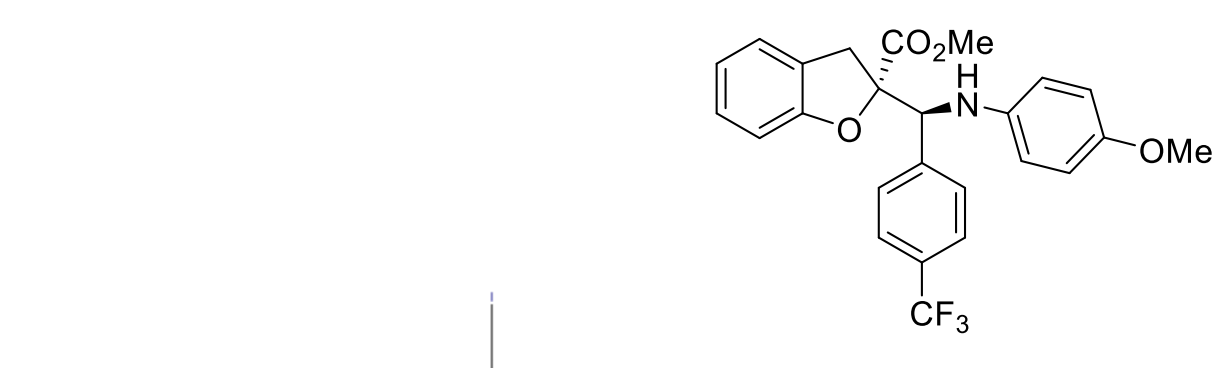

$5 r$

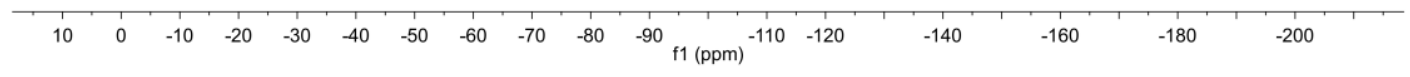

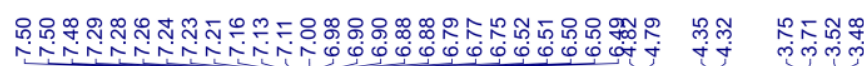

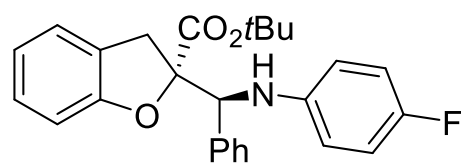

5s

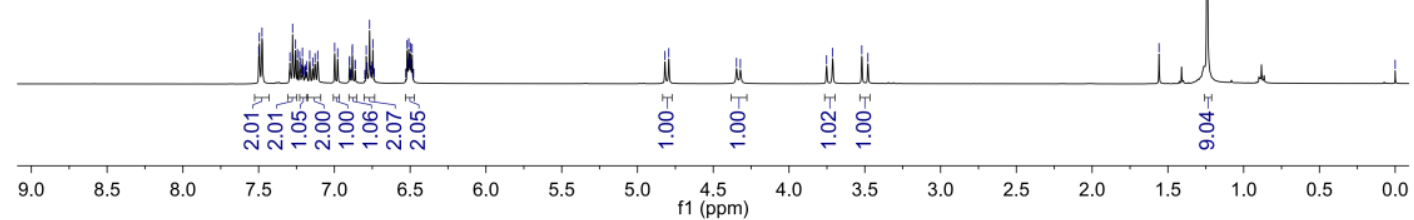




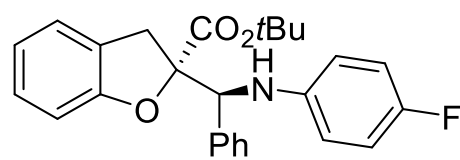

5s

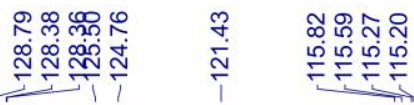

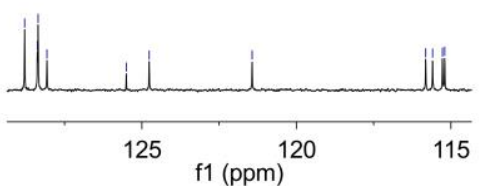

$\begin{array}{lllllllllllllllllllllll}200 & 190 & 180 & 170 & 160 & 150 & 140 & 130 & 120 & 110 & 100 & 90 & 80 & 70 & 60 & 50 & 40 & 30 & 20 & 10 & 0\end{array}$<smiles></smiles>

5 s

$\begin{array}{llllllllllllllllll}10 & 0 & -10 & -20 & -30 & -40 & -50 & -60 & -70 & -80 & -90 & \mathrm{f} 1(\mathrm{ppm}) & -110 & -120 & -140 & -160 & -180 & -200\end{array}$




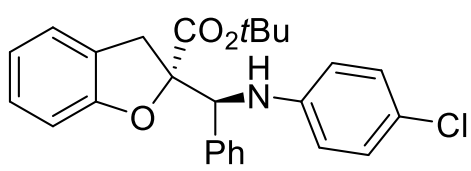

$5 t$

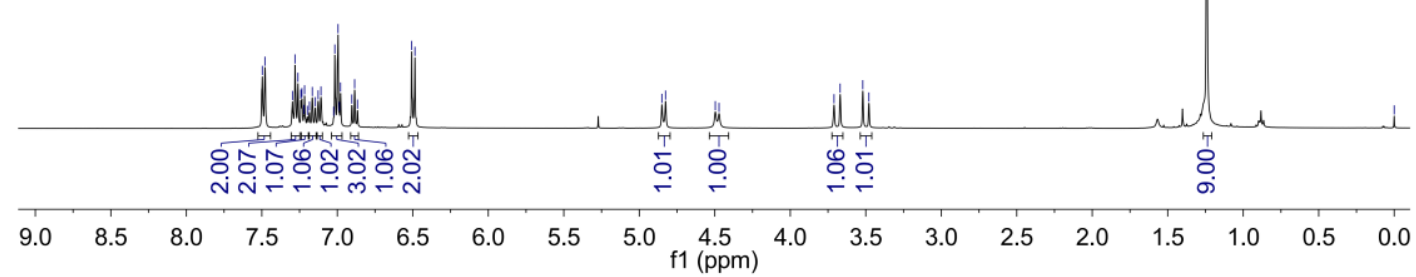

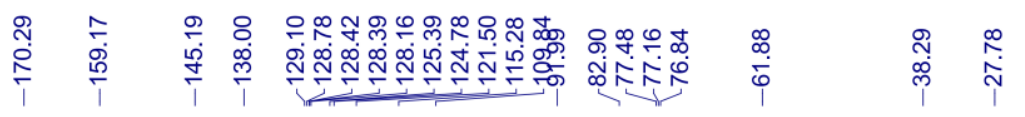<smiles>CCCOC(=O)C1(C(Nc2ccc(Cl)cc2)c2ccccc2)Cc2ccccc2O1</smiles>

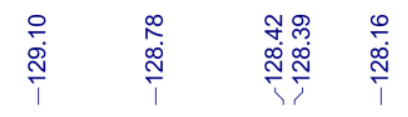

5t
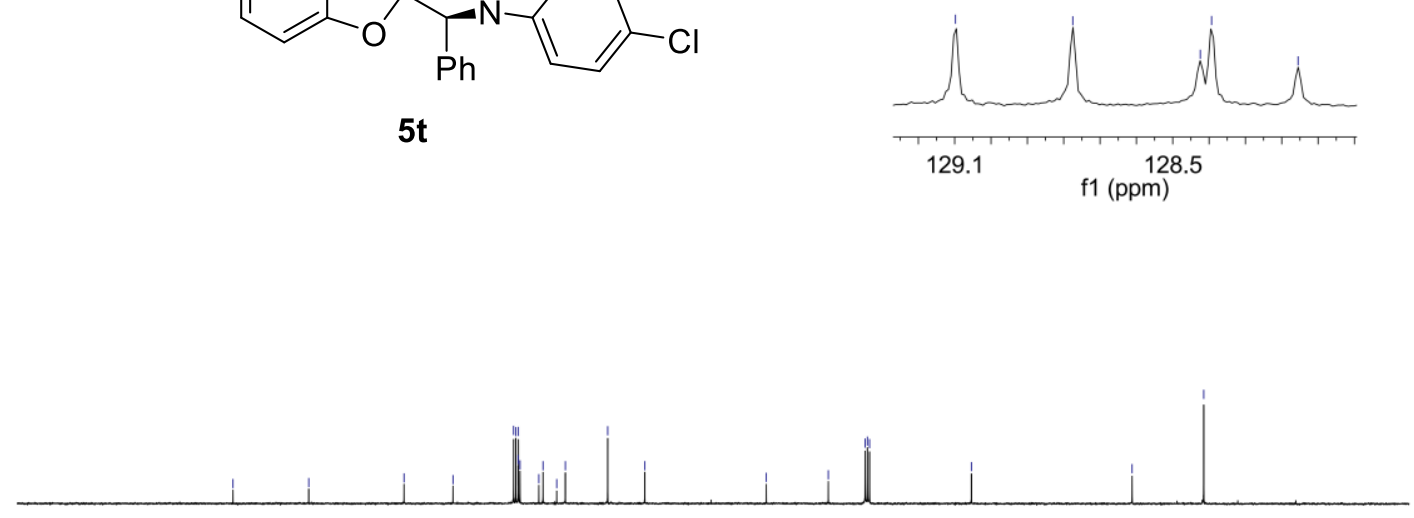

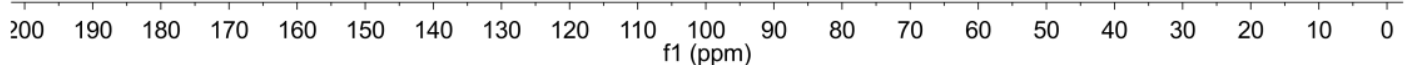




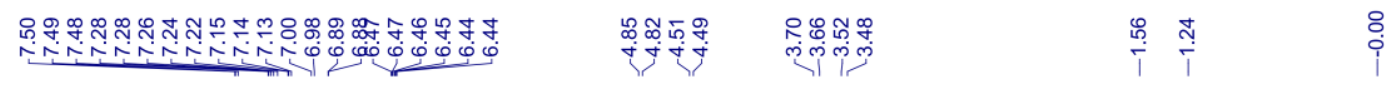<smiles>CCC(C)OC(=O)C1([C@H](Nc2ccc(Br)cc2)c2ccccc2)Cc2ccccc2O1</smiles>

$5 u$

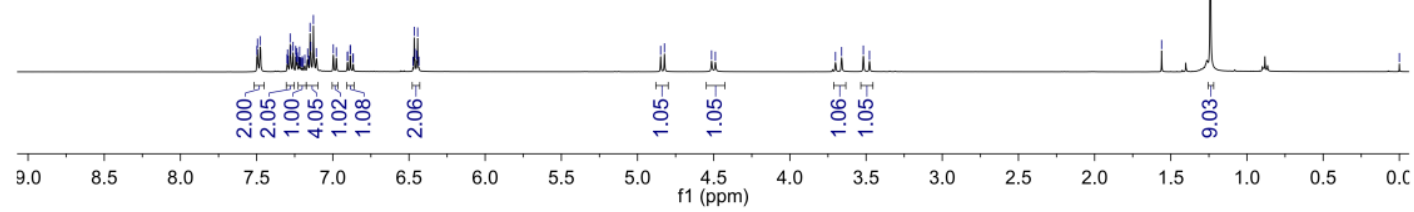

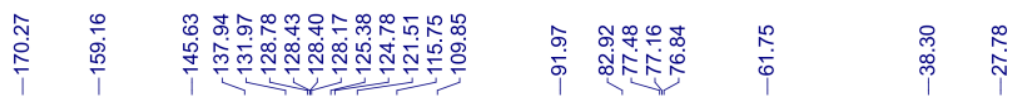<smiles>CCCC(=O)OC(Nc1ccc(Br)cc1)C(c1ccccc1)[C@]1(C(=O)OCC)Cc2ccccc2O1</smiles>

5u
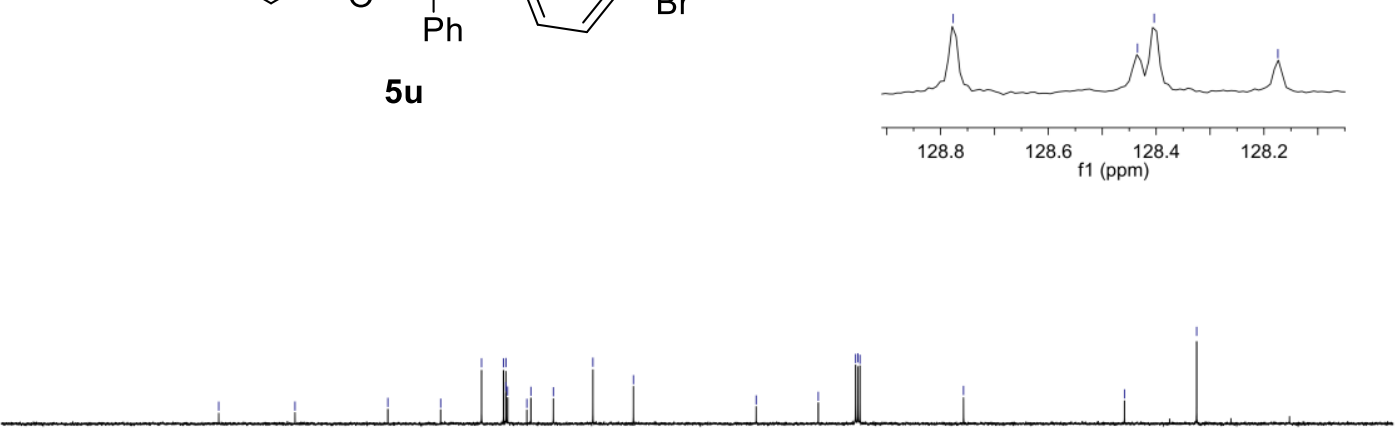

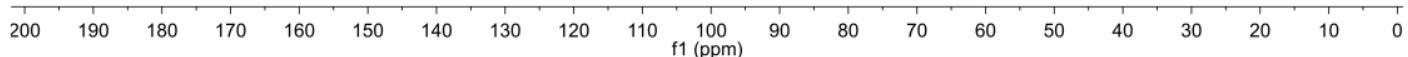




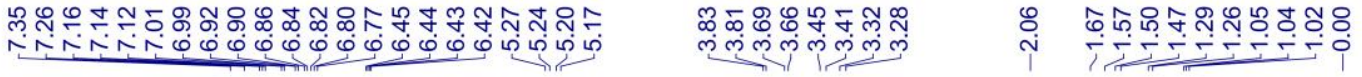
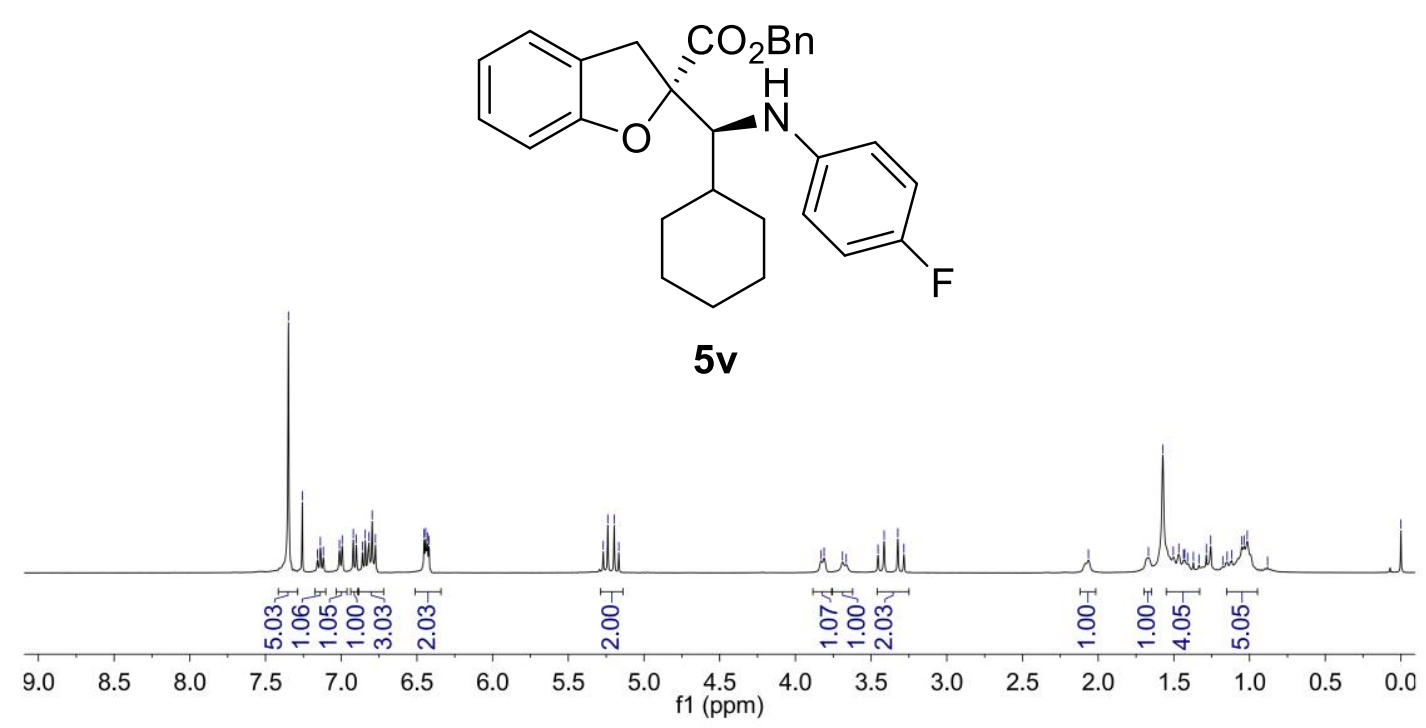

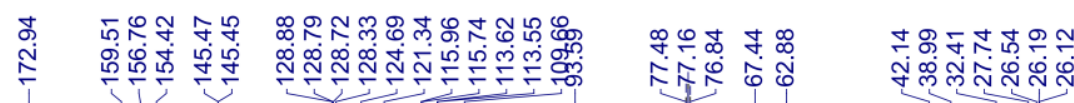

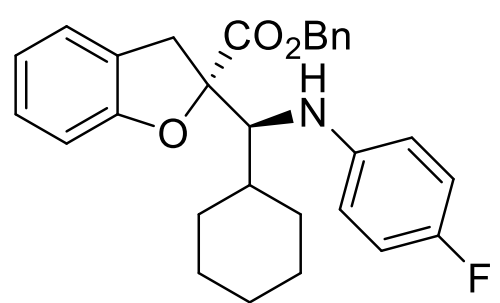

$5 v$

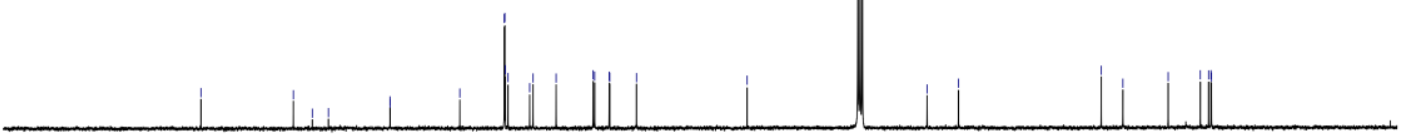

$\begin{array}{llllllllllllllllllllllllll}0 & 190 & 180 & 170 & 160 & 150 & 140 & 130 & 120 & 110 \begin{array}{l}100 \\ \mathrm{f} 1(\mathrm{ppm})\end{array} & 90 & 80 & 70 & 60 & 50 & 40 & 30 & 20 & 10 & 0\end{array}$ 


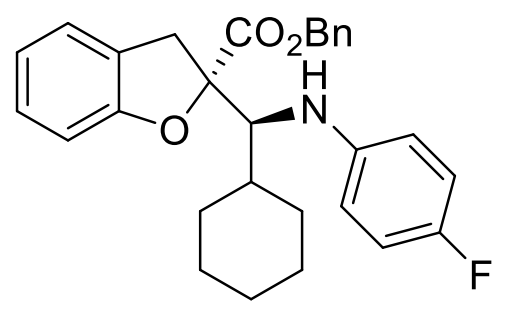

5v

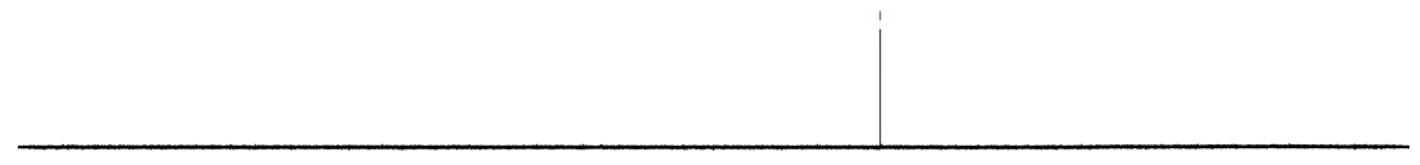

\begin{tabular}{llllllllllll}
\hline 10 & 0 & -20 & -40 & -60 & -80 & $\begin{array}{c}-100 \\
\mathrm{f} 1(\mathrm{ppm})\end{array}$ & -120 & -140 & -160 & -180 & -200
\end{tabular}

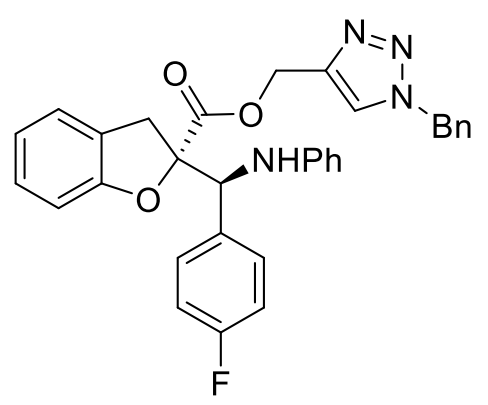

6

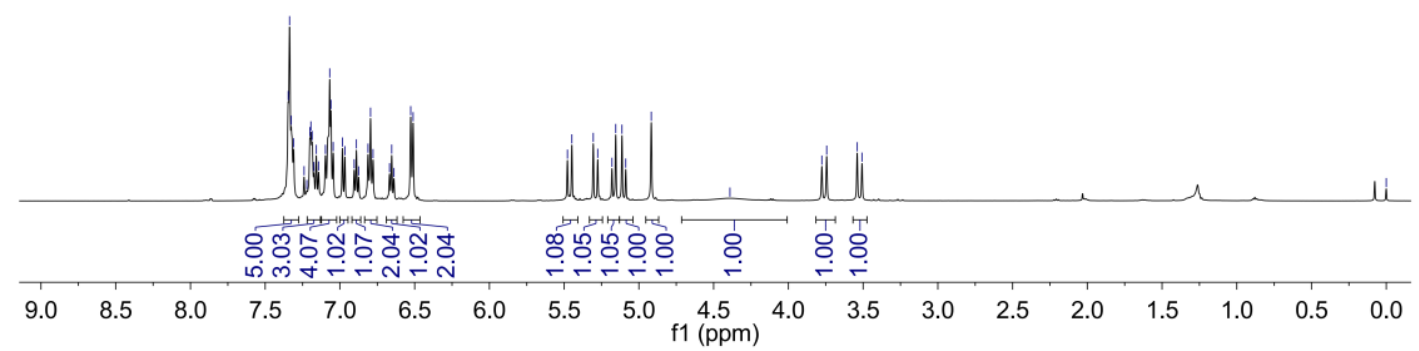




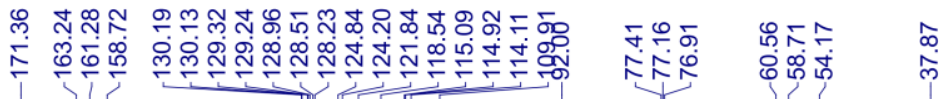

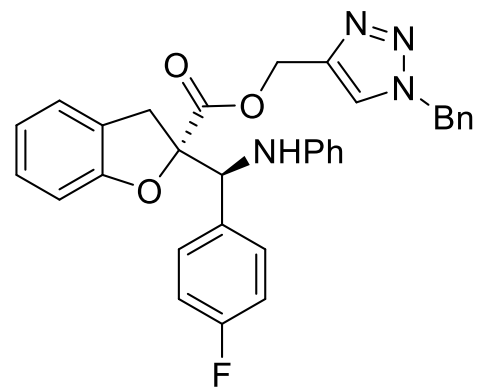

6

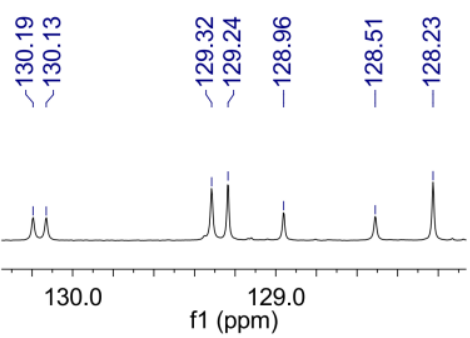

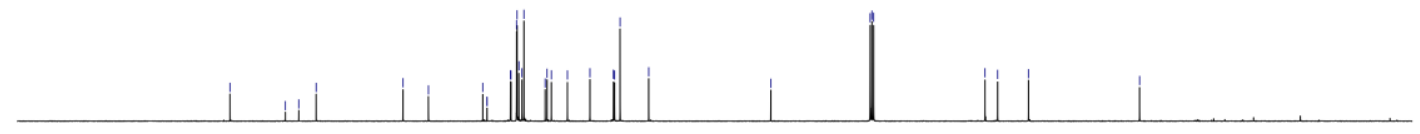

$\begin{array}{lllllllllllllllllllllllll}200 & 190 & 180 & 170 & 160 & 150 & 140 & 130 & 120 & 110 \begin{array}{l}100 \\ \mathrm{f} 1(\mathrm{ppm})\end{array} & 90 & 80 & 70 & 60 & 50 & 40 & 30 & 20 & 10 & 0\end{array}$

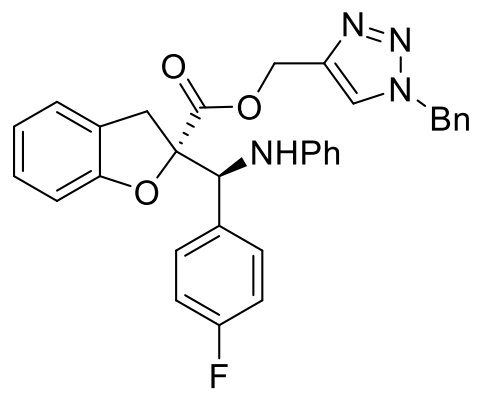

6

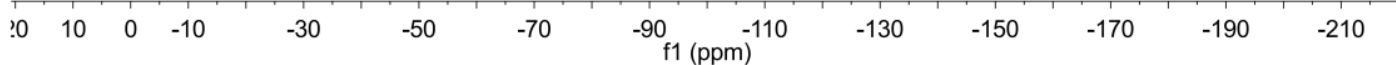




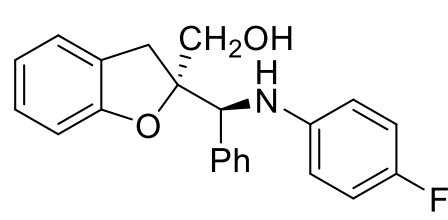

7

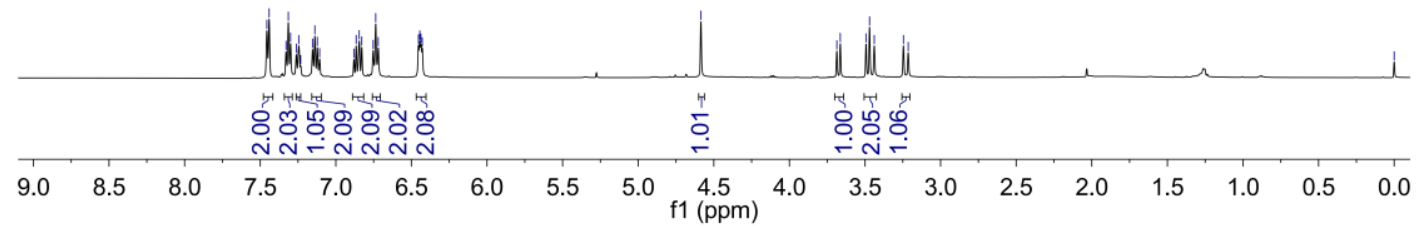

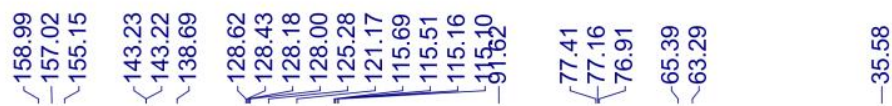
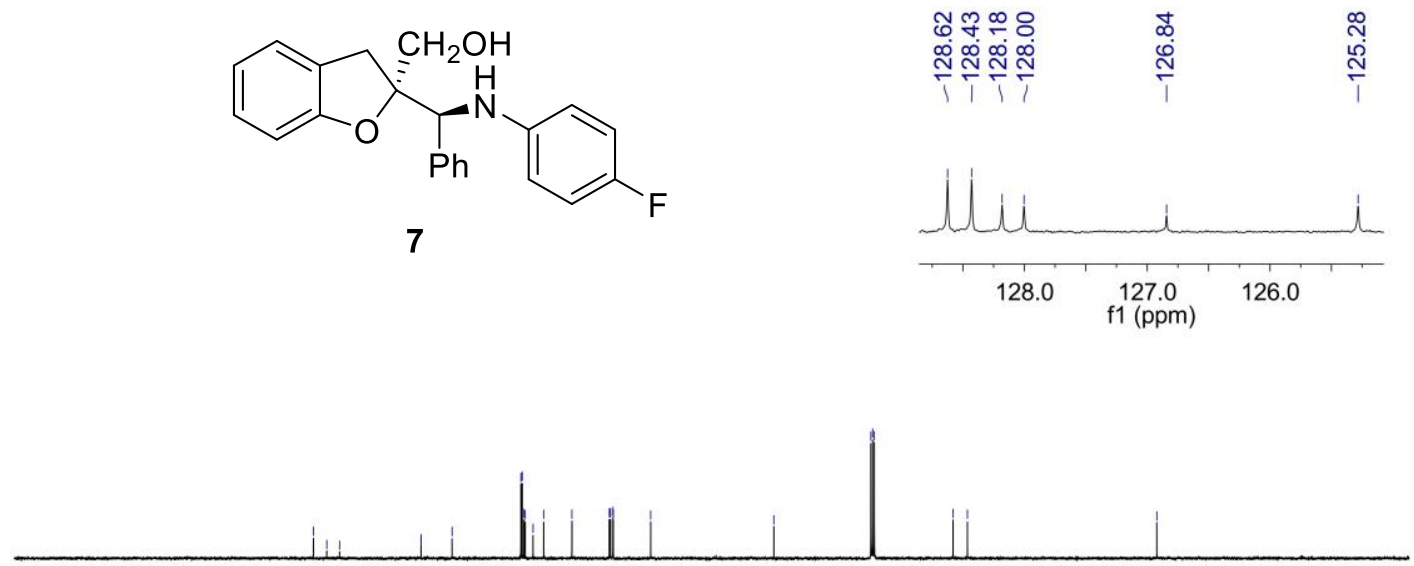

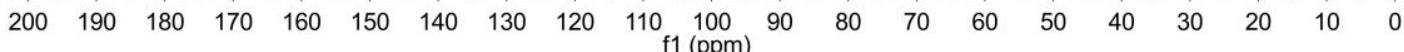




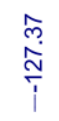

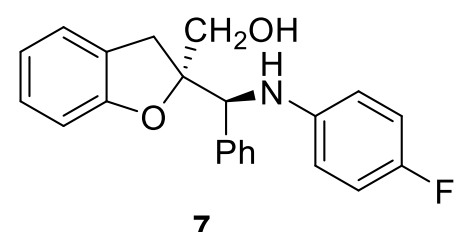

7

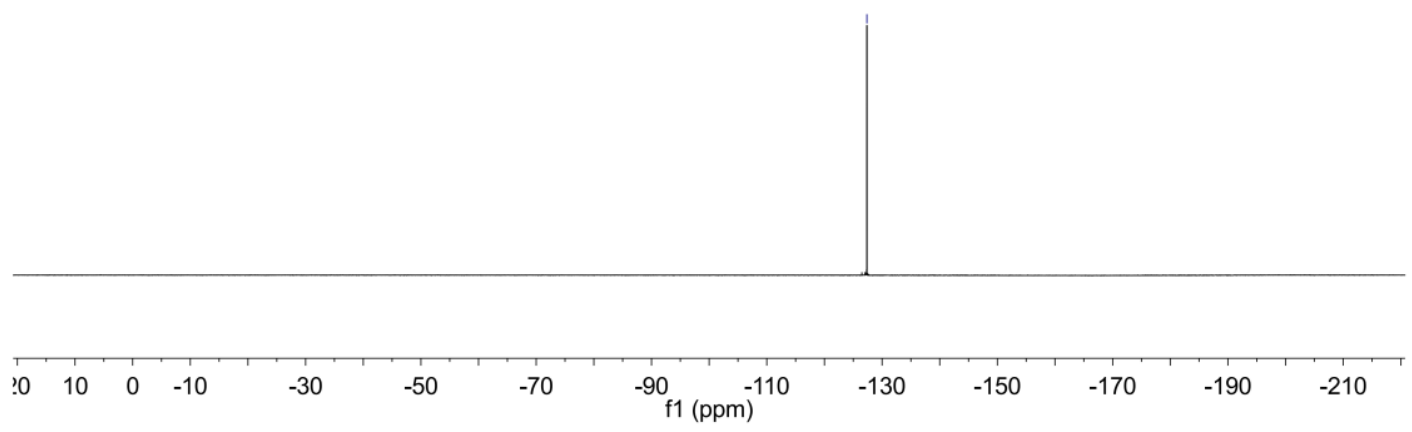

84 


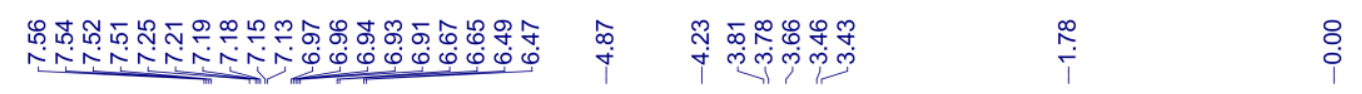<smiles>COc1ccc(NC(c2ccc(C(F)(F)F)cc2)[C@]2(C(C)=O)Cc3ccccc3O2)cc1</smiles>

8

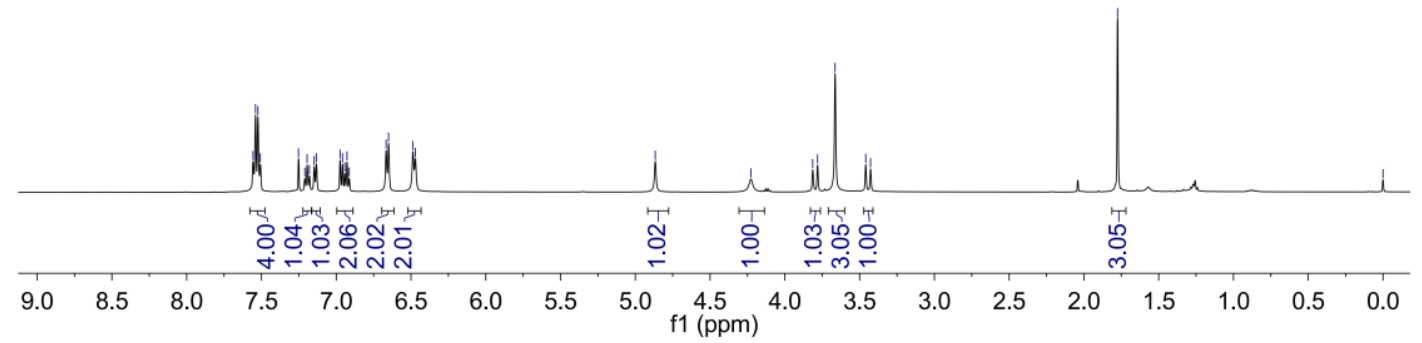

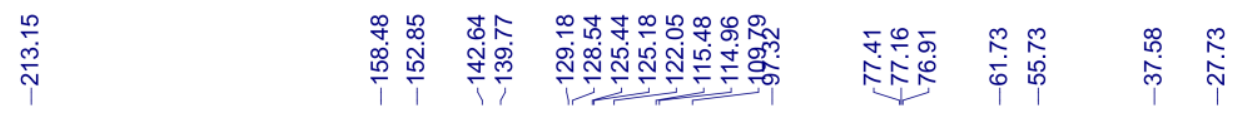<smiles>COc1ccc(NC(c2ccc(C(F)(F)F)cc2)[C@]2(C(C)=O)Cc3ccccc3O2)cc1</smiles>

8
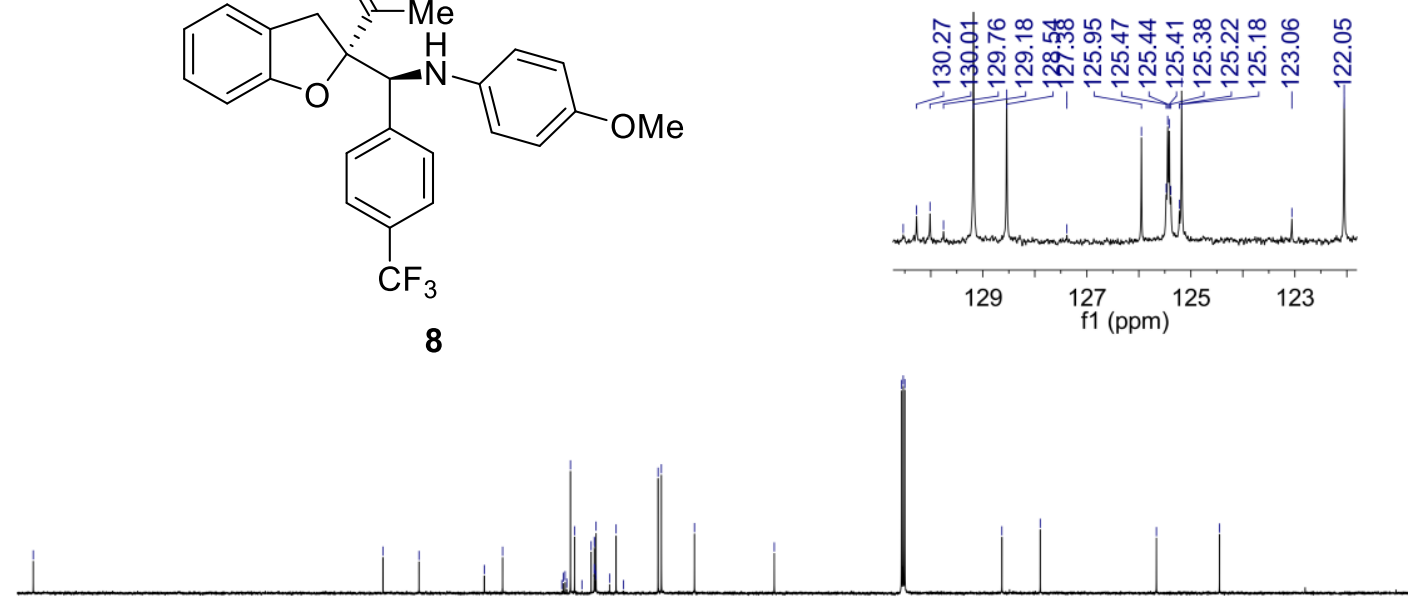

\begin{tabular}{llllllllllllllllll}
\hline 210 & 190 & 170 & 150 & 130 & $\begin{array}{c}110 \\
\mathrm{f} 1(\mathrm{ppm})\end{array}$ & 90 & 80 & 70 & 60 & 50 & 40 & 30 & 20 & 10 & 0
\end{tabular} 


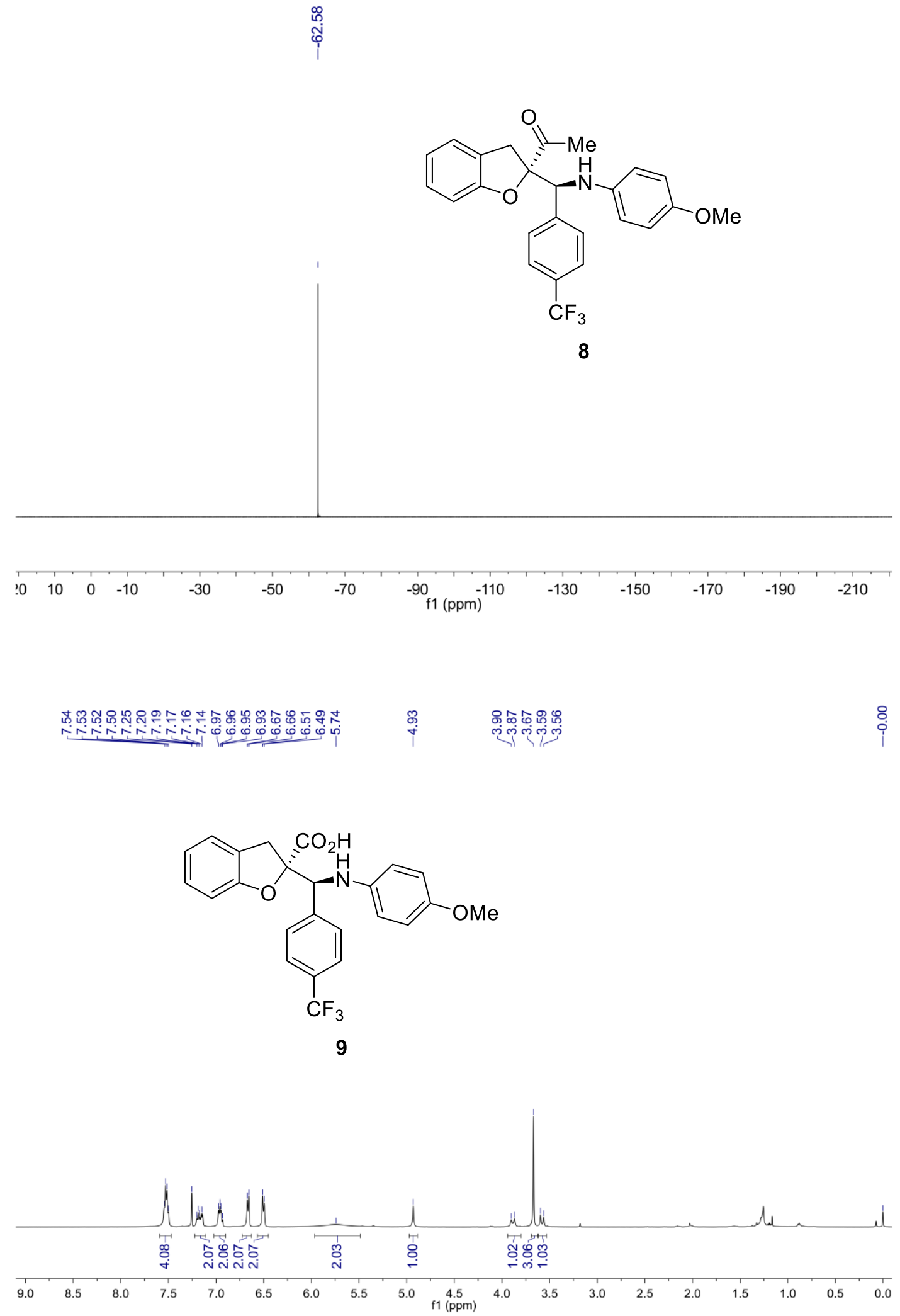



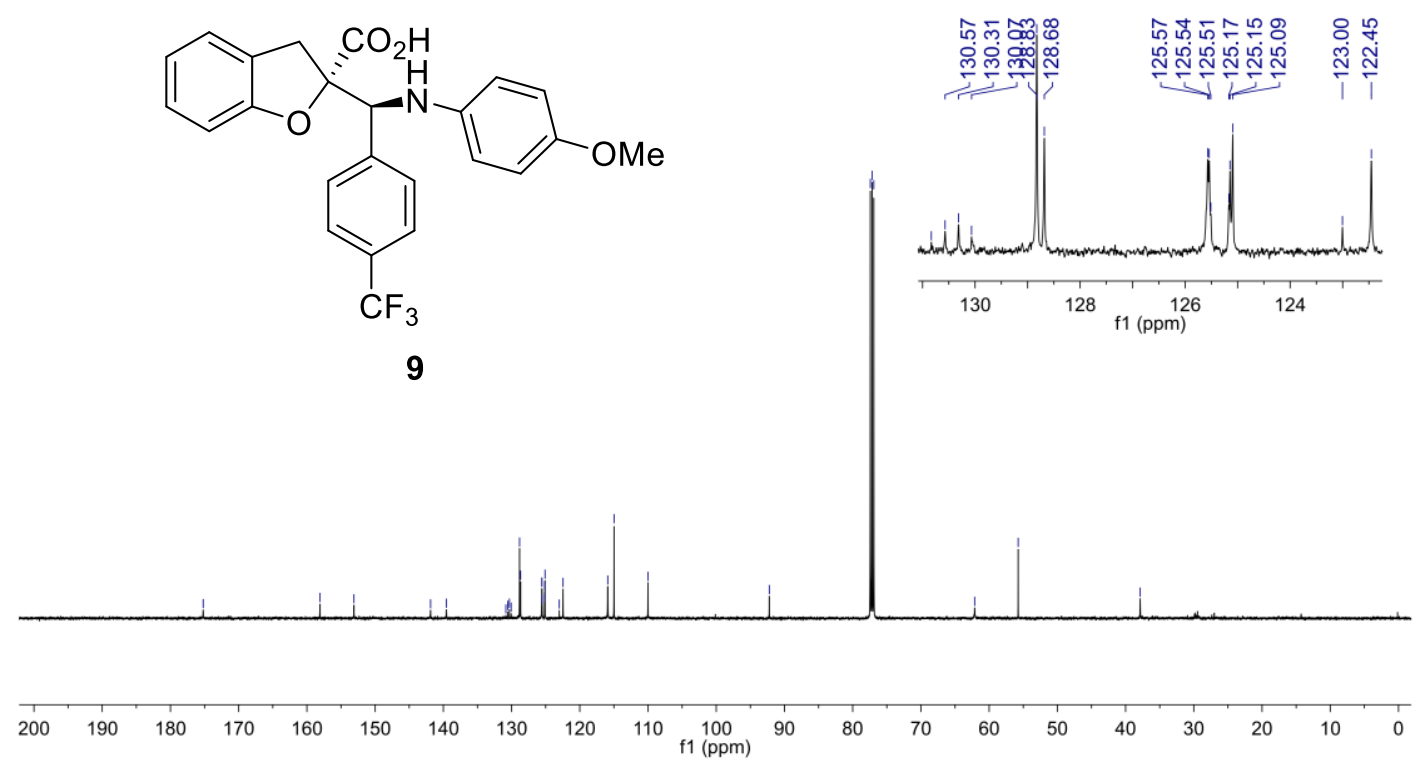

กิ

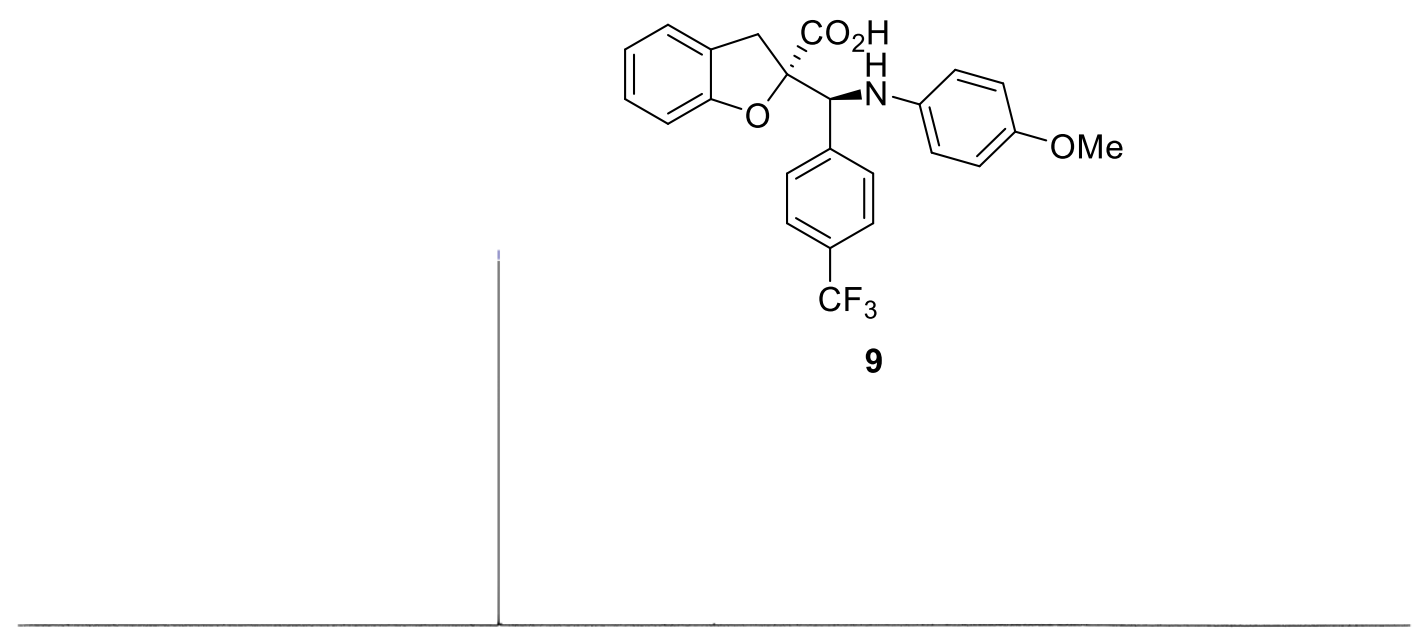

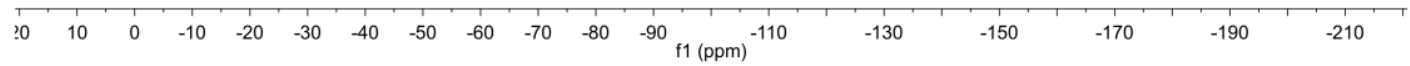


Condition: hexane $: 2$-propanol $=95: 5$

Flow rate $=1.0 \mathrm{~mL} / \mathrm{min}, \lambda=254 \mathrm{~nm}$, Daicel Chiralpak AD-H
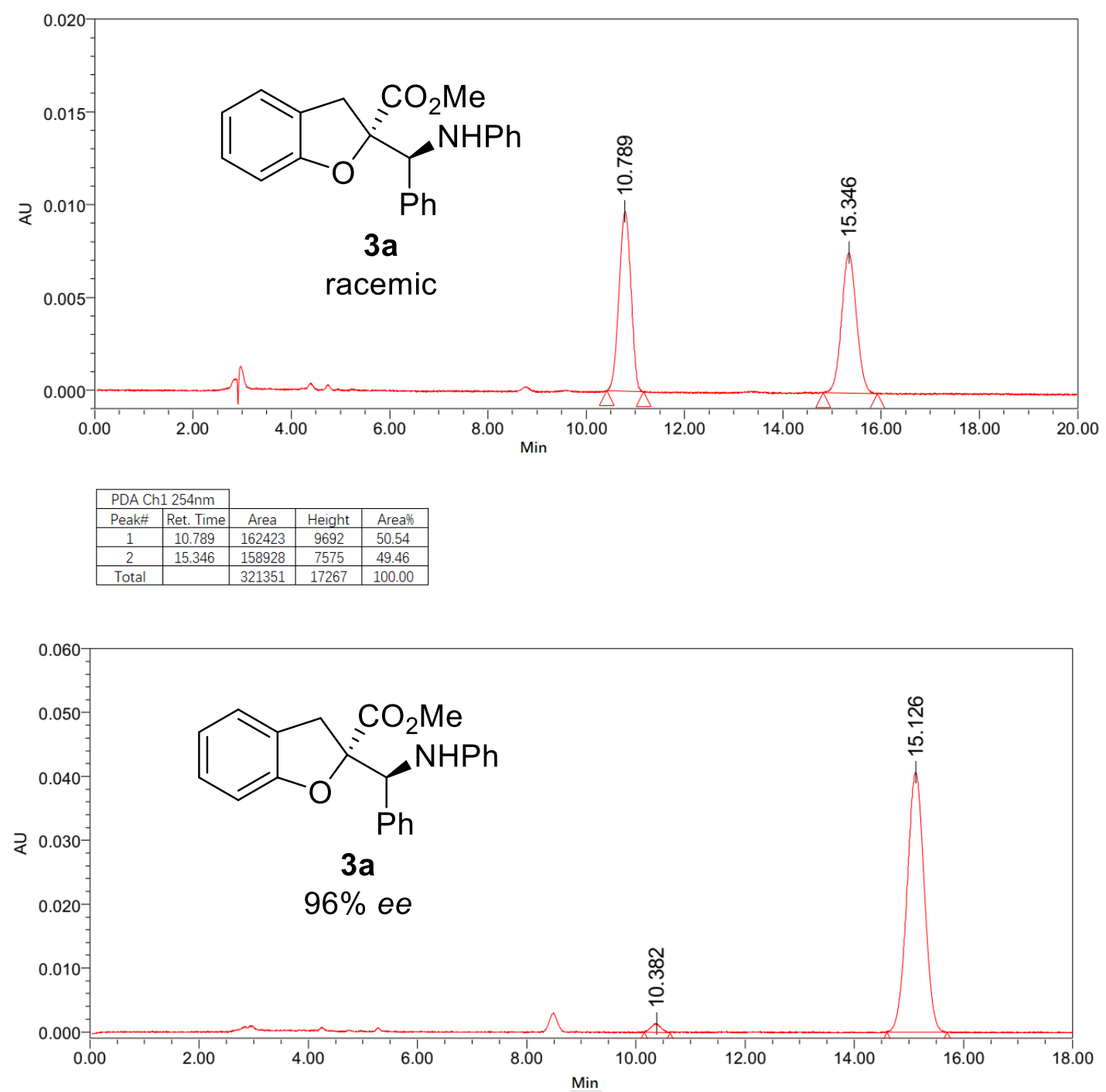

\begin{tabular}{|c|c|c|c|c|}
\hline \multicolumn{2}{|c|}{ PDA Ch1 254nm } & \multicolumn{3}{l|}{} \\
\cline { 1 - 2 } Peak\# & Ret. Time & Area & Height & Area\% \\
\hline 1 & 10.382 & 16992 & 1379 & 1.85 \\
\hline 2 & 15.126 & 901794 & 40697 & 98.15 \\
\hline Total & & 918786 & 42076 & 100.00 \\
\hline
\end{tabular}


Condition: hexane $:$ 2-propanol $=96: 4$

Flow rate $=1.0 \mathrm{~mL} / \mathrm{min}, \lambda=254 \mathrm{~nm}$, Daicel Chiralpak IF-3
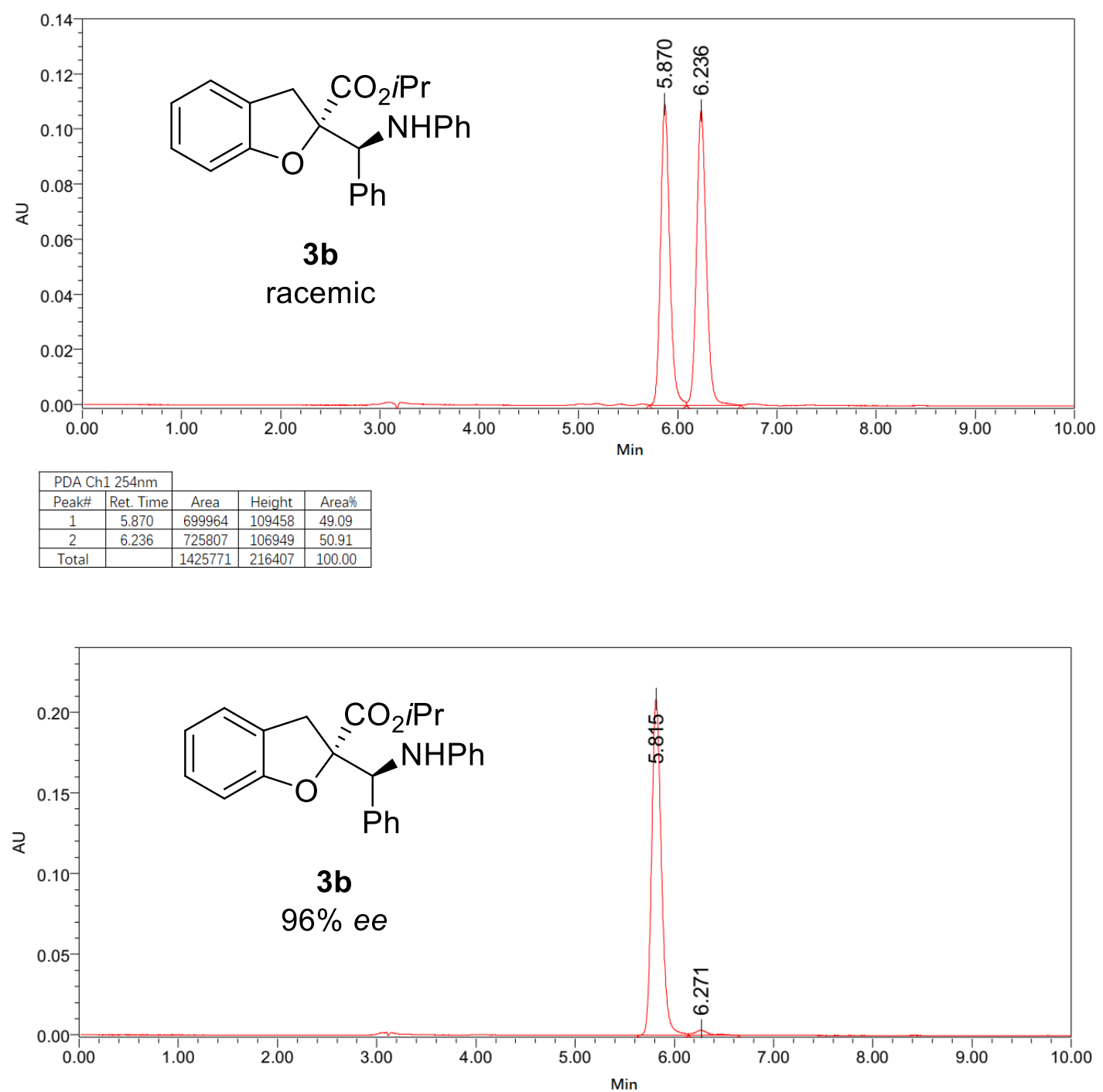

\begin{tabular}{|c|c|c|c|c|}
\hline \multicolumn{2}{|c|}{ PDA Ch1 254nm } & \multicolumn{1}{l}{} \\
\cline { 1 - 3 } Peak\# & Ret. Time & Area & Height & Area\% \\
\hline 1 & 5.815 & 1418530 & 208217 & 98.01 \\
\hline 2 & 6.271 & 28863 & 2978 & 1.99 \\
\hline Total & & 1447393 & 211195 & 100.00 \\
\hline
\end{tabular}


Condition: hexane $: 2$-propanol $=99.5: 0.5$

Flow rate $=1.0 \mathrm{~mL} / \mathrm{min}, \lambda=254 \mathrm{~nm}$, Daicel Chiralpak IE-3
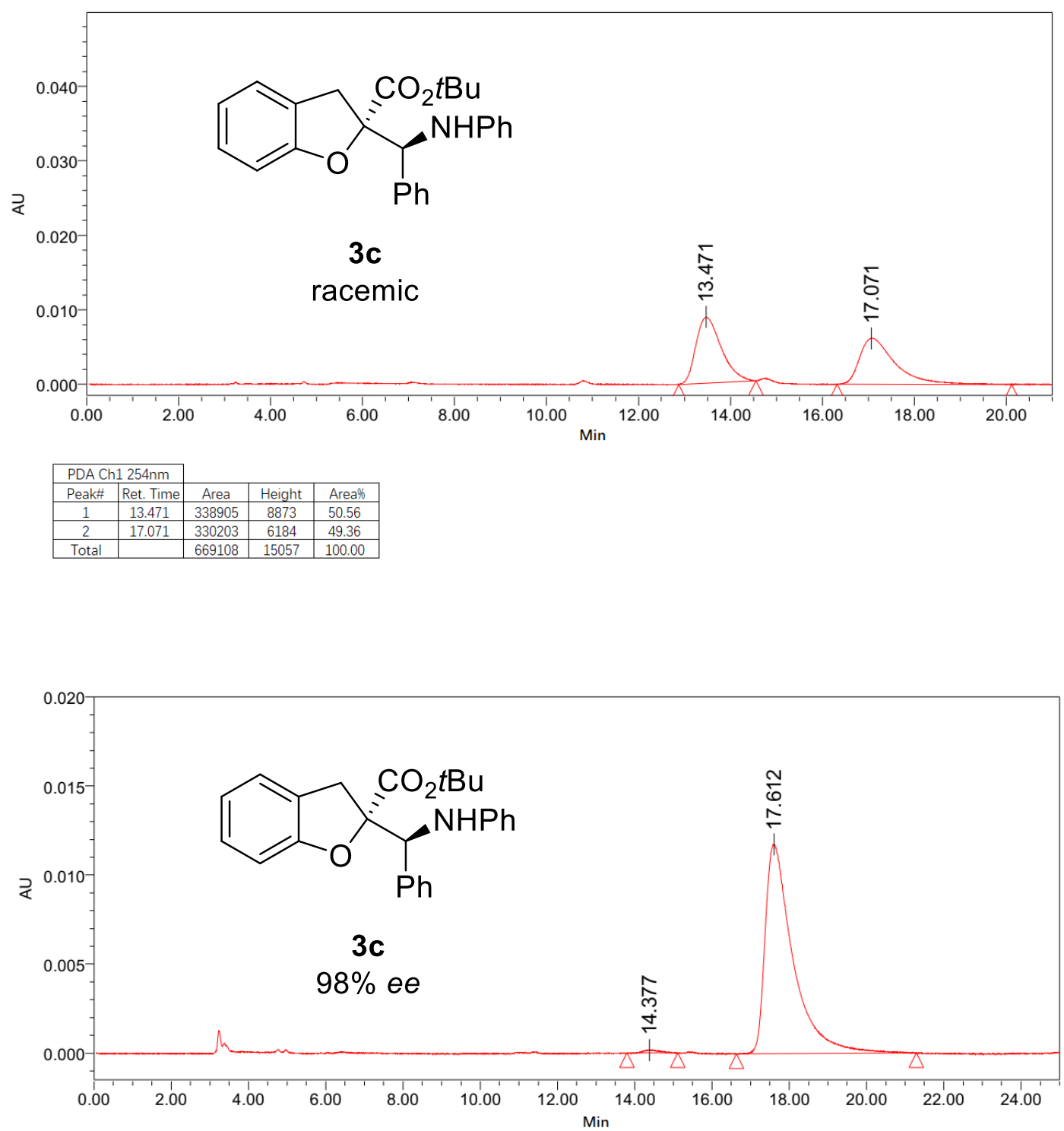

\begin{tabular}{|c|c|c|c|c|}
\hline \multicolumn{2}{|c|}{ PDA Ch1 254nm } & & & \\
\hline Peak\# & Ret. Time & Area & Height & Area\% \\
\hline 1 & \begin{tabular}{|l|}
14.377 \\
\end{tabular} & 4974 & 163 & 0.83 \\
\hline 2 & 17.612 & 594433 & 11751 & 99.17 \\
\hline Total & & 599407 & 11914 & 100.00 \\
\hline
\end{tabular}


Condition: hexane $: 2$-propanol $=95: 5$

Flow rate $=1.0 \mathrm{~mL} / \mathrm{min}, \lambda=254 \mathrm{~nm}$, Daicel Chiralpak IF-3

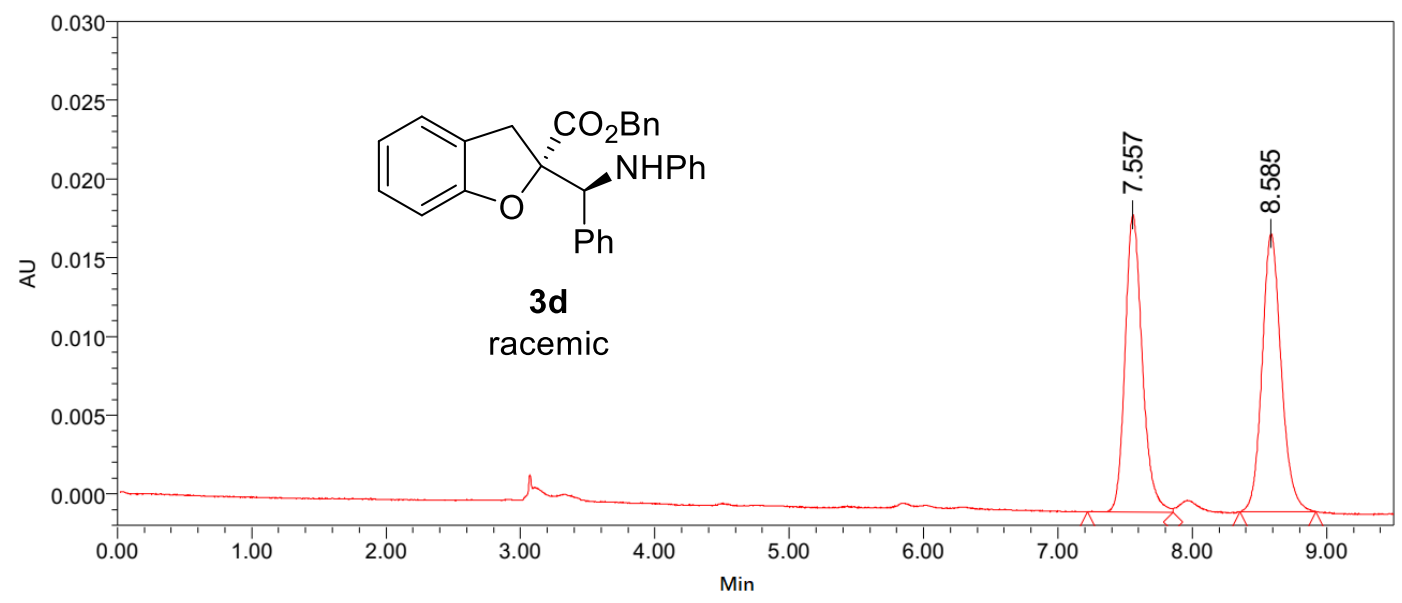

\begin{tabular}{|c|c|c|c|c|}
\hline \multicolumn{2}{|c|}{ PDA Ch1 254nm } & \multirow[b]{2}{*}{ Area } & \multirow[b]{2}{*}{ Height } & \multirow[b]{2}{*}{ Area\% } \\
\hline Peak\# & Ret. Time & & & \\
\hline 1 & 7.557 & 168471 & 18891 & 49.07 \\
\hline 2 & 8.585 & 174853 & 17668 & 50.93 \\
\hline Total & & 343324 & 36559 & 100.00 \\
\hline
\end{tabular}

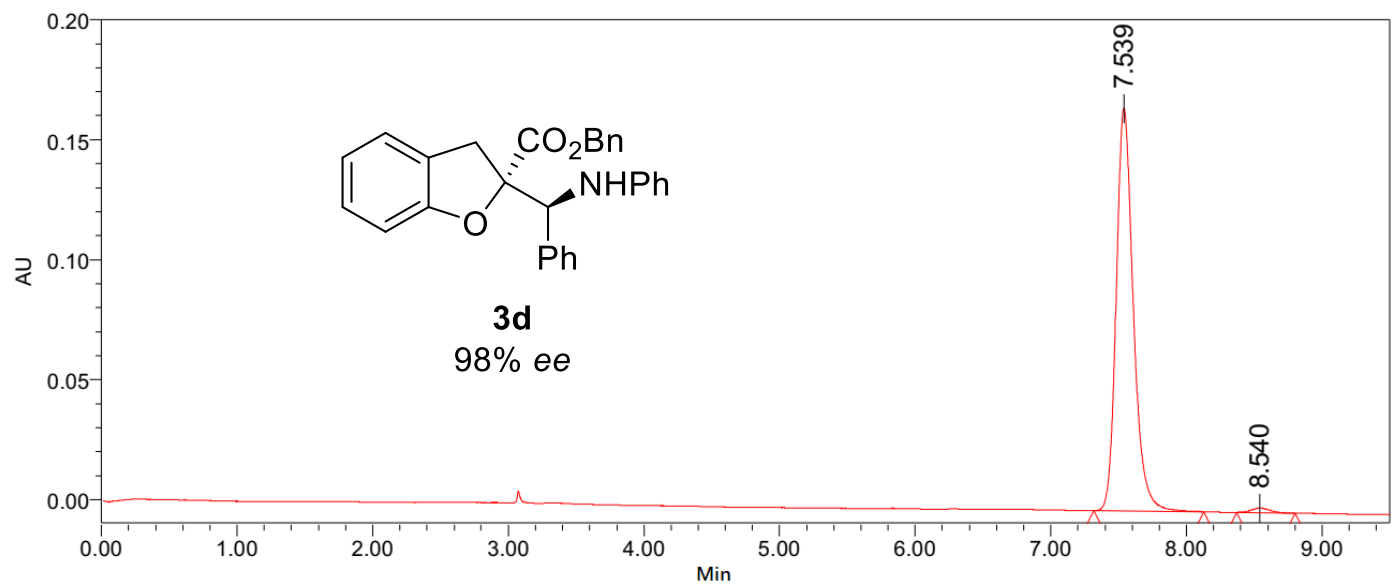

\begin{tabular}{|c|c|c|c|c|}
\hline \multicolumn{2}{|c|}{ PDA Ch1 254nm } & \multicolumn{1}{l|}{} \\
\cline { 1 - 2 } Peak\# & Ret. Time & Area & Height & Area\% \\
\hline 1 & 7.539 & 1470167 & 167790 & 98.76 \\
\hline 2 & 8.540 & 18393 & 1933 & 1.24 \\
\hline Total & & 1488560 & 169723 & 100.00 \\
\hline
\end{tabular}


Condition: hexane $: 2$-propanol $=95: 5$

Flow rate $=1.0 \mathrm{~mL} / \mathrm{min}, \lambda=254 \mathrm{~nm}$, Daicel Chiralpak IA
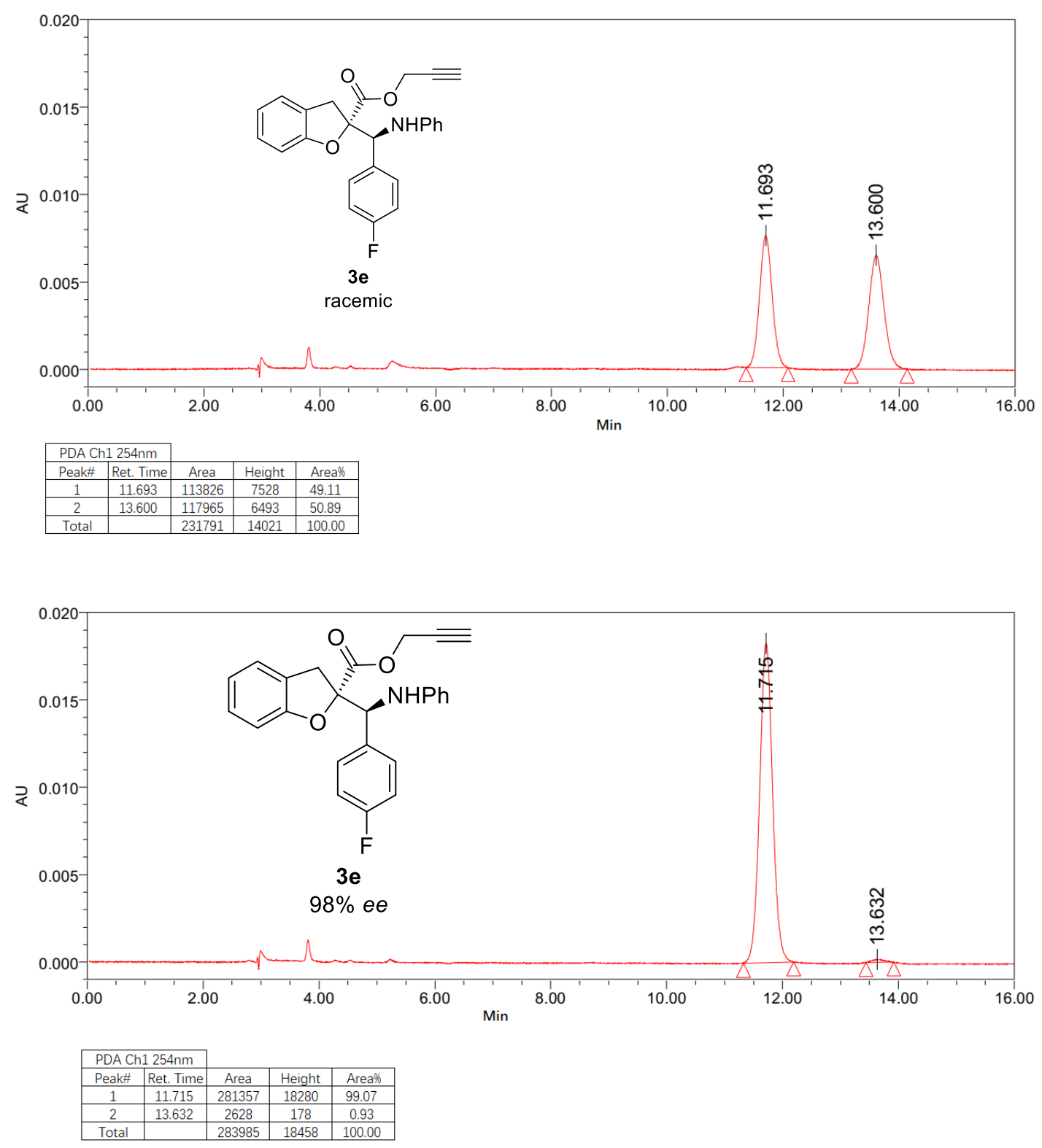
Condition: hexane $:$-propanol $=99: 1$

Flow rate $=1.0 \mathrm{~mL} / \mathrm{min}, \lambda=254 \mathrm{~nm}$, Daicel Chiralpak IE-3

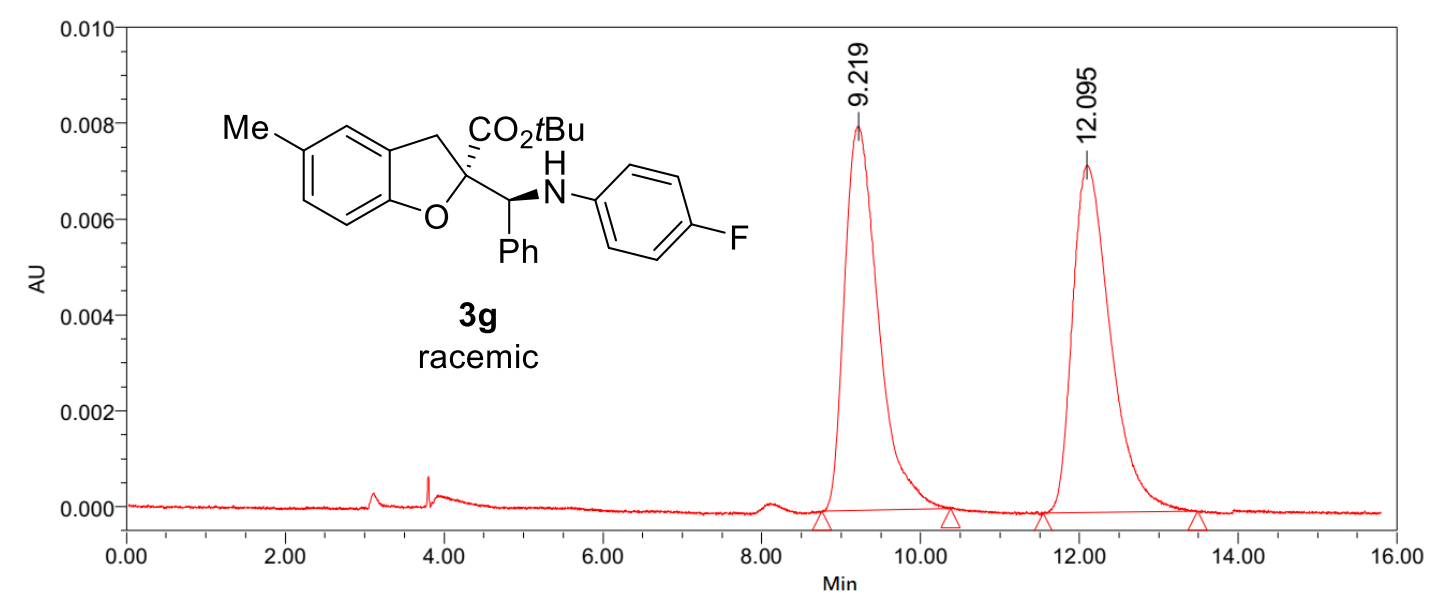

\begin{tabular}{|c|c|c|c|c|}
\hline \multicolumn{2}{|c|}{ PDA Ch1 254nm } & \multirow[b]{2}{*}{ Area } & \multirow[b]{2}{*}{ Height } & \multirow[b]{2}{*}{ Area\% } \\
\hline Peak\# & Ret. Time & & & \\
\hline 1 & \begin{tabular}{|l|}
9.219 \\
\end{tabular} & 237182 & 8011 & 49.60 \\
\hline 2 & 12.095 & 240972 & 7245 & 50.40 \\
\hline Total & & 478154 & 15256 & 100.00 \\
\hline
\end{tabular}

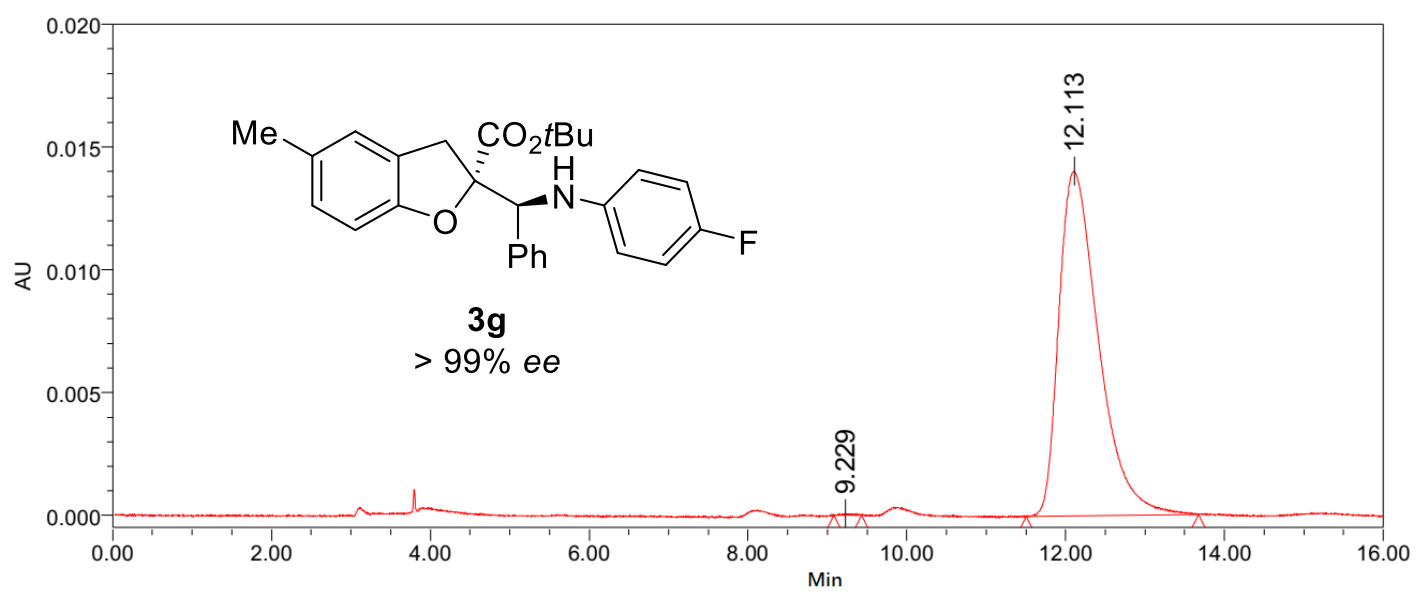

\begin{tabular}{|c|c|c|c|c|}
\hline \multicolumn{2}{|c|}{ PDA Ch1 254nm } & \multirow[b]{2}{*}{ Area } & \multirow{2}{*}{ Height } & \multirow[b]{2}{*}{ Area\% } \\
\hline Peak\# & Ret. Time & & & \\
\hline 1 & 9.229 & 507 & 65 & 0.10 \\
\hline 2 & 12.113 & 487273 & 14032 & 99.90 \\
\hline Total & & 487780 & 14097 & 100.00 \\
\hline
\end{tabular}


Condition: hexane $: 2$-propanol $=99: 1$

Flow rate $=1.0 \mathrm{~mL} / \mathrm{min}, \lambda=254 \mathrm{~nm}$, Daicel Chiralpak IE-3

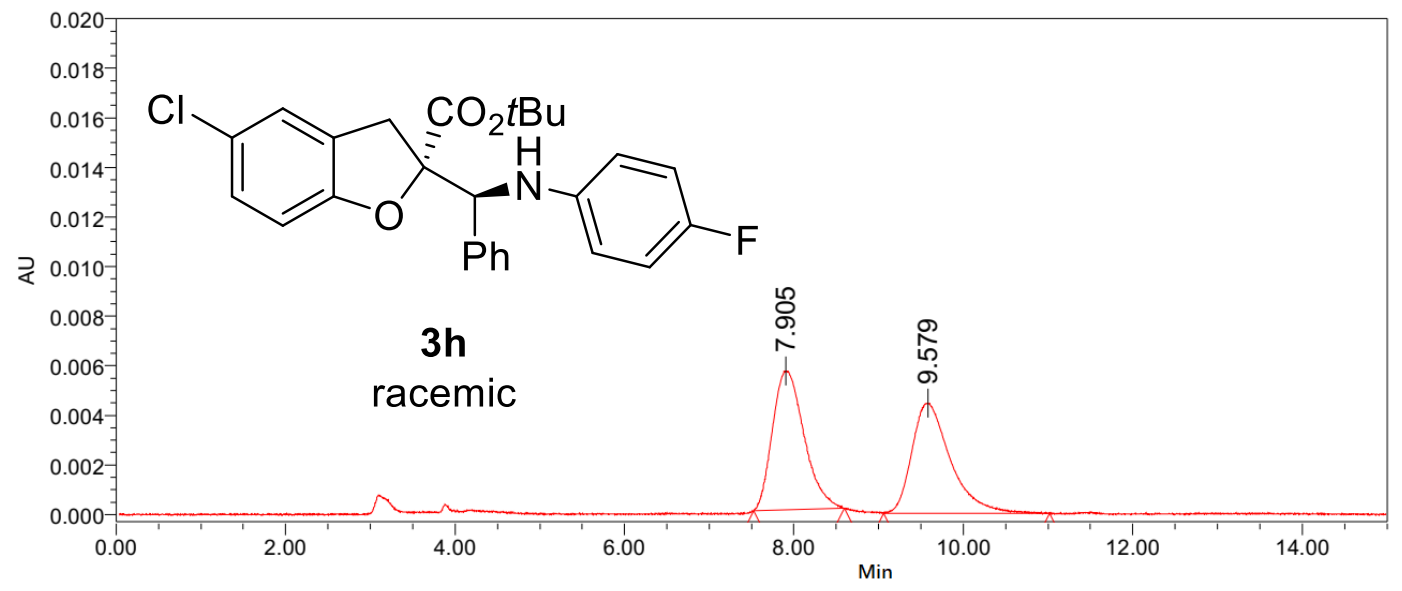

\begin{tabular}{|c|c|c|c|c|}
\hline \multicolumn{2}{|c|}{ PDA Ch1 254nm } & \multicolumn{1}{l|}{} \\
\cline { 1 - 2 } Peak\#\# & Ret. Time & Area & Height & Area\% \\
\hline 1 & 7.905 & 145205 & 5603 & 50.84 \\
\hline 2 & 9.579 & 140402 & 4438 & 49.16 \\
\hline Total & & 285607 & 10041 & 100.00 \\
\hline
\end{tabular}

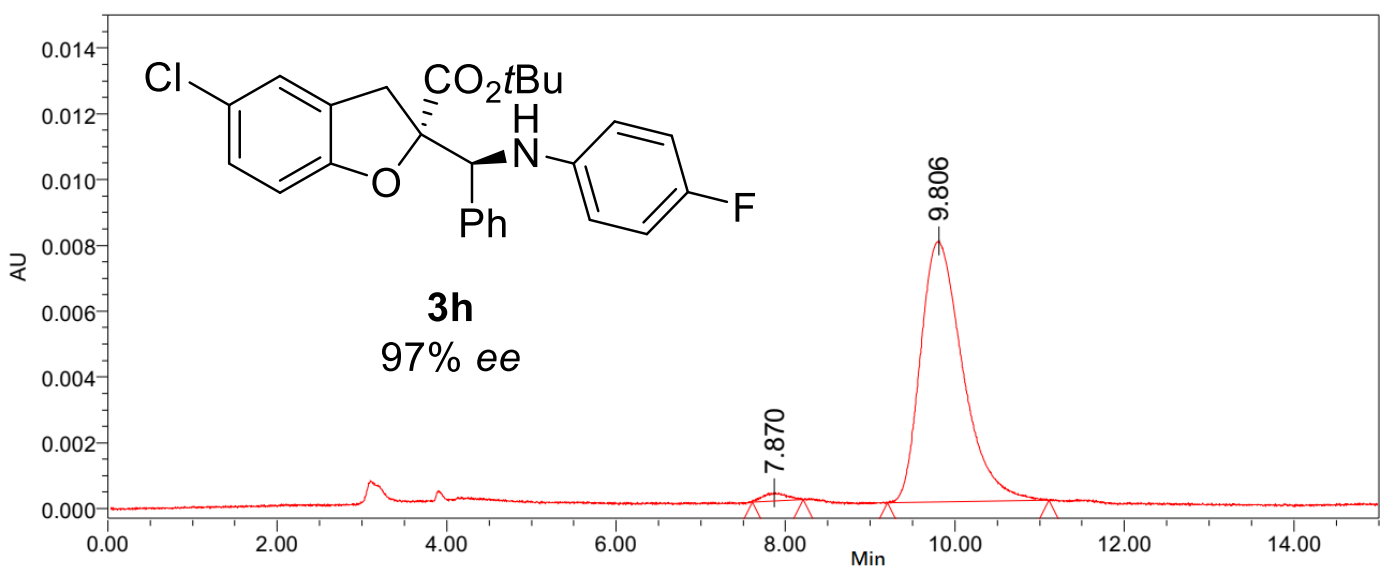

\begin{tabular}{|c|c|c|c|c|}
\hline \multicolumn{2}{|c|}{ PDA Ch1 254nm } & \multirow[b]{2}{*}{ Area } & \multirow[b]{2}{*}{ Height } & \multirow[b]{2}{*}{ Area\% } \\
\hline Peak\# & Ret. Time & & & \\
\hline 1 & \begin{tabular}{|l|}
7.870 \\
\end{tabular} & 4658 & 245 & 1.67 \\
\hline 2 & 9.806 & 274093 & 7946 & 98.33 \\
\hline Total & & 278751 & 8191 & 100.00 \\
\hline
\end{tabular}


Condition: hexane $:$-propanol $=99: 1$

Flow rate $=1.0 \mathrm{~mL} / \mathrm{min}, \lambda=254 \mathrm{~nm}$, Daicel Chiralpak IE-3
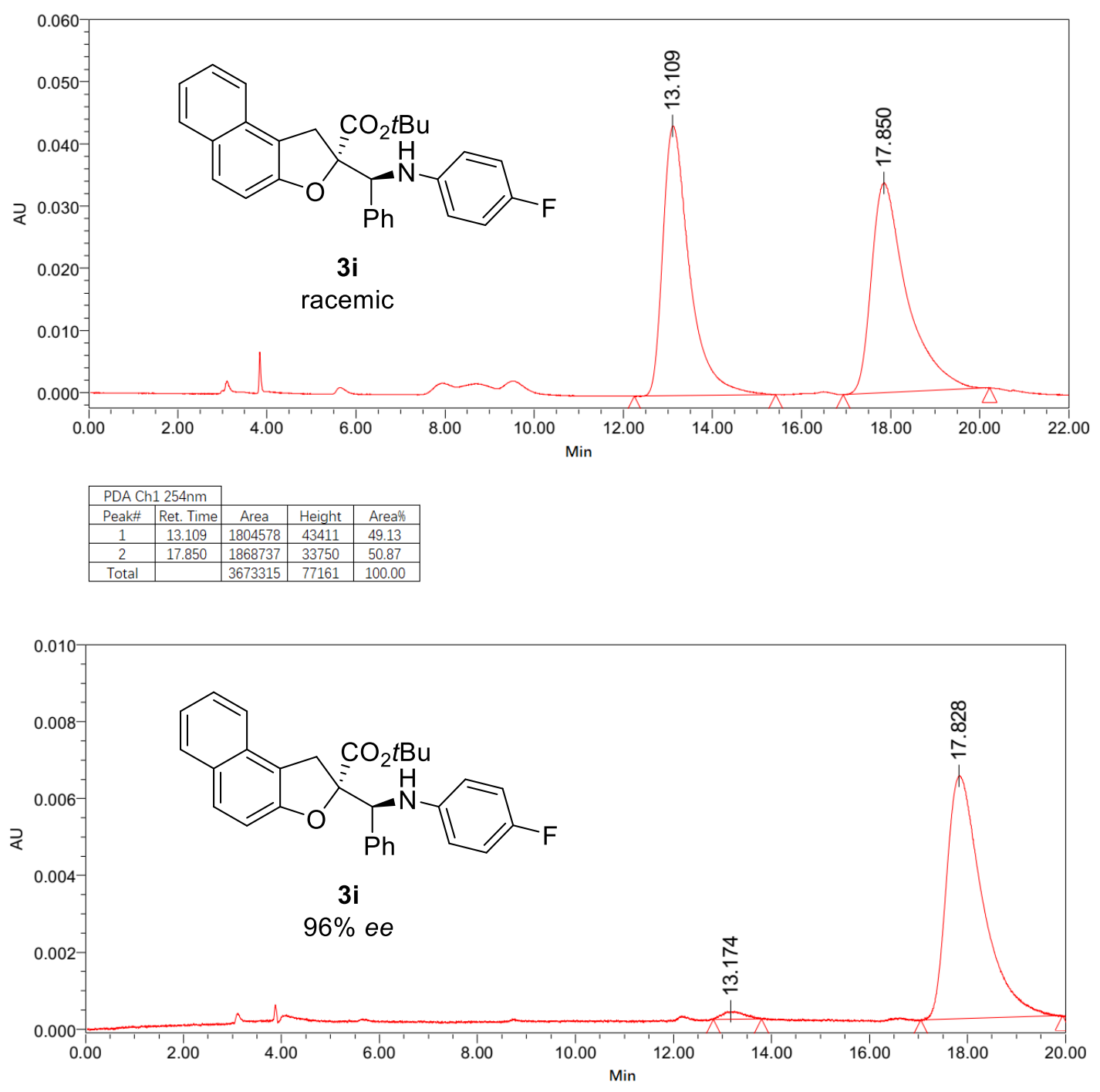

\begin{tabular}{|c|c|c|c|c|}
\hline \multicolumn{3}{|c|}{ PDA Ch1 254nm } & \multicolumn{3}{l|}{} \\
\cline { 1 - 2 } Peak\# & Ret. Time & Area & Height & Area\% \\
\hline 1 & 13.174 & 6240 & 201 & 1.89 \\
\hline 2 & 17.828 & 323316 & 6327 & 98.11 \\
\hline Total & & 329556 & 6528 & 100.00 \\
\hline
\end{tabular}


Condition: hexane $:$-propanol $=99: 1$

Flow rate $=1.0 \mathrm{~mL} / \mathrm{min}, \lambda=254 \mathrm{~nm}$, Daicel Chiralpak IA

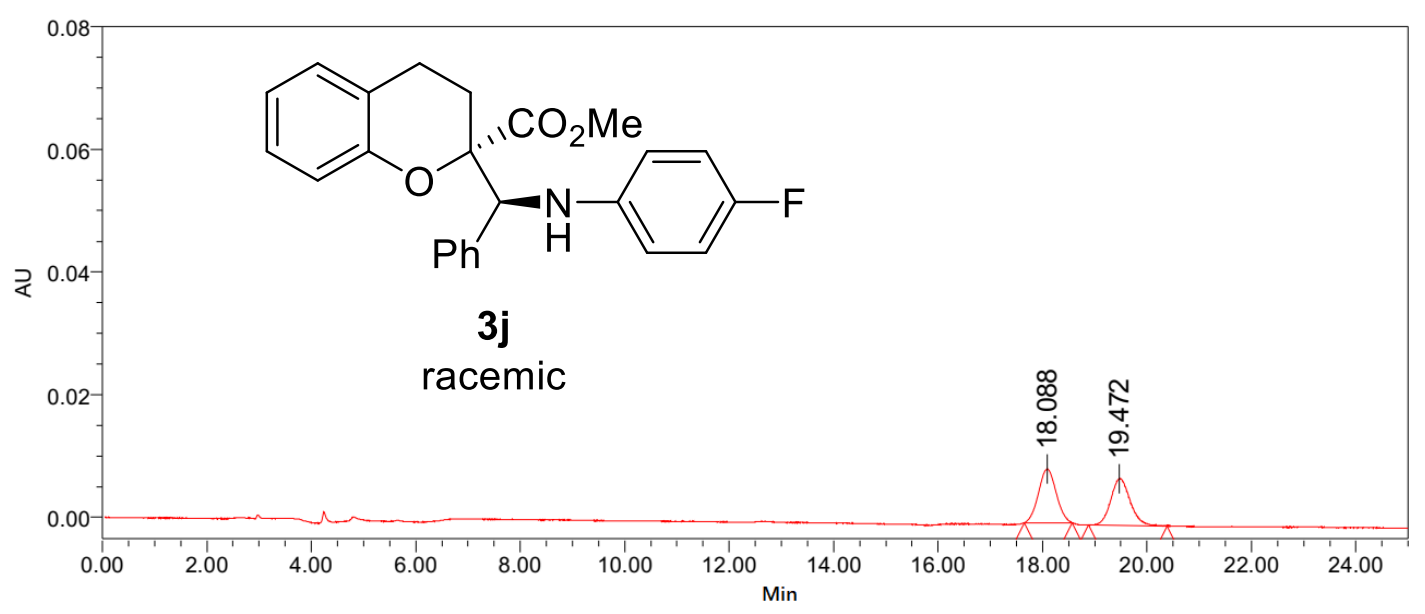

\begin{tabular}{|c|c|c|c|c|}
\hline \multicolumn{3}{|c|}{ PDA Ch1 254nm } & \multicolumn{3}{l|}{} \\
\cline { 1 - 2 } Peak\# & Ret. Time & Area & Height & Area\% \\
\hline 1 & 18.088 & 205339 & 8773 & 50.96 \\
\hline 2 & 19.002 & 197578 & 7661 & 49.04 \\
\hline Total & & 402917 & 16434 & 100.00 \\
\hline
\end{tabular}

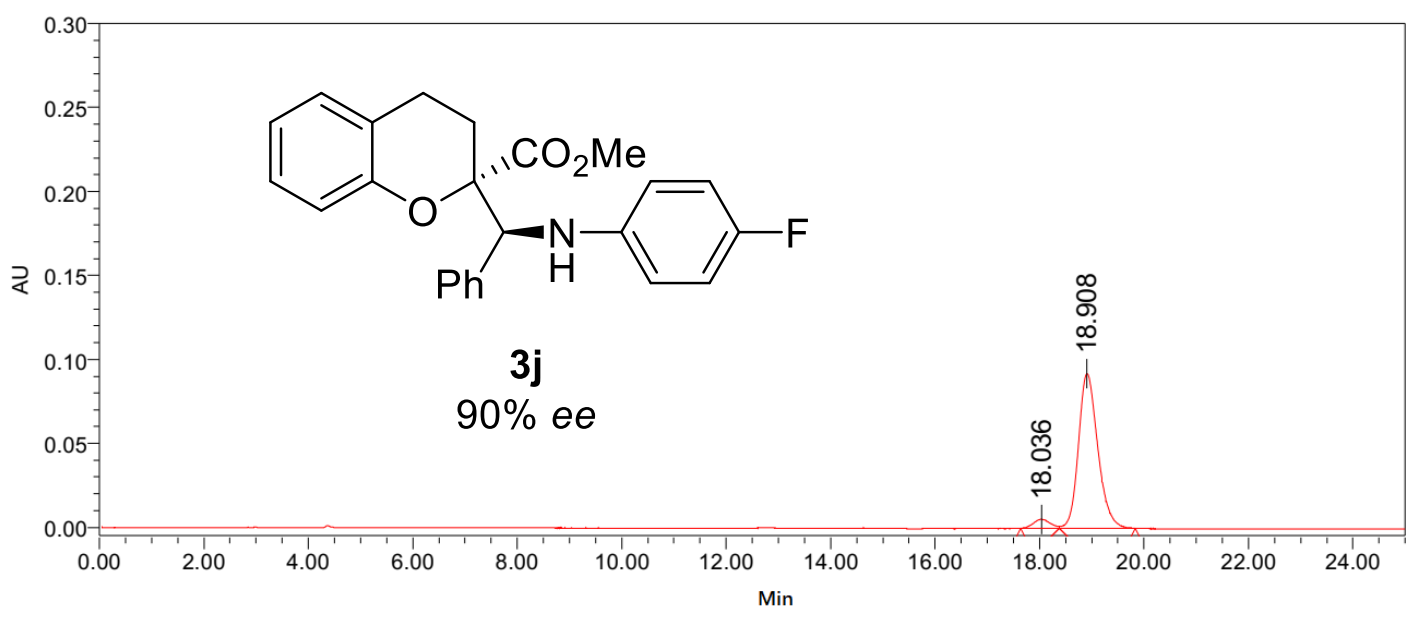

\begin{tabular}{|c|c|c|c|c|}
\hline \multicolumn{3}{|c|}{ PDA Ch1 254nm } & \multicolumn{1}{l|}{} \\
\cline { 1 - 2 } Peak\# & Ret. Time & Area & Height & Area\% \\
\hline 1 & 18.036 & 121489 & 5385 & 4.89 \\
\hline 2 & 18.908 & 2363239 & 92200 & 95.11 \\
\hline Total & & 2484728 & 97585 & 100.00 \\
\hline
\end{tabular}


Condition: hexane $:$-propanol $=99: 1$

Flow rate $=1.0 \mathrm{~mL} / \mathrm{min}, \lambda=254 \mathrm{~nm}$, Daicel Chiralpak IA
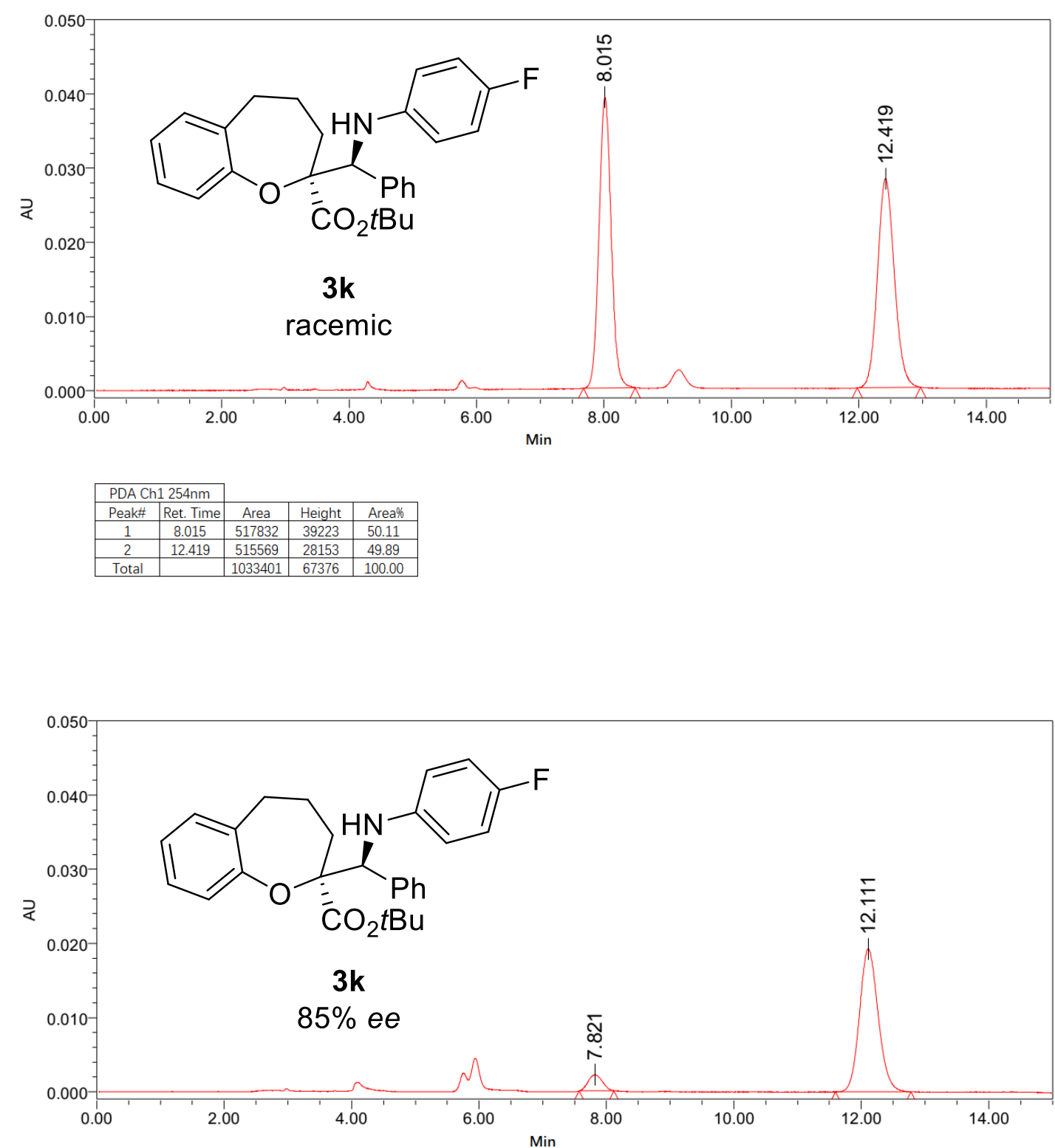

\begin{tabular}{|l|c|c|c|c|}
\hline \multicolumn{2}{|c|}{ PDA Ch1 254nm } & \multicolumn{1}{l}{} \\
\cline { 1 - 2 } Peak\# & Ret. Time & Area & Height & Area\% \\
\hline 1 & 7.821 & 33244 & 2164 & 7.73 \\
\hline 2 & 12.111 & 396608 & 19289 & 92.27 \\
\hline Total & & 429852 & 21453 & 100.00 \\
\hline
\end{tabular}


Condition: hexane $:$-propanol $=95: 5$

Flow rate $=1.0 \mathrm{~mL} / \mathrm{min}, \lambda=254 \mathrm{~nm}$, Daicel Chiralpak IC
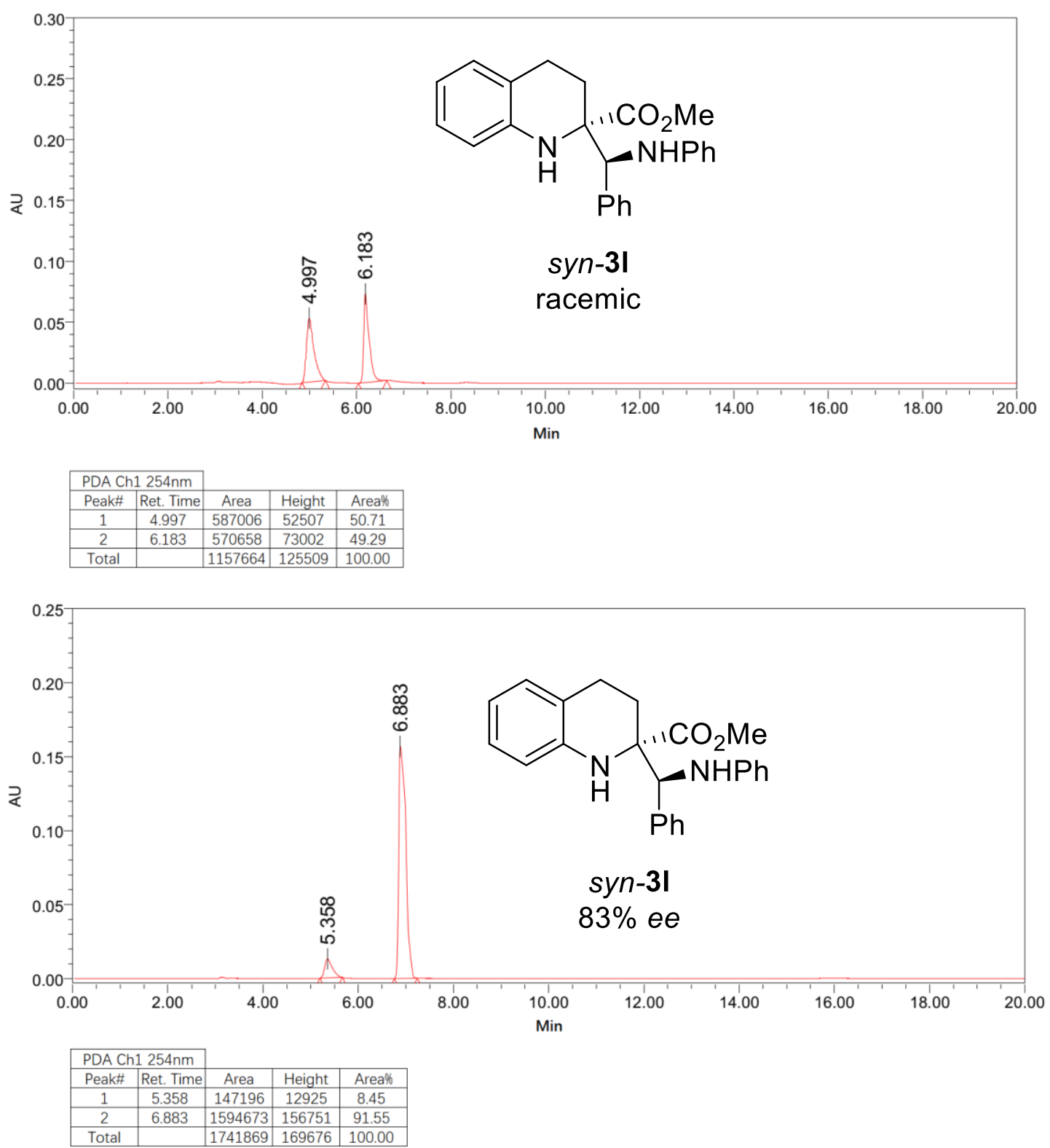
Condition: hexane $: 2$-propanol $=95: 5$

Flow rate $=1.0 \mathrm{~mL} / \mathrm{min}, \lambda=254 \mathrm{~nm}$, Daicel Chiralpak AD-H

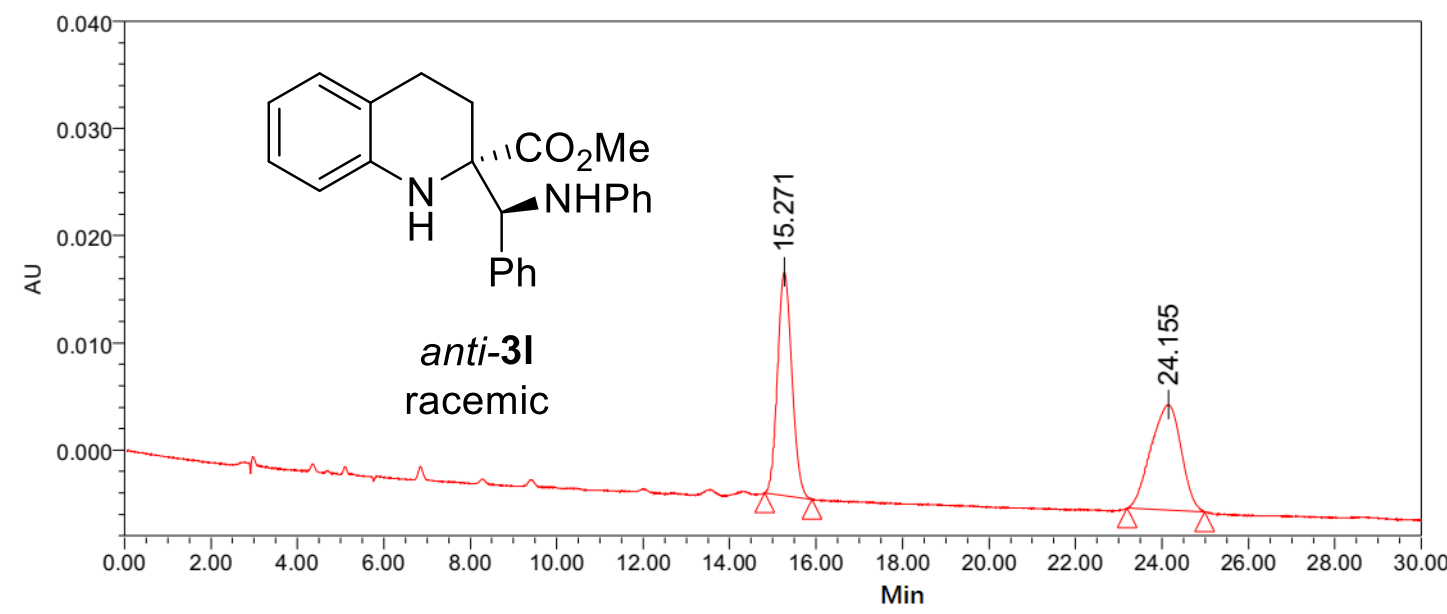

\begin{tabular}{|c|c|c|c|c|}
\hline \multicolumn{3}{|c|}{ PDA Ch1 254nm } & \multicolumn{3}{l|}{} \\
\cline { 1 - 2 } Peak\# & Ret. Time & Area & Height & Area\% \\
\hline 1 & 15.271 & 478945 & 20859 & 50.09 \\
\hline 2 & 24.155 & 477314 & 9839 & 49.91 \\
\hline Total & & 956259 & 30698 & 100.00 \\
\hline
\end{tabular}

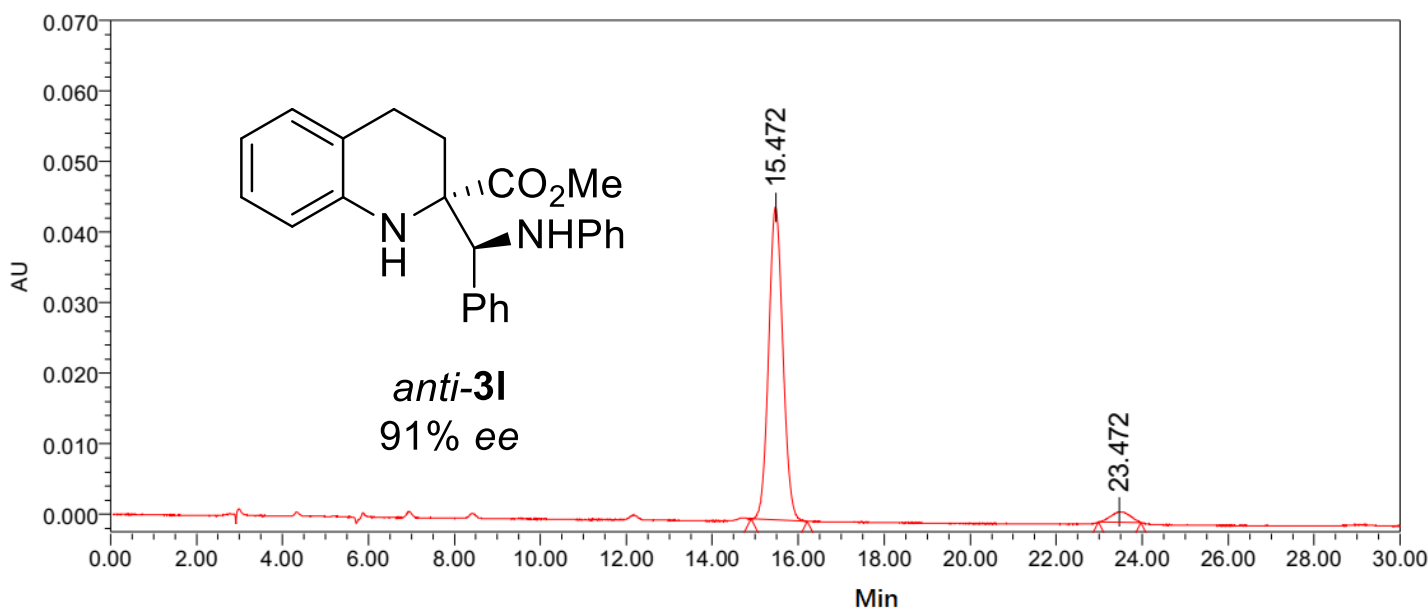

\begin{tabular}{|c|c|c|c|c|}
\hline \multicolumn{2}{|c|}{ PDA Ch1 254nm } & \multicolumn{3}{l|}{} \\
\cline { 1 - 2 } Peak\# & Ret. Time & Area & Height & Area\% \\
\hline 1 & 15.472 & 1009266 & 44329 & 95.56 \\
\hline 2 & 23.472 & 46901 & 1484 & 4.44 \\
\hline Total & & 1056167 & 45813 & 100.00 \\
\hline
\end{tabular}


Condition: hexane $: 2$-propanol $=95: 5$

Flow rate $=1.0 \mathrm{~mL} / \mathrm{min}, \lambda=254 \mathrm{~nm}$, Daicel Chiralpak IF-3

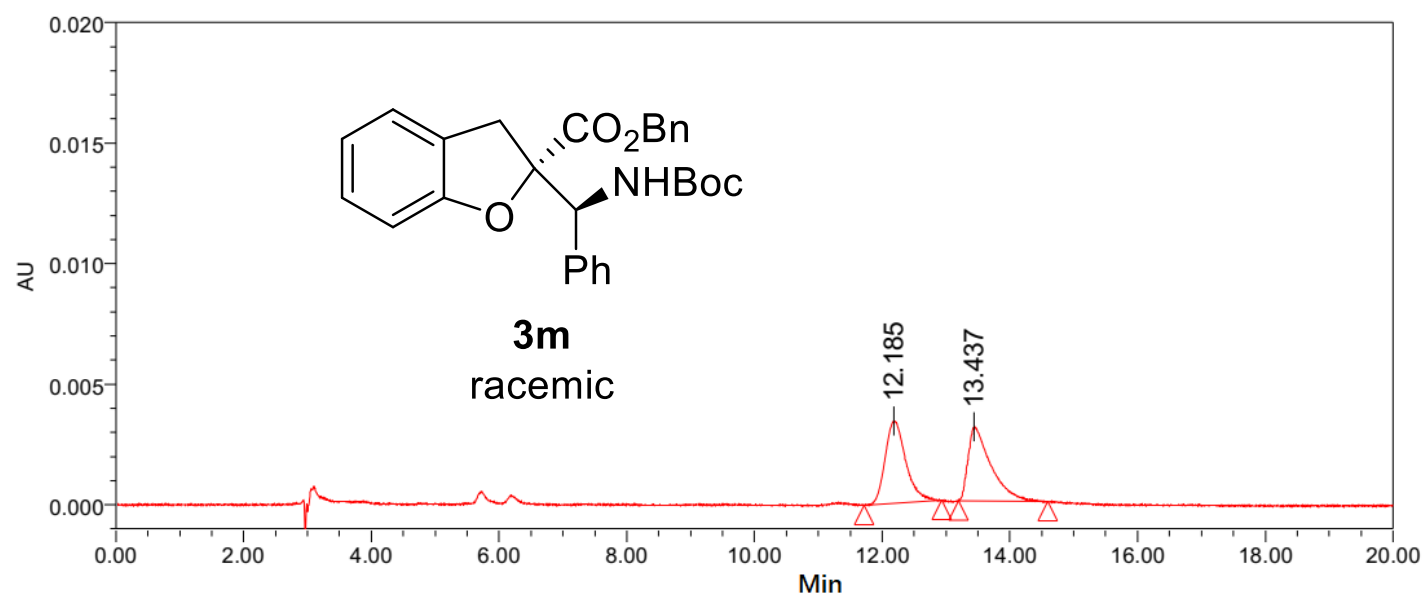

\begin{tabular}{|c|c|c|c|c|}
\hline \multicolumn{2}{|c|}{ PDA Ch1 254nm } & \multicolumn{5}{l|}{} \\
\cline { 1 - 2 } Peak\# & Ret. Time & Area & Height & Area\% \\
\hline 1 & 12.185 & 76961 & 3433 & 50.44 \\
\hline 2 & 13.437 & 75630 & 3064 & 49.56 \\
\hline Total & & 152591 & 6497 & 100.00 \\
\hline
\end{tabular}

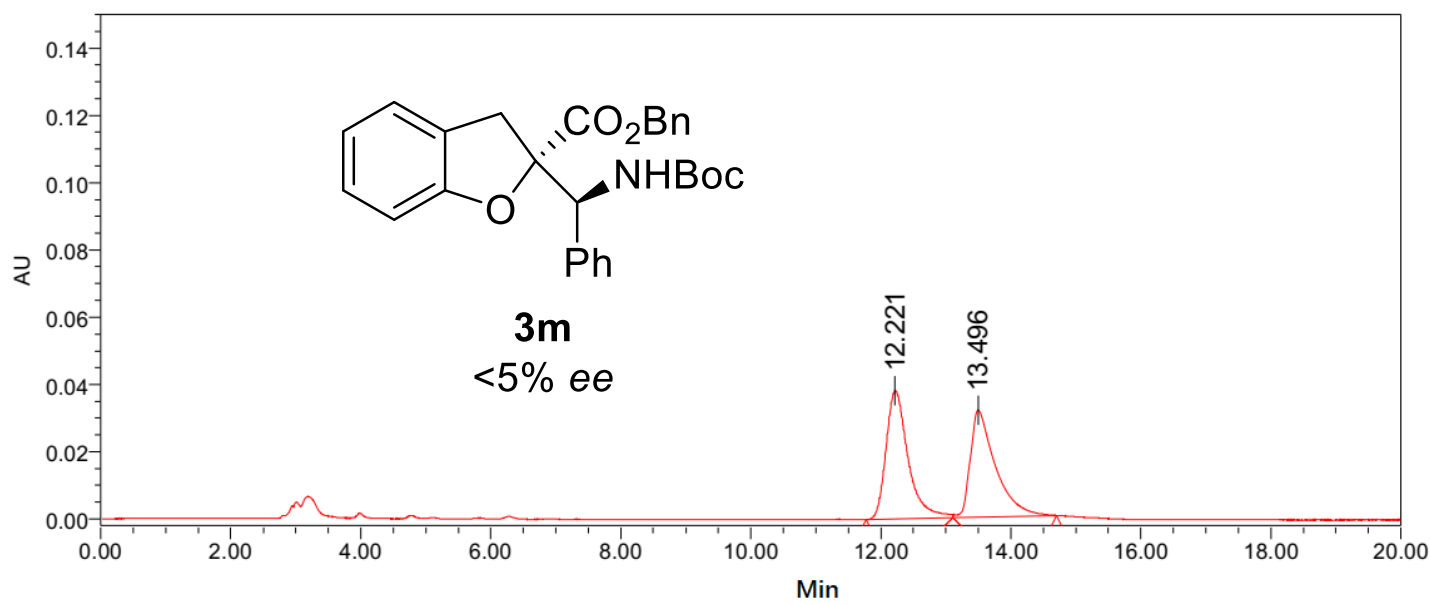

\begin{tabular}{|c|c|c|c|c|}
\hline \multicolumn{3}{|l|}{ PDA Ch1 254nm } & \multicolumn{1}{l}{} \\
\cline { 1 - 2 } Peak\# & Ret. Time & Area & Height & Area\% \\
\hline 1 & 12.221 & 904382 & 38192 & 51.50 \\
\hline 2 & 13.496 & 851640 & 31829 & 48.50 \\
\hline Total & & 1756022 & 70021 & 100.00 \\
\hline
\end{tabular}


Condition: hexane $: 2$-propanol $=95: 5$

Flow rate $=1.0 \mathrm{~mL} / \mathrm{min}, \lambda=254 \mathrm{~nm}$, Daicel Chiralpak AD-H

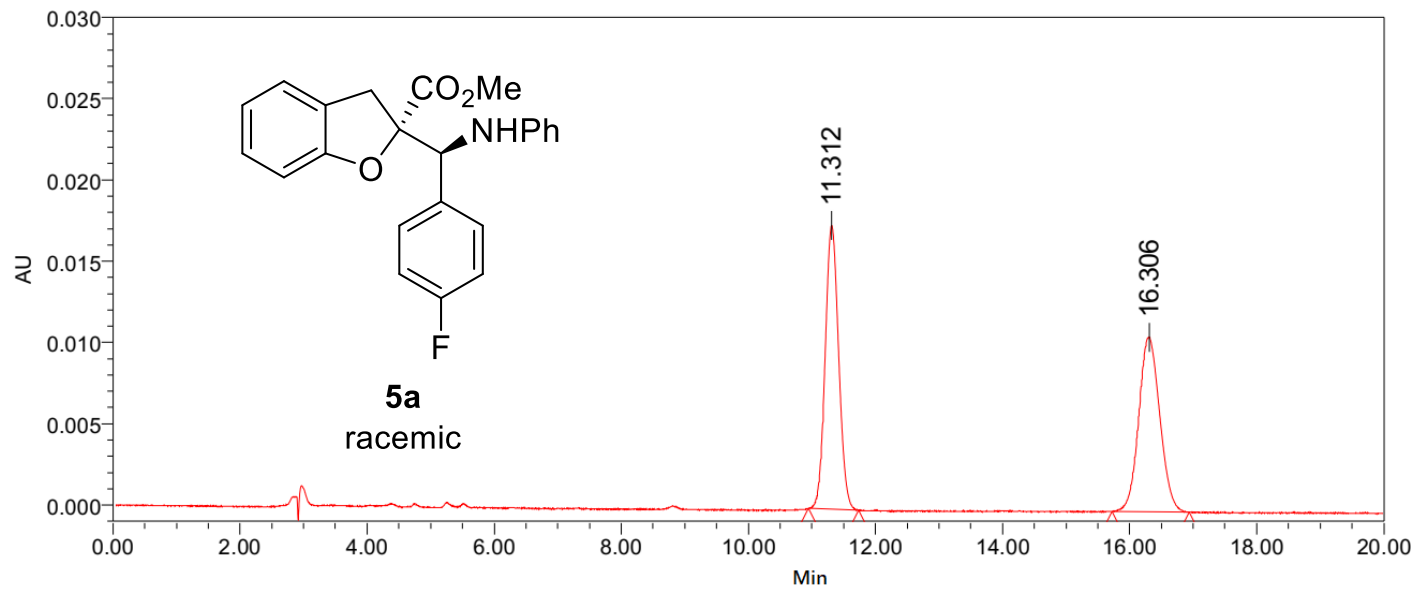

\begin{tabular}{|c|c|c|c|c|}
\hline \multicolumn{2}{|c|}{ PDA Ch1 254nm } & & & \\
\hline Peak\# & Ret. Tim & Area & Height & Area\% \\
\hline 1 & 11.312 & 254050 & 17450 & 50.46 \\
\hline 2 & 16.306 & 249442 & 10752 & 49.54 \\
\hline Total & & 503492 & 28202 & 100.00 \\
\hline
\end{tabular}

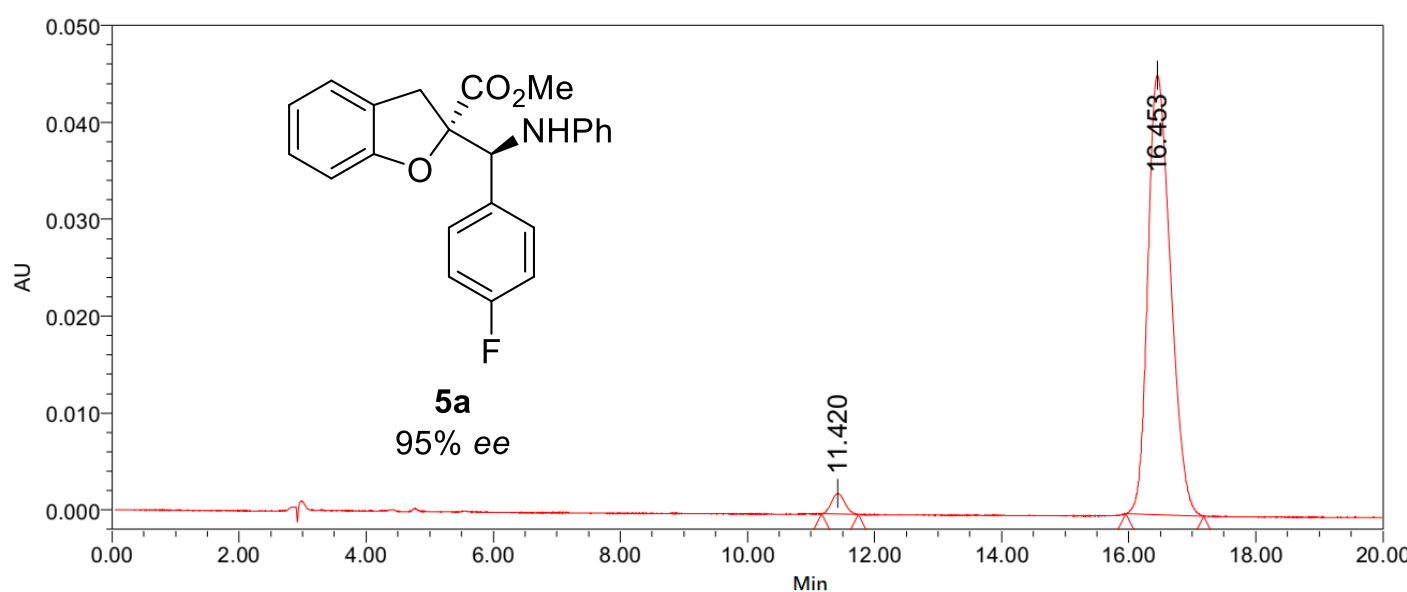

\begin{tabular}{|c|c|c|c|c|}
\hline \multicolumn{2}{|c|}{ PDA Ch1 254nm } & \multirow[b]{2}{*}{ Area } & \multirow[b]{2}{*}{ Height } & \multirow[b]{2}{*}{ Area\% } \\
\hline Peak\# & Ret. Time & & & \\
\hline 1 & 11.420 & 30921 & 2132 & 2.70 \\
\hline 2 & 16.453 & 1116332 & 45340 & 97.30 \\
\hline Total & & 1147253 & 47472 & 100.00 \\
\hline
\end{tabular}




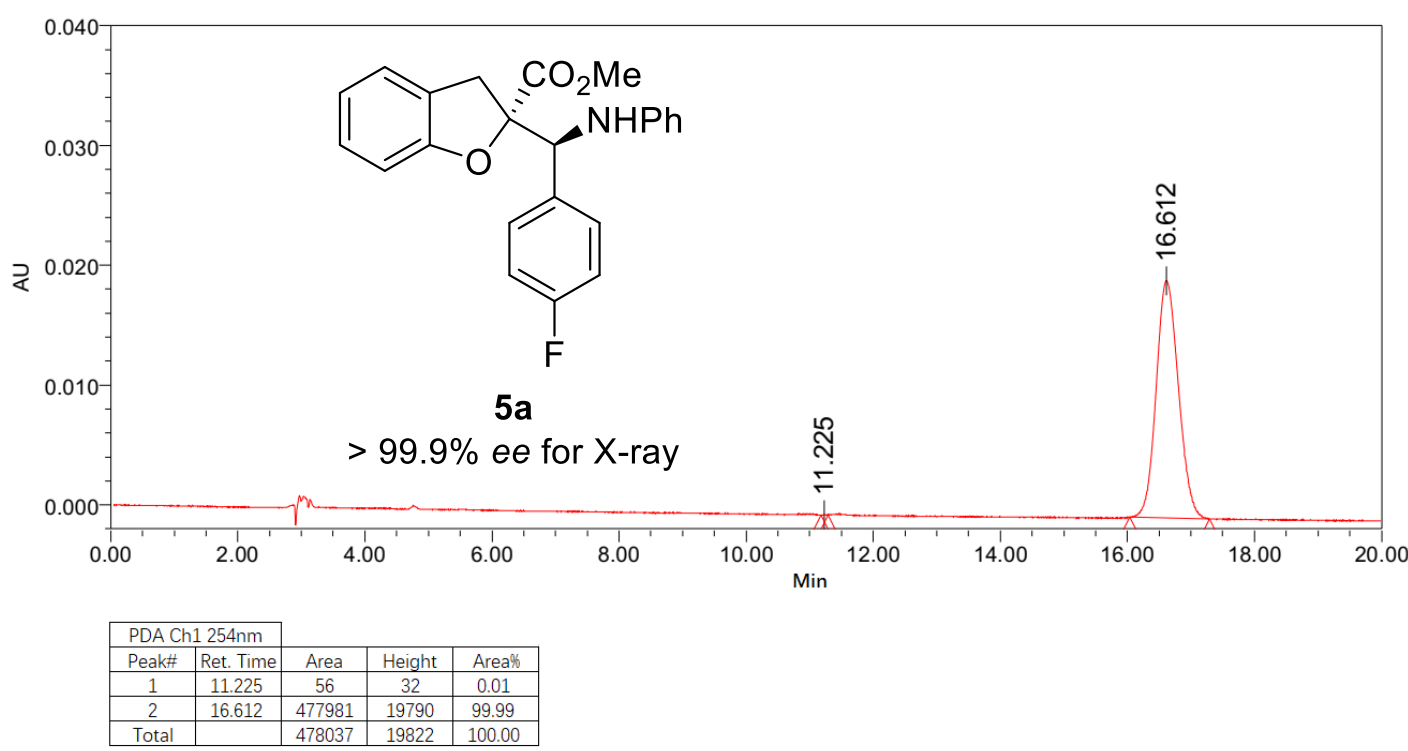


Condition: hexane : 2-propanol $=90: 10$

Flow rate $=1.0 \mathrm{~mL} / \mathrm{min}, \lambda=254 \mathrm{~nm}$, Daicel Chiralpak AD-H
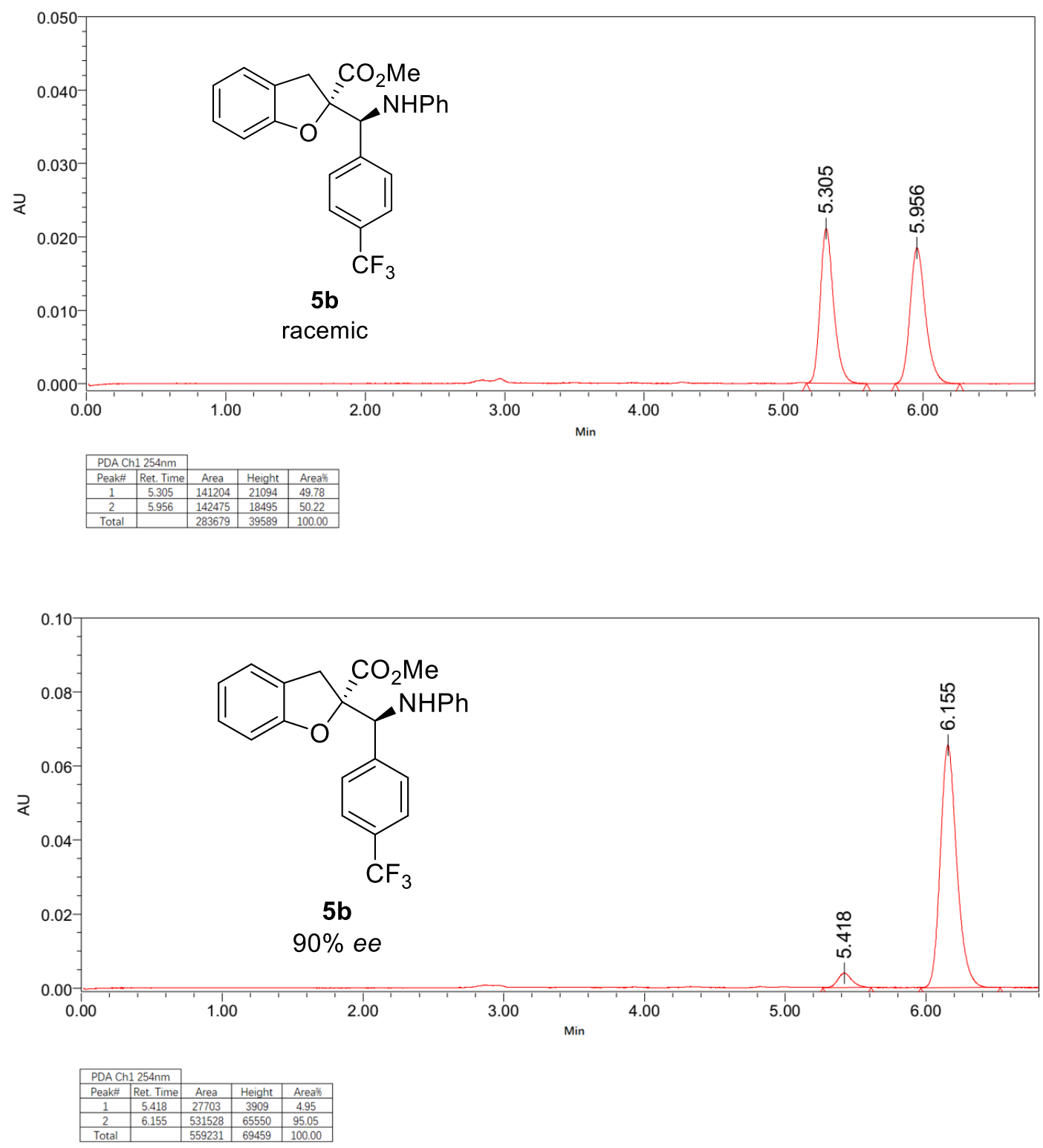
Condition: hexane $:$-propanol $=99: 1$

Flow rate $=1.0 \mathrm{~mL} / \mathrm{min}, \lambda=254 \mathrm{~nm}$, Daicel Chiralpak IE-3
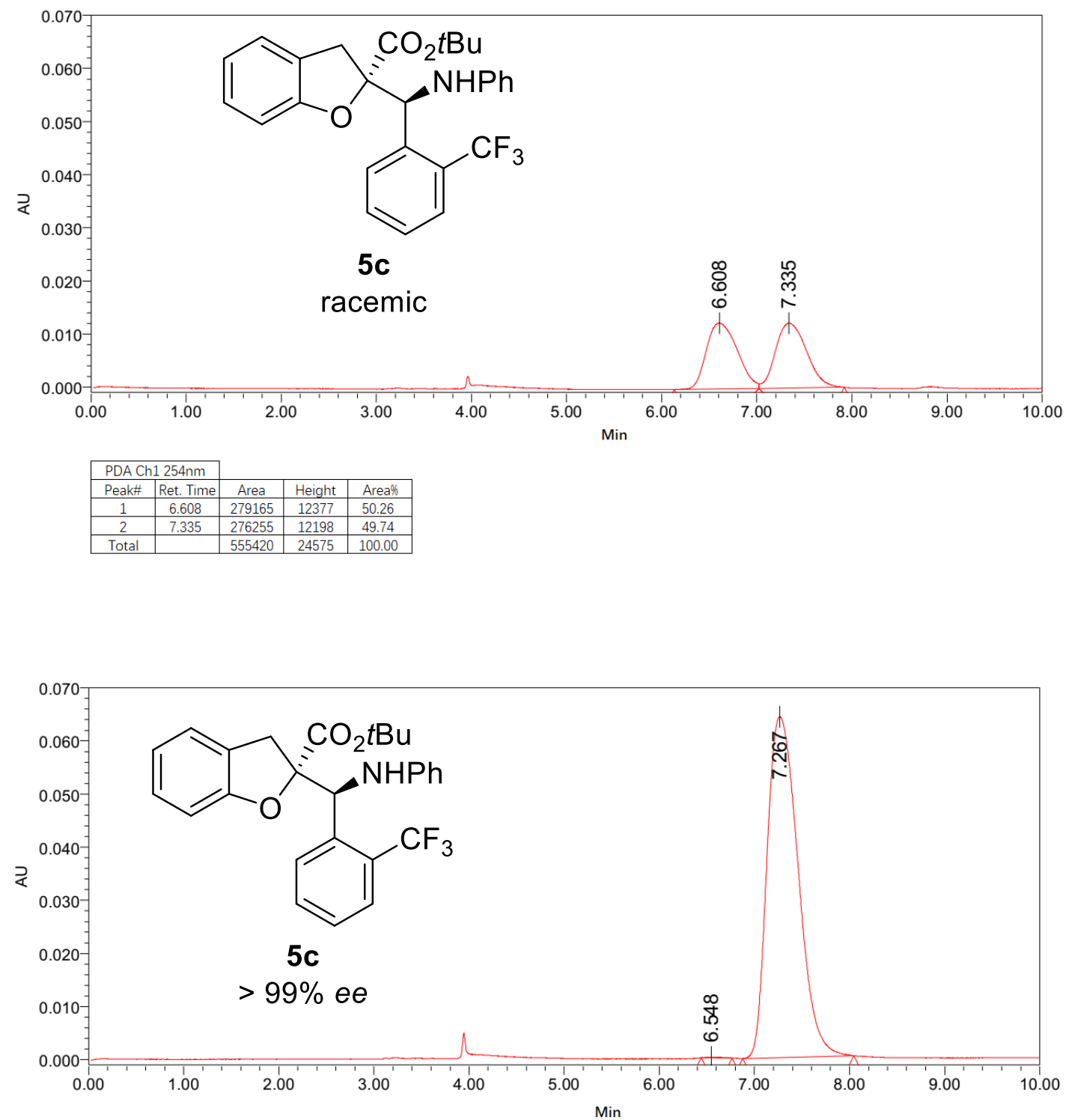

\begin{tabular}{|c|c|c|c|c|}
\hline \multicolumn{2}{|c|}{ PDA Ch1 254nm } & & & \\
\hline Peak\# & Ret. Time & Area & Height & Area\% \\
\hline 1 & \begin{tabular}{|l|}
6.548 \\
\end{tabular} & 1637 & 139 & 0.11 \\
\hline 2 & 7.267 & 1447172 & 64141 & 99.89 \\
\hline Total & & 1448809 & 64280 & 100.00 \\
\hline
\end{tabular}


Condition: hexane $:$-propanol $=99: 1$

Flow rate $=1.0 \mathrm{~mL} / \mathrm{min}, \lambda=254 \mathrm{~nm}$, Daicel Chiralpak IE-3

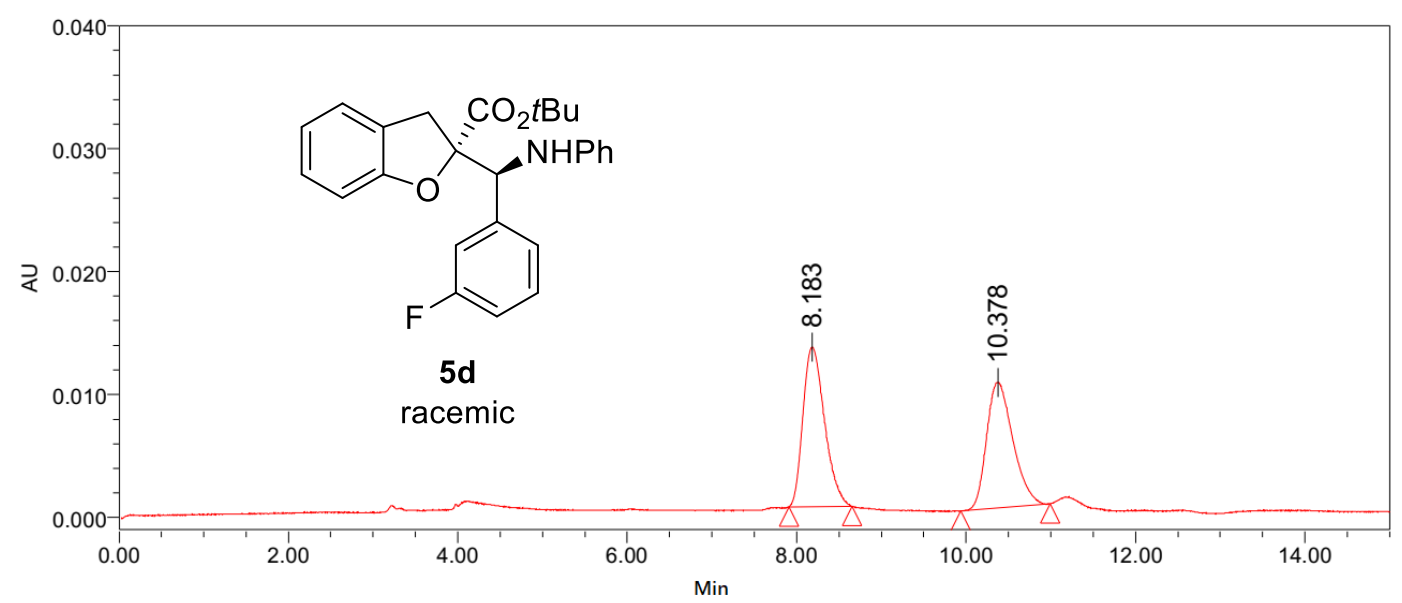

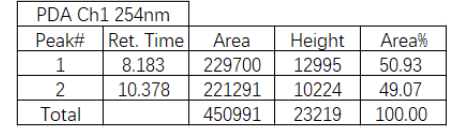

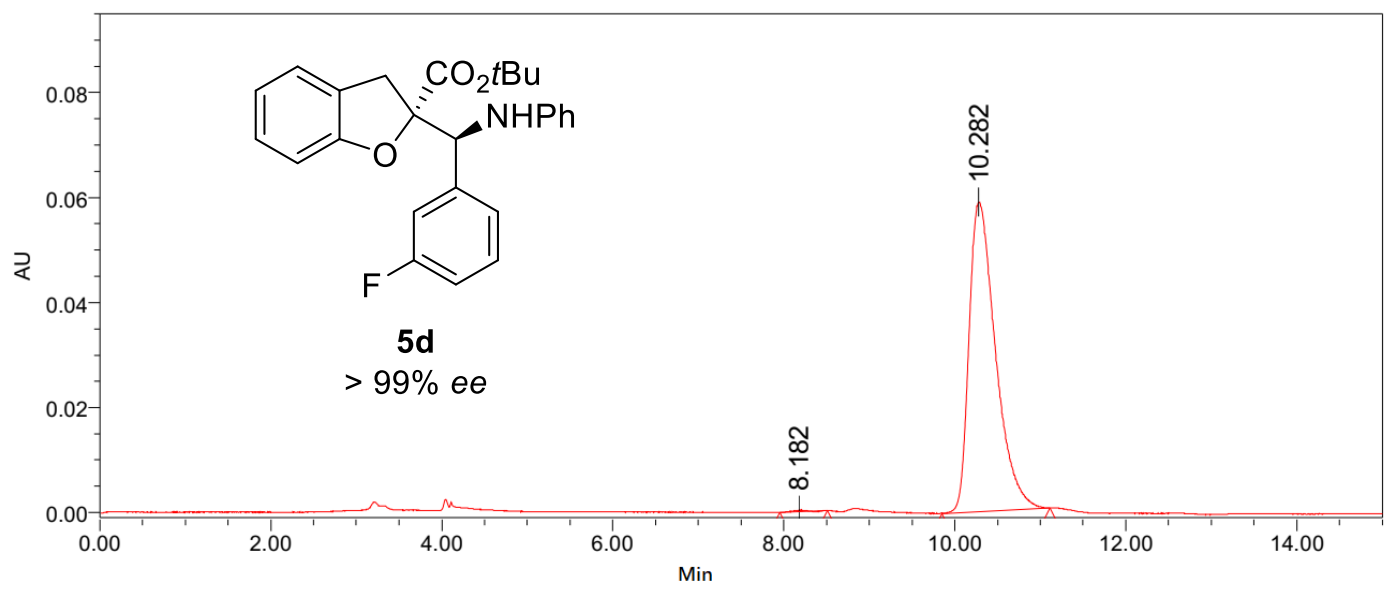

\begin{tabular}{|l|c|c|c|c|}
\hline \multicolumn{2}{|c|}{ PDA Ch1 254nm } & \multicolumn{1}{l}{} \\
\cline { 1 - 2 } Peak\# & Ret. Time & Area & Height & Area\% \\
\hline 1 & 8.182 & 3496 & 271 & 0.27 \\
\hline 2 & 10.282 & 1268952 & 58983 & 99.73 \\
\hline Total & & 1272448 & 59254 & 100.00 \\
\hline
\end{tabular}


Condition: hexane $:$-propanol $=99: 1$

Flow rate $=1.0 \mathrm{~mL} / \mathrm{min}, \lambda=290 \mathrm{~nm}$, Daicel Chiralpak IE-3
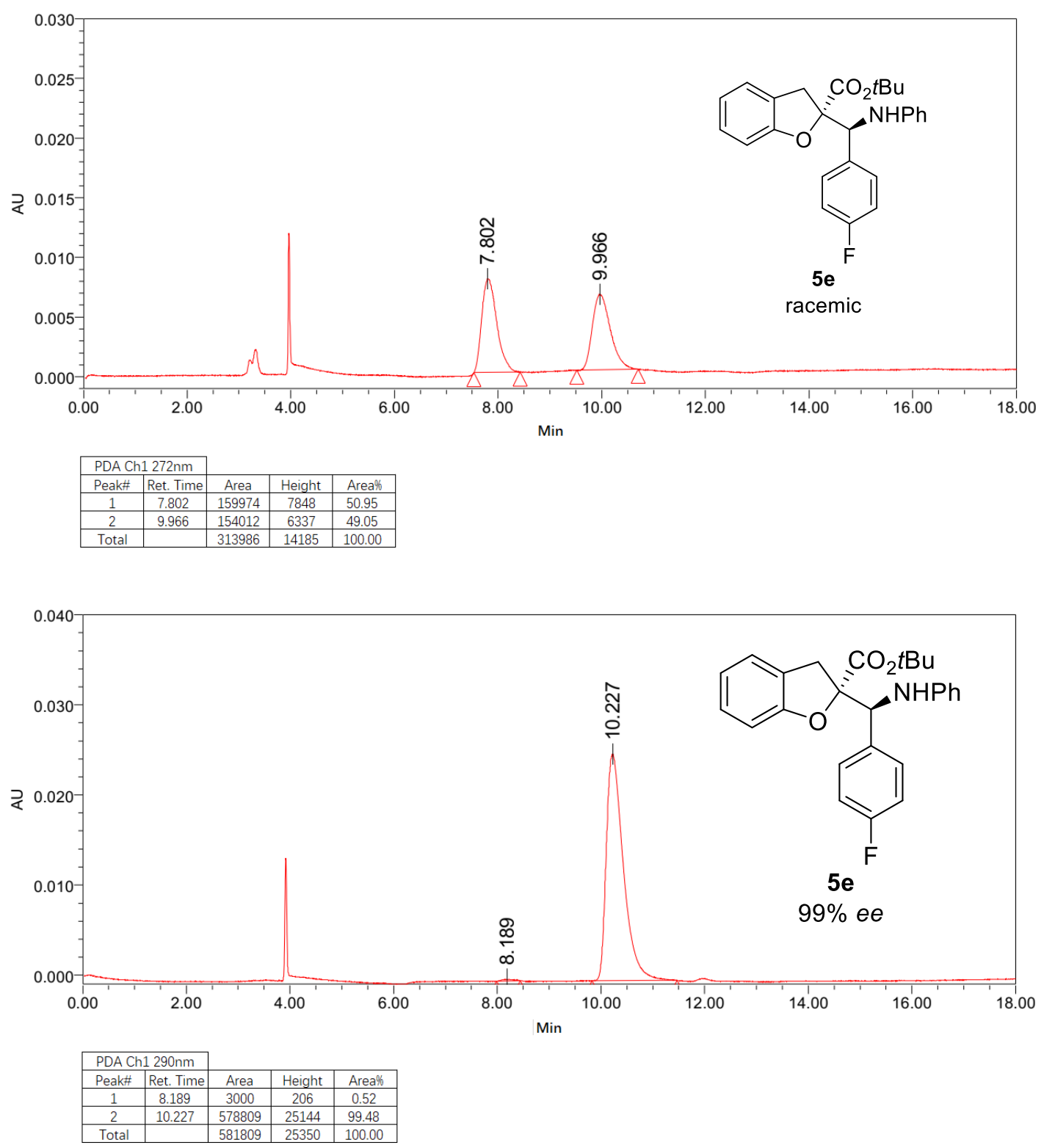
Condition: hexane $: 2$-propanol $=99: 1$

Flow rate $=1.0 \mathrm{~mL} / \mathrm{min}, \lambda=254 \mathrm{~nm}$, Daicel Chiralpak IE-3

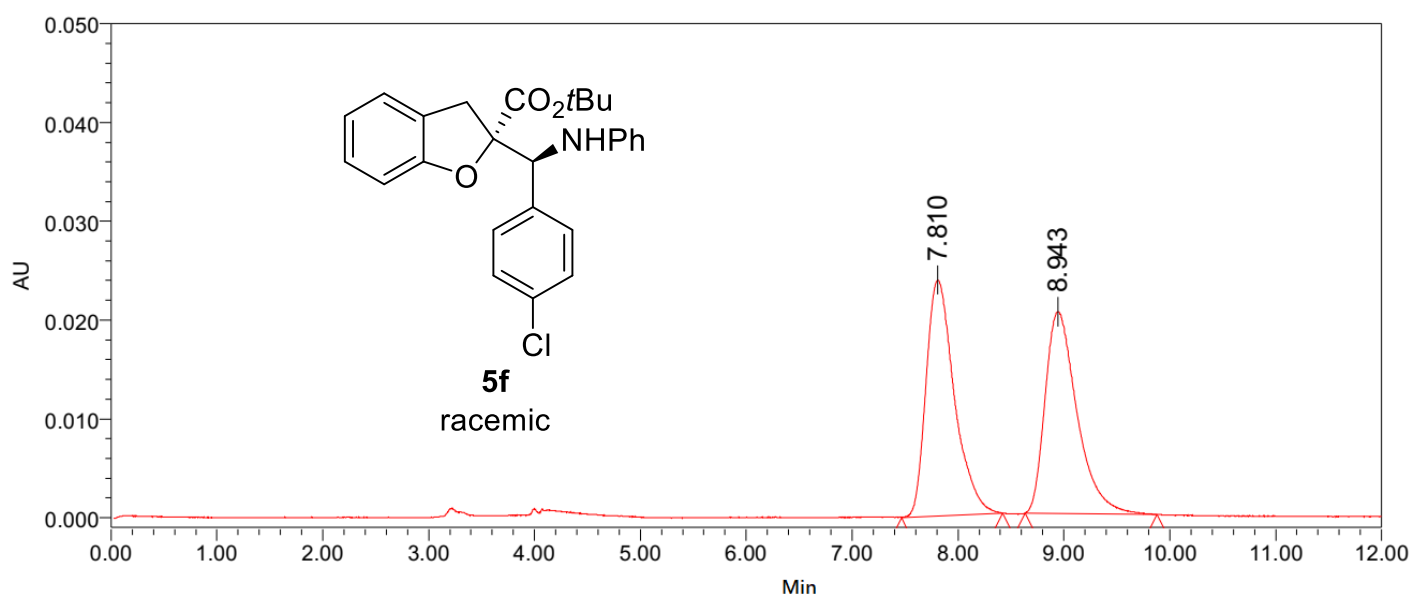

\begin{tabular}{|c|c|c|c|c|}
\hline \multicolumn{2}{|c|}{ PDA Ch1 254nm } & \multicolumn{1}{c|}{} \\
\cline { 1 - 2 } Peak\# & Ret. Time & Area & Height & Area\% \\
\hline 1 & 7.810 & 442521 & 23862 & 50.74 \\
\hline 2 & 8.943 & 429608 & 20402 & 49.26 \\
\hline Total & & 872129 & 44264 & 100.00 \\
\cline { 1 - 1 }
\end{tabular}

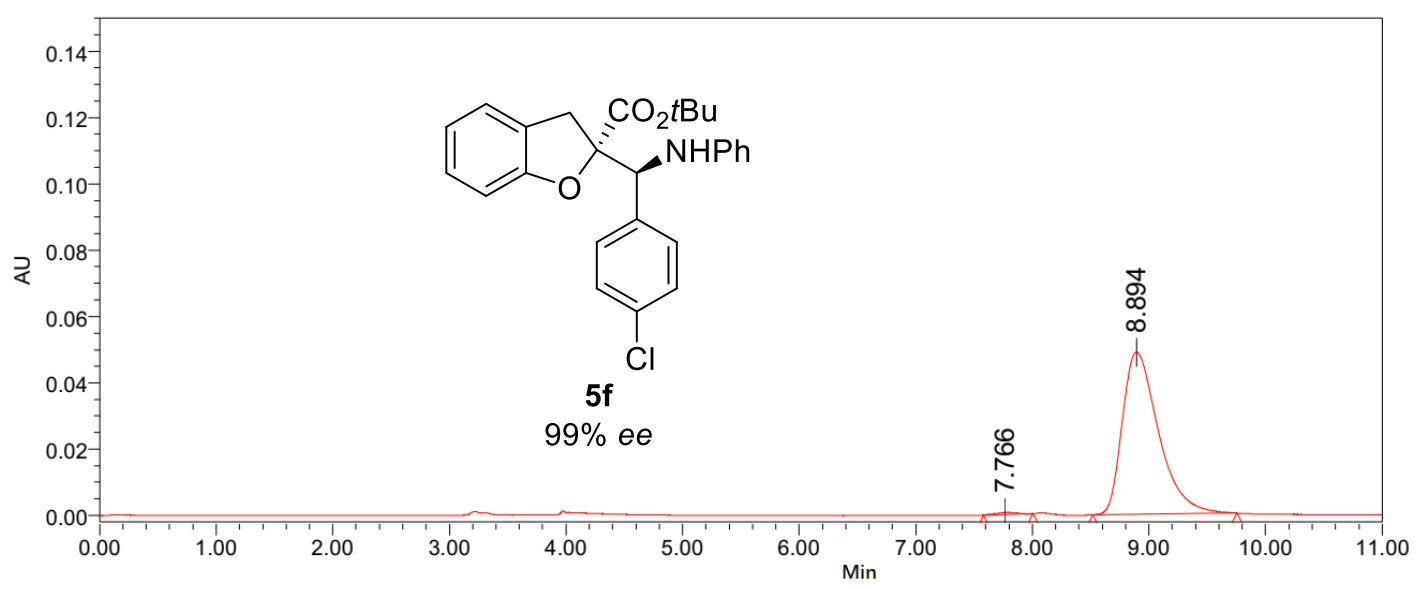

\begin{tabular}{|c|c|c|c|c|}
\hline \multicolumn{2}{|c|}{ PDA Ch1 254nm } & & & \\
\hline Peak\# & Ret. Time & Area & Height & Area\% \\
\hline 1 & 7.766 & 7217 & 576 & 0.68 \\
\hline 2 & 8.894 & 1053325 & 48930 & 99.32 \\
\hline Total & & 1060542 & 49506 & 100.00 \\
\hline
\end{tabular}


Condition: hexane $:$-propanol $=99: 1$

Flow rate $=1.0 \mathrm{~mL} / \mathrm{min}, \lambda=254 \mathrm{~nm}$, Daicel Chiralpak IE-3
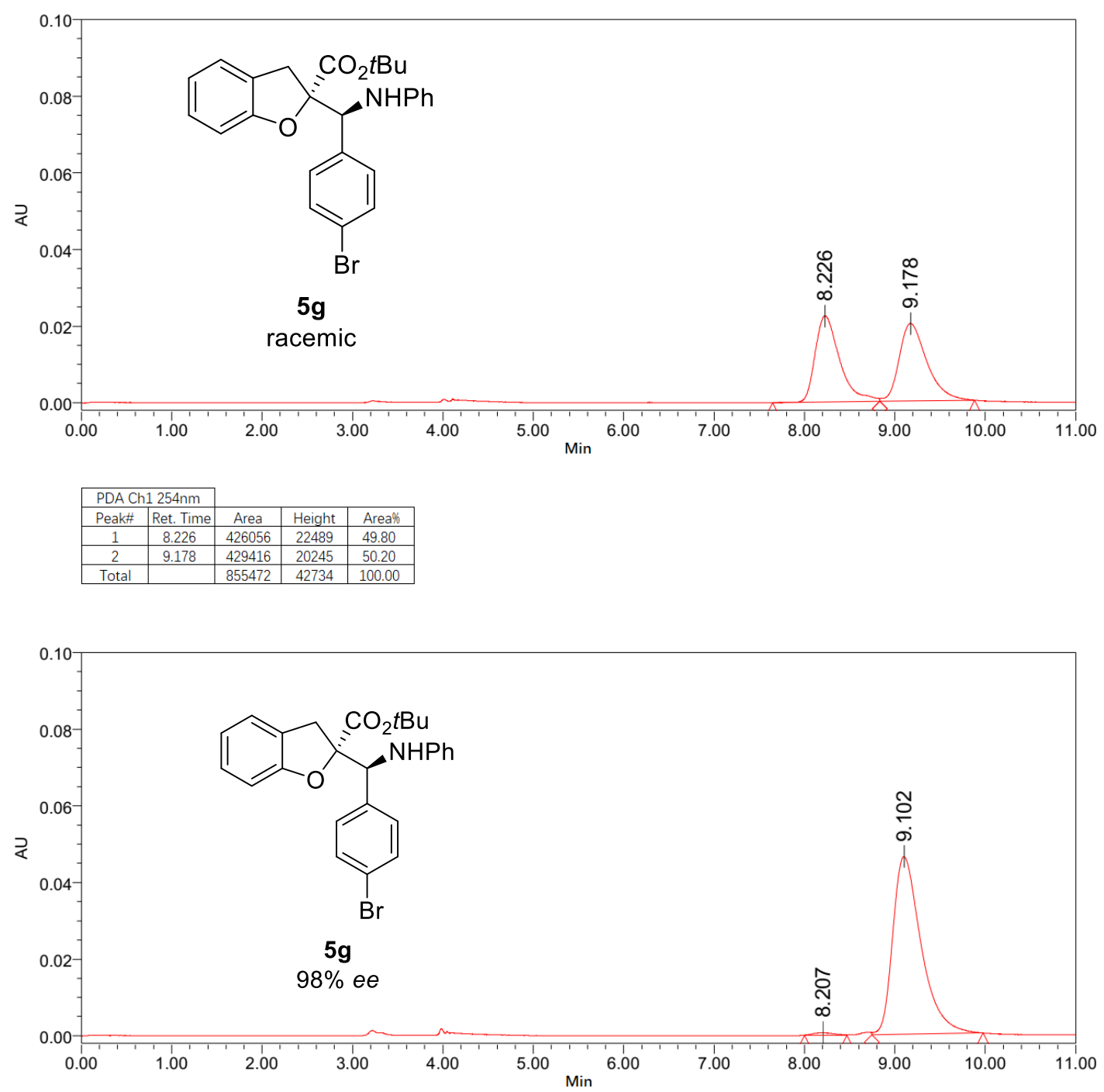

\begin{tabular}{|c|c|c|c|c|}
\hline \multicolumn{2}{|c|}{ PDA Ch1 254nm } & & & \\
\hline Peak\# & Ret. Time & Area & Height & Area\% \\
\hline 1 & 8.207 & 9531 & 633 & 0.94 \\
\hline 2 & 9.102 & 1008631 & 46340 & 99.06 \\
\hline Total & & 1018162 & 46973 & 100.00 \\
\hline
\end{tabular}


Condition: hexane $:$-propanol $=99: 1$

Flow rate $=1.0 \mathrm{~mL} / \mathrm{min}, \lambda=254 \mathrm{~nm}$, EnantioPak Y1

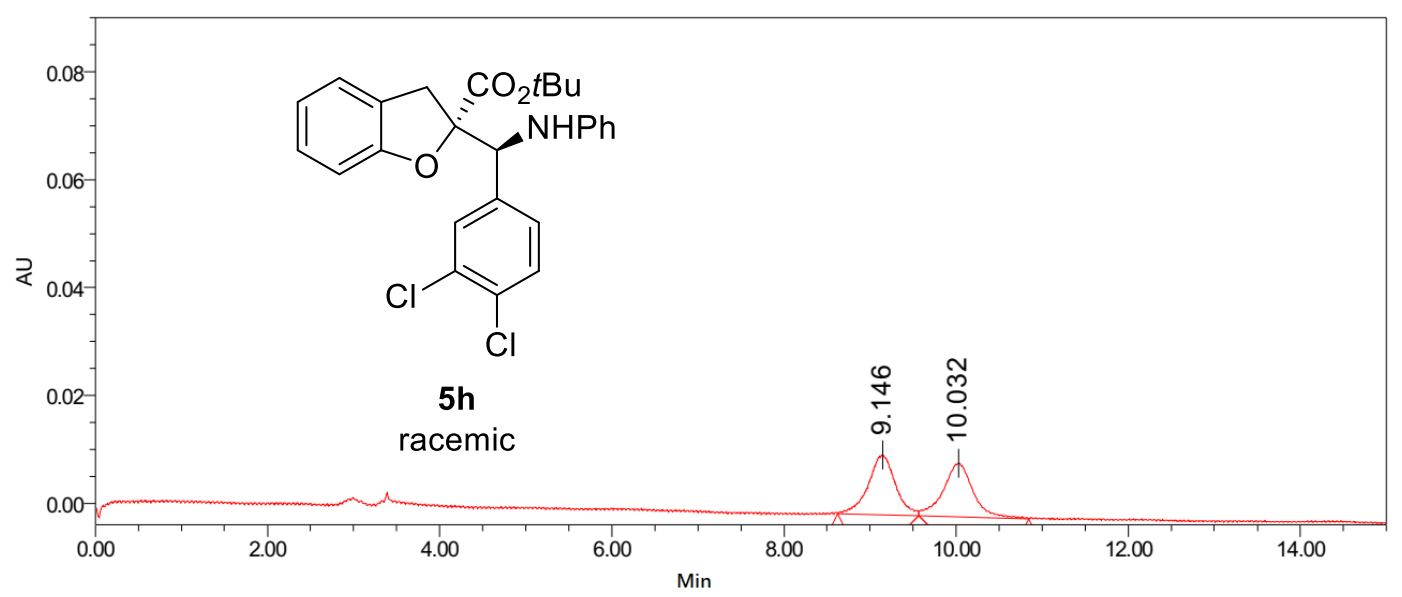

\begin{tabular}{|c|c|c|c|c|}
\hline \multicolumn{2}{|c|}{ PDA Ch1 254nm } & \multicolumn{3}{l|}{} \\
\cline { 1 - 2 } Peak\# & Ret. Time & Area & Height & Area\% \\
\hline 1 & 9.146 & 240432 & 11109 & 50.11 \\
\hline 2 & 10.032 & 239422 & 9946 & 49.89 \\
\hline Total & & 479854 & 21055 & 100.00 \\
\hline
\end{tabular}

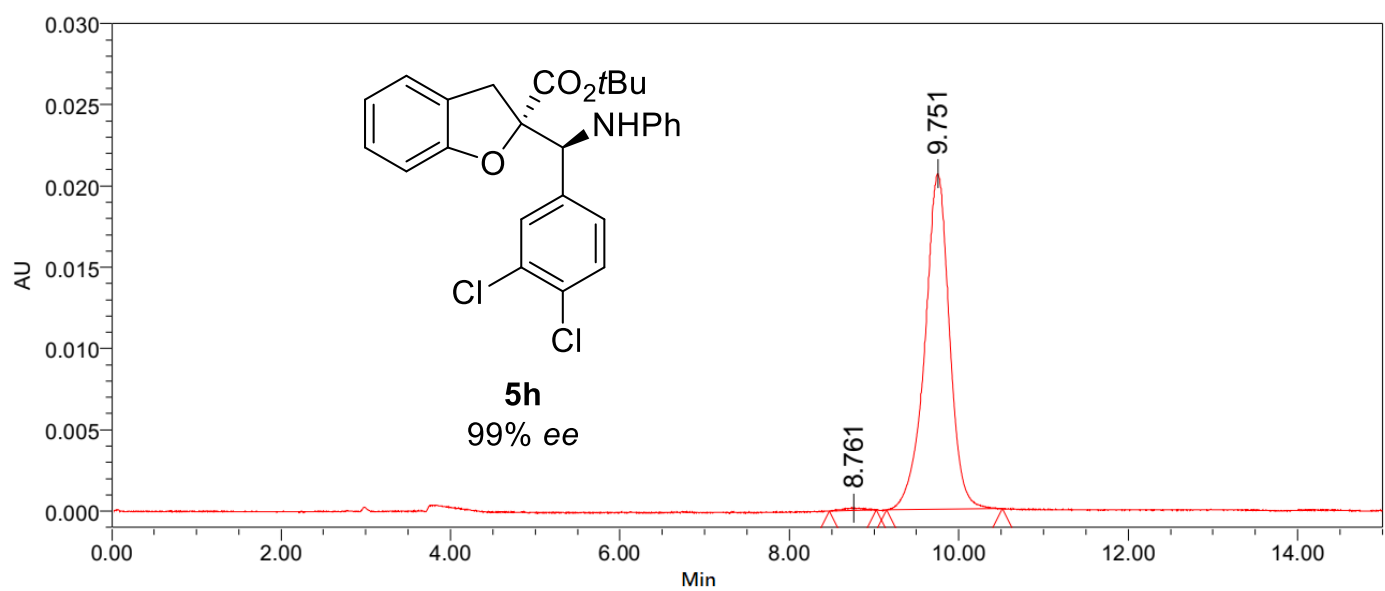

\begin{tabular}{|l|c|c|c|c|}
\hline \multicolumn{2}{|c|}{ PDA Ch1 254nm } & \multicolumn{1}{l|}{} \\
\cline { 1 - 2 } Peak\# & Ret. Time & Area & Height & Area\% \\
\hline 1 & 8.761 & 2305 & 143 & 0.55 \\
\hline 2 & 9.751 & 420267 & 20644 & 99.45 \\
\hline Total & & 422572 & 20787 & 100.00 \\
\hline
\end{tabular}


Condition: hexane $:$-propanol $=95: 5$

Flow rate $=1.0 \mathrm{~mL} / \mathrm{min}, \lambda=254 \mathrm{~nm}$, Daicel Chiralpak IA
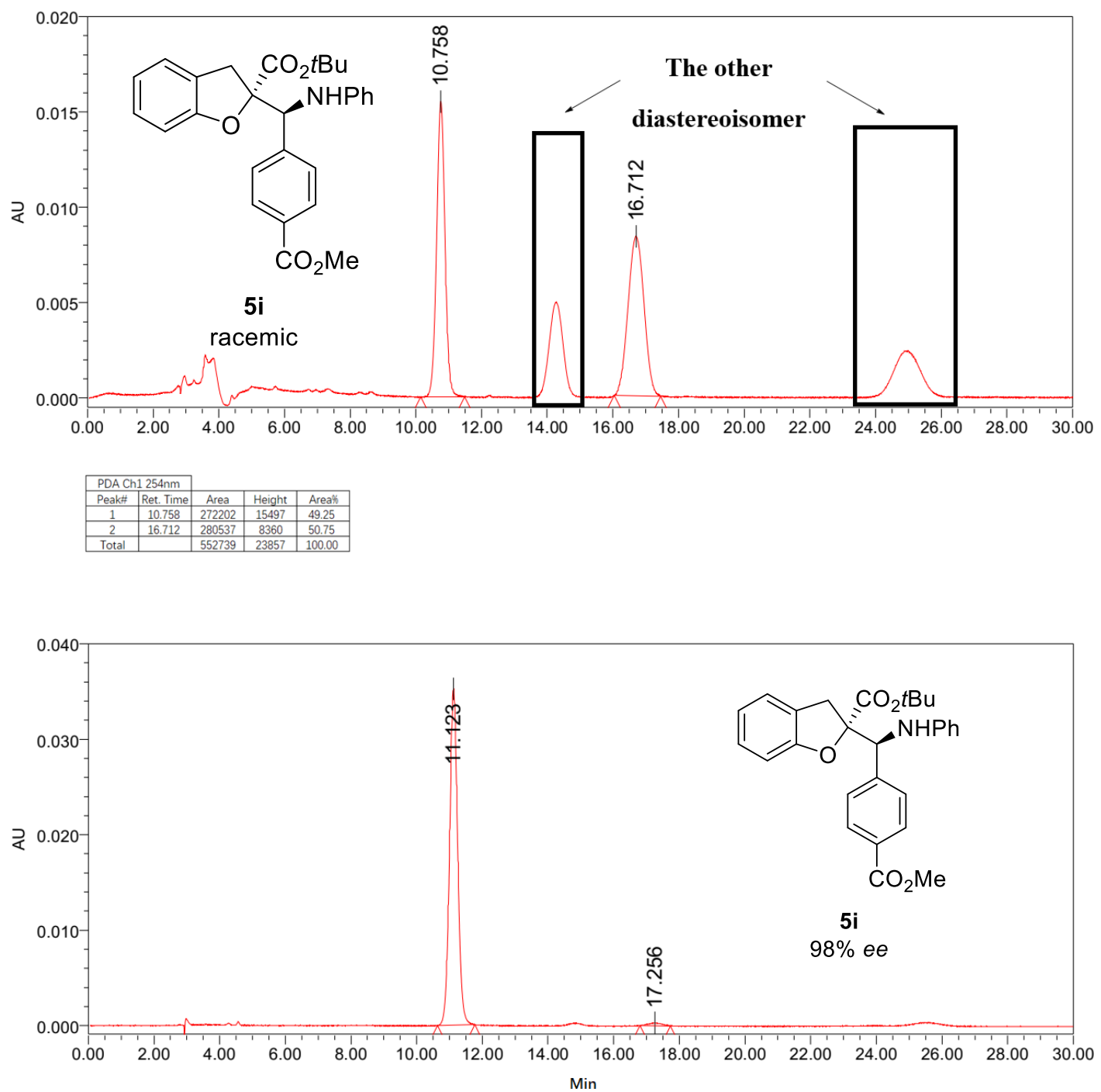

\begin{tabular}{|c|c|c|c|c|}
\hline \multicolumn{2}{|c|}{ PDA Ch1 254nm } & \multicolumn{1}{l|}{} \\
\cline { 1 - 2 } Peak\# & Ret. Time & Area & Height & Area\% \\
\cline { 1 - 2 } 1 & 11.123 & 618415 & 35258 & 98.76 \\
\hline 2 & 17.256 & 7778 & 284 & 1.24 \\
\hline Total & & 626193 & 35542 & 100.00 \\
\hline
\end{tabular}


Condition: hexane $: 2$-propanol $=95: 5$

Flow rate $=1.0 \mathrm{~mL} / \mathrm{min}, \lambda=254 \mathrm{~nm}$, Daicel Chiralpak IC-3
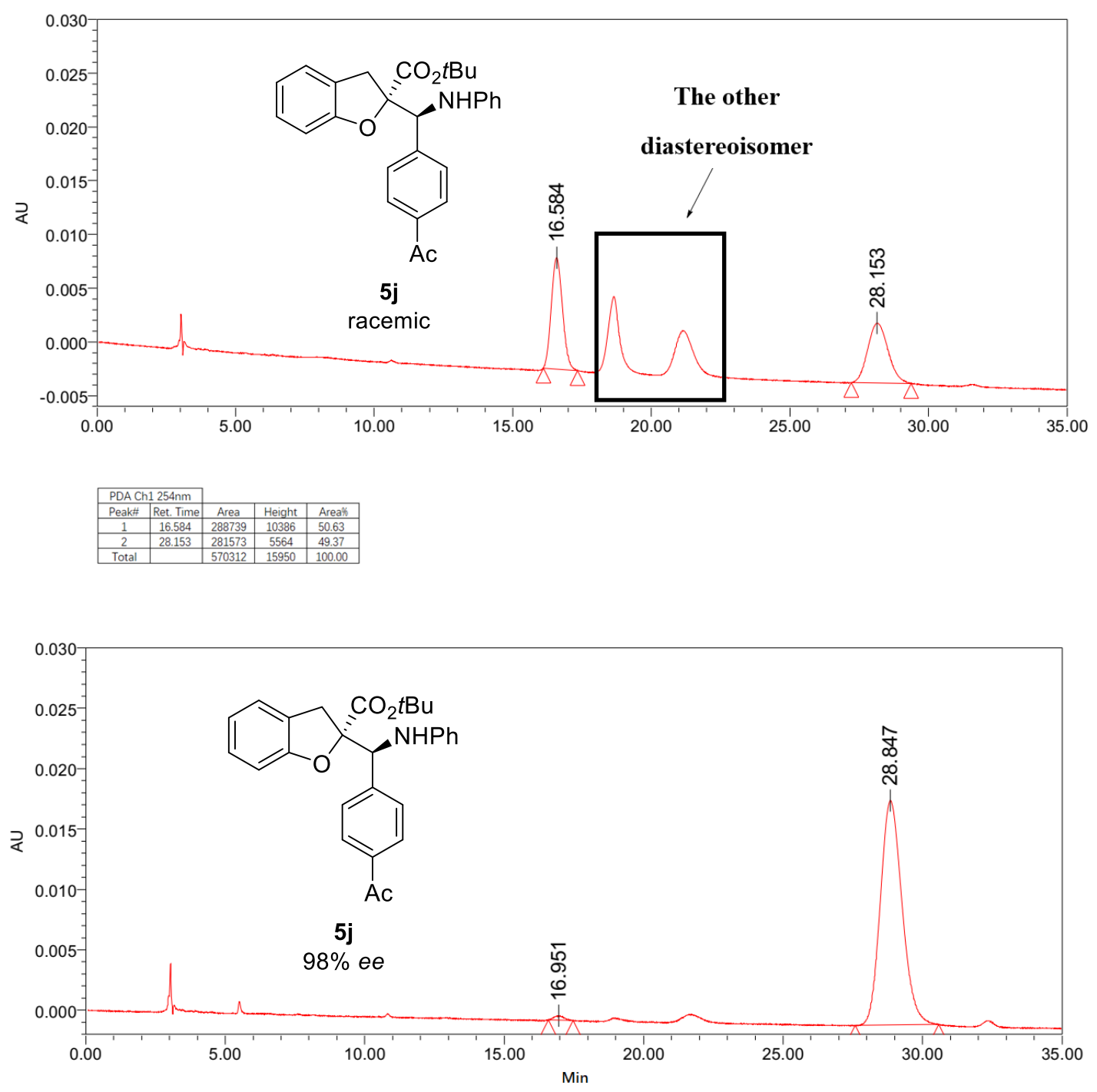

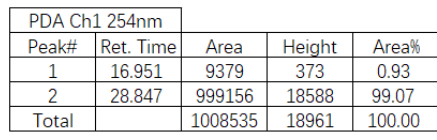


Condition: hexane $:$-propanol $=99: 1$

Flow rate $=1.0 \mathrm{~mL} / \mathrm{min}, \lambda=254 \mathrm{~nm}$, EnantioPak Y1

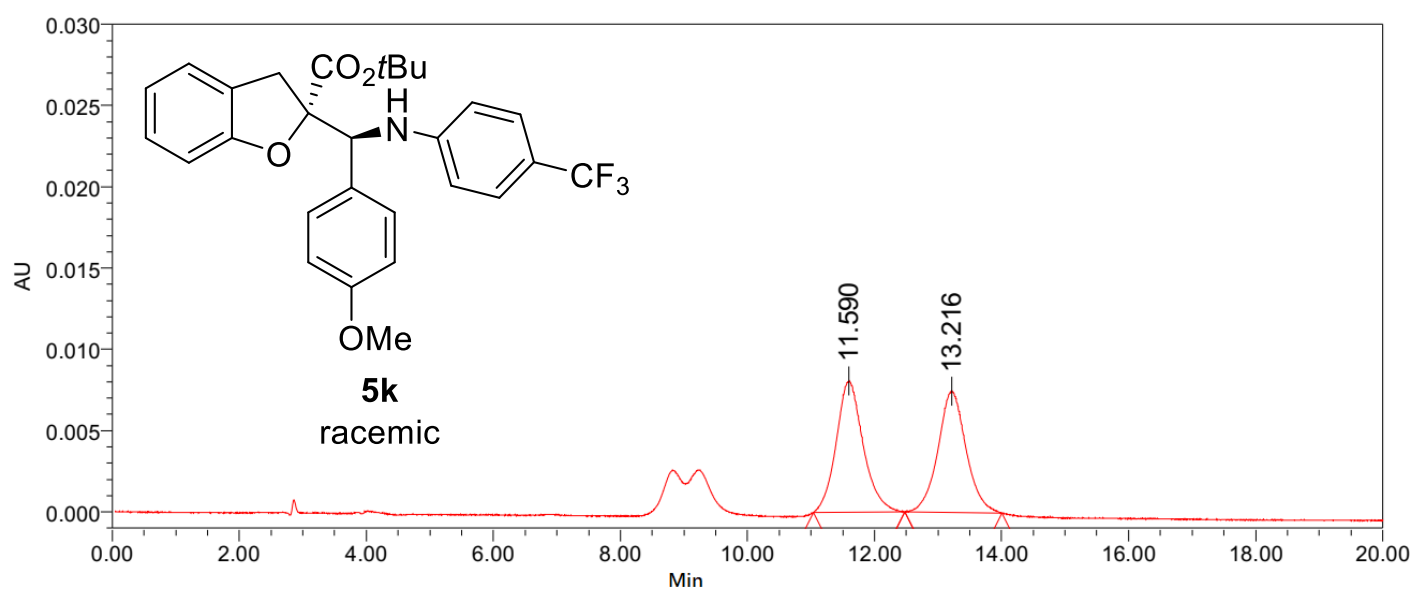

\begin{tabular}{|l|c|c|c|c|}
\hline \multicolumn{2}{|c|}{ PDA Ch1 254nm } & \multicolumn{1}{l|}{} \\
\cline { 1 - 2 } Peak\# & Ret. Time & Area & Height & Area\% \\
\hline 1 & 11.590 & 239656 & 8058 & 50.89 \\
\hline 2 & 13.216 & 231276 & 7458 & 49.11 \\
\hline Total & & 470932 & 15516 & 100.00 \\
\hline
\end{tabular}

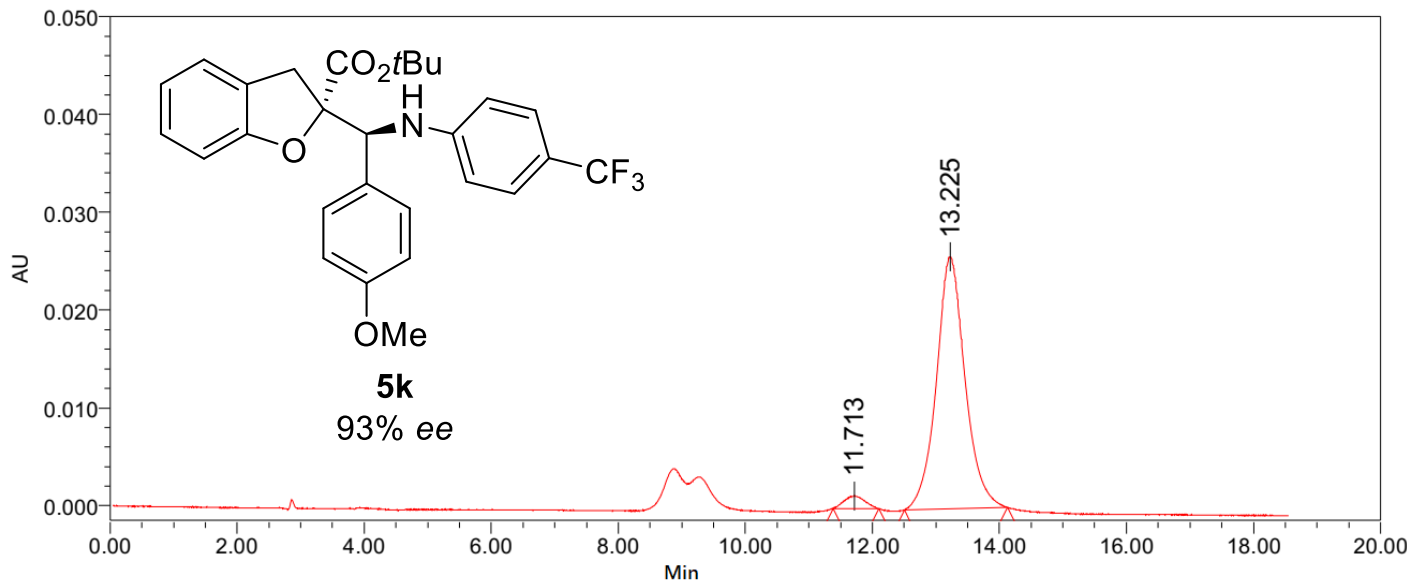

\begin{tabular}{|c|c|c|c|c|}
\hline \multicolumn{3}{|c|}{ PDA Ch1 254nm } & \multicolumn{1}{c|}{} \\
\cline { 1 - 2 } Peak\# & Ret. Time & Area & Height & Area\% \\
\hline 1 & 11.713 & 29242 & 1277 & 3.48 \\
\hline 2 & 13.225 & 810818 & 25749 & 96.52 \\
\hline Total & & 840060 & 27026 & 100.00 \\
\hline
\end{tabular}


Condition: hexane $: 2$-propanol $=99.5: 0.5$

Flow rate $=1.0 \mathrm{~mL} / \mathrm{min}, \lambda=254 \mathrm{~nm}$, EnantioPak Y1
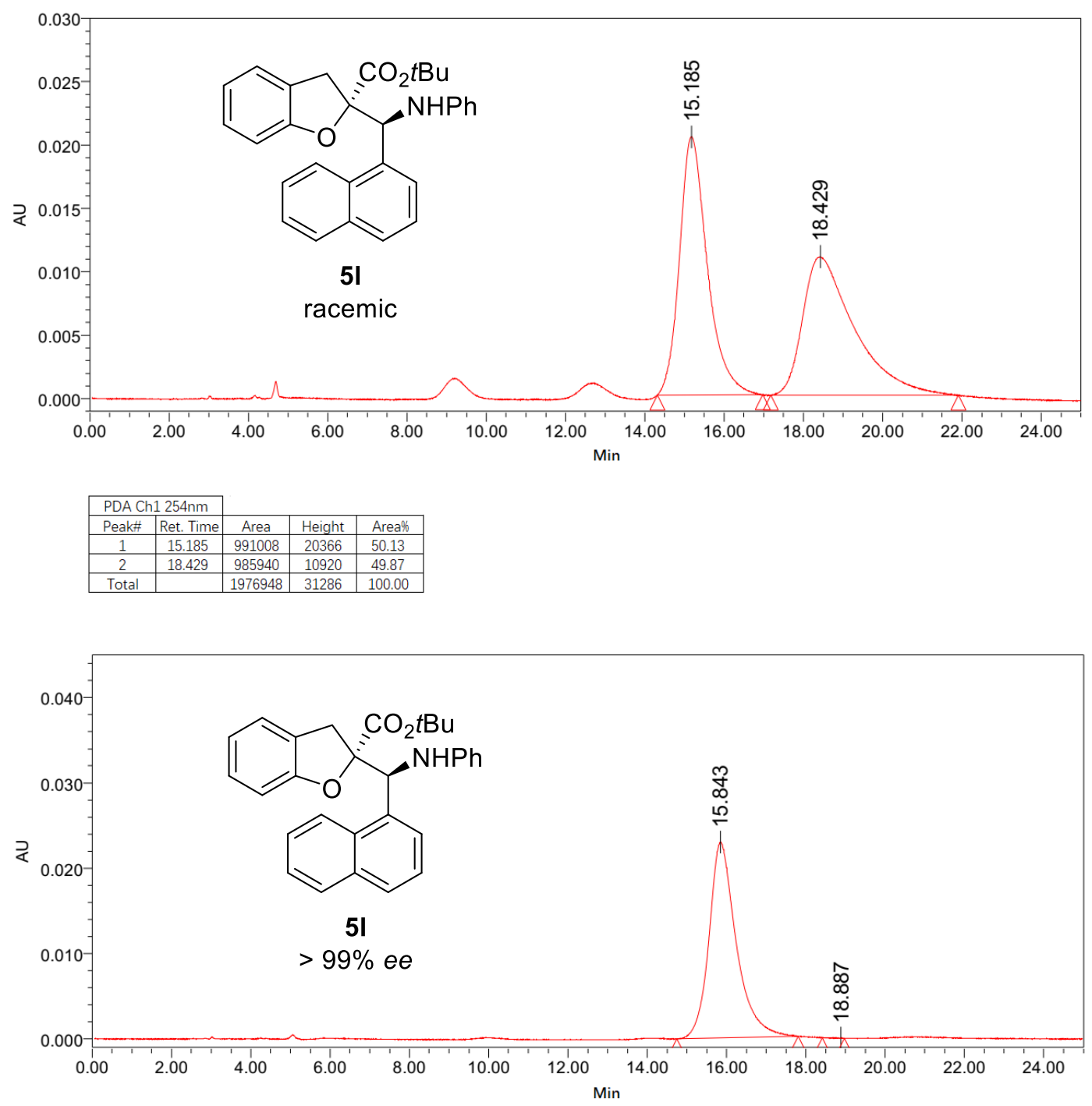

\begin{tabular}{|c|c|c|c|c|}
\hline \multicolumn{2}{|c|}{ PDA Ch1 254nm } & & & \\
\hline Peak\# & Ret. Time & Area & Height & Area\% \\
\hline 1 & \begin{tabular}{|l|}
15.843 \\
\end{tabular} & 1098097 & 22925 & 99.96 \\
\hline 2 & 18.887 & 426 & 42 & 0.04 \\
\hline Total & & 1098523 & 22967 & 100.00 \\
\hline
\end{tabular}


Condition: hexane $:$ 2-propanol $=99.5: 0.5$

Flow rate $=1.0 \mathrm{~mL} / \mathrm{min}, \lambda=254 \mathrm{~nm}$, EnantioPak Y1

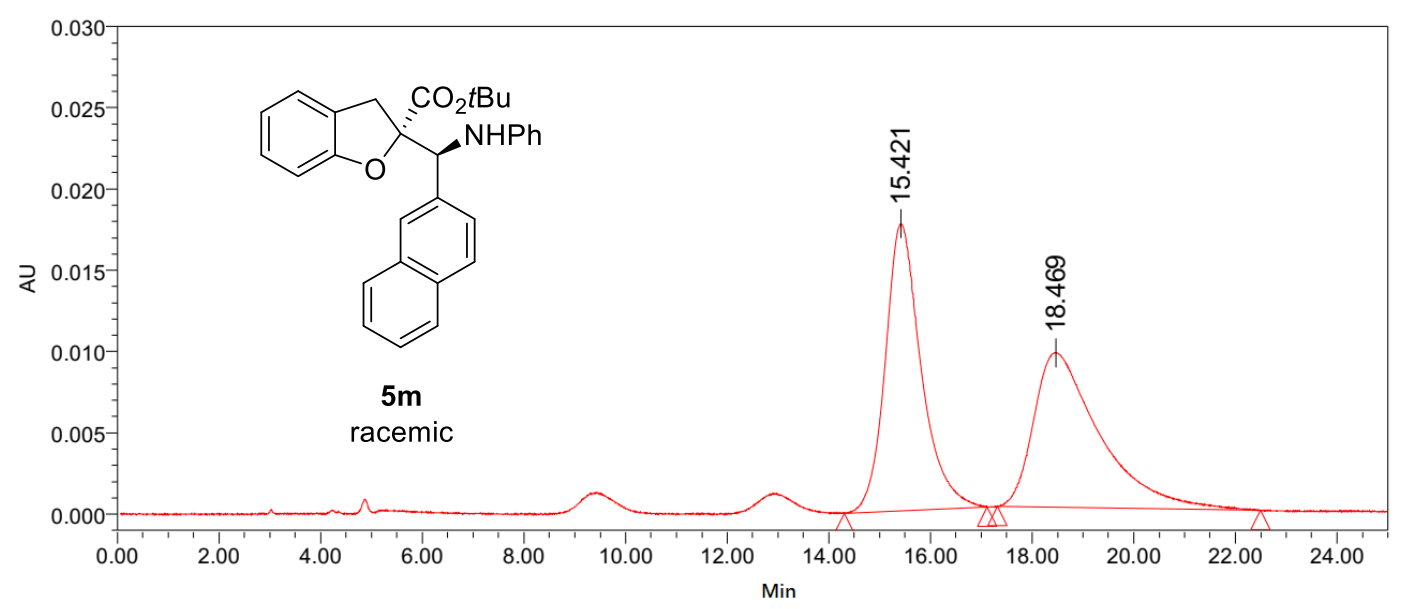

\begin{tabular}{|c|c|c|c|c|}
\hline \multicolumn{2}{|c|}{ PDA Ch1 254nm } & \multirow[b]{2}{*}{ Area } & \multirow[b]{2}{*}{ Height } & \multirow[b]{2}{*}{ Area\% } \\
\hline Peak\# & Ret. Time & & & \\
\hline 1 & 15.421 & 866299 & 17651 & 50.32 \\
\hline 2 & 18.469 & 855302 & 9513 & 49.68 \\
\hline Total & & 1721601 & 27164 & 100.00 \\
\hline
\end{tabular}

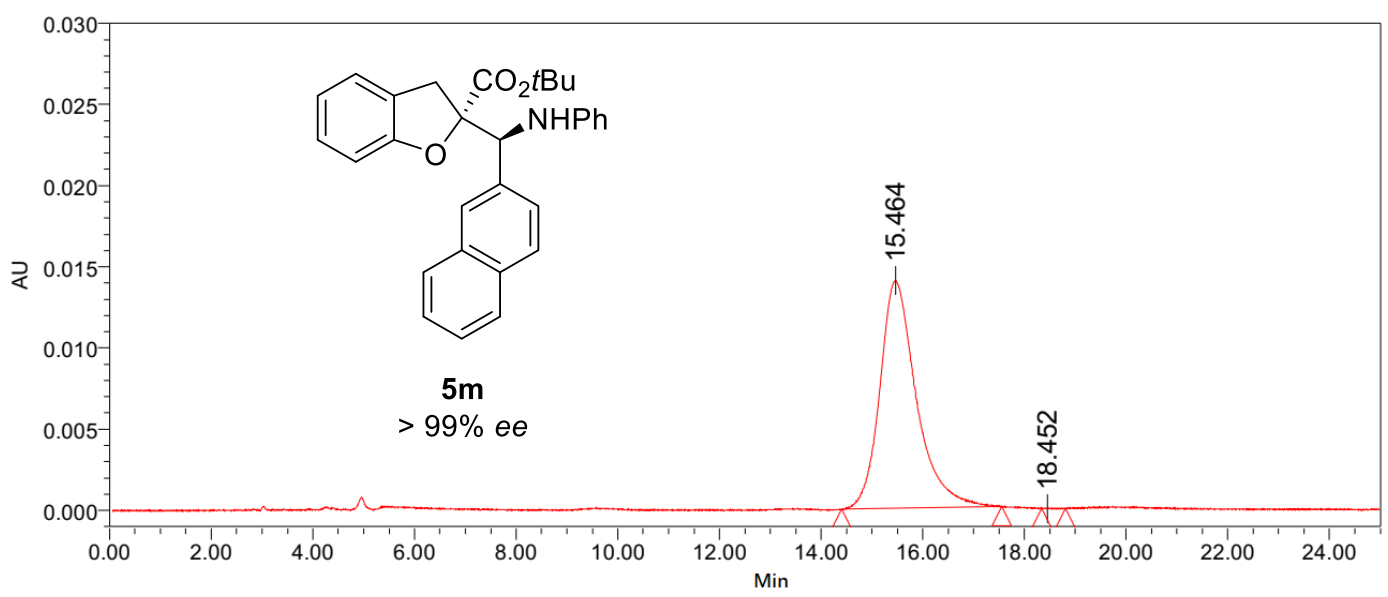

\begin{tabular}{|c|c|c|c|c|}
\hline \multicolumn{3}{|l|}{ PDA Ch1 254nm } & \multicolumn{3}{l|}{} \\
\cline { 1 - 2 } Peak\# & Ret. Time & Area & Height & Area\% \\
\hline 1 & 15.464 & 698739 & 14024 & 99.96 \\
\hline 2 & 18.452 & 264 & -32 & 0.04 \\
\hline Total & & 699003 & 13992 & 100.00 \\
\hline
\end{tabular}


Condition: hexane $:$-propanol $=99: 1$

Flow rate $=1.0 \mathrm{~mL} / \mathrm{min}, \lambda=254 \mathrm{~nm}$, Daicel Chiralcel OD-H

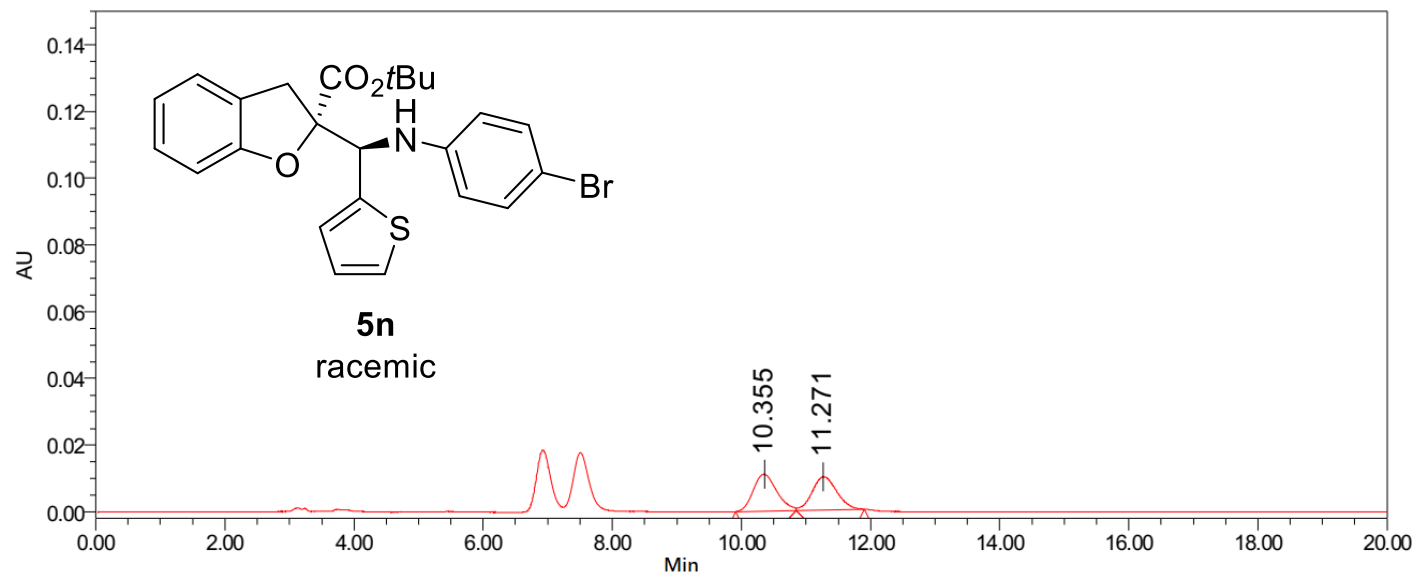

\begin{tabular}{|c|c|c|c|c|}
\hline \multicolumn{2}{|c|}{ PDA Ch1 254nm } & \multirow[b]{2}{*}{ Area } & \multirow[b]{2}{*}{ Height } & \multirow[b]{2}{*}{ Area\% } \\
\hline Peak\# & Ret. Time & & & \\
\hline 1 & 10.355 & 277745 & 11017 & 51.69 \\
\hline 2 & 11.271 & 259593 & 9964 & 48.31 \\
\hline Total & & 537338 & 20981 & 100.00 \\
\hline
\end{tabular}

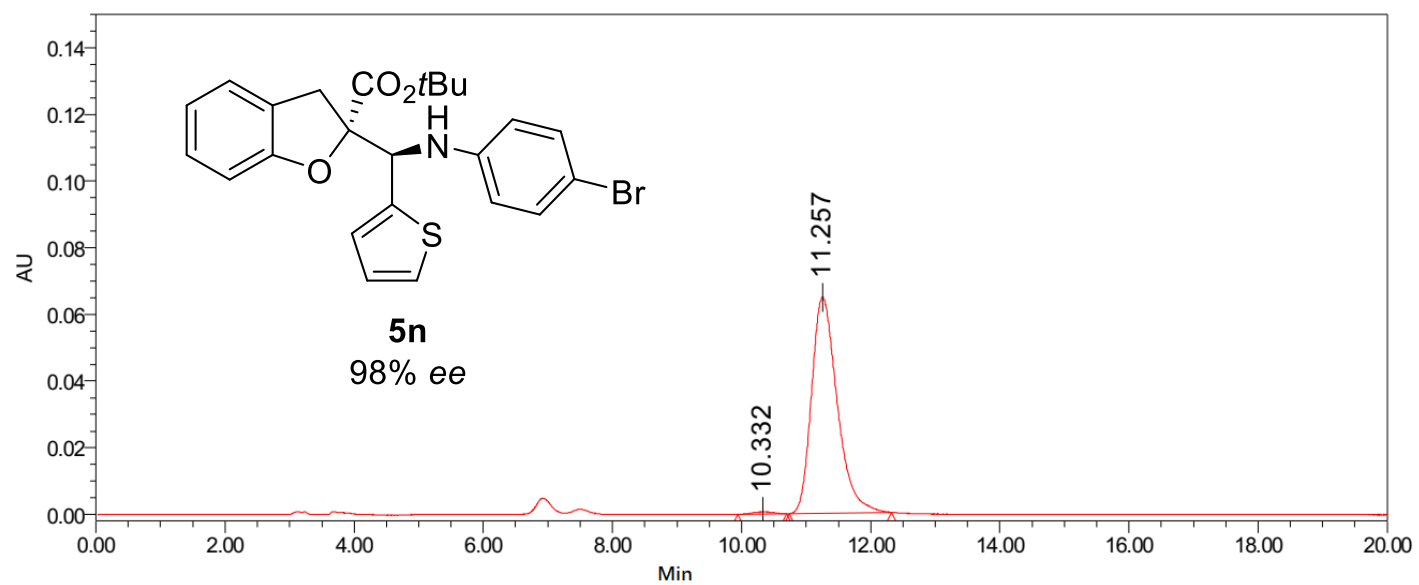

\begin{tabular}{|c|c|c|c|c|}
\hline \multicolumn{2}{|c|}{ PDA Ch1 254nm } & \multirow[b]{2}{*}{ Ara } & \multirow[b]{2}{*}{ Heiaht } & \multirow[b]{2}{*}{ Area\% } \\
\hline Peak\# & Ret. Time & & & \\
\hline 1 & 10.332 & 14770 & 692 & 0.82 \\
\hline 2 & 11.257 & 1777165 & 64818 & 99.18 \\
\hline Total & & 1791935 & 65510 & 100.00 \\
\hline
\end{tabular}


Condition: hexane $:$-propanol $=99: 1$

Flow rate $=1.0 \mathrm{~mL} / \mathrm{min}, \lambda=254 \mathrm{~nm}$, Daicel Chiralpak IA

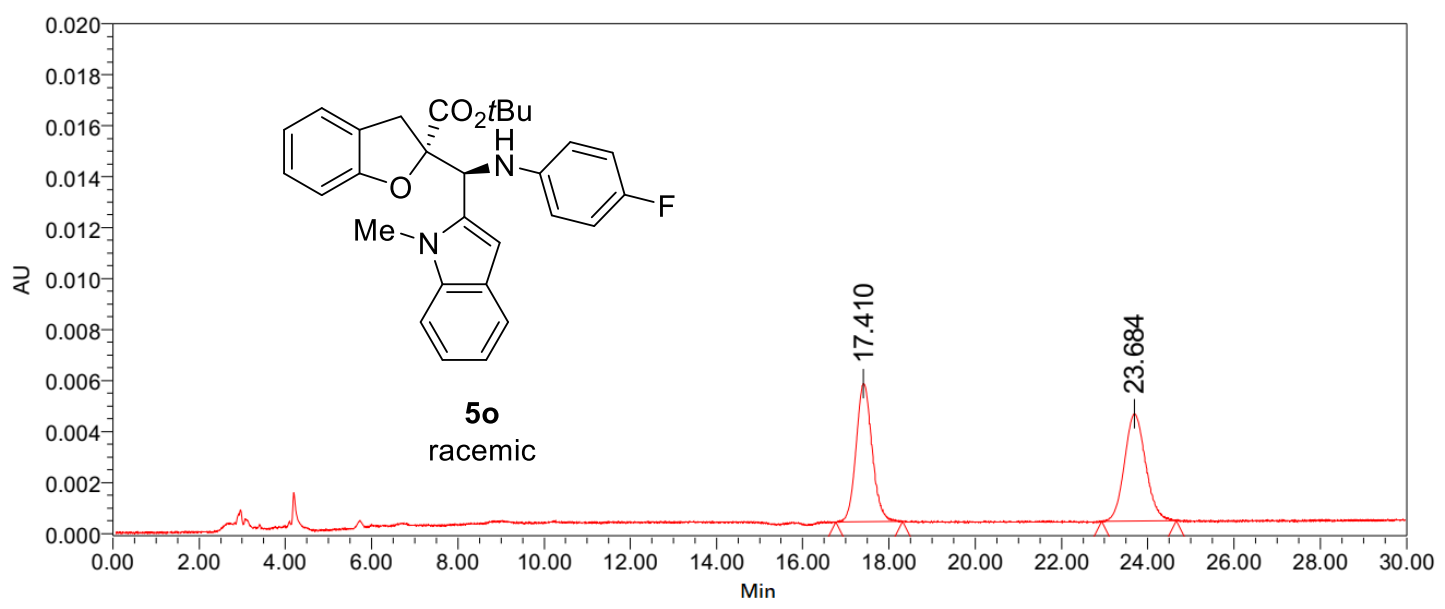

\begin{tabular}{|c|c|c|c|c|}
\hline \multicolumn{2}{|c|}{ PDA Ch1 254nm } & \multicolumn{1}{l}{} \\
\cline { 1 - 2 } Peak\# & Ret. Time & Area & Height & Area\% \\
\cline { 1 - 2 } 1 & 17.410 & 139540 & 5428 & 49.48 \\
\hline 2 & 23.684 & 142498 & 4199 & 50.52 \\
\hline Total & & 282038 & 9627 & 100.00 \\
\hline
\end{tabular}

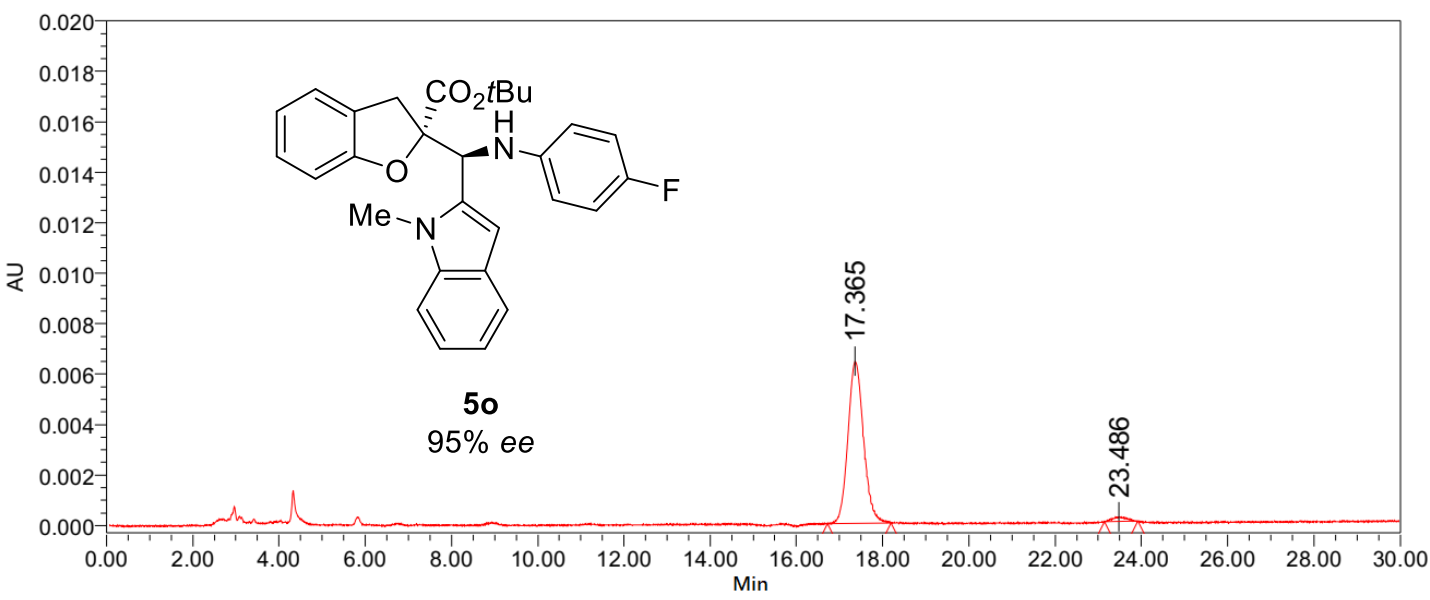

\begin{tabular}{|l|c|c|c|c|}
\hline \multicolumn{2}{|c|}{ PDA Ch1 254nm } & \multicolumn{1}{l|}{} \\
\cline { 1 - 2 } Peak\# & Ret. Time & Area & Height & Area\% \\
\hline 1 & 17.365 & 160138 & 6415 & 97.58 \\
\hline 2 & 23.486 & 3972 & 182 & 2.42 \\
\hline Total & & 164110 & 6597 & 100.00 \\
\hline
\end{tabular}


Condition: hexane $:$-propanol $=99: 1$

Flow rate $=1.0 \mathrm{~mL} / \mathrm{min}, \lambda=254 \mathrm{~nm}$, Daicel Chiralpak IA

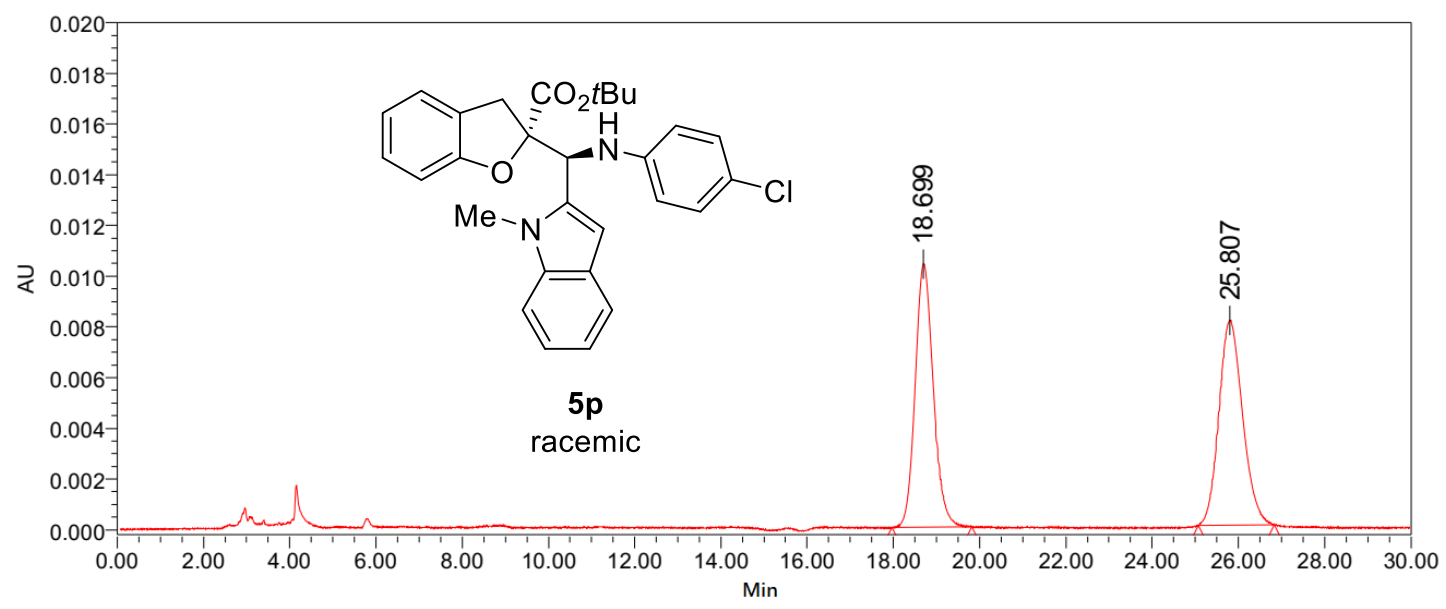

\begin{tabular}{|c|c|c|c|c|}
\hline \multicolumn{2}{|c|}{ PDA Ch1 254nm } & \multirow[b]{2}{*}{ Area } & & \multirow[b]{2}{*}{ Area\% } \\
\hline Peak\# & Ret. Time & & & \\
\hline 1 & 18.699 & 303472 & 10386 & 49.62 \\
\hline 2 & 25.807 & 308156 & 8066 & 50.38 \\
\hline Total & & 611628 & 18452 & 100.00 \\
\hline
\end{tabular}

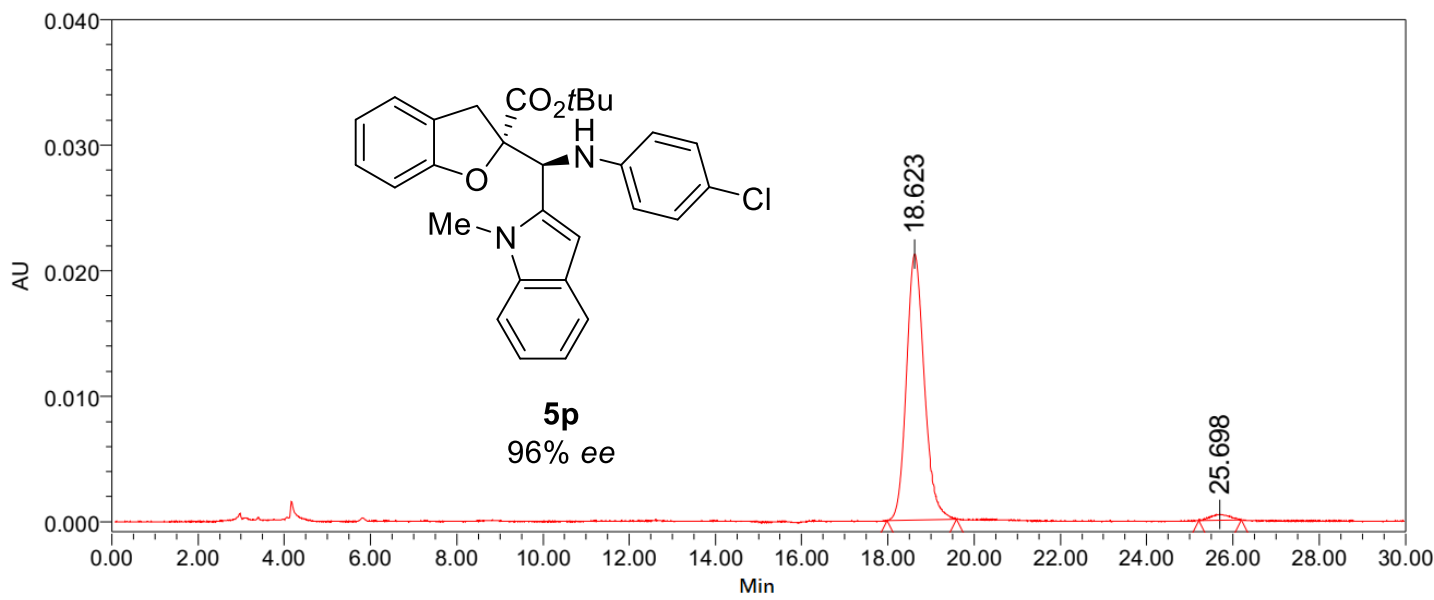

\begin{tabular}{|c|c|c|c|c|}
\hline \multicolumn{3}{|c|}{ PDA Ch1 254nm } & \multicolumn{3}{l|}{} \\
\cline { 1 - 2 } Peak\# & Ret. Time & Area & Height & Area\% \\
\hline 1 & 18.623 & 606193 & 21179 & 97.82 \\
\hline 2 & 25.698 & 13521 & 456 & 2.18 \\
\hline Total & & 619714 & 21635 & 100.00 \\
\hline
\end{tabular}


Condition: hexane $:$ 2-propanol $=97: 3$

Flow rate $=1.0 \mathrm{~mL} / \mathrm{min}, \lambda=254 \mathrm{~nm}$, Daicel Chiralpak IF-3

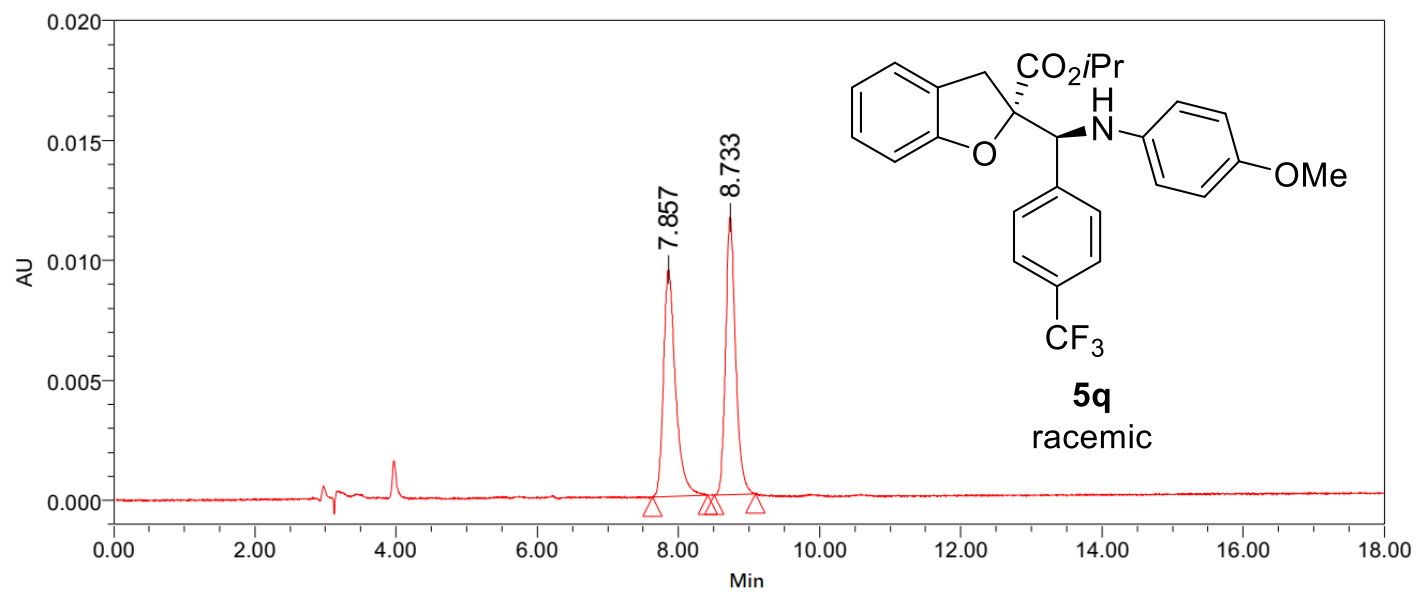

\begin{tabular}{|c|c|c|c|c|}
\hline \multicolumn{2}{|c|}{ PDA Ch1 254nm } & \multirow[b]{2}{*}{ Area } & \multirow[b]{2}{*}{ Height } & \multirow[b]{2}{*}{ Area\% } \\
\hline Peak\# & Ret. Time & & & \\
\hline 1 & 7.857 & 113516 & 9446 & 49.67 \\
\hline 2 & 8.733 & 115035 & 11562 & 50.33 \\
\hline Total & & 228551 & 21008 & 100.00 \\
\hline
\end{tabular}

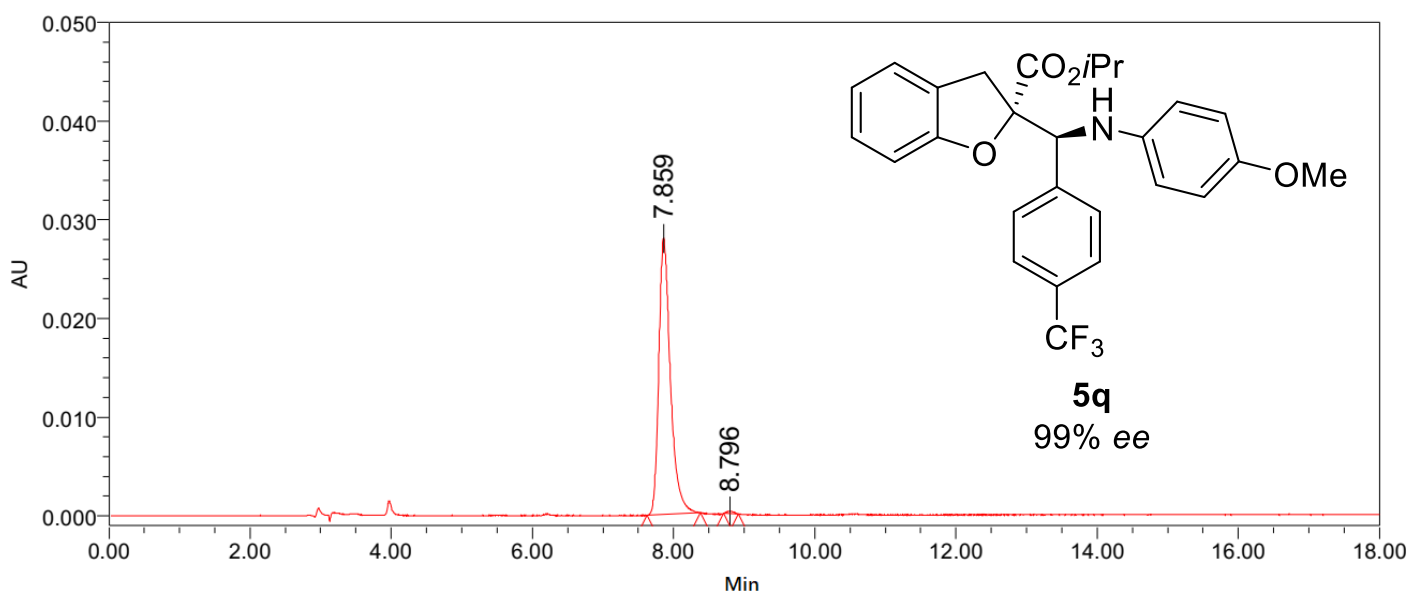

\begin{tabular}{|l|c|c|c|c|}
\hline \multicolumn{2}{|c|}{ PDA Ch1 254nm } & \multicolumn{1}{l|}{} \\
\cline { 1 - 2 } Peak\# & Ret. Time & Area & Height & Area\% \\
\hline 1 & 7.859 & 323623 & 27988 & 99.48 \\
\hline 2 & 8.796 & 1705 & 257 & 0.52 \\
\hline Total & & 325328 & 28245 & 100.00 \\
\hline
\end{tabular}


Condition: hexane $: 2$-propanol $=95: 5$

Flow rate $=1.0 \mathrm{~mL} / \mathrm{min}, \lambda=213 \mathrm{~nm}$, Daicel Chiralpak AD-H
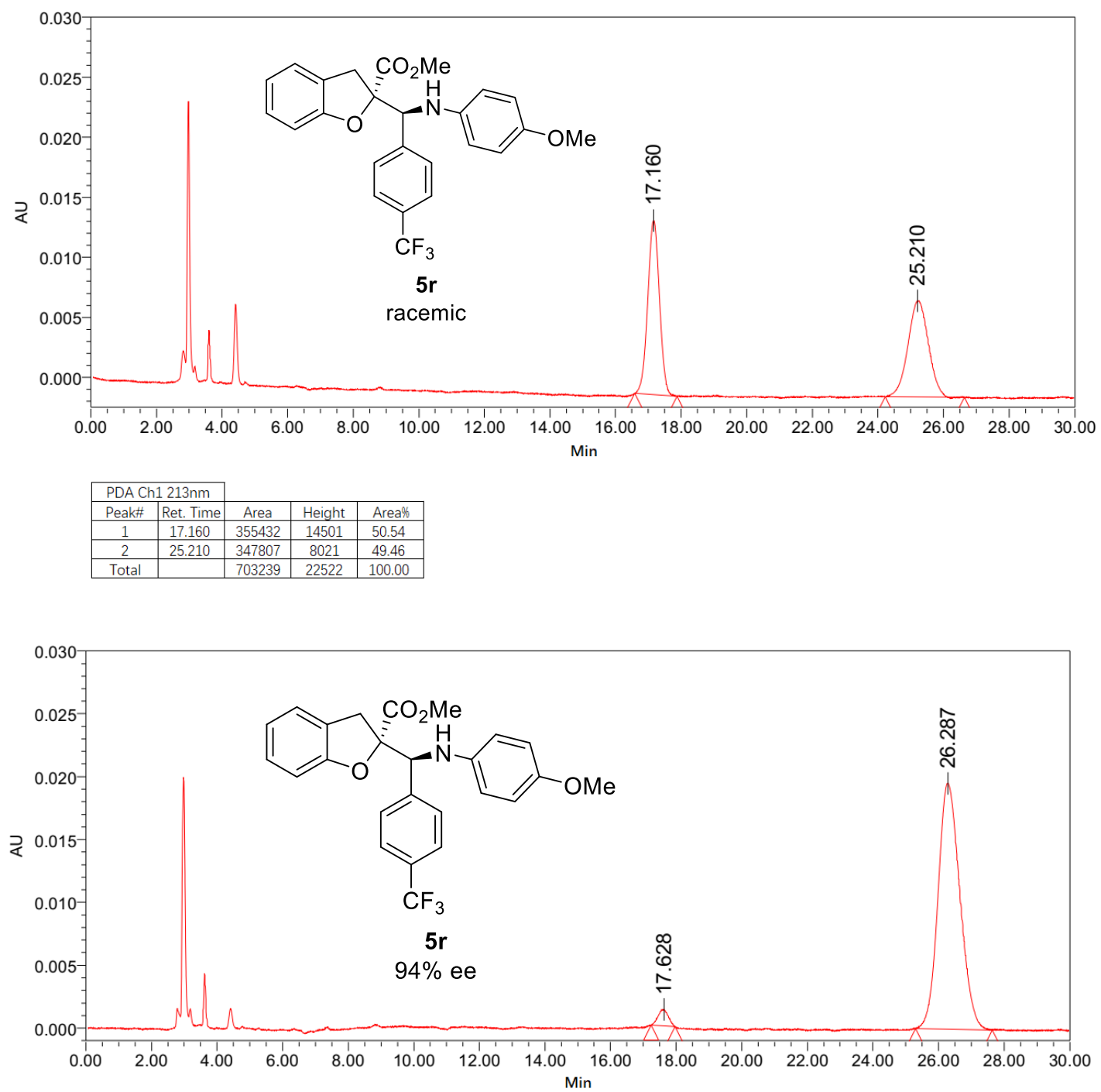

\begin{tabular}{|l|c|c|c|c|}
\hline \multicolumn{2}{|c|}{ PDA Ch1 213nm } & \multicolumn{3}{l|}{} \\
\cline { 1 - 2 } Peak\# & Ret. Time & Area & Height & Area\% \\
\hline 1 & 17.628 & 28746 & 1302 & 3.09 \\
\hline 2 & 26.287 & 902928 & 19539 & 96.91 \\
\hline Total & & 931674 & 20841 & 100.00 \\
\hline
\end{tabular}


Condition: hexane $:$-propanol $=99: 1$

Flow rate $=1.0 \mathrm{~mL} / \mathrm{min}, \lambda=254 \mathrm{~nm}$, Daicel Chiralpak IE-3
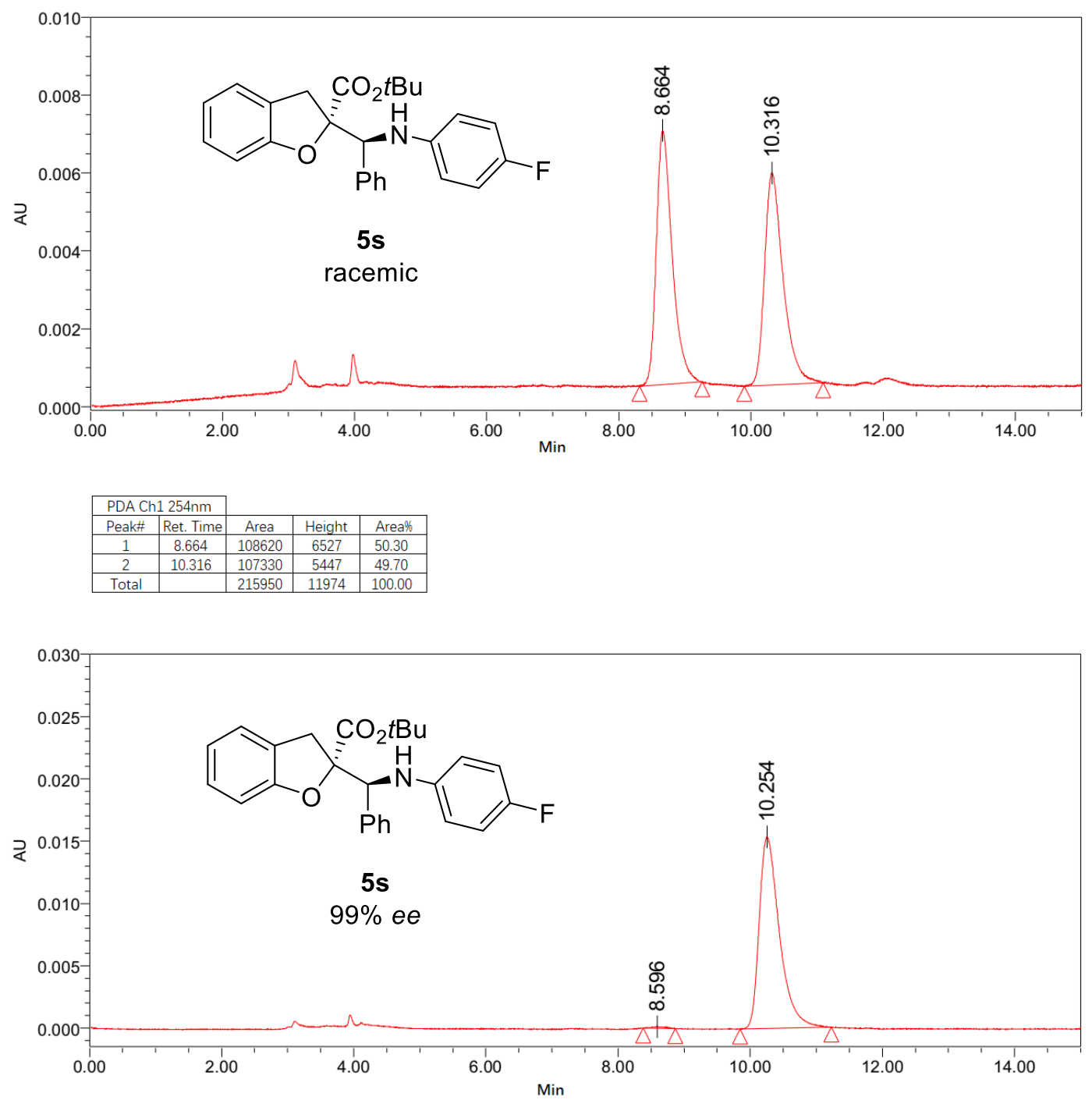

\begin{tabular}{|l|c|c|c|c|}
\hline \multicolumn{2}{|c|}{ PDA Ch1 254nm } & \multicolumn{1}{l|}{} \\
\cline { 1 - 2 } Peak\# & Ret. Time & Area & Height & Area\% \\
\hline 1 & 8.596 & 1654 & 116 & 0.50 \\
\hline 2 & 10.254 & 329099 & 15387 & 99.50 \\
\hline Total & & 330753 & 15503 & 100.00 \\
\hline
\end{tabular}


Condition: hexane $:$-propanol $=99: 1$

Flow rate $=1.0 \mathrm{~mL} / \mathrm{min}, \lambda=254 \mathrm{~nm}$, EnantioPak Y1

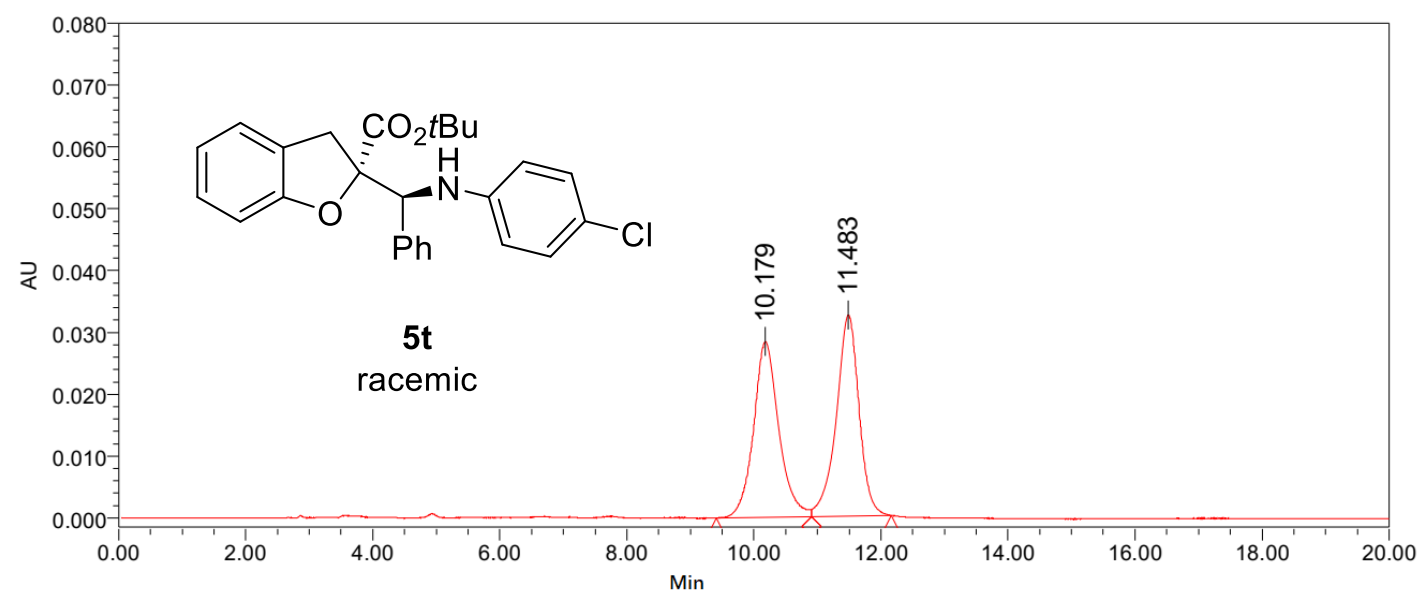

\begin{tabular}{|c|c|c|c|c|}
\hline \multicolumn{2}{|c|}{ PDA Ch1 254nm } & \multirow[b]{2}{*}{ Area } & \multirow[b]{2}{*}{ Height } & \multirow[b]{2}{*}{ Area\% } \\
\hline Peak\# & Ret. Time & & & \\
\hline 1 & 10.179 & 786453 & 28429 & 49.22 \\
\hline 2 & 11.483 & 811411 & 32569 & 50.78 \\
\hline Total & & 1597864 & 60998 & 100.00 \\
\hline
\end{tabular}

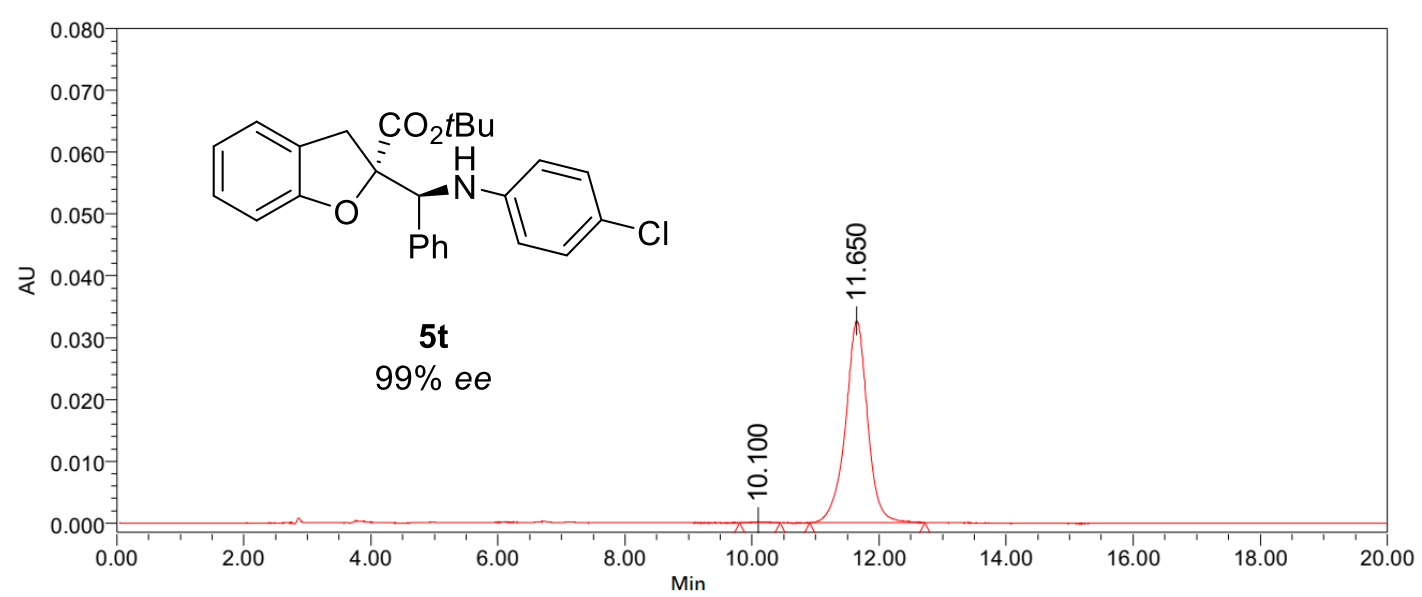

\begin{tabular}{|c|c|c|c|c|}
\hline \multicolumn{2}{|c|}{ PDA Ch1 254nm } & & & \\
\hline Peak\# & Ret. Time & Area & Height & Area\% \\
\hline 1 & 10.100 & 3489 & 185 & 0.44 \\
\hline 2 & 11.650 & 791017 & 32610 & 99.56 \\
\hline Total & & 794506 & 32795 & 100.00 \\
\hline
\end{tabular}


Condition: hexane $:$-propanol $=99: 1$

Flow rate $=1.0 \mathrm{~mL} / \mathrm{min}, \lambda=254 \mathrm{~nm}$, Daicel Chiralpak IE-3
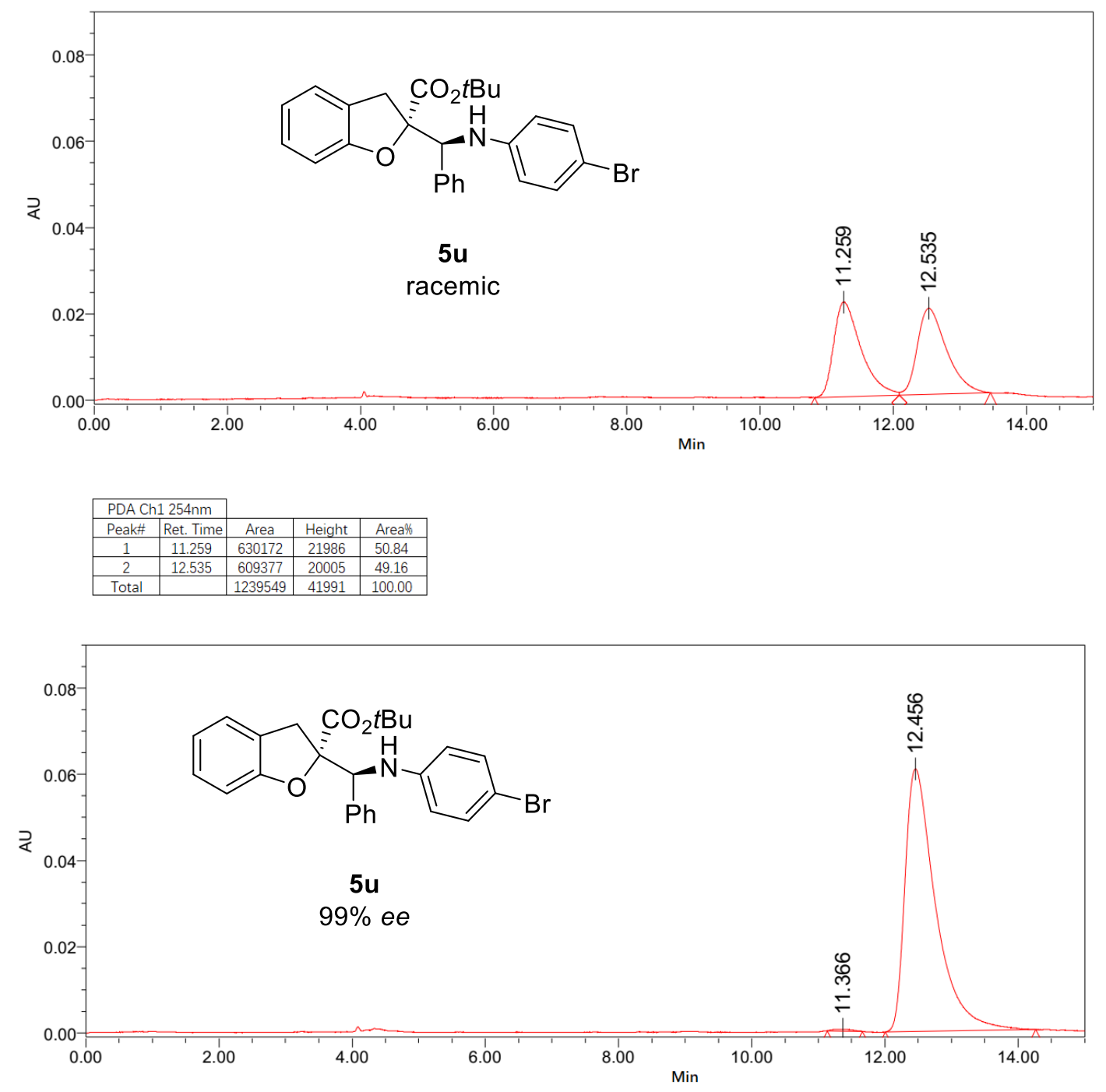

\begin{tabular}{|c|c|c|c|c|}
\hline \multicolumn{2}{|c|}{ PDA Ch1 254nm } & \multicolumn{3}{l|}{} \\
\cline { 1 - 2 } Peak\# & Ret. Time & Area & Height & Area\% \\
\hline 1 & 11.366 & 7660 & 425 & 0.39 \\
\hline 2 & 12.456 & 1945859 & 60995 & 99.61 \\
\hline Total & & 1953519 & 61420 & 100.00 \\
\hline
\end{tabular}


Condition: hexane $:$-propanol $=98: 2$

Flow rate $=1.0 \mathrm{~mL} / \mathrm{min}, \lambda=254 \mathrm{~nm}$, Daicel Chiralpak AD-H

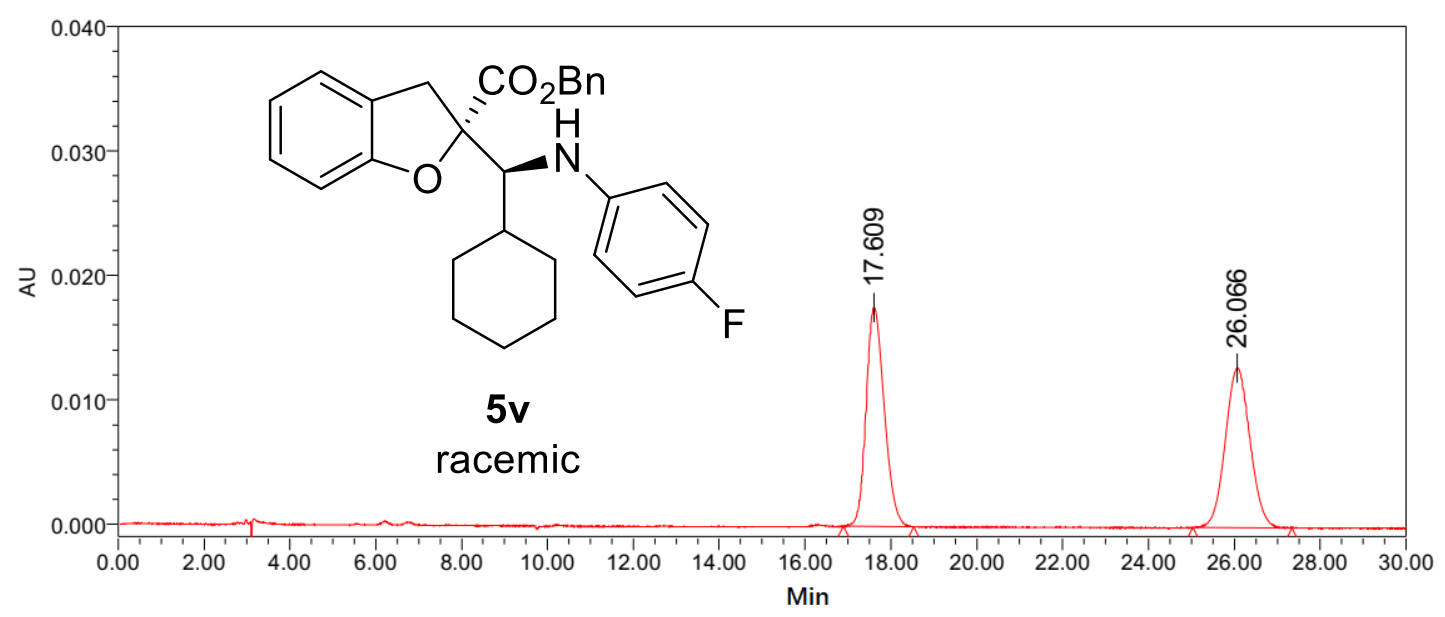

\begin{tabular}{|c|c|c|c|c|}
\hline \multicolumn{2}{|c|}{ PDA Ch1 254nm } & \multicolumn{3}{l}{} \\
\cline { 1 - 2 } Peak\# & Ret. Time & Area & Height & Area\% \\
\hline 1 & 17.609 & 517341 & 17620 & 50.00 \\
\hline 2 & 26.066 & 517298 & 12840 & 50.00 \\
\hline Total & & 1034639 & 30460 & 100.00 \\
\hline
\end{tabular}

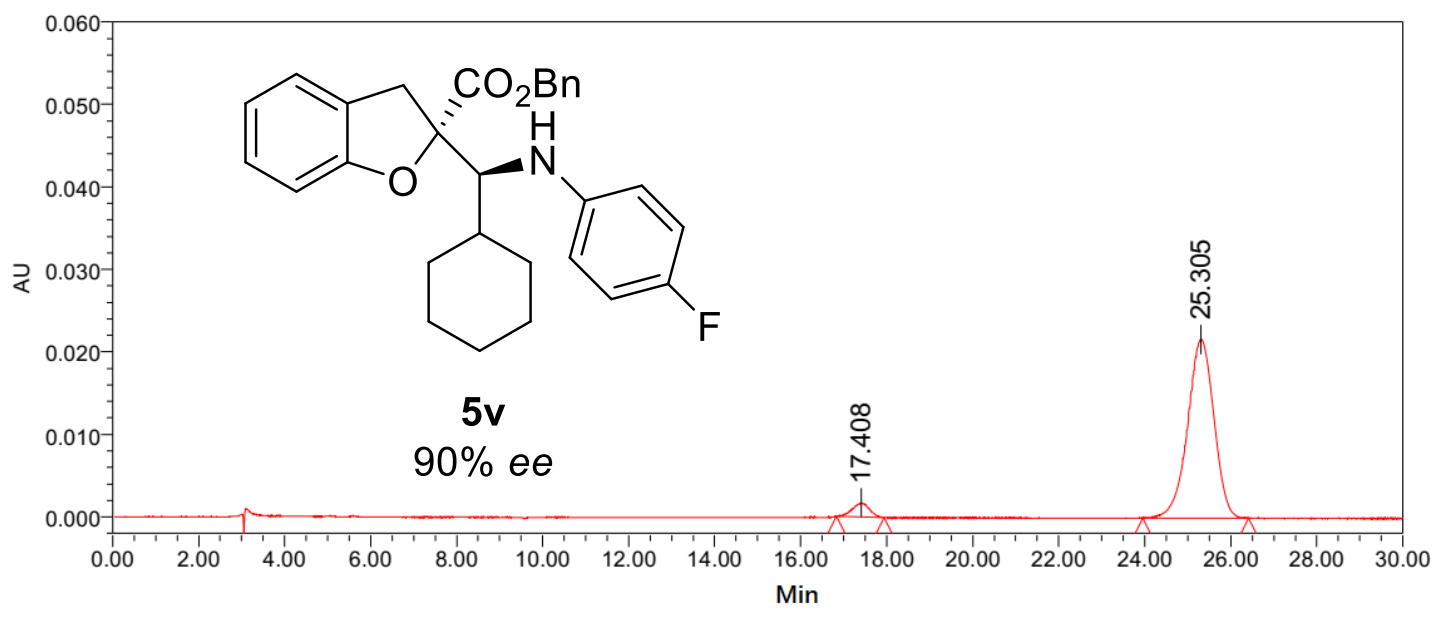

\begin{tabular}{|c|c|c|c|c|}
\hline \multicolumn{2}{|c|}{ PDA Ch1 254nm } & \multicolumn{3}{l|}{} \\
\cline { 1 - 2 } Peak\# & Ret. Time & Area & Height & Area\% \\
\hline 1 & 17.408 & 47862 & 1685 & 4.92 \\
\hline 2 & 25.305 & 925178 & 21649 & 95.08 \\
\hline Total & & 973040 & 23334 & 100.00 \\
\hline
\end{tabular}


Condition: hexane $:$ 2-propanol $=90: 10$

Flow rate $=1.0 \mathrm{~mL} / \mathrm{min}, \lambda=254 \mathrm{~nm}$, Daicel Chiralpak IA

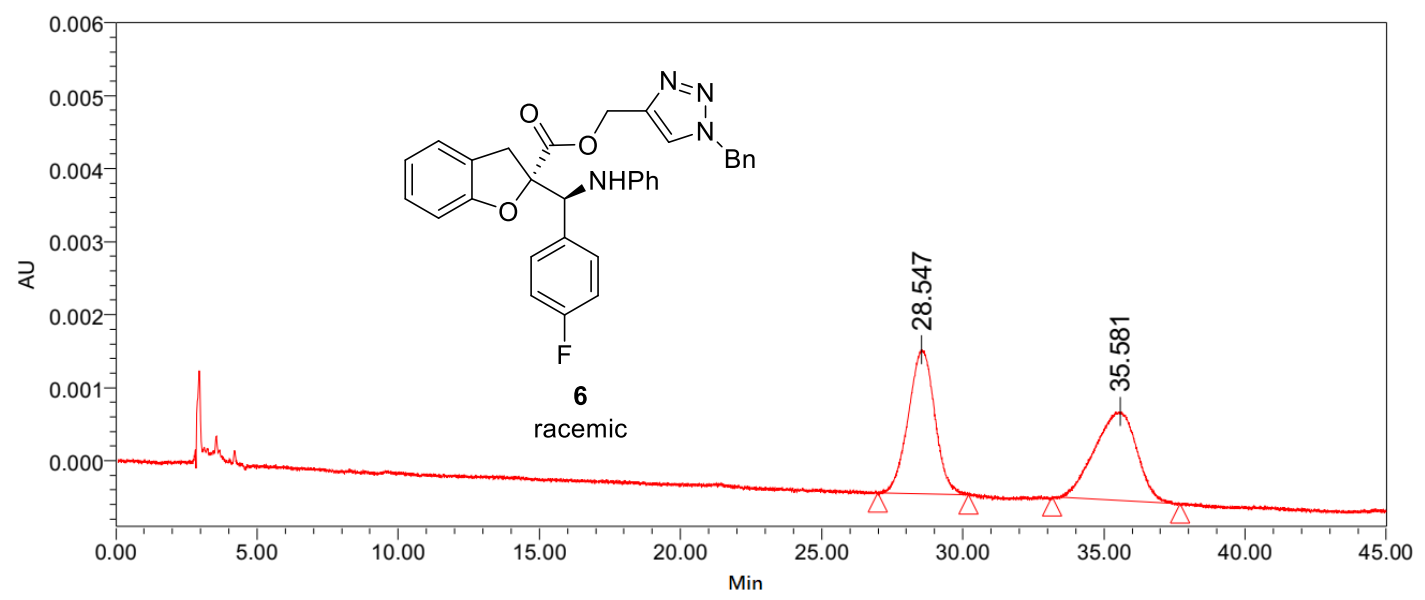

\begin{tabular}{|l|c|c|c|c|}
\hline \multicolumn{2}{|c|}{ PDA Ch1 254nm } & \multicolumn{1}{l|}{} \\
\cline { 1 - 2 } Peak\# & Ret. Time & Area & Height & Area\% \\
\hline 1 & 28.547 & 127998 & 1972 & 50.23 \\
\hline 2 & 35.581 & 126848 & 1221 & 49.77 \\
\hline Total & & 254846 & 3193 & 100.00 \\
\hline
\end{tabular}

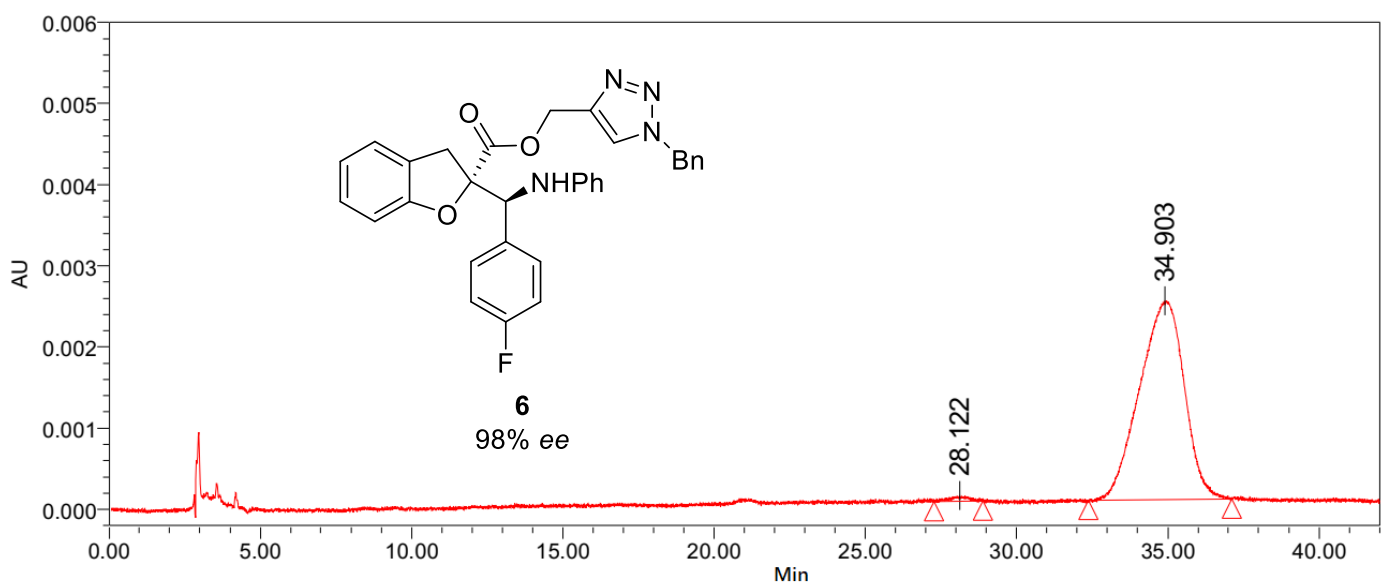

\begin{tabular}{|c|c|c|c|c|}
\hline \multicolumn{2}{|c|}{ PDA Ch1 254nm } & \multirow[b]{2}{*}{ Area } & \multirow[b]{2}{*}{ Height } & \multirow[b]{2}{*}{ Area\% } \\
\hline Peak\# & Ret. Time & & & \\
\hline 1 & 28.122 & 2626 & 70 & 1.03 \\
\hline 2 & 34.903 & 251362 & 2449 & 98.97 \\
\hline Total & & 253988 & 2519 & 100.00 \\
\hline
\end{tabular}


Condition: hexane $:$ 2-propanol $=90: 10$

Flow rate $=1.0 \mathrm{~mL} / \mathrm{min}, \lambda=254 \mathrm{~nm}$, Daicel Chiralpak IA-3

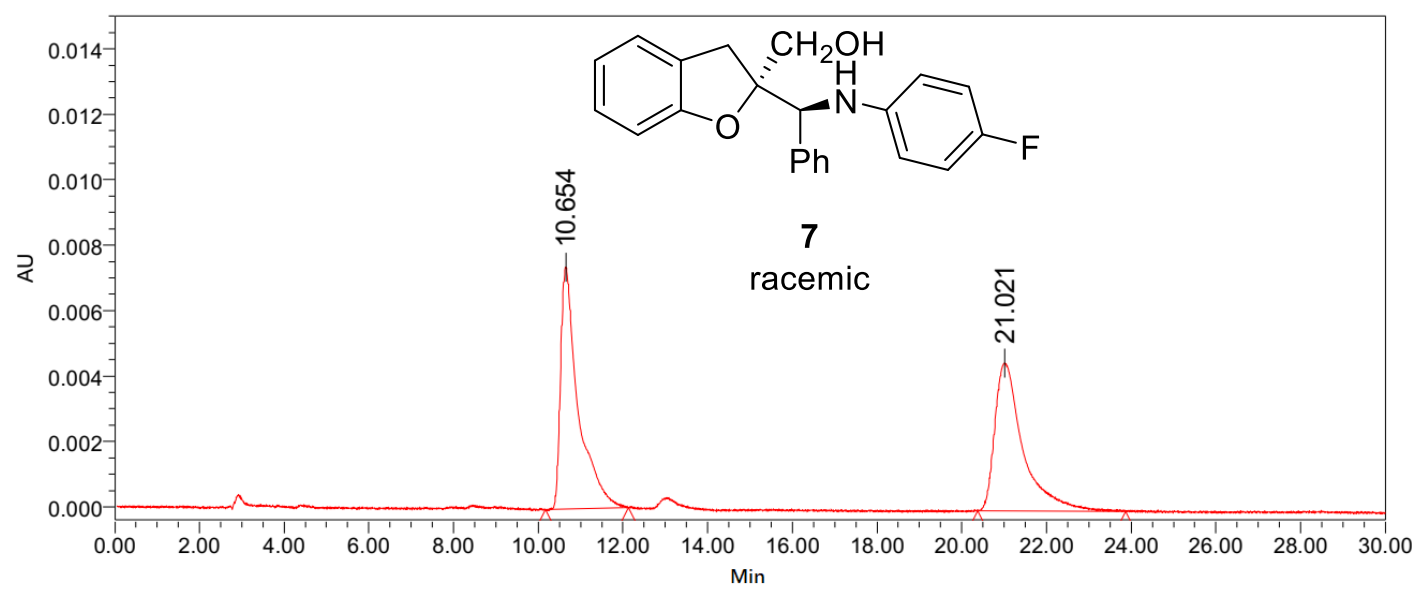

\begin{tabular}{|c|c|c|c|c|}
\hline \multicolumn{3}{|l|}{ PDA Ch1 254nm } & \multicolumn{1}{l|}{} \\
\cline { 1 - 2 } Peak\# & Ret. Time & Area & Height & Area\% \\
\hline 1 & 10.654 & 215485 & 7399 & 50.63 \\
\hline 2 & 21.021 & 210110 & 4532 & 49.37 \\
\hline Total & & 425595 & 11931 & 100.00 \\
\hline
\end{tabular}

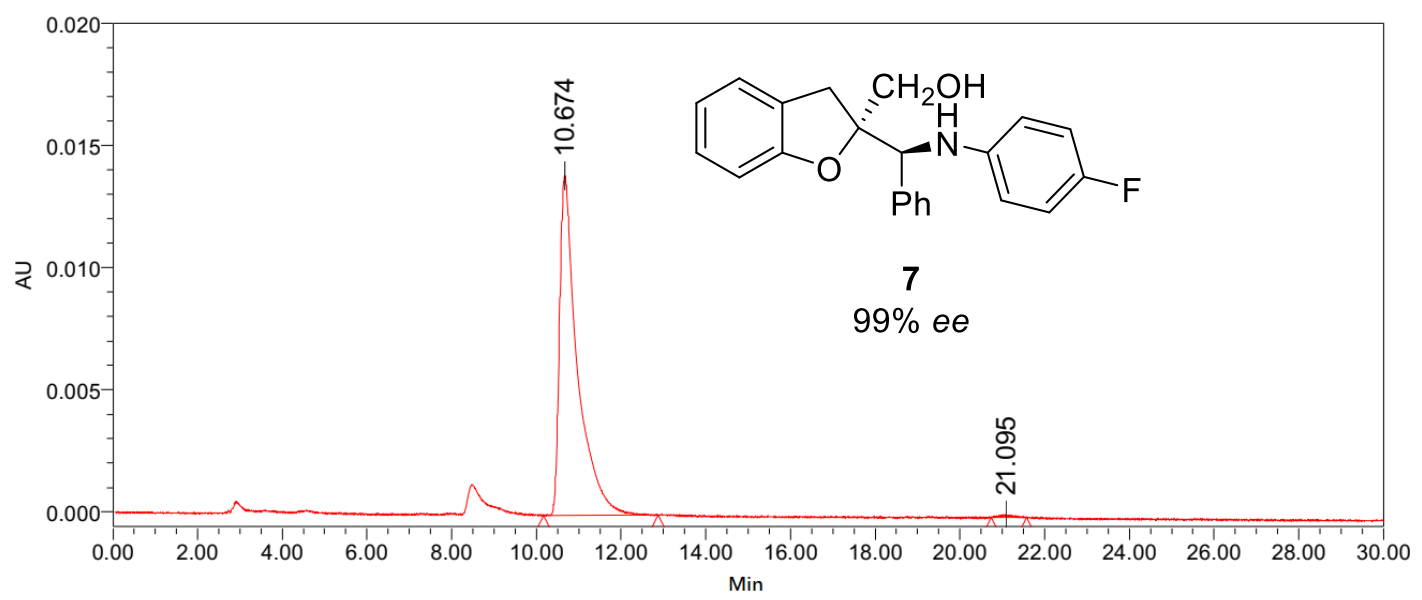

\begin{tabular}{|c|c|c|c|c|}
\hline \multicolumn{2}{|c|}{ PDA Ch1 254nm } & & & \\
\hline Peak\# & Ret. Time & Area & Height & Area\% \\
\hline 1 & \begin{tabular}{|l|}
10.674 \\
\end{tabular} & 409792 & 13893 & 99.48 \\
\hline 2 & 21.095 & 2137 & 98 & 0.52 \\
\hline Total & & 411929 & 13991 & 100.00 \\
\hline
\end{tabular}


Condition: hexane $: 2$-propanol $=95: 5$

Flow rate $=1.0 \mathrm{~mL} / \mathrm{min}, \lambda=254 \mathrm{~nm}$, Daicel Chiralpak AD-H

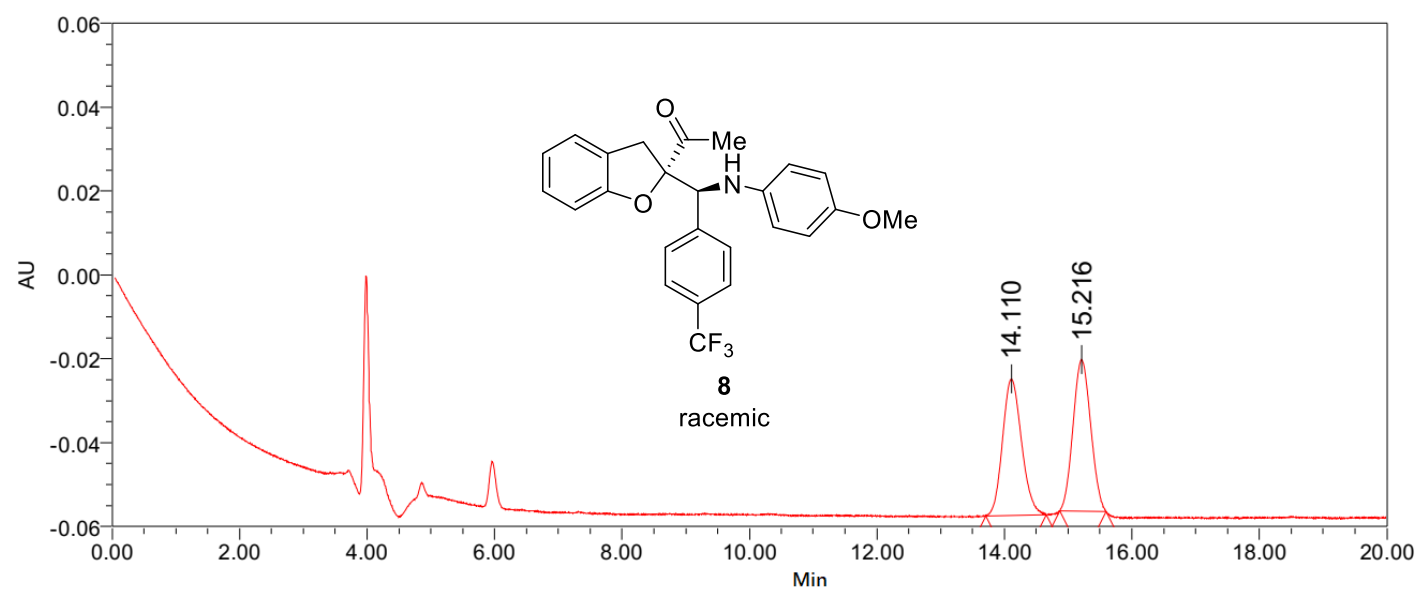

\begin{tabular}{|c|c|c|c|c|}
\hline \multicolumn{5}{|c|}{ PDA Ch1 210nm } \\
\cline { 1 - 2 } Peak\# & Ret. Time & Area & Height & Area\% \\
\hline 1 & 14.110 & 667409 & 32619 & 49.19 \\
\hline 2 & 15.216 & 689456 & 36120 & 50.81 \\
\hline Total & & 1356865 & 68739 & 100.00 \\
\hline
\end{tabular}

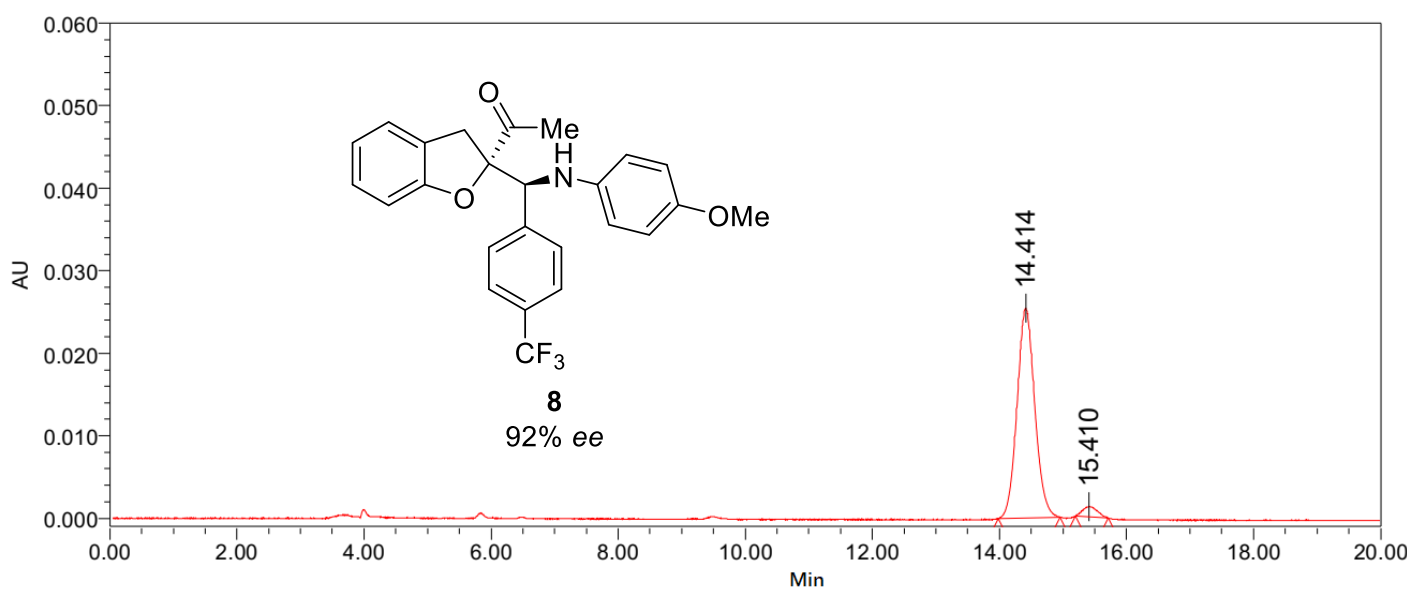

\begin{tabular}{|c|c|c|c|c|}
\hline \multicolumn{2}{|c|}{ PDA Ch1 254nm } & & & \\
\hline Peak\# & Ret. Time & Area & Height & Area\% \\
\hline 1 & 14.414 & 497668 & 25418 & 96.06 \\
\hline 2 & 15.410 & 20438 & 1269 & 3.94 \\
\hline Total & & 518106 & 26687 & 100.00 \\
\hline
\end{tabular}




\section{Single-Crystal X-ray Diffraction of 5a}
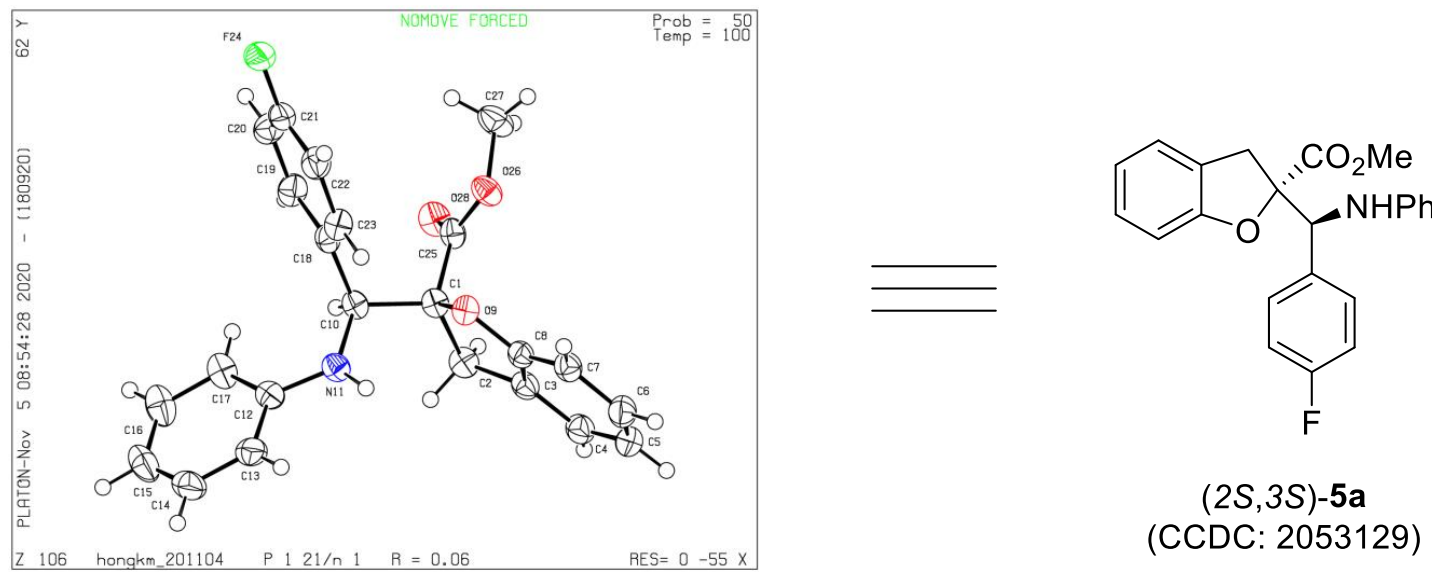

\section{Datablock: hongkm_201104}

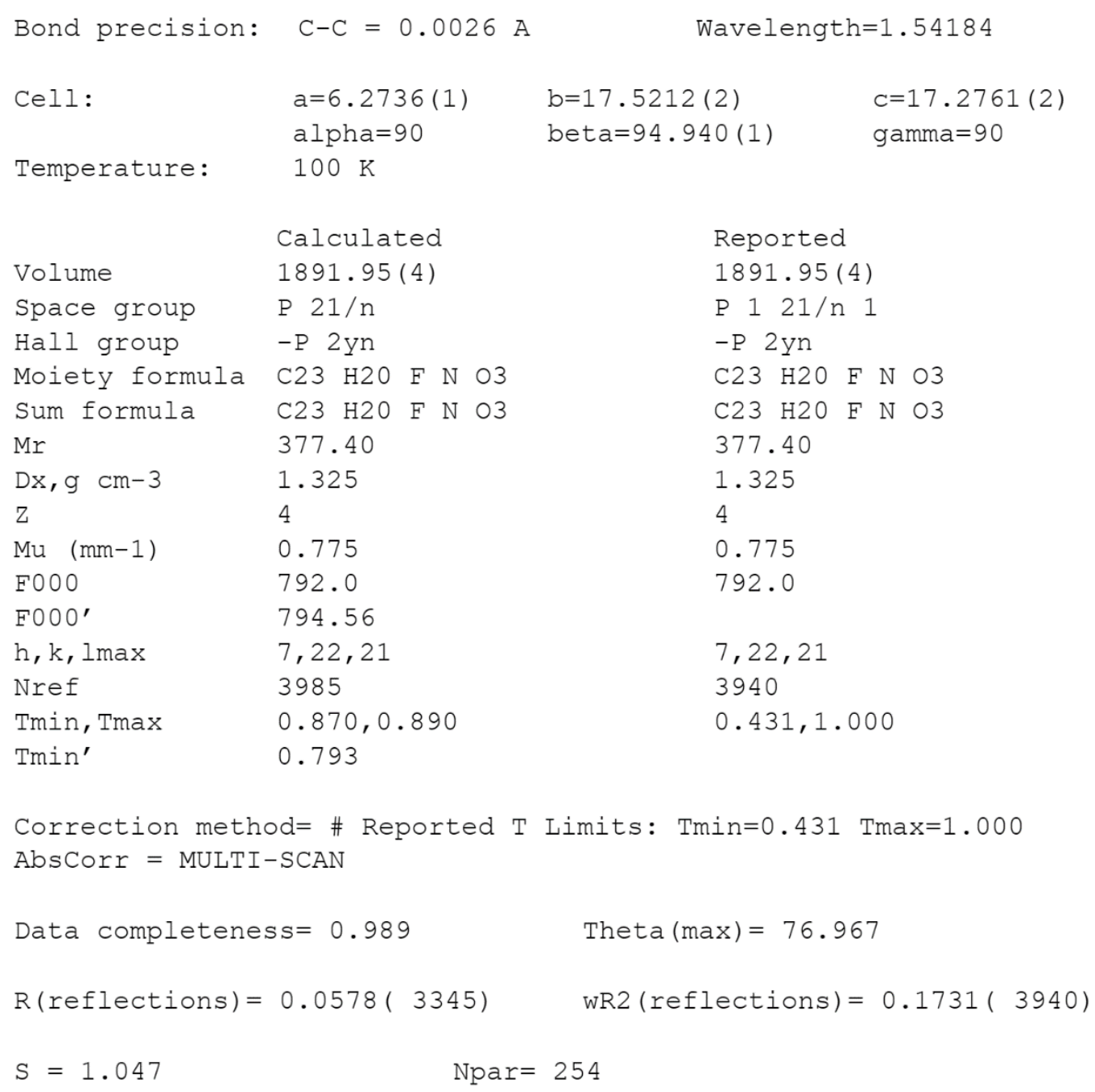




\section{General Procedure for the in vitro Anti-tumor Activity Study}

\section{Cell viability was measured by CCK-8 assay}

Human cancer cell lines HCT116, A549 and SJSA-1 were obtained from Cell Cook. Cells were cultured in RPMI1640 medium containing 10\% fetal bovine serum and 1\% penicillin/streptomycin (Gibco) in a humidified incubator containing $5 \% \mathrm{CO}_{2}$ at $37^{\circ} \mathrm{C}$. Human cancer cell lines MCF-7 was obtained from Procell and cells were cultured in MEM medium containing 10\% fetal bovine serum, 1\% penicillin/streptomycin (Gibco) and $0.01 \mathrm{mg} / \mathrm{mL}$ insulin (Procell) in a humidified incubator containing $5 \% \mathrm{CO}_{2}$ at $37{ }^{\circ} \mathrm{C}$. For cell viability, cells were seeded in 96-well plates at 5000 cells per well. After 24 hours, serially diluted compounds were added and cells were cultured for another 48 hours. Cell viability was measured using a Cell Counting Kit-8 (CCK-8) assay according to the manufacturer's instructions (Yeasen Biotechnology, China).

These representative products $\mathbf{3 b}-\mathbf{3 d}, \mathbf{3 g}, \mathbf{3 i}, \mathbf{5 b}-\mathbf{5 j}, \mathbf{5 l}-\mathbf{5 n}, \mathbf{5 q}-\mathbf{5 u}, \mathbf{7}$, and 8 on cell viability was evaluated via CCK8 assay in HCT116 (colon cancer), MCF-7 (breast cancer), A549 (lung adenocarcinoma), and SJSA-1 (osteosarcoma cancer) human cancer cell lines, and the in vitro anti-tumor activity results are listed in Table S1. The results show that compound $\mathbf{7}$ exhibits high anticancer potency against human lung adenocarcinoma cells (A549 cells, $\mathrm{IC}_{50}=9.13 \mu \mathrm{M}, \mathrm{R}^{2}=0.9397$ ). The results were presented as percentages and vehicle-treated cells set at 100 (Figure S2).

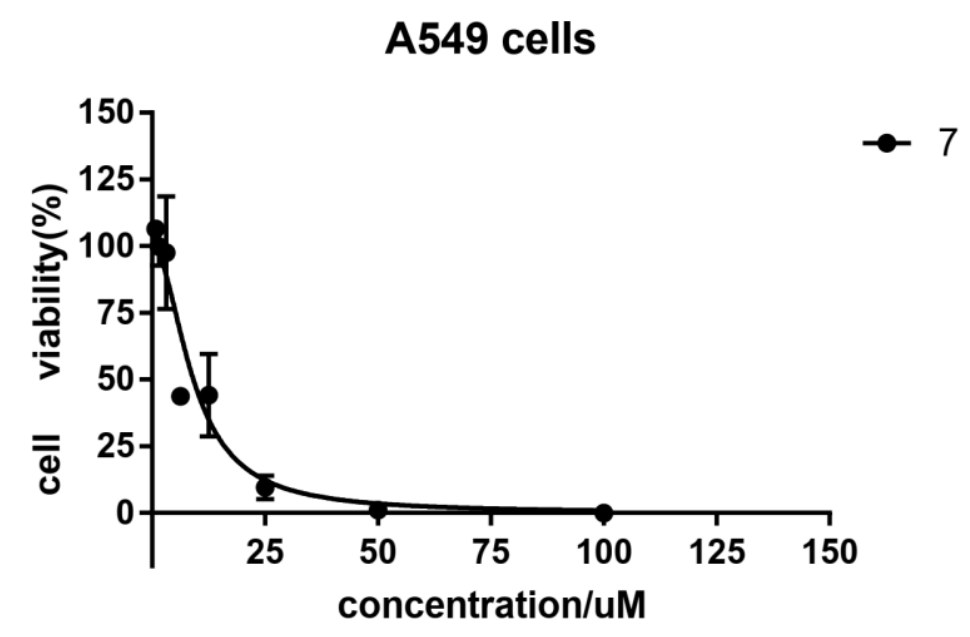

Figure S2. Compounds 7 on the viabilities of A549 cells 
Table S1. Anti-tumor activities of compounds 3b - 3d, 3g, 3i, 5b - 5j, 5l - 5n, 5q - 5u, $\mathbf{7}$ and $\mathbf{8}$ (Inhibition rate at $20 \mu \mathrm{M}$ )

\begin{tabular}{|c|c|c|c|c|}
\hline Compound. & НCТ-116 (\%) & MCF-7 (\%) & A549 (\%) & SJSA-1 (\%) \\
\hline $\mathbf{3 b}$ & $51.08 \pm 7.02$ & $60.77 \pm 1.67$ & $55.36 \pm 6.14$ & $16.87 \pm 6.72$ \\
\hline $3 c$ & $36.00 \pm 8.01$ & $62.16 \pm 1.24$ & $31.91 \pm 4.07$ & $<0$ \\
\hline 3d & $<0$ & $10.45 \pm 5.2$ & 8.13 & 41.22 \\
\hline $3 g$ & $19.89 \pm 0.25$ & $63.72 \pm 2.23$ & $<0$ & $10.65 \pm 7.14$ \\
\hline $3 \mathbf{i}$ & $16.95 \pm 14.34$ & $35.46 \pm 7.41$ & $<0$ & $<0$ \\
\hline $5 b$ & $64.75 \pm 4.37$ & $49.45 \pm 4.00$ & $35.63 \pm 7.75$ & $26.85 \pm 10.03$ \\
\hline $5 c$ & $33.90 \pm 7.67$ & $9.12 \pm 6.06$ & $22.22 \pm 5.09$ & $9.35 \pm 0.34$ \\
\hline $5 d$ & $30.73 \pm 10.38$ & $31.66 \pm 5.68$ & $20.65 \pm 16.68$ & $31.16 \pm 8.81$ \\
\hline $5 e$ & $41.33 \pm 2.67$ & $68.81 \pm 4.95$ & $28.93 \pm 5.06$ & $16.77 \pm 7.40$ \\
\hline $5 f$ & $40.86 \pm 3.09$ & $66.93 \pm 2.54$ & $10.88 \pm 7.06$ & $19.63 \pm 2.94$ \\
\hline $5 g$ & $35.88 \pm 3.22$ & $27.92 \pm 6.58$ & $19.71 \pm 5.49$ & $32.12 \pm 1.22$ \\
\hline $5 h$ & $61.29 \pm 1.39$ & $46.53 \pm 5.03$ & $60.28 \pm 2.20$ & $62.66 \pm 2.69$ \\
\hline $5 i$ & $47.38 \pm 0.91$ & $42.87 \pm 1.55$ & $29.84 \pm 9.48$ & $1.07 \pm 1.51$ \\
\hline $5 \mathbf{j}$ & $31.11 \pm 1.34$ & $46.28 \pm 1.17$ & 24.81 & $<0$ \\
\hline 51 & $24.95 \pm 1.72$ & $39.42 \pm 1.68$ & $20.89 \pm 6.05$ & $36.72 \pm 6.64$ \\
\hline $5 \mathrm{~m}$ & $31.42 \pm 1.27$ & $40.05 \pm 4.13$ & $28.63 \pm 3.78$ & $17.58 \pm 8.16$ \\
\hline $5 n$ & $26.44 \pm 5.28$ & $31.29 \pm 5.16$ & $78.63 \pm 0.76$ & $49.81 \pm 2.46$ \\
\hline $5 q$ & $21.63 \pm 4.67$ & $27.64 \pm 7.36$ & $37.95 \pm 9.20$ & 21.03 \\
\hline $5 r$ & 20.99 & $45.36 \pm 5.16$ & $34.28 \pm 5.85$ & 9.2 \\
\hline $5 s$ & $21.93 \pm 10.68$ & $52.93 \pm 0.68$ & $41.92 \pm 12.58$ & $<0$ \\
\hline $5 t$ & $12.62 \pm 0.182$ & $19.07 \pm 6.19$ & $33.98 \pm 11.67$ & 33.35 \\
\hline $5 u$ & $57.16 \pm 6.20$ & $32.56 \pm 7.08$ & $30.81 \pm 0.31$ & 5.72 \\
\hline 7 & $39.12 \pm 8.28$ & $77.41 \pm 4.82$ & $87.94 \pm 1.11$ & $66.83 \pm 2.24$ \\
\hline 8 & $19.19 \pm 3.32$ & $57.16 \pm 5.44$ & $27.56 \pm 0.71$ & $<0$ \\
\hline
\end{tabular}

